\title{
CAMBIOS DE RADÓN EN SUELO Y ELEMENTOS QUIIMICOS MAYORES Y TRAZAS EN AGUA SUBTERRÁNEA ASOCIADOS A ACTIVIDAD SÍSMICA
}

TESIS QUE PRESENTA EL

M. en C. PABLO PEÑA GARCÍA

PARA LA OBTENCIÓN DEL GRADO DE DOCTOR EN CIENCIAS

MÉXICO, D.F. ABRIL DE 2003

\section{UNIVERSIDAD AUTÓNOMA METROPOLITANA}

UNIDAD IZTAPALAPA División de Ciencias Básicas e Ingeniería 


\section{Universidad Autónoma Metropolitana}

Casa abierta al tiempo

\section{CAMBIOS DE RADÓN EN SUELO Y ELEMENTOS QUÍMICOS MAYORES Y TRAZAS EN AGUA SUBTERRÁNEA ASOCIADOS A ACTIVIDAD SÍSMICA}

Tesis que presenta el M. en C. PABLO PEÑA GARCÍA

Para la obtención del grado de Doctor en Ciencias

Directores de tesis: Maria de Nuria Segovia Aguilar (ININ) Juan Azorin Nieto (UAM-I)

México, D.F. Abril de 2003 
El presente trabajo se realizó en el Instituto Nacional de Investigaciones Nucleares y en la Universidad Metropolitana unidad Iztapalapa bajo la dirección de la Dra. María de Nuria Segovia Aguilar y del Dr. Juan Azorin Nieto. Parte del trabajo experimental también se llevó a cabo en el Instituto de Geofísica de la Universidad Nacional Autónoma de México, en el Laboratorio de Dosimetría y Monitoreo Ambiental de la Planta Nuclear de Laguna Verde - Comisión Federal de Electricidad, en la Facultad de Química de la Universidad Autónoma del Estado de México y en la Universidad de Montpellier, Francia. El Trabajo forma parte de los proyectos CONACYT 3791-P-T "Radón ambiental", 32467-T "Radón en aire y agua y elementos traza en agua" y 324564-E "Estudio de las propiedades TL y FL de óxidos metálicos dopados con tierras raras y su aplicación a la dosimetría de la radiación ionizante de baja energía".

Agradezco a las instituciones participantes el apoyo que brindaron para la realización de esta tesis. 
A la Universidad Autónoma Metropolitana unidad Iztapalapa, por la oportunidad de mi superación académica.

Al Instituto Nacional de Investigaciones Nucleares, a través de la Gerencia de Ciencias Ambientales, por el apoyo y facilidades prestadas en el transcurso del desarrollo de este trabajo.

A la Dra. Nuria Segovia Aguilar, por su valiosa orientación y el gran apoyo incondicional que me permitieron realizar este trabajo.

Al Dr. Juan Azorin Nieto, por haber aceptado ser mi codirector de tesis y el gran apoyo recibido.

Mis agradecimientos a todo el jurado de la tesis Dra. María Elena Montero Cabrera, Dr. Maximiliano Asomoza Palacios, Dr. Juan Manuel Navarrete Tejero y Dr. Salvador Cruz. Por su crítica revisión y comentarios enriquecieron esta tesis.

Agradezco el apoyo de mis compañeros Enrique Taméż, López, Saúl Cevallos Hernández, Delfino Cruz Pérez y todo el personal que laboró durante mi estancia en el desarrollo del proyecto. Gracias a ello fue posible la realización del mismo.

Al Dr. Jean Luc Seidel de la Universidad de Montpellier, Francia, por el gran apoyo en los análisis de elementos químicos traza.

A Dra. Ma. Aurora Armienta del Instituto de Geofísica de la UNAM, por su colaboración en los análisis realizados a las muestras.

Al Físico Armando Chávez Bautista, por el valioso apoyo y los grandes consejos que me brindó.

A QFB Perla Luna Carvajal y al Dr. Alberto Sandoval Jiménez, por su amistad incondicional y sugerencias.

A mi familia, por su comprensión y paciencia. 


\section{ÍNDICE}

\section{RESUMEN}

Lista de figuras

Lista de tablas

Lista de apéndices

\section{INTRODUCCIÓN}

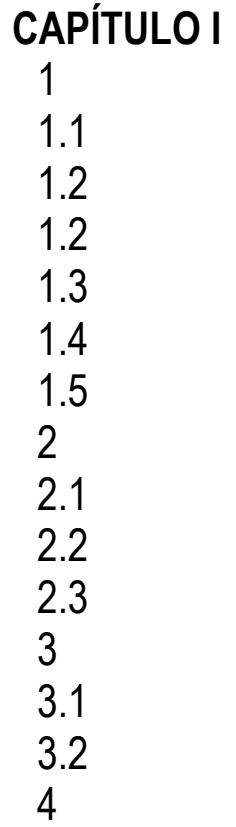

CAPÍTULO II

1

2

\section{CAPÍTULO III}

1

2

3

4

5

\section{GENERALIDADES}

Zonas sísmicas y volcánicas de México …………………..................

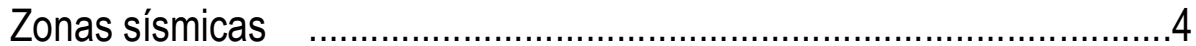

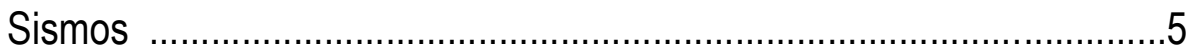

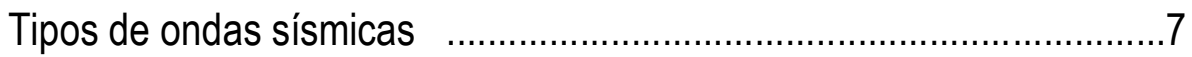

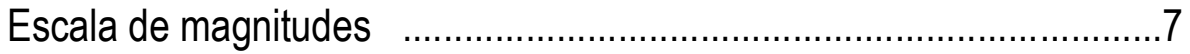

Efectos precursores de sismos ........................................................

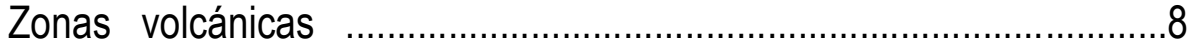

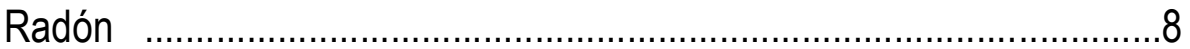

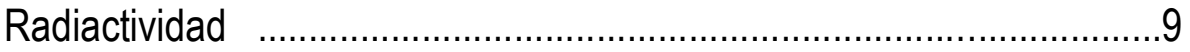

Propiedades físicas, químicas y nucleares del radón …………..........11

Características de los detectores de radón ....................................... 14

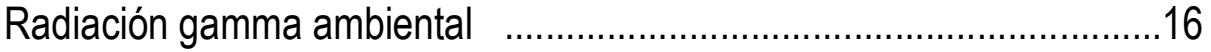

Dosimetría termoluminiscente .........................................................16

Detectores temoluminiscentes ……..............................................18

Elementos químicos mayores y trazas en solución .............................. 18

\section{SITIOS DE ESTUDIO}

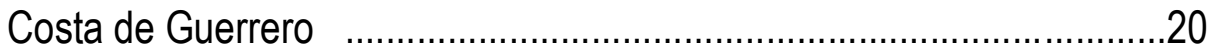

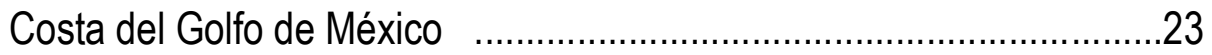

6

7

8

8.1

8.2

\section{PARTE EXPERIMENTAL}

Medición de radón .26

Medición de la radiación gamma ambiental ………….......................27

Muestreo de agua subterránea …........................................................27

Análisis de parámetros fisicoquímicos in situ y en laboratorio de

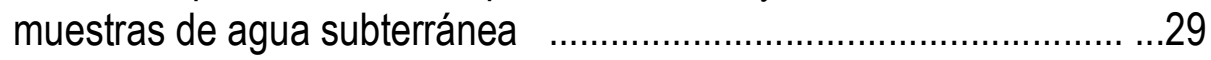

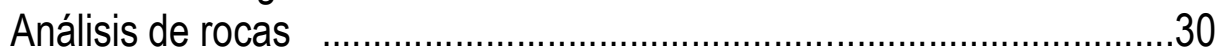

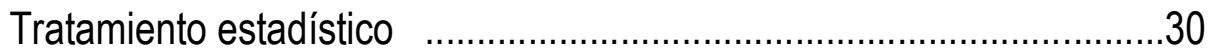

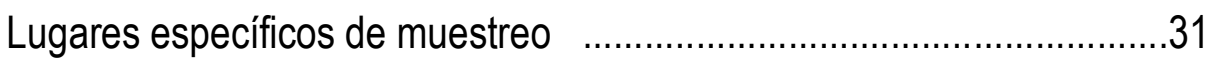

Costa del Golfo de México .............................................................

Costa de Guerrero ............................................................................. 


\section{CAPÍTULO IV RESULTADOS Y DISCUSIÓN. \\ Costa del Golfo de México ................................................. . ........33 \\ Radón .33 \\ 1.2 \\ Elementos químicos mayores \\ Elementos traza en solución .40 \\ 2 \\ Costa de Guerrero \\ Radón 44 \\ Dosis gamma .52 \\ Análisis mineralógico .53 \\ Elementos y compuestos químicos mayores .54 \\ 4 \\ Elementos traza en solución .58 Análisis de elementos químicos mayores y trazas por medio de componente principal 60 APÉNDICES}




\section{LISTA DE FIGURAS}

I-1

I-2

|-3

I-4

I-5

I-6

I-7

I-8

I-9

I-10

|I-1

॥-2

II-3

|I-4

|||-1

III-2

A-III-1

A-III-2

A-III-3

IV-1

IV-2

IV-3

IV-4

IV-5

IV-6

IV-7a

IV-7b

IV-8

\section{IV-9}

IV-10

IV-11

IV-12

IV-13

IV-14 Concentración de radón en suelo en Acapulco, Gro., monitoreada con la sonda Clipperton

(CPEG). Un sismo (M=7.4) ocurrió dentro del periodo de muestreo.

IV-15 Distribución mensual de la concentración de radón y de la dosis gamma (CPEG).

Tectónica de Placas.

Localización de los sismos en México.

Placas tectónicas y la sismicidad en México.

Profundidad de los sismos y su distancia desde la trinchera.

Subducción de la placa oceánica y la formación de la actividad volcánica.

Generación de las ondas sísmicas debido al movimiento de una falla.

Cadena de decaimiento del ${ }^{238} \mathrm{U}$.

Niveles de energía del fenómeno de luminiscencia.

Bandas de energía en sólidos dieléctricos.

Diagrama de bloque de un equipo lector de TL.

Plano geológico de la Costa del Pacífico - Estado de Guerrero (CPEG).

Promedio mensual de la temperatura y de la precipitación (1993-1998), Acapulco, Gro. (CPEG).

Plano geológico de la Costa del Golfo de México-zona aledaña a la PNLV (CGMPNLV).

Promedio mensual de la temperatura y de la precipitación (1994-1996), (CGMPNLV).

Detectores pasivos y activos.

Mapa de localización de las zonas de muestreo.

Esquema del circuito de un contador de chispa.

Curva de calibración TL.

Diagrama triangular de Piper.

Localización de sismos (1994-1996) (CGMPNLV).

Valores de la concentración de radón en agua en: RN, EV y PNLV (CGMPNLV).

Valores de la media geométrica y la desviación estándar de la concentración de radón en agua (CGMPNLV).

Concentración de radón en agua en la PNLV y RN, monitoreada con la sonda Clipperton. Valores de la concentración de radón en suelo en: PNLV, P, EV, RN, L y LL (CGMPNLV). Valores de la media geométrica y la desviación estándar de la concentración de radón en suelo (CGMPNLV).

Diagrama triangular de Piper. Época de lluvias (CGMPNLV).

Diagrama triangular de Piper. Época de secas (CGMPNLV).

Porcentaje de los eventos en cada uno de pozos en PNLV que presentaron mayor mineralización (elementos traza) (CGMPNLV).

Distribución temporal de los elementos traza (CGMPNLV).

Distribución temporal y espacial de los elementos traza (CGMPNLV).

Localización de sismos (M>4) (1993-1998) en la costa de Guerrero.

Valores de la concentración de radón en suelo en la costa de Guerrero.

Valores de la media geométrica y desviación estándar de la concentración del radón en suelo (CPEG). 
IV-16 Diagrama de correlación de la concentración de radón y la dosis gamma.

IV-17 Diagrama triangular de Piper (CPEG).

IV-18 Porcentaje de los eventos en cada uno de pozos en la costa de Guerrero que presentaron mayor mineralización (elementos traza) (CPEG).

IV-19a Distribución temporal de los elementos traza - Guacamayas (CPEG).

IV-19b Distribución temporal de los elementos traza - El Cayaco (CPEG).

IV-19c Distribución temporal de los elementos traza - El Cortés (CPEG).

IV-20 Variación temporal de los elementos traza (CPEG).

V-21-A Correlación por medio del ACP de elementos mayores (Abril de 1994 PNLV).

V-21-B Correlación por medio del ACP de elementos mayores (Agosto de 1995 PNLV).

V-22-A Correlación por medio del ACP de elementos traza (Octubre de 1995 PNLV).

V-22-B Correlación por medio del ACP de elementos traza (Febrero de 1996 PNLV).

IV-23-A Correlación por medio del ACP de elementos mayores - Guacamayas (CPEG).

IV-23-B Correlación por medio del ACP de elementos mayores - El Cayaco (CPEG).

IV-23-C Correlación por medio del ACP de elementos mayores - El Cortés (CPEG).

IV-24-A Correlación por medio del ACP de elementos traza - Guacamayas (CPEG).

IV-24-B Correlación por medio del ACP de elementos traza - El Cayaco (CPEG).

IV-24-C Correlación por medio del ACP de elementos traza - El Cortés (CPEG).

IV-25 Correlación por medio del ACP de elementos mayores y trazas - Guacamayas, El Cayaco y El Cortés (CPEG). 


\section{LISTA DE TABLAS}

$1-1$

Elementos y compuestos solubles en agua subterránea de acuerdo con la abundancia relativa.

A-III-1 Factores de corrección por espesor en detectores LR-115 tipo II.

A-III-2-1 Características técnicas del DTL (CaSO4; Dy+PTFE).

IV-1 Epicentros, fecha, profundidad, magnitud y distancia epicentral con respecto a la PNLV de los sismos (M >2.9) ocurridos de 1994 a 1996 en los alrededores de la PNLV.

IV-2 Valores de la concentración de radón en agua con detectores LR-115 (CGMPNLV).

IV-3 Valores de la concentración de radón en agua. Media aritmética y desviación estándar, máximos, media geométrica y desviación estándar (CGMPNLV).

IV-4 Valores de la concentración de radón en suelo con detectores LR-115 (CGMPNLV).

IV-5 Valores de la concentración de radón en suelo. Media aritmética y desviación estándar, máximos, media geométrica y desviación estándar (CGMPNLV).

IV-6 Valores de los componentes químicos mayores obtenidos de muestras de agua subterránea en la zona de la PNLV y EV (CGMPNLV).

IV-7 Análisis de los elementos traza obtenidos en pozos para agua subterránea en la zona de la PNLV (CGMPNLV).

IV-8 Rango de concentración de los elementos traza en agua subterránea.

IV-9 Epicentros, fecha, profundidad y magnitud de los sismos ( $M>5.9)$ ocurridos en 1993-1999 en la costa de Guerrero (CPEG).

IV-10 Valores de la concentración de radón en suelo con detectores LR-115 (CPEG).

IV-11 Valores de la concentración de radón en suelo. Media aritmética y desviación estándar, máximos, media geométrica y desviación estándar. (CPEG).

IV-12 Valores de la dosis gamma por medio de DTL (CPEG).

IV-13 Valores promedio de la dosis gamma y concentración de radón (CPEG).

IV-14 Compuestos químicos obtenidos mediante el difractómetro de RX.

IV-15 Principales elementos que constituyen las muestras de roca (\%).

IV-16 Valores del número de sismos, valor promedio de la concentración de radón (DSTN), dosis gamma (DTL), ${ }^{225} \mathrm{U},{ }^{226} \mathrm{Ra}$ y ${ }^{40 \mathrm{~K}}$ en muestras de roca obtenidas en GSL (1) y GAC (2) (CPEG).

IV-17 Valores de los elementos químicos obtenidos de muestras de agua subterránea en pozos (CPEG).

IV-18 Distintos grados de mineralización.

IV-19 Análisis de elementos traza obtenidos en muestras de agua subterránea en pozos y manantiales en Guacamayas, El Cayaco y El Cortés (CPEG).

IV-20 Matriz de correlación de elementos mayores PNLV.

A (abril/1994)

B (agosto/1994)

IV-21 Matriz de correlación de elementos traza PNLV.

A (octubre/1995).

B (febrero/1996)

IV-22 Matriz de correlación de elementos químicos mayores (CPEG).

A (MG) 
$B($ GEC)

C (EC)

IV-23 Matriz de correlación de elementos traza (CPEG).

A (MG)

$B(G E C)$

$C$ (EC)

IV-24 Matriz de correlación de elementos químicos mayores y trazas: MG, GEC y EC (CPEG). 


\section{LISTA DE APÉNDICES}

A-I-1 Glosario.

A-I-2 Características fisicoquímicas de algunos compuestos y elementos químicos mayores y trazas del agua.

A-ll-1 Parámetros meteorológicos de Acapulco, Gro. (CPEG).

A-II-2 Corte litológico de los pozos de la PNLV (CGMPNLV).

A-ll-3 Parámetros meteorológicos de la PNLV (CGMPNLV).

A-III-1 Determinación de la densidad de trazas.

A-III-2 Determinación de la radiación gamma ambiental.

A-III-3 Métodos para la determinación de los parámetros fisicoquímicos en situ y en el laboratorio de muestras de agua subterránea.

A-III-4 Elaboración del diagrama triangular de Piper. 


\section{CAMBIOS DE RADÓN EN SUELO Y ELEMENTOS MAYORES $Y$ TRAZAS EN AGUA SUBTERRÁNEA ASOCIADOS A ACTIVIDAD SÍSMICA}

\section{RESUMEN}

En las últimas décadas se ha realizado un gran número de estudios geofísicos y geoquímicos en diferentes países que presentan gran actividad sísmica. Entre los estudios que se han realizado, destacan aquellos relacionados con el comportamiento de gases en el suelo y agua subterránea, siendo el radón $\left({ }^{222} \mathrm{Rn}\right)$ un parámetro importante. El presente trabajo tiene como objetivo la determinación de la concentración del radón en el suelo y en el agua subterránea, así como el análisis de elementos químicos mayores y trazas en agua subterránea de las costas de Guerrero y del Golfo de México para estudiar su posible correlación con la actividad sísmica.

La costa del Pacífico Mexicano es una de las zonas sísmicas más activas del mundo, debido a la subducción de las placas de Cocos y Rivera bajo la placa de Norteamérica. Los sismos que ocurren en esta parte de México son de gran magnitud y afectan la meseta central del país donde se encuentra la mayor densidad de población. Mientras que en la costa del Golfo de México, que presenta una actividad sísmica relativamente baja, se tiene localizada la planta nuclear de Laguna Verde (PNLV) por lo que los estudios de sismicidad deben conocerse por cuestiones de seguridad nuclear.

La determinación de la concentración del radón tanto en suelo como en agua subterránea se llevó a cabo con mediciones de largo periodo, utilizando detectores sólidos de trazas nucleares (LR-115). Eventualmente se utilizaron detectores automáticos para mediciones continuas que registran las fluctuaciones de la concentración del radón en tiempos cortos (sonda Clipperton). En algunos casos se analizó la radiación gamma en suelo utilizando detectores termoluminiscentes ( $\mathrm{CaSO}_{4}$ :Dy+PTFE). La medida de parámetros fisicoquímicos in situ y en laboratorio se realizó por métodos físicos y químicos convencionales. Los elementos traza se obtuvieron utilizando un espectrómetro de masas con plasma de acoplamiento inductivo (ICP-MS). El análisis estadístico se llevó a cabo mediante el análisis de componente principal. Se obtuvo la composición mineralógica de muestras de roca, mediante técnicas convencionales y microscopía electrónica de barrido, para determinar la composición química elemental de algunas muestras; para identificar los tipos de compuestos cristalinos se utilizó un difractrómetro de rayos $X$. La localización de los sitios de muestreo se llevó a cabo mediante un sistema global de posicionamiento (GPS).

El muestreo se realizó a lo largo de la costa de Guerrero, desde Guacamayas, Mich. hasta Marquelia, Gro., de 1993 a 1998; en cuanto a la costa del Golfo de México, éste se llevó acabo en la PNLV y sus alrededores de 1994 a 1996.

Las fluctuaciones de la concentración de radón, dosis gamma, elementos químicos mayores y trazas, se analizaron en función de los parámetros meteorológicos, las características geológicas y la actividad sísmica local. 
En la zona de la PNLV, los resultados muestran que por lo general los promedios de los valores de la concentración de radón fueron bajos. Las variaciones de los valores de la concentración de radón tanto en el suelo como en el agua subterránea, fueron diferentes en cada estación de muestreo y están en función de los parámetros meteorológicos y de las características geológicas. La estación de Rancho Nuevo localizada en una zona de falla, al norte de la PNLV fue la que presentó los valores más altos de concentración de radón. Los valores más bajos se obtuvieron en la estación de la PNLV. Las fluctuaciones de la concentración de radón en el suelo fueron mayores que la concentración de radón en agua. Las anomalías de los valores de la concentración del radón se presentaron durante la época de lluvias, este comportamiento quizás se deba a la humedad del suelo ya que coincide con la época de mayor precipitación. Se observó una mayor mineralización en los análisis de los elementos químicos mayores y traza en las muestras de agua subterránea en la época de lluvias. La actividad sísmica durante el periodo de muestreo fue esporádica y de baja intensidad y sólo se pudo observar que la zona de falla fue la que tuvo valores de la concentración de radón mayores, debido a la circulación preferente de gases.

En cuanto a la costa del Pacífico, se observó que las fluctuaciones de la concentración del radón en suelo muestran ocasionalmente dependencia con los parámetros meteorológicos. Los valores máximos de la concentración de radón se obtuvieron principalmente en la época de lluvias. El factor primordial que influyó en la concentración del radón fue la geología local de los sitios de estudio, es decir, la respuesta del radón en el suelo depende del tipo de sustrato. Las estaciones de muestreo de radón ubicadas en suelo residual, indicaron valores menores que aquellas que están ubicadas en suelo granítico y metamórfico; así mismo las estaciones cercanas entre sí y que corresponden a la misma región geológica presentan un comportamiento parecido. Se observó una intensa actividad sísmica en el periodo de muestreo. La mayoría de los sismos fueron de magnitud $(M>4)$ y someros $(<20 \mathrm{~km})$. La concentración del radón en suelo medido en periodos largos de tiempo no pareció responder con picos uno a uno a los sismos locales, pero muestra las variaciones globales en una zona de alta actividad sísmica, ya que se observaron paquetes de la concentración de radón antes y después de la ocurrencia de algunos sismos. La concentración de los elementos químicos de los sitios muestreados fue diferente, esto se debe a la diversidad del tipo de rocas por donde circula el agua, así como a los mecanismos de recarga. Se observaron incrementos en la concentración de los elementos

químicos en la época de secas. Las variaciones de la concentración de radón y de la dosis gamma mostraron en algunos casos una correlación fuerte entre sí, lo cual puede explicarse por el hecho que el dosímetro termoluminiscente se colocó dentro de la cámara de exposición de radón. Las diferencias en composición de los tipos de rocas mostraron diferencias tanto en la emanación de radón como en los niveles de dosis gamma en la zona estudiada.

En la correlación por grupos de los elementos químicos mayores y trazas obtenidos en las muestras de agua, se observó una separación geoquímica de los grupos, definiendo así que se trata de acuíferos que provienen de diferentes tipos de formaciones rocosas. La respuesta de las características geoquímicas para cada acuífero estudiado en el presente trabajo depende del contexto geológico específico.

\section{Palabras clave}

Concentración de radón en suelo y agua subterránea; elementos y compuestos químicos mayores y trazas en agua subterránea; sismicidad; dosis gamma en el suelo; análisis de componente principal. 


\title{
SOIL RADON CHANGES AND MAJOR AND TRACE ELEMENTS IN GROUNDWATER ASSOCIATED TO SEISMIC ACTIVITY
}

\begin{abstract}
In the last decades, many geochemical and geophysical studies have been performed in different countries having high seismic activity. Among these studies, those about gases behavior in the soil and groundwater have had special importance, ${ }^{222} \mathrm{Rn}$ being one of the most important parameters. The objective of this work was the determination of radon behavior in soil and groundwater. Also, major and trace chemical elements were analyzed in groundwater from wells and springs located at Guerrero State and the Gulf of Mexico coasts, in Mexico.
\end{abstract}

The Mexican Pacific coast is one of the most seismologically active areas in the world, due to the subduction of the Cocos and Rivera Plates under the North America Plate. On the other side at the Gulf of Mexico coast, low seismic activity occurs, however the Laguna Verde nuclear power plant (PNLV) is settled in the area and the seismicity studies should be known for nuclear safety.

Radon measurements in soil and groundwater were carried out in long term measurements using solid state nuclear track detectors (LR-115). Eventually, automatic detectors were also used for continuous determinations in the short term (Clipperton probe). In some cases gamma radiation was analyzed in the soil by using thermoluminiscent detectors (CaSO4:Dy+PTFE). The physiochemical parameters analysis in water samples were determined by conventional wet chemistry. The water family types were determined with the Piper diagram. Trace elements were obtained using an inductively coupled plasma mass spectrometer (ICP. MS). The statistical analysis was carried out through principal compound analysis. The mineralogical composition of rock samples was also determined using conventional techniques and scanner electron microscope. In order to identify the crystalline compound in some rock samples an X-ray diffractrometer was used.

The sampling sites were localized by means of a global positioning system (GPS). The sampling was performed along the Guerrero coast, from Guacamayas to Marquelia, from 1993 to 1998. At the Gulf of Mexico coast, sampling was performed at the PNLV and surrounding sites, from 1994 to 1996.

Radon fluctuations, gamma radiation, major and trace chemical elements, were analyzed as a function of meteorological parameters, geologic characteristics and the local seismicity.

At the PNLV results show relatively low average radon concentration. Variations of radon values in the soil and groundwater were different at each sampling station and they were a function of the meteorological parameters and of the geologic characteristics. Rancho Nuevo station, located in a fracture zone, $35 \mathrm{~km}$ north of PNLV, showed the highest radon concentration. The lowest values were obtained at the PNLV station. The radon fluctuations were larger in the soil than in groundwater. Anomalies of radon values appeared during the rainy season; this behavior may be due to soil humidity because of its coincidence with the rainy season. During the rainy season the major and trace elements analysis in groundwater samples showed a larger mineralization. A strong correlation $\mathrm{Na}-\mathrm{Cl}$ was obtained during the dry season while, in both seasons a moderate correlation between (Ca-D) was obtained. Concerning the trace elements, strong correlations (Mn-Co-U) and (Rb-As) 
were also obtained during the winter season and additionally, at the dry season ( $\mathrm{Cu}-\mathrm{Pb}-\mathrm{B})$ and $(\mathrm{Li}-\mathrm{Rb})$ were strongly correlated. The seismic activity during the sampling period was sporadic and of low intensity and it could be observed that the fracture zone was the one that had higher radon values due to a preferential gaz flow.

The fluctuations of soil radon at the Pacific coast showed an occasional dependence on the meteorological parameters. The maximum radon values were obtained mainly during the rainy season, as observed at the Gulf of Mexico zone. The local geology was the main factor that influenced the radon behavior; indicating that the gas behavior in soil depends on the substrate. The sampling sites located on residual soil showed lower values that those located on granitic and metamorphic soil. Also, sites close to each other and corresponding to the same geological zone presented similar behavior. An intense seismical activity was observed during the sampling campaigns. Most of the earthquakes were reported to be $M>4$ and at shallow depth ( $<20 \mathrm{~km})$. Soil radon behavior measured in the long term did not responded with peaks one to one to the local earthquakes, but showed global variations when located at a high seismical activity zone, with radon packages before and after the occurrence of some earthquakes. The springs chemistry corresponded to different water families, with different mineralization. They belong in general to waters from meteoric origin of recent infiltration. Different chemical element concentrations were found for each well or spring, due to the diversity of the rocks through which water circulates, as well as to the recharge patterns of the aquifers. Increases in chemical elements concentration were observed during the dry season. Radon concentration and gamma radiation fluctuations showed a moderate correlation in some cases, which can be explained due to the fact that termoluminiscent detectors were placed inside the radon exposure chamber. Differences in composition of rock types indicated differences in radon emanation and in gamma radiation levels in the studied zone.

The groundwater analysis at Guerrero coast showed the presence of organic matter pollution due to the presence of near by human communities. The studied wells presented variations in the water composition. In the major and trace elements a group correlation was observed generating the separation of groups when variance analysis was performed, indicating that aquifers originate from different types of rock formations.

The geochemical response of each aquifer depends on the specific geological context and on the recharge patterns. For seismic activity, at the Gulf of Mexico region, with sporadic and low magnitude earthquakes, differences in radon concentration were found only at the fracture zone. At the Pacific zone, anomalies related to the shallow seismicity were found for earthquakes magnitudes between ( $\mathrm{M}$ and 7 ), whose epicenters were located up to $60 \mathrm{~km}$ from the sampling station.

\section{Keywords}

Radon in soil and groundwater; major and trace chemical components in groundwater; earthquake; gamma radiation in the soil; principal component analysis. 


\section{INTRODUCCIÓN}

Los sismos constituyen una fuente de desastres que afecta la infraestructura civil y la económica (Molnar y Sykes, 1969; Stoiber y Carr, 1973; Dean y Drake, 1978; Nixon, 1982; Bevis y lsacks, 1984; Burbach et al., 1984; Nishenko y Singh, 1987). En las últimas tres décadas se han reportado un gran número de estudios geofísicos y geoquímicos llevados a cabo en varias localidades con gran actividad sísmica. Se han realizado estudios del comportamiento de los gases en suelo y agua subterránea con diferentes métodos de muestreo y análisis (Papastefanou, 2003; Negarestani et al., 2002). Entre los gases estudiados, el ${ }^{222} \mathrm{Rn}$ se ha investigado más intensamente debido que se han observado anomalías en su concentración las cuales, en varias ocasiones, han podido correlacionarse con eventos sísmicos (Ulomov y Mavashev, 1967, 1971; Wakita et al., 1986; Igarashi y Wakita, 1990, 1995; King et al., 1995; Takahata et al., 1997; Kingsley et al., 2001; Virk et al., 2001; Virk y Walia, 2001; Kharatian et al., 2002).

Las variaciones de las concentraciones del ${ }^{222} \mathrm{Rn}$ a corto y largo plazo en suelo y agua subterránea se han reportado generalmente en relación con eventos sísmicos de gran magnitud (Segovia et al., 1989a, 1995a; Zhaocheng y Zhang, 1999; Biagi et al., 1999; Castro-Morales y LaBrecque, 1999; Fedeli et al., 2001; Wysocka et al., 2001; Zhang y Zhang, 1999; LaBrecque et al., 2001). Estudios experimentales de los mecanismos sismo-químicos han mostrado que las anomalías geoquímicas se han podido relacionar con las deformaciones elástica y plástica de las rocas, cuando éstas están sometidas a grandes esfuerzos y al movimiento de placas tectónicas previos a eventos sísmicos (Ulomov y Mavashev, 1967; Virk, 1999; Virk et al., 2001). En particular en zonas sísmicas, las fracturas podrían cambiar los niveles de concentración de algunos elementos en las aguas subterráneas debido a que aumenta la superficie de contacto agua-roca (Noguchi y Wakita, 1997; Tsunogai y Wakita, 1995; Loria et al., 1995; Virk y Singh, 1995; Mukherji, 1999; Virk et al., 2000). Sin embargo, aunque en algunos casos se han observado cambios en el incremento de la tasa promedio de la emanación del ${ }^{222} \mathrm{Rn}$ antes de la ocurrencia de un evento sísmico, se han reportado también anomalías de la concentración del ${ }^{222} \mathrm{Rn}$ que no son seguidas por sismos, así como sismos que no fueron precedidos por anomalías de ${ }^{222} \mathrm{Rn}$. Una parte del radón generado en los acuíferos permanece en la matriz sólida y solo una fracción fluye y se mueve a través de los poros migrando por las fisuras (Abumurad y Al-Tamimi, 2001; Al-Tamimi y Abumurad, 2001). Los cambios en los esfuerzos de la corteza terrestre crean nuevas interfaces sólido-fluido, aumentando la emanación y por lo mismo la migración del radón y de otros elementos a nivel de traza que pueden cambiar su concentración en el fluido (Segovia et al., 1989a; Pane et al., 1995; Zmazek et al., 2002).

Las mediciones realizadas en zonas de falla tienen mayor probabilidad de mostrar anomalías en los sitios donde el transporte de fluidos hacia la superficie se facilita y donde las estaciones de monitoreo del ${ }^{222} \mathrm{Rn}$ están localizadas a una distancia del epicentro que sea comparable al área de ruptura del sismo (Segovia et al., 1989a; Djeffal et al., 1995). Los parámetros ambientales como precipitación y temperatura, generan también cambios en las concentraciones de radón y otras especies químicas, así como en elementos del suelo y del agua subterránea, por lo tanto es importante contar con registros meteorológicos locales para poder discernir entre las diferentes contribuciones tectónicas y no tectónicas (Tidjani et al., 1990; Singh y Virk, 1994; Abbad et al., 1995; Planinic et al., 2001). También es de importancia el contar con información referente a los elementos químicos mayores y a 
nivel de traza en agua subterránea que puedan dar información sobre microfracturamientos en acuíferos (Segovia et al., 1997a; Amrani, et al., 2000).

Las técnicas geoquímicas pueden proporcionar señales de alta calidad, como resultado del avance tecnológico de los instrumentos de medición. Anomalías geoquímicas han sido vinculadas con la actividad sísmotectónica, evidenciando relaciones entre flujos subterráneos, la química de fluidos y los procesos de fallamiento. La mayoría de los estudios relacionados con los precursores geoquímicos de sismos, han sido realizados por la Ex - Unión Soviética, Japón, China y EUA (Toutain y Baubron, 1999). Se han observado cambios en los flujos de manantiales y niveles de agua antes y después de grandes sismos, incluyendo los ocurridos en 1906 en San Francisco (Lawson, 1908). Muir-Wood y King (1993), demostraron que pueden ocurrir anomalías de baja intensidad en gases del subsuelo después de sismos compresionales, mientras que descargas anómalas de alta intensidad se asocian a sismos de origen extensional. Otros estudios han documentado cambios en la química de manantiales y pozos, antes y después de eventos sísmicos con magnitud ( $M>4.0)$ (Tsunogai y Waquita, 1995; Sugisaki et al., 1996). Los manantiales en la parte central de California, han sido caracterizados y documentados durante más de 100 años, habiéndose reportado, en relación con la sismicidad local, descargas de agua tibia, un alto contenido de sólidos totales y otras manifestaciones de cambios químicos (Melchiorre y Criss, 1999). Irwin y Barnes (1975), por su lado, notaron la asociación de manantiales salinos con segmentos de la brecha sísmica en la Falla de San Andrés.

Se han reportado anomalías geoquímicas antes de la ocurrencia de sismos en varias regiones del mundo. Dichas anomalías fueron atribuidas a cambios de esfuerzos presísmicos, los cuales indujeron mezclas geoquímicas de diferentes acuíferos (Toutain et al., 1997; Tsunogai y Wakita, 1995; Igarashi et al., 1995; Matsuda y lkeya, 2001).

La costa del Pacífico Mexicano es una de las zonas sísmicas más activas del mundo debido a la subducción de las placas de Cocos y Rivera bajo la placa de Norteamérica (Segovia y Mena, 1997; Valdés y Novelo, 1997; Singh et al., 1998; Kostoglodov y Pacheco, 1999; Kostoglodov et al., 2002). Los sismos que ocurren en esta parte de México son de gran magnitud y afectan la meseta central del país donde se encuentra la mayor densidad de población.

Los epicentros de los sismos de mayor magnitud ( $M>7)$ ocurridos en México en los últimos 100 años se han localizado entre Jalisco y Oaxaca a lo largo de la trinchera Mesoamericana. El de mayor magnitud ocurrió en Jalisco-Colima el 3 de junio de 1932 ( $M=8.2)$ (Espindola y Jimenéz, 1994). Por otro lado México cuenta con 13 volcanes activos localizados esencialmente en el Eje Neovolcánico Mexicano, que inicia en Colima y termina en Veracruz. Volcanes como el Chichón y el Tacaná en Chiapas están ligados a la linea de volcanes centroamericanos.

En el estado de Veracruz, donde termina el Eje Neovolcanico, ocurre sismicidad de baja magnitud. En esa región se encuentra ubicada la Planta Nuclear de Laguna Verde y los estudios de sismicidad deben conocerse por cuestiones de seguridad nuclear. 
A partir de la década de 1980, se iniciaron en las dos regiones citadas estudios de radón en suelo y agua subterránea para contribuir al estudio de las zonas sísmicas (Segovia et al., 1989a; 1993; 1995a; 1996; Peña et al., 2001; Edmunds et al., 2002).

Debido a la gran importancia que tiene la costa de Guerrero en el marco de la generación de catástrofes naturales del tipo sísmico, se plantea en ésta tesis un estudio de radón en suelo y agua subterránea en esta región, como un complemento adicional a las medidas geofísicas y geoquímicas existentes con el fin de que a través del análisis de su comportamiento se pueda contribuir al conocimiento de la región. Así mismo en la costa del estado de Veracruz, se hizo un estudio que involucra los alrededores de la Planta Nuclear de Laguna Verde.

El objetivo general de este trabajo consiste en determinar la concentración del radón en suelo y en el agua subterránea, con registros de corto y largo plazo, así como los elementos químicos mayores y a nivel de trazas en solución en muestras obtenidas en la costa del Pacifico y en los alrededores de la Planta Nuclear de Laguna Verde para estudiar su posible correlación con la actividad sísmica. Como un corolario adicional se determinó la correlación entre la concentración de radón en suelo y la tasa de dosis absorbida producida por la radiación gamma en el suelo.

Una clasificación de los elementos químicos se basa en los niveles de concentración: elementos químicos mayores ( $\mathrm{mg} \mathrm{L}^{-1}$ ) y elementos químicos traza ( $\mu \mathrm{g} \mathrm{L}^{-1}$ ) (Domenico y Schwartz, 1998).

En el Capitulo I se presentan las generalidades referentes a las zonas sísmicas y volcánicas del país, al radón en suelo y agua subterránea y a la radiación gamma ambiental. Así mismo se presenta la importancia de los elementos mayores y trazas en solución en pozos de agua para el estudio de cambios en acuíferos debidos a eventos geoquímicos o geofísicos locales. El Capitulo II describe las características de las zonas de estudio. El Capitulo III contiene los métodos experimentales utilizados para la cuantificación del radón y de la dosis absorbida producida por la radiación gamma, así como la valorización de los elementos mayores y trazas en solución. En el Capitulo IV se presentan los resultados y se discute su significado. En el capitulo $\mathrm{V}$ se presentan las conclusiones del trabajo. 


\section{CAPITULO I GENERALIDADES}

\section{ZONAS SÍSMICAS Y VOLCÁNICAS DE MÉXICO.}

\subsection{Zonas sísmicas.}

La Tierra ha sido dividida en núcleo, manto y corteza a partir de las ondas sísmicas (Núñez-Cornú, 1994). El núcleo interno y externo son muy similares desde el punto de vista de su composición; su división se basa en las diferencias de estados físicos. El núcleo externo está formado por una capa gruesa fluida de un material en el que predomina el hierro, a una temperatura suficientemente alta para mantenerlo fundido; el núcleo interno está constituido por una esfera sólida central. Más del $69 \%$ del volumen de la Tierra está contenida en el manto, se extiende hasta cerca de $2900 \mathrm{~km}$ de profundidad y contiene la mayor cantidad de los elementos radiactivos de vida larga como el uranio, el torio y el ${ }^{40} \mathrm{~K}$, que al decaer, generan calor. $\mathrm{El}$ movimiento de este material que fluye en el interior de la Tierra origina las celdas convectivas que a su vez dieron origen a la tectónica de placas. En el manto, por la forma como se transmiten las ondas sísmicas, los materiales que lo componen se comportan como un sólido de una rigidez considerable. La corteza es la capa rígida más externa de la Tierra, se divide en corteza oceánica y continental y está compuesta por placas tectónicas que cubren grandes áreas de la superficie terrestre y se mueven en diferentes direcciones produciéndose choques entre ellas (De la Cruz-Reyna, 1994). Algunas se deslizan rozando una contra otra (movimiento transformación) y otras al chocar frontalmente, generan lo que se denominan zonas de subducción (Tarbuck y Lutgens, 1999) (Fig.- I-1). Las zonas de subducción se identifican por ser las regiones más profundas del suelo oceánico. En estas regiones una placa cabalga sobre la otra (movimiento de convergencia); la placa más densa (generalmente las placas bajo los océanos) penetra bajo las placas menos densas (generalmente las placas sobre las que viajan los continentes). En las regiones en donde se presenta el movimiento de divergencia (dorsales oceánicas) se produce un distanciamiento entre las placas. Las dorsales se caracterizan por su volcanismo activo, ya que a través de ellas se forma un nuevo suelo oceánico con material que proviene del interior de la Tierra (Dewey, 1982; Murck et al., 1996; Michaud et al., 200).

El territorio mexicano se encuentra localizado entre cinco placas tectónicas. La mayor parte del país se encuentra sobre a placa de Norteamérica. Esta placa contiene a todo Norteamérica, parte de Asia y del Océano Atlántico. La península de Baja California se encuentra en la placa tectónica del Pacifico y el sur de Chiapas se encuentra dentro de la placa del Caribe. Otras placas más pequeñas la de Ribera y la de Cocos, se localizan frente a las costas de Guerrero y Michoacán. Estas dos placas se encuentran bajo el Océano Pacifico (Kostoglodov y Pacheco, 1999). La sismicidad y la tectónica del sur de México se caracterizan por la subducción de esas placas oceánicas de Ribera y Cocos, bajo la placa de Norteamérica a lo largo de la Trinchera Mesoamericana (Singh et al., 1998) (Fig.- I-2). Una de las principales características de la zona de subducción es la variación del buzamiento de la placa oceánica de subducción. La existencia de la placa de Rivera fue sugerida en 1970, y sus limites fueron definidos por las zonas de fractura de Rivera y Tamayo. Se han presentado datos que confirman que las placas de Rivera y Cocos son independientes y tienen velocidades de convergencia diferentes. Entre la placa de Rivera y la

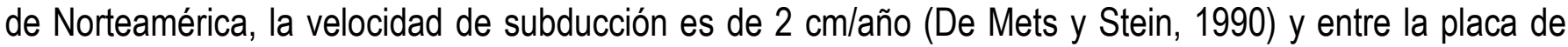
Cocos y la de Norteamérica se tiene una velocidad relativa que aumenta hacia el sureste a lo largo de la trinchera (Pardo y Suárez, 1994), siendo de 6 cm/año (Singh et al., 1981; De Mets et al., 1990). En el área 


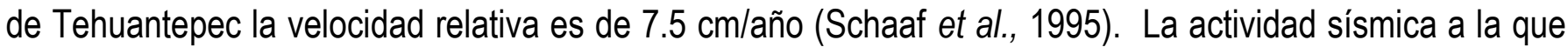
está sujeta la costa de Guerrero es asociada a la interacción entre dichas placas tectónicas, en la interacción se han originado los sismos más grandes que han afectado estructuras civiles de México (Nixon, 1982; Burbach et al., 1984).

Al sur de la zona de Petatlán, en la parte central de la costa del Pacífico se encuentra un área donde no han ocurrido grandes sismos, conocida como la brecha o "gap" sísmico de Michoacán (Kelleher et al., 1973; Eissler et al., 1994; Houston y Kanamori, 1994). Se sugiere que este gap se debe a la subsidencia asismica o a largos periodos de recurrencia (Priestley y Masters, 1994), tal vez relacionados con la intercepción de las zonas de fracturas Orozco en la trinchera Mesoamericana (Singh et al., 1981). Esta área fue designada como un "gap" sísmico, ya que transcurrieron 74 años entre el último evento ocurrido en ésta zona en 1911 (Ms=7.5) y el evento de 1985. (McNally et al., 1994). La notable ausencia de eventos sísmicos con profundidad de foco mayores que $70 \mathrm{~km}$ al norte de la Faja Volcánica Transmexicana suponen que la placa subductora pierde sus características de fragilidad y se hunde asismicamente en el manto al norte de la faja volcánica (Pardo y Suárez, 1994).

\subsection{Sismos}

Se han realizado un cierto número de observaciones de eventos naturales y experimentos con fuentes controladas que indican que la roca en la corteza terrestre es anisotrópica. Se piensa que esa anisotropía se debe a la presencia de grietas en la roca, que está alineada a acierta dirección debido a esfuerzos dominantes (Sabina, 1994).

Un sismo es el resultado del movimiento repentino de una masa de roca con respecto a otra. Los sismos tectónicos se producen por el rompimiento de las rocas que constituye la corteza terrestre. La corteza terrestre se comporta como un material frágil que se rompe por la acción de una fuerza que sobrepasa la resistencia del material. Cuando dos placas o bloques de la corteza terrestre están en contacto se produce fricción entre ellas manteniéndolas en contacto hasta que la fuerza que se acumula por el movimiento entre las placas sea mayor que la fuerza de fricción que las mantiene en contacto. Al romperse ese contacto se produce un sismo. La energía elástica que se ha acumulado en la zona de contacto se libera en forma de calor, deformación de la roca y energía sísmica que se propaga en el interior de la Tierra en forma de ondas sísmicas. El tamaño de un sismo es una función de la región que sufre el rompimiento. Entre mayor sea el área que se rompe por la acción de las fuerzas tectónicas, mayor es el tamaño del sismo. Como la mayor área de contacto entre placas se encuentra en las zonas de subducción, es ahí donde ocurren los sismos más grandes (Fig.- I-2). En México la zona de subducción comprende la costa del Pacifico entre Puerto Vallarta en el Estado de Jalisco hasta Tapachula en Estado de Chiapas (Kostoglodov y Pacheco, 1999 (Fig.- I-3).

La superficie de las placas en contacto no es lisa sino que presenta asperezas (montañas) que se oponen al movimiento. Cuando aumenta la presión ocurre el rompimiento del obstáculo desarrollando un sismo. Los sismos interplaca ocurren en México por el roce entre la placa de Norteamérica y las placas oceánicas de Rivera y de Cocos a lo largo de su zona de contacto. El sismo más grande en el siglo XX ocurrió el 3 de junio de 1932 en la costa de Jalisco ( $M=8.2)$ con una longitud de ruptura de $280 \mathrm{~km}$, otro sismo importante 
fue el 19 de septiembre 1985 en la costa de Michoacán (M=8.1) con una longitud de ruptura de $180 \mathrm{~km}$. Este tipo de sismos son someros, localizándose a profundidades entre 5 y $35 \mathrm{~km}$ (Fig. - I-4).

Ocurren también sismos de menor magnitud que se presentan a profundidades mayores de $40 \mathrm{~km}$, en la interface de las placas subducidas. Las grandes presiones que se encuentran a mas de $100 \mathrm{~km}$ de profundidad hacen que los materiales pierdan el contenido de agua y otros líquidos que al reaccionar químicamente con el manto, se vuelven más livianos y suben a la superficie terrestre. Es así como se genera la actividad de la mayoría de los volcanes, por donde sale este material caliente del interior de la Tierra (Fig.- I-5). Otros sismos se observan lo largo de la Faja Volcánica Transmexicana y son los principales en la zona de Veracruz. Tanto en el Golfo de México como en el Océano Pacifico se presentan sismos oceánicos ligados a las zonas de fractura oceánica. (Kostoglodov y Pacheco, 1999).

Se ha observado que los grandes sismos $(M>7)$ tienen un periodo de recurrencia, es decir, que los sismos más grandes en una región rompen áreas que fueron previamente rotas por sismos comparables a ellos y que las áreas adyacentes casi no se traslapan. Se ha propuesto que el mayor sismo registrado en cada una de las áreas marca el límite superior para sismos generados en ellas y si una de estas áreas no hubiera generado un gran sismo en un tiempo largo debería considerarse como hueco en el patrón de liberación de energía sísmica. Esto implicaría que el hueco debe ser llenado por un gran sismo en un futuro próximo. A estos huecos se les conoce como brechas sísmicas (gap). La teoría de las brechas sísmicas permite tener una idea, si no del punto en donde comenzará el sismo esperado, si de la extensión y localización posible del área cuya ruptura lo generará (Nava, 1994). El periodo de recurrencia de sismos grandes se ha estimado entre 30 y 70 años (Singh et al., 1981; Kostoglodov et al., 2002). Se ha propuesto usar 30 años como tiempo de referencia para considerar un área como brecha sísmica. La identificación de las brechas sísmicas sirve para señalar regiones de alto potencial sísmico. Todos los grandes sismos que han ocurrido en México desde 1973 han llenado brechas sísmicas identificadas previamente: Colima, 1973, ( $M=7.5)$; Oaxaca, 1978, (M=7.8); Petatlán, 1979, (M=7.9); Michoacán, 1985, ( $M=8.2$ y 7.5). Se tienen 3 regiones donde no se tienen evidencias convincentes de la ocurrencia de sismos grandes que son la costa de Jalisco-Colima, Costa Grande de Guerrero y Oaxaca Central (Nava, 1994). Se ha identificado una brecha sísmica en el estado de Guerrero, dicha brecha sísmica tendría un alto potencial de ruptura, donde un gran sismo ( $M>8.2$ ) sería probable que ocurriera en un futuro próximo (Singh y Mortera, 1991), debido a que el tiempo de recurrencia para grandes eventos en este segmento de la placa ha sido rebasado y que los momentos sísmicos acumulados evidencian un déficit en la liberación de energía (Nishenko y Singh, 1987; Kostoglodov et al., 2002 ). Se podría dividir esta ultima zona en dos posibles brechas sísmicas. La brecha sísmica de la Costa de Guerrero y la brecha sísmica de Oaxaca, localizadas entre la zona de ruptura de Acapulco de 1957 ( $(M=7.7)$ y las proyecciones de las zonas de fractura de Orozco y O'Gorman respectivamente (Nishenko y Singh, 1987). La brecha de Guerrero se encuentra limitado al NW por el evento sísmico de Petatlán del 14 de marzo de $1979(\mathrm{M}=7.6)$, al SE con la segmentación de la placa (Singh y Mortera, 1991). En esta zona han ocurrido varios sismos: $1899(\mathrm{M}=7.9), 1907(\mathrm{M}=7.7), 1908$ ( $\mathrm{M}$ $=7.6$; 7.0), 1909 ( $M=6.9), 1911$ ( $M=7.6), 1957$ ( $M=7.7), 1962(M=7.2 ; 6.9), 1989$ ( $M=6.9)$ (Nishenko y Singh, 1987). Estudios realizados de los momentos sísmicos acumulados, dan evidencias de un déficit en la liberación de energía por lo que rompimiento en la brecha y se podría generar un gran sismo de magnitud ( $M=8.2$ ) (Suarez et al., 1990; Singh y Mortera, 1991; Valdéz y Novelo, 1997; Kostoglodov et al., 2002). 


\subsection{Tipos de ondas sísmicas}

Las ondas sísmicas que se propagan por el interior de la Tierra reciben el nombre de ondas internas o de cuerpo. Estas ondas son generadas en el momento de producirse el sismo (Fig.- I-6). Existen otro tipo de ondas sísmicas que se propagan por la superficie de la Tierra y que son producidas por la interacción de las ondas internas con la superficie libre y las discontinuidades existentes en la corteza terrestre, estas son las ondas superficiales (Núñez-Cornú, 1994).

En el siglo XIX se crearon las bases matemáticas para aprovechar la teoría de las ondas sísmicas. Al principio se pensaba que las ondas sísmicas eran de una sola clase, iguales a las ondas de sonido. En 1940, se predijo la existencia de ondas sísmicas de corte, más lentas que las ondas de sonido. Al principio se les llamaba simplemente ondas primeras y ondas segundas. Actualmente se les conoce con las iniciales P y S. Posteriormente Lord Rayleigh elaboró la teoría de las ondas sísmicas. En 1905, A.E.H.Love completó la teoría y dió su nombre a la cuarta onda sísmica, la onda superficial de cortante (Lomnitz, 1994). Se tienen entonces dos tipos de onda de cuerpo (P y S) y dos de corte (las Love y las Rayleigh). Las ondas $\mathrm{P}$ y $\mathrm{S}$ se propagan por el interior de un cuerpo sólido y no se quedan en la superficie. En todos los casos lo que se transmite a través de una onda, es energía.

Esta energía se reparte entre las cuatro formas de onda y se propaga por toda la Tierra. Como todas las ondas, las ondas sísmicas se reflejan y se refractan. Pueden refractarse en las diversas capas terrestres 0 reflejarse en la superficie de la Tierra (Lomnitz, 1994).

\subsection{Escalas de magnitudes}

Para cuantificar un sismo se requieren diversos parámetros (orientación, buzamiento y sentido del movimiento en el plano de la falla, la longitud y área de la zona de ruptura, desplazamiento de la falla, velocidad y aceleración de partículas del movimiento de la falla, duración de la ruptura y las energías sísmicas total e irradiada. Sin embargo, solo se dispone de esta cantidad de información para unos cuantos sismos, puesto que para obtenerlos es necesario complejos análisis, así como datos de muy alta calidad. $\mathrm{Si}$ se empleara un solo parámetro para describir el tamaño del sismo, este parámetro debería ser la cantidad de energía sísmica liberada (Singh y Ordaz, 1994). La escala de magnitud, que mide la energía disipada en el foco de un sismo y transformada en ondas elásticas (Udias, 1971). Una alternativa simple para medir sismos está basada en las amplitudes de las ondas sísmicas (Castro, 1994; Havskov y Macias, 1983; Singh y Ordaz, 1994).

\subsection{Efectos precursores de sismos.}

Antes de la ocurrencia de algunos sismos (Nava, 1994), se han observado en la región epicentral los siguientes fenómenos sísmicos: cambios en la distribución espacial de los sismos pequeños, brechas sísmicas, cambios en las velocidades de las ondas sísmicas de cuerpo, así como cambios en la orientación de los esfuerzos principales del terreno deducidos a partir de cambios en los mecanismos focales. Entre los fenómenos no sísmicos detectados están: cambios en la elevación o deformación del terreno, cambios en el campo gravitatorio, cambios en el contenido del radón (en suelo y en agua subterránea), cambio en los niveles y en el gasto de los pozos, temperatura y composición química de manantiales, etc. Existen otros como por ejemplo: variaciones en la resistividad eléctrica del terreno y aparición de señales de autopotencial (voltajes espontáneos entre puntos del terreno), efectos geomagnéticos, comportamiento anómalo de algunos animales, efectos luminosos, etc. 


\subsection{Zonas volcánicas.}

El Eje Neovolcánico Mexicano cruza el sur de México de este a oeste alrededor de los $19^{\circ} \mathrm{N}$. Tiene un ancho de 20 a $150 \mathrm{~km}$ y $1000 \mathrm{~km}$ de largo, extendiéndose aproximadamente en la dirección E-W desde cerca de Puerto Vallarta hasta Veracruz (Negendank et al., 1985; De la Fuente y Verma, 1993). La orientación no es paralela a la trinchera Mesoamericana sino oblicua con respecto a ella. A lo largo de dicho eje se encuentra una gran variedad de estructuras volcánicas de carácter calco-alcalino de edad PlioCuaternaria como son los grandes estratovolcanes, conos cineríticos, monogenéticos, y numerosas calderas. En su sector central y occidental es evidente su sobre posición a la provincia de la Sierra Madre Oriental (Garduño-Monroy y Gutiérrez-Negrin, 1992; Pardo y Suárez, 1994; Zuñiga et al., 2000). El origen del volcanismo en el occidente de México ha sido relacionado con la subducción de la placa de Rivera y Cocos (Nixon et al., 1987; Negendank et al., 1985; Pardo y Suárez, 1994). Más de tres cuartas partes de los volcanes, por encima del nivel del mar, se encuentran en la zona de subducción, hubiéndose consignado aproximadamente 8000 edificios volcánicos. Aunque se han identificado 3225 estructuras de origen volcánico, las estructuras volcánicas se clasifican en cerros (2364), lomas (1289, mesetas(126), volcanes (67), hoyas (26), estratovolcanes (3), domos (1), estructuras no definidas (514). De éstas, aproximadamente el $60 \%$ han arrojado rocas de composición máfica (basaltos), el restante $40 \%$ roca de composición intermedia-félsica (riolitas) (De la Fuente y Verma, 1993). La actividad volcánica puede tener una repercusión directa en los acuíferos cercanos al edificio volcánico, ya que puede cambiar las concentraciones de elementos disueltos en agua (Peña et al., 1998a).

Yang et al. (2002) observaron en Taiwán una relación en una zona con fallas con la actividad sísmica, en nuestro caso el Eje Neovolcánico Mexicano genera una serie de fallamientos que continúan en el Golfo de México y que generan sismicidad de baja magnitud en la zona. En el Estado de Veracruz, se localiza la Planta Nuclear de Laguna Verde donde se observa ese tipo de sismicidad.

\section{RADÓN}

Las rocas que constituyen la corteza terrestre contienen concentraciones de uranio a nivel de trazas de 2 a 4 ppm (Abu-Jarad y Fremlin, 1983; Segovia et al., 1994), algunas rocas ígneas contienen mayor concentración de uranio que las rocas metamórficas y sedimentarias (Thomas et al., 1993). El uranio y su progenie emiten radiación $\alpha, \beta$ y $\gamma$ (Peña, et al., 1999). El 238U es el isótopo natural más abundante del uranio, es radiactivo y por decaimientos sucesivos forma lo que se denomina una serie radiactiva natural. Entre los elementos generados en dicha serie radiactiva se presenta sólo uno, el radón, que es un gas noble (Tidjani et al., 1990) los demás son sólidos (Fig.- I-7).

\subsection{Radiactividad}

La radiactividad es un fenómeno en el cual el núcleo atómico emite espontáneamente partículas atómicas 0 radiaciones electromagnéticas transformándose en otro diferente al original (Segovia, 1994; Azorin, 1997; Semat y Albright, 1972; Navarrete y Cabrera, 1993; Iturbe, 2001). 
Cuando un isótopo radiactivo emite una partícula alfa $(\alpha)$, se transforma en otro isótopo con un número atómico $(Z)$ inferior en dos unidades al del núcleo original y una masa atómica $(A)$ inferior en cuatro unidades.

$$
(Z, A) \rightarrow(Z-2, A-4)+\alpha^{++}
$$

Cuando un isótopo radiactivo emite una partícula beta $(\beta)$, se emite un electrón negativo, el núcleo conserva su masa atómica pero su número atómico aumenta en una unidad.

$$
(Z, A) \rightarrow(Z+1, A)+\beta^{-}
$$

Los isótopos radiactivos son inestables y por desintegraciones progresivas se van transformando en otros hasta terminar en uno estable.

La medida de la radiactividad es la actividad. Si se tienen $N$ núcleos radiactivos en un determinado instante, la actividad $A$ se define como el número de átomos desintegrados en la unidad de tiempo:

$$
A=-\frac{d N}{d t}
$$

En el Sistema Internacional de Unidades, la unidad de actividad es el Becquerel, donde $1 \mathrm{~Bq}=1$ desintegración $\mathrm{s}^{-1}$.

El número de átomos radiactivos $d N$ que se desintegran en un intervalo de tiempo $d t$ es constante para cada isótopo radiactivo, lo cual se puede expresar como:

$$
A=\frac{d N}{d t}=-\lambda N
$$

donde: $\lambda=$ la constante de desintegración, es específica para cada radionúclido y representa la probabilidad de que un núcleo radiactivo se desintegre en la unidad de tiempo. El símbolo negativo indica que el número de átomos radiactivos disminuye al aumentar el tiempo transcurrido.

De la relación (2) se tiene:

$$
\begin{array}{r}
\frac{d N}{N}=\lambda d t \\
\ln \left[\frac{N}{N o}\right]=-\lambda t \\
{\left[\frac{N}{N o}\right]=e^{-\lambda t}}
\end{array}
$$


Por lo tanto:

$$
N=N o e^{-\lambda t}
$$

Donde:

$$
\text { No }=\text { número de átomos radiactivos en el tiempo } t=0
$$

El tiempo necesario para que $\mathrm{N}$ se convierta en $\mathrm{N} / 2$ se le conoce como la vida media ( $\mathrm{T} 1 / 2)$ y se expresa como:

$$
N=1 / 2 \text { No }
$$

De las relaciones (4) y (5) y substituyendo los valores $t$ y $N$ por $T_{1 / 2}$ y $N_{1 / 2}$ se tiene:

$$
T_{1 / 2}=\frac{0.693}{\lambda}
$$

El comportamiento de los átomos radiactivos $N_{1}$, de los isótopos primarios de las series radiactivas naturales, ${ }^{235} \mathrm{U},{ }^{232} \mathrm{Th}$ y del ${ }^{238} \mathrm{U}$, está regido por la siguiente ecuación:

$$
\frac{d N_{1}}{d t}=-\lambda_{1} N_{1}
$$

cuya solución es:

$$
N_{1}=-N_{1}^{0} e^{-\lambda_{1} t}
$$

Donde: $N_{1}^{0}=$ valor de $N_{1}$ al tiempo $t=0$

$\lambda_{1}=$ constante de desintegración radiactiva del isótopo correspondiente.

La segunda especie $N_{2}$, se forma a partir de $N_{1}$, con una rapidez igual al decaimiento de la primera especie $\lambda_{1} N_{1}$, y a su vez decae con una rapidez $\lambda_{2} N_{2}$, es decir:

$$
\frac{d N_{2}}{d t}=\lambda_{1} N_{1}-\lambda_{2} N_{2}
$$

o sea:

$$
\frac{d N_{2}}{d t}+\lambda_{2} N_{2}-\lambda_{1} N_{1}^{0} e_{1}^{-\lambda t}=0
$$

Esta es una ecuación diferencial lineal de primer orden y su solución es la siguiente:

$$
N_{2}=\left(\frac{\lambda_{1}}{\lambda_{2}-\lambda_{1}}\right) N_{1}^{0}\left(e_{1}^{-\lambda t}-e_{2}^{-\lambda t}\right)+N_{2}^{0} e_{2}^{-\lambda t}
$$


El primer grupo de términos de la ecuación 10 muestra el crecimiento del núcleo hijo a partir de la especie primaria y su decaimiento. El último término muestra la contribución del núcleo hijo presente inicialmente, ya que $\mathrm{N}_{2}{ }^{\circ}$ es el valor de $\mathrm{N}_{2}$ cuando $\mathrm{t}=0$.

Para el ${ }^{226} \mathrm{Ra}$ y el ${ }^{222} \mathrm{Rn}$ se establece el caso llamado equilibrio secular debido a que $\lambda{ }^{226} \mathrm{Ra}<<\lambda{ }^{222} \mathrm{Rn}$. Sustituyendo este criterio en la ecuación 10 y simplificando la ecuación se obtiene la siguiente relación:

$$
\lambda_{1} N_{1}=\lambda_{2} N_{2}
$$

Que indica que la vida del padre es tan larga que su actividad no decrece en forma notoria durante muchas vidas del nucleo hijo.

\subsection{Propiedades físicas, químicas y nucleares del radón.}

El radón es un gas noble, incoloro e inodoro, es un emisor de partículas alfa $(\alpha)$ de $5.49 \mathrm{MeV}$ (Tidjani et al., 1990; Segovia, 1994). Su configuración electrónica de la capa externa es $6 s^{2} 6 p^{6}$, por lo que es un elemento químicamente inerte. De los gases nobles, el radón posee los puntos más altos de ebullición y fusión, así como los valores más elevados de temperatura, presión critica y calor de vaporización. № existen isótopos estables del radón, por lo tanto sus propiedades químicas se han estudiado con cantidades imponderables de este elemento. Es soluble en agua fría (Cothern, 1987), su solubilidad decrece cuando se incrementa la temperatura. El coeficiente de solubilidad en agua está definido como la relación $\mathrm{Cw} / \mathrm{Ca}$, donde $\mathrm{Cw}$ y Ca son las concentraciones de radón en agua y aire respectivamente.

El radón se genera en la naturaleza como producto del decaimiento de las series radiactivas naturales. Existen tres isótopos radiactivos de éste elemento, todos ellos emisores de partículas alfa, el actinón $\left({ }^{219} \mathrm{Rn}\right)$, el torón $\left({ }^{220} \mathrm{Rn}\right)$ y el radón $\left({ }^{222} \mathrm{Rn}\right)$, con vidas medias de $3.9 \mathrm{seg}, 54.5$ seg y 3.824 días, productos de las series radiactivas del ${ }^{235} \mathrm{U},{ }^{232} \mathrm{Th}$ y del $238 \mathrm{U}$ respectivamente. Por ser de vida media más larga el ${ }^{222} \mathrm{Rn}$, es el que tiene mayor probabilidad de integrarse a los acuíferos y llegar a la atmósfera (Igarashi y Waquita, 1995; Maldonado, et al., 1996; Bonotto y Andrews, 1997; Zouridakis et al., 2002).

El ${ }^{222} \mathrm{Rn}$ se origina por la desintegración de los átomos del ${ }^{226} \mathrm{Ra}$ dentro de los granos de las rocas que contienen al uranio y a su progenie en equilibrio secular (Segovia, et al., 1994; Nishizawa, et al., 1998). No todos los átomos de radón generados por el radio contenido en las rocas o en los granos del suelo son liberados en los poros, puede suceder que viajen distancias cortas y queden en el mismo grano, que viajen a través de los poros y permanezcan empotrados en un grano adyacente, o que escapen a través de la superficie de los granos y se mezclen con los fluidos intergranulares (Schumann y Gundersen, 1996; Sesana et al., 1999). Cuando el radón es liberado de los granos minerales de un material poroso tal como las rocas o el suelo, éste migra a través de los espacios intergranulares bajo 2 mecanismos: la difusión y el arrastre (Hess, 1985; Vasarhelyl, et al., 1997). La difusión molecular es un proceso en el cual la materia se transporta de un lugar a otro dentro de un sistema, como resultado de movimientos moleculares al azar inducidos por diferencias de concentración. La mayor probabilidad ocurre desde donde existe una mayor concentración hacia donde es menor. Esta tendencia está descrita por la Ley de Fick, la cual relaciona el gradiente de concentración con el flujo por unidad de masa (Bird et al., 1992; Hines y Maddox, 1987; Lobo, 
1997); La difusión molecular depende de la concentración, la porosidad del terreno y la distancia a recorrer (Martinelli, 1998; Shweikanni et al., 1995). El arrastre que es el movimiento de los fluidos que lo transporta se ve impulsado por diversos factores: corrientes de fluidos terrestres (agua y/o gases) (Segovia, et al., 1994), presión, fallas geológicas, etc. (Poole et al., 1997; Etiope y Martinelli, 2000). El radón presente en el suelo 0 en las rocas puede también ser transportado por fuerzas que originan cambios en los poros mediante esfuerzos de compresión causados por las mareas terrestres, o por cambios en la relación de esfuerzos como ocurre en el caso de los sismos (Igarashi y Waquita, 1995). El radón tiene gran movilidad porque es un gas inerte (Thomas et al., 1993). El radón es reconocido como una fuente importante de exposición a la radiación natural (Segovia et al.,1999c).

El estudio de elementos radiactivos naturales en el agua subterránea puede contribuir al conocimiento hidrogeológico de las cuencas, los factores como son la corta vida media y la falta de reactividad química hacen del radón una herramienta geoquímica interesante para la investigación de las aguas subterráneas (Segovia y Bulbulian, 1992; Pane, 1995; Low, 1996; Segovia et al., 1997a; Hamada, 2000).

Una vez que el radón penetró en el agua circundante o en la fase aérea es transportado por ésta por medio del arrastre. En algunos manantiales se puede perder hasta el $41 \%$ del contenido de radón después de fluir más de 1 metro en superficie, así mismo las aguas subterráneas de origen termal que ascienden rápidamente a través de fallas pueden contener concentraciones altas de radón (Davis y De Wiest, 1971; Tamimi y Abumurad, 2001). De ésta manera, el radón fluye en las fisuras llegando eventualmente a la superficie terrestre (Monnin y Seidel, 1992; Porstendorfer, 1993; Csige et al., 1995). En los acuíferos se producen continuamente cantidades de ${ }^{222} \mathrm{Rn}$ que proceden de la desintegración radiactiva del ${ }^{226} \mathrm{Ra}$. La mayor parte del radón que entra en contacto con el agua subterránea es la consecuencia de su migración en la roca o el suelo (Kitto et al., 1996; Bonotto y Andrews, 1997), permanece en este medio hasta que el agua entra en contacto con la atmósfera o hasta que el radón se desintegra. La vida media del radón, así como la velocidad de desplazamiento del agua subterránea le permiten transportarse hacia la superficie (Asikainen y Kahlos, 1980; Monnin y Seidel, 1992). Aunque se tienen teorías más recientes acerca del transporte del radón en el agua subterránea y en el suelo, como es el caso del modelo de transporte por medio de microburbujas, que se basa en el transporte natural por flujos del geogas (cualquier gas originado o presente dentro de la corteza terrestre) (Etiope, 1998; Beaubien y Lombardi, 2001; Etiope y Hakl, 2001), por lo general este proceso se lleva a cabo en zonas falladas en donde el gas puede canalizarse (Guerra y Etiope, 1999). El radón y otros elementos presentan buena disposición para concentrarse en la interfase del agua-gas de las micro burbujas y realizar su transporte a grandes distancias (Varhegyi, et al., 1992; Etiope y Martinelli, 2002.

La concentración de radón en agua subterránea depende además de su progenitor, del grado de fracturamiento de las rocas y del tiempo de precolación del agua, obteniéndose valores altos cuando la velocidad del agua es suficientemente baja, de manera que ésta pueda captar una gran cantidad de radón proveniente de las rocas, pero no demasiado lenta para que el radón no decaiga en cantidades substanciales (Segovia y Bulbulian, 1992). Así mismo la concentración de radón en las aguas subterráneas es aproximadamente proporcional al tamaño efectivo del grano de la roca en un acuífero. En rocas ígneas el flujo del agua subterránea se lleva a cabo casi siempre a lo largo de fracturas, en consecuencia altas concentraciones de radón pueden ser transportadas por las aguas subterráneas por medio de dichas 
fracturas (Gascoyne y Durrance, 1993). La presencia de microfracturas puede reducir el tamaño efectivo del grano de la roca y aumentar la concentración de radón en las aguas subterráneas (Igarashi et al., 1995). Las rocas ígneas ácidas (granitos) contienen más elementos radiactivos que las sedimentarias y menos que las ígneas básicas (basaltos) (Al-Bataina et al., 1997; lelsch et al., 2001; Karpinska et al., 2002).

Aunque la detección del radón en la superficie terrestre se ve afectada por factores tales como: presión, temperatura, precipitación, etc. (Porstendorfer, et al., 1994), se ha logrado establecer la base para suponer que la eminencia de un sismo puede alterar sensiblemente la emanación de radón hacia la superficie y en consecuencia la concentración de éste gas antes y después de ocurrir dicho sismo (Monnin y Seidel, 1998).

En este sentido se han realizado en varias regiones del mundo registros continuos de la concentración de radón tanto en suelo como en agua subterránea con la finalidad de predecir sismos (King, 1980; Wakita, et al., 1986,1988, 1996; Igarashi y Wakita, 1990,1995; Virk y Singh, 1993; Djeffal, et al., 1995; Hakl, et al., 1995; Igarashi, et al., 1995; Loria, et al., 1995; Bella y Pettinelli, 1997; Papastefanou, et al., 1997; Yasuoka y Shinogi, 1997; Virk, et al., 1997, 2000; LaBrecque et al., 2001).

Así mismo, se ha observado en algunos casos que antes de un evento sísmico los valores promedio del gas radón cambian, generalmente incrementando la emanación de éste (Ulomov y Mavashev,1967; King et al., 1995; Igarashi et al., 1995; LaBrecque et al., 2001). Estas anomalías se han observado como un incremento gradual con mediciones integradas de largo plazo, como en forma de señales muy breves y de alta intensidad (Loria et al., 1995). Para relacionar los niveles de la concentración de la emanación de radón y los eventos sísmicos, es necesario la medición de dicho gas preferentemente en la vecindad de una falla o fractura, o en el área de alta o frecuente actividad sísmica. Además, se debe obtener la información ambiental del entorno, para discriminar los factores no-tectónicos que pudieran afectar los niveles de radón (precipitación, temperatura, etc.). Si los valores de concentración de radón se desvían por más de $2 \sigma$, (donde $\sigma$ es la desviación estándar), se considera la desviación como una anomalía (Segovia et al., 1993). El evento podría llamarse precursor si ocurre antes de un sismo. Puede ocurrir que los niveles de la concentración de radón estén caracterizados por una tendencia de aumento en las concentraciones previas al sismo. Debido a la alta movilidad en el suelo y a su carácter radiactivo se puede utilizar el radón como un trazador natural eficaz en los estudios del transporte de fluidos (gases y líquidos) asociados a movimientos de la corteza terrestre, en estudios de estructuras y comportamiento de acuíferos (Segovia y Bulbulian, 1992; Monnin y Seidel,1992; Pane, 1995; Low, 1996; Segovia et al., 1997a; Wysocka et al., 2001). Las variaciones en el suelo y en el agua subterránea han permitido en algunas ocasiones obtener correlaciones de algunas anomalías con eventos geofísicos de gran magnitud.

Entre las técnicas usadas en las investigaciones acerca de los precursores sísmicos, se encuentra la geoquímica de fluidos, la cual ha proporcionado señales de alta calidad, como resultado del avance tecnológico de los instrumentos de medición. Se puede considerar que las anomalías geoquímica del agua de manantiales y en pozos pueden en ocasiones, tener una asociación con la actividad sísmica regional antes y después de eventos sísmicos (Igarashi y Wakita, 1995; King et al., 1995; Tsunogai y Wakita, 1995; Sugisaki et al., 1996; Castro-Morales y LaBrecque, 1999; Papastefanou et al., 1999; Zhang y Zhang, 1999), lo que ha permitido evidenciar la relacion genética entre el flujo, la química de fluidos y los procesos de fallamiento y que concentraciones de diferentes compuestos o elementos químicos pueden variar debido 
a los mecanismos locales de los sismos. Se han realizado estudios acerca de los precursores geoquímicos en URSS, Japón, China y EU entre otros (Toutain y Baubron, 1999). Se ha determinado que existe una estrecha relación entre las anomalías geoquímicas y las condiciones hidrogeológicas. Un ejemplo sería, las estaciones de muestreo localizadas en los abanicos aluviales que suelen estar controladas por las características meteorológicas, sin embargo, las estaciones que están localizadas sobre rocas basálticas pueden mostrar cierta respuesta relacionada con los sismos grandes (Fong-liah y Gui-ro, 1981; Virk et al., 2000).

\subsection{Características de los detectores de radón.}

Los métodos de la detección de la radiación nuclear, independientemente de la forma de emisión, se realizan por la transmisión de toda o parte de su energía de la radiación al medio detector ya sea por ionización directa de los átomos del medio detector o provocando la emisión de partículas cargadas, las cuales a su vez producen ionización en el medio (Espinosa, 1994). La ionización así producida puede detectarse por varios métodos, donde la selección de los instrumentos depende de la aplicación específica, información necesaria, duración de la muestra y requerimientos de sensibilidad (Somogyi, 1990). En los últimos años se han desarrollado una gran variedad de instrumentos para la detección del radón, éstos pueden ser divididos en 2 categorías: activos y pasivos. Para su operación los detectores activos requieren de una fuente de energía eléctrica para el registro de las partículas $\alpha$ mientras que los pasivos integran la información sin necesidad de fuentes de energía (George, 1996; Papastefanou, 2003).

\section{DETECTORES ACTIVOS}

Detectores con diodos de silicio. Son detectores semiconductores muy sensibles a las cargas de las partículas pesadas (alfa). El principio de detección se basa en la creación de pares electrón-vacancia, debidas al paso de una partícula $\alpha$ a través del diodo. Estas cargas generan una corriente eléctrica cuya amplitud es proporcional a la energía depositada.

\section{DETECTORES PASIVOS}

Detectores sólidos de trazas nucleares (DSTN). El principio de detección de los DSTN, está basado en la producción de daños a nivel atomico debido al paso de partículas pesadas por materiales dieléctricos sólidos (Monnin y Seidel, 1992; Espinosa, 1994).

Los DSTN son materiales, tales como polímeros orgánicos, vidrios o cristales, en los cuales las partículas nucleares, al incidir, forman regiones de daño intenso a escala atómica. Estas regiones pueden representarse como un cilindro de material que ha sufrido ionización y desplazamientos atómicos alrededor de la trayectoria de las partículas. El resultado son cambios estructurales permanentes en la materia original. A la región afectada a lo largo de las trayectorias de las partículas, se le conoce como traza latente. En materiales aislantes a temperatura ambiente, la traza latente es permanente. En materiales conductores, por el contrario, no se observan trazas permanentes, debido a que la movilidad de los electrones del material permite la regeneración del daño por ionización provocado por el paso de la partícula, de manera que el material vuelve a su forma original antes de que se forme cualquier traza incipiente. 
Dado el tamaño de la traza latente, es preciso amplificarla para observarla. Un método sencillo para amplificar las trazas latentes consiste en sumergir el material irradiado en una solución química que actúe como un abrasivo de forma preferente en la región dañada. Esto da lugar a pequeños canales huecos en el material en los sitios donde se formaron las trazas latentes. Estas concavidades se denominan trazas reveladas. Una traza puede ser revelada debido al hecho de que al formarse la traza latente la estructura original del material ha sido alterada y presenta una reactividad química distinta a la del resto del material, de esta manera, cualquier traza latente que cruce una superficie del detector que se encuentre en contacto con la solución química se disolverá más rápidamente que el resto del material, produciendo una concavidad cuyo diámetro y profundidad aumenta si se prolonga el tiempo de acción de dicha solución química. El diámetro superficial de estas trazas puede llegar a medir unas cuantas micras, lo que las hace observables por microscopía óptica convencional. Al disminuir el espesor, el número de trazas registradas y sus dimensiones pueden variar, ya que aquellas partículas que no tuvieron suficiente energía para formar una traza latente muy profunda desaparecen al disminuir el espesor de la película detectora. Cada material detector tiene un umbral de detección por debajo del cual no registra daño el material.

Los detectores de trazas son en general insensibles al paso de las partículas beta $(\beta)$ o radiación gamma $(\gamma)$. Para el caso de las partículas $\alpha$ de la emisión del radón se utilizan en general plásticos (Segovia et al., 1992) que dan resultados proporcionales a la concentración del radón (Miles y Sinnave,1984). Como los detectores sólidos de trazas nucleares tienen la finalidad de medir el número de trazas de partículas $\alpha$ en determinado intervalo de tiempo de exposición (Nelson, 1987), con éstos detectores se puede integrar la actividad a lo largo de varias semanas, así como medir concentraciones bajas (Tommasino, 1990). El muestreo con detectores sólidos de trazas es un muestreo de exposición in situ ya que los detectores se colocan con diferentes dispositivos que permiten la llegada del radón y registrar las partículas $\alpha$ del decaimiento de aquellos núcleos que se desintegran en la vecindad del detector (Peña et al., 1992). Estos detectores se utilizan en el muestreo de la concentración de radón ambiental (Singh et al., 1984; Segovia, et al., 1989a; Tommasino, 1990; Kleis et al., 1992; Monnin y Seidel, 1992; Khan y Qureshi, 1994; King, et al., 1995; Papastefanou, 2003).

\section{RADIACIÓN GAMMA AMBIENTAL}

Las radiaciones de alta energía que penetran en la atmósfera terrestre desde el espacio extra-atmosférico se denominan rayos cósmicos primarios. Cuando interaccionan con los núcleos atómicos en la atmósfera se forman partículas secundarias y radiaciones electromagnéticas, que reciben el nombre de rayos cósmicos secundarios. Los rayos cósmicos producen igualmente radionúclidos por interacción con los núcleos contenidos en el aire, tierra y agua (OIEA, 1996). Así mismo, la radiación cósmica está influenciada por las grandes erupciones solares. El ambiente contribuye a la exposición de los seres vivos a la radiación gamma la cual proviene de la geología local, de los materiales de construcción, de la concentración de isótopos radiactivos en el tejido humano, de la ingesta de agua y de los alimentos, etc. (Shenber, 1997; Noureddine et al., 1997; Saito et al.,1998). En este trabajo se utilizará la definición de "dosis gamma" cuando se quiera referir a "dosis absorbida producida por la radiación gamma". La detección de la radiación 
terrestre natural puede ser muy variable en el tiempo y la ubicación (Segovia et al., 1989b; Sroor et al., 2001).

\subsection{Dosimetría termoluminiscente}

En algunos materiales (sólidos dieléctricos), la excitación inducida por la radiación coloca a los átomos y moléculas en un estado excitado. La luminiscencia se presenta en una gran variedad de materiales tanto orgánicos (compuestos orgánicos, materiales biológicos y bioquímicos), como inorgánicos (cristales inorgánicos, vidrios y cerámicos) (Azorin, 1990; Chen y McKeever, 1997). La luminiscencia en los materiales orgánicos se debe a la formación de radicales libres, en cuanto a los inorgánicos se debe a la formación de electrones libres y agujeros. Ocasionalmente se emite luz mientras se mantiene la excitación, a éste fenómeno se le llama fluorescencia. Los electrones de un átomo pueden permanecer en estado excitado aproximadamente $10^{-8} \mathrm{~s}$, volviendo a su estado original con la emisión de un fotón. En otros casos la luz persiste cuando se elimina la excitación, a éste fenómeno se le conoce como fosforescencia con una duración mucho mayor $\left(10^{2} \mathrm{~s}\right)$. La explicación de éste retraso, es la existencia de estados excitados metaestables, cuyo retorno al estado base se ve impedido por algunas causas como: la temperatura a la cual el material es excitado, la naturaleza del agente excitante y las características de saturación del material. La transición del estado metaestable al fundamental se puede llevar a cabo mediante la aplicación de una estimulación complementaria (térmica) (González, 1999; Chen y McKeever, 1997).

En la Figura l-8a se presenta el esquema de niveles de energía usados en luminiscencia. El sistema emisor es producido por la excitación del nivel fundamental (f) al nivel excitado (e). El regreso al nivel fundamental se efectúa espontáneamente con emisión de luz dando lugar a la fluorescencia. En la Figura I-8b se observa un esquema semejante al anterior, en este caso interviene un estado metaestable $(\mathrm{m})$ dando lugar a que el sistema quede en un estado excitado (e) y posteriormente pase al nivel metaestable $(\mathrm{m})$ el cual juega el papel de trampa, del cual el electrón no puede ser extraído por lo que permanece en ese nivel hasta que se le proporciona la energía suficiente para liberarlo de su trampa. Si el sistema no regresa al estado metaestable, es decir, no es vuelto a capturar por la trampa, entonces pasa al estado fundamental (f) emitiendo un fotón de luz con lo que se produce el fenómeno de fosforescencia (González, 1999).

En un sólido dieléctrico, se consideran tres espacios continuos de energía a los que se les denomina bandas (Fig. I-9), formadas por: la banda de valencia (BV) donde se encuentran los electrones que originan los enlaces químicos; la banda prohibida (BP) que es la brecha que separa las bandas y la banda de conducción $(\mathrm{BC})$ donde se realiza el flujo de electrones.

El fenómeno de luminiscencia recibe varios nombres dependiendo del agente excitante. Cuando el agente excitante es la radiación ionizante se le llama radioluminiscencia y ésta se denomina de acuerdo con el tipo de energía que se le proporciona a los centros luminiscentes para desexcitarlos. Ciertos sólidos previamente irradiados tienen la propiedad de emitir luz, si se eleva su temperatura a un valor suficiente por debajo de su temperatura de incandescencia. A este fenómeno se le conoce como termoluminiscencia (TL). La importancia de éste fenómeno en la dosimetría de la radiación ionizante radica en el hecho que la cantidad de luz emitida es proporcional a la dosis absorbida por el material irradiado (González, 1999; McKeever y Chen, 1997). 
El mecanismo general para explicar el fenómeno de TL es el siguiente: al interaccionar la radiación nuclear con un sólido, se puede proporcionar la energía suficiente para crear los entes móviles (electrones y agujeros), portadores de carga, que pueden viajar por el cristal hasta quedar atrapados en defectos de la red. Los electrones son transferidos de la BV a la BC. Mientras que los agujeros quedan en la BV al ocurrir la transferencia de electrones. De esta manera se generan centros de color, que son configuraciones electrónicas originadas por los defectos de la red cristalina, cuyos niveles de energía producen bandas de absorción óptica de longitud de onda a las que el cristal es normalmente transparente, la posibilidad de absorber luz hace que el cristal se coloree. Los electrones permanecen atrapados hasta que se proporciona al material la energía suficiente para liberarlos, volviéndolos a su estado natural antes de la irradiación. Cuando esto ocurre se desprenden del exceso de energía que adquirieron, emitiendo fotones de luz visible. Si la energía que se proporciona al cristal para que los entes móviles vuelvan a su estado original es térmica, se produce el fenómeno de TL. A la energía necesaria para liberar a los entes atrapados se le denomina energía de activación o profundidad de la trampa (Azorín, 1990).

En un material TL, el número de recombinaciones radiactivas es proporcional al número de iones atrapados y por lo tanto, al número de pares "electrón-agujero" creados por ionización. La luminiscencia emitida es proporcional dentro de ciertos límites, a la dosis absorbida por el material TL. Además, tanto el área bajo un pico TL como la amplitud del mismo, a una rapidez de calentamiento constante, son proporcionales al número total de electrones o agujeros capturados en las trampas. Por lo tanto, el área bajo la curva TL es representativa de la energía luminosa liberada. Esto hace que los materiales TL puedan utilizarse como detectores en el intervalo en que su respuesta es lineal con respecto a la dosis absorbida.

En la Figura l-10 se muestra el diagrama de bloques de un equipo lector de TL, cuyos componentes básicos son: el sistema de calentamiento y el sistema detector de luz. Uno de los requisitos para el calentamiento de un material TL es que exista un buen contacto térmico entre el dispositivo que calienta y dicho material, ya que un contacto térmico inapropiado afectará la reproductibilidad de los resultados. Por otro lado el sistema detector de luz debe concentrar la mayor cantidad posible de luz emitida. La curva termoluminiscente (TL) indica la representación gráfica de la cantidad de luz emitida (intensidad TL) en función de la temperatura o del tiempo. Este patrón de luminiscencia es característico para cada material TL y puede presentar uno o varios máximos llamados picos TL (González, 1999).

\subsection{Detectores termoluminiscentes (DTL)}

Estos detectores son cristales de fluoruro de litio $(\mathrm{LiF})$, fluoruro de calcio $\left(\mathrm{CaF}_{2}\right)$ o sulfato de calcio dopados con diversos elementos ( $\left.\mathrm{CaSO}_{4}: \mathrm{Dy}\right)$. Cuando la dosis gamma incide sobre estos materiales, ésta interacciona en forma tal que un calentamiento posterior origina una emisión luminosa proporcional a la energía total depositada por la radiación gamma en el DTL. La respuesta de los DTL al radón y a otros elementos que emiten la radiación gamma en el suelo, han sido reportados por Pressyanov et al., (1996). En este trabajo se utilizaron detectores termoluminiscentes para determinar la dosis absorbida producida por la radiación gamma (dosis gamma). En el Apéndice A-IIl-2 se presentan los métodos para detectar la dosis gamma ambiental. 


\section{ELEMENTOS QUÍMICOS MAYORES Y TRAZAS EN SOLUCION}

El agua subterránea que se encuentra en la litósfera se debe a varias fuentes: Aquella proveniente de la actividad magmática y volcánica, la que queda atrapada en los intersticios de las rocas sedimentarias y como fuente principal, el agua que proviene de la infiltración (Appelo y Postma, 1993). Del agua de precipitación una parte se escurre, otra se evapora y el resto se infiltra. Al infiltrarse el agua pasa a constituir lo que se conoce como agua subterránea. El agua subterránea que llega en ésta forma al subsuelo genera reacciones fisicoquímicas en el transcurso de su recorrido entre las rocas. Ejemplos de esas reacciones son la disolución, la precipitación, la oxidación, la reducción o el intercambio iónico.

Las características geológicas y el flujo del agua subterránea, son parámetros esenciales que influyen en los parámetros fisicoquímicos y en la actividad especifica de los radionúclidos. Los cambios en la química del agua subterránea pueden estar en función de los patrones de recarga, el grado de fracturamiento de las rocas o el tiempo de residencia del agua (Freeze y Cherry, 1979; Custodio y Llamas, 1983; Drever, 1988; Appelo y Postma, 1993; Deutsch, 1997; Segovia et al.,1999c). De ésta manera el agua subterránea adquiere mineralización, que será diferente dependiendo del estrato geológico por el que circule. El estrato geológico de una determinada región, es quizá el elemento más importante que influye en la composición química del agua subterránea, ya que en su recorrido a través de los poros del suelo y la roca disuelve a su paso elementos radiactivos o estables. Se han realizado medidas químicas en pozos y manantiales que puedan ser usados en zonas sísmicas como posibles precursores hidrogeológicos. La composición química ha mostrado en ocasiones variaciones que no son correlacionables con la lluvia y pueden atribuirse a sismos (King et al., 1994).

La determinación en aguas subterráneas de los parámetros fisicoquímicos (in situ y en el laboratorio), permite estimar la interacción entre el fluido y la matriz sólida y puede dar información referente al transporte de contaminantes en acuíferos, así mismo se pueden observar las variaciones de la calidad química que ocurren en el espacio y en el tiempo, que en muchos casos en posible relacionar con las condiciones climatológicas, la geología regional, etc. (Appelo y Postma, 1993; Viers et al., 2000; Adams et al., 2001). El conocimiento de los elementos traza aporta información complementaria sobre el origen, la estructura y propiedades hidráulicas así como las características fisicoquímicas de los acuíferos. La presencia y movilidad de los elementos traza en las aguas subterráneas puede estar influenciada por procesos de adsorción. Dicha adsorción se produce debido al contacto del agua con minerales arcillosos, materia orgánica y otras sustancias cristalinas y amorfas que constituyen el medio poroso. Es importante realizar estudios de elementos traza en solución ya que estos son generados por la interacción agua-roca así como por la transferencia en el transporte del agua (Cardona et al., 1993; Wheat y Mottl, 2000; Marini et al., 2001).

Se definen los elementos químicos del agua subterránea a partir de su abundancia, la mayoría de éstos son: sodio $\left(\mathrm{Na}^{+}\right)$, calcio $\left(\mathrm{Ca}^{+2}\right)$, magnesio $\left(\mathrm{Mg}^{+2}\right)$, sulfatos $\left(\mathrm{SO}_{4}^{-2}\right)$, bicarbonatos $\left(\mathrm{HCO}_{3}^{-}\right)$, cloruros $\left(\mathrm{Cl}^{-}\right)$, hierro $\left(\mathrm{Fe}^{-3}\right)$, potasio $\left(\mathrm{K}^{+}\right)$, nitratos $\left(\mathrm{NO}_{3}^{-}\right)$y sílice $\left(\mathrm{SiO}_{2}\right)$. Elementos traza como: boro $(\mathrm{B})$, bario $(\mathrm{Ba})$, uranio $(\mathrm{U})$, cinc $(\mathrm{Zn})$, litio $(\mathrm{Li})$, manganeso $(\mathrm{Mn})$, vanadio $(\mathrm{V})$, cobre $(\mathrm{Cu})$, cobalto $(\mathrm{Co})$, arsénico (As), molibdeno (Mo), cadmio (Cd), rubidio $(\mathrm{Rb})$, cromo $(\mathrm{Cr})$ y plomo $(\mathrm{Pb})$, son solubles en agua, al menos en un mínimo grado (Freeze y Cherry, 1979; Appelo y Postma, 1993; Salbu y Steinnes, 1995; Deutsch, 1997). 
En el Apéndice I-2, se muestran las características fisicoquímicas de algunos compuestos y elementos químicos mayores y trazas del agua.

Una clasificación de los elementos químicos establecida por Domenico y Schwartz (1998) divide a estos en tres categorías. Las dos primeras (mayores y menores) se basan en los niveles de concentración a $\mathrm{mg} \mathrm{L}^{-1}$, mientras que la última (trazas) se considera al nivel de $\mu \mathrm{g} \mathrm{L}^{-1}$. Esta clasificación se muestra en la Tabla I-1.

Tabla l-1 - Elementos y compuestos solubles en agua subterránea de acuerdo a su abundancia relativa

(Domenico y Schwartz, 1998).

\begin{tabular}{|c|c|c|c|c|c|}
\hline CONSTITUYENTE & \multicolumn{4}{|c|}{ ELEMENTOS Y COMPUESTOS } & $\begin{array}{c}\text { CONCENTRACIÓ } \\
\text { N }\end{array}$ \\
\hline \multirow{2}{*}{ MAYORES } & $\begin{array}{c}\text { Bicarbonat } \\
0 \\
\text { Calcio }\end{array}$ & $\begin{array}{c}\text { Cloruro } \\
\text { Magnesio }\end{array}$ & $\begin{array}{c}\text { Sílice } \\
\text { Sodio }\end{array}$ & Sulfato & $>5 \mathrm{mg} \mathrm{L}^{-1}$ \\
& Potasio & Hierro & Nitrato & & $0.01-10.0 \mathrm{mg} \mathrm{L}^{-1}$ \\
\hline MENORES & Arsénico & Cesio & Cromo & Molibden & \\
& Bario & Cinc & Estroncio & 0 & \\
TRAZAS & Boro & Cobalto & Litio & Plomo & $<0.1 \mathrm{mg} \mathrm{L}^{-1}$ \\
& Cadmio & Cobre & Manganeso & $\begin{array}{c}\text { Rubidio } \\
\text { Uranio }\end{array}$ & \\
& & & & & \\
\end{tabular}




\section{CAPITULO II SITIOS DE ESTUDIO.}

Los sitios en donde se realizó el estudio se encuentran en la costa del Pacifico y en la costa del Golfo de México.

\section{COSTA DEL PACIFICO.}

La margen del Pacífico Norteamericano desde Alaska hasta el SW de México está considerada como un mosaico de terrenos tectonoestratigráficos (Campa, 1978; Salinas-Prieto et al., 1993). El marco tectónico Mesozoico, indica una evolución geológica caracterizada por deformaciones orogénicas, relacionando recurrencias convergentes entre las placas oceánicas del Pacífico y la placa continental de Norteamérica. Una de sus características es el cinturón plutónico cálcico-alcalino expuesto desde Puerto Vallarta hasta Tehuantepec (Morán-Zenteno et al., 2000) que comprende rocas volcánico-sedimentarias (rocas marinas, volcánicas continentales, y sedimentarias), cuya edad varía del Jurásico Superior al Cretácico Medio (Schaaf et al., 1995).

La presencia de un cinturón plutónico en la trinchera de Acapulco es la indicación principal de los episodios de tectonismo a lo largo de la margen continental del Pacífico (Morán-Zenteno et al., 1996; Singh et al., 1998; Kostoglodov et al., 2002).

La zona de estudio comprende aproximadamente $500 \mathrm{~km}$ a lo largo de la trinchera Mesoamericana en el Estado de Guerrero, desde el poblado de Guacamayas, Mich., hasta Marquelia, Gro. (16 $30^{\prime}-18^{\circ} 00^{\prime} \mathrm{N}$; $\left.98^{\circ} 45^{\prime}-102^{\circ} 15^{\prime} \mathrm{W}\right)$. Se encuentra localizada en la porción centro - meridional de México con un alineamiento general de NNE-SSW y atraviesa casi perpendicularmente la vertiente austral de la provincia fisiográfica Sierra Madre del Sur. Está localizada dentro de 2 terrenos tectonoestratigráficos, el del NNE de Acapulco (terreno Guerrero) y el del SSW de Acapulco (terreno de Xolapa) (Fig. II-1).

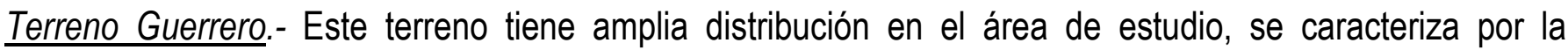
presencia

de rocas metamórficas del complejo Xolapa (Xog), aunadas a cuarcitas y filitas (Pzx). Existen también rocas extrusivas constituidas por ignimbritas y andesitas (Tv) y rocas intrusivas que varían litológicamente desde granito (Tgr) hasta granodiorita (Tgd), además de clásticos continentales (Tc) (Centeno-García et al., 1993). La edad de estas rocas varía de 34 a 44 Ma y pertenecen al Eoceno - Oligoceno (Delgado-Argote et al., 1986). En la parte superficial existen sedimentos aluviales del Reciente (Q), que estructuralmente forman abanicos aluviales, constituidos por conglomerados y aluviones que originan depósitos deltaicos areno-arcillosos.

Terreno Xolapa.- Campa y Coney (1983) adoptaron el nombre de Xolapa para el terreno ocupado en la margen continental Pacífica, desde Acapulco hasta la zona del Istmo de Tehuantepec. El terreno Xolapa consiste principalmente de una secuencia de rocas metamórficas que afloran ya sea directamente en la superficie o por debajo de las rocas Mesozoicas - Terciarias y que son intrusionadas por numerosos plutones de composición granítica (Xog) (Morán-Zenteno, 1992, 1993). 
Las rocas metamórficas varían del Jurásico Medio al Eoceno (Morán-Zenteno et al., 2000) y presentan bajo grado de metamorfismo; están formadas por una diversidad litológica y sobreyacen a lutitas, tobas y detritos. En localidades restringidas se las encuentra cubiertas por rocas volcánicas del Terciario.

Los cuerpos plutónicos ocupan más del $50 \%$ del terreno Xolapa, lo que dá a dicho terreno la visión de un cinturón plutónico - metamórfico cuya edad fluctúa del Paleozoico al Terciario (Morán-Zenteno, 1992; Moran-Zenteno et al., 1993a). Están formados por las siguientes unidades estratigráficas: granodioritas y tonalitas (Tgd-Tn), granodioritas (Tgd), granitos (Tgr), complejo Xolapa (Xog). Dichos plutones cubren en discordancia

al macizo granítico de Guerrero (Morán-Zenteno et al., 1993b). Los sedimentos del Reciente (Q) presentes en la región costera están constituidos por conglomerados, así como por sedimentos que han sido acumulados por los ríos y forman depósitos de playa y aluviales (arenas y gravas de diferente granulometría con intercalaciones arcillosas (SPP/DGGTENAL, 1981).

Región de Acapulco.- La región de Acapulco presenta 3 cuerpos principales: Tronco de Ocotito, tronco de Xaltianguis y tronco de Acapulco. La mayor parte del contacto de estos troncos están en el complejo Xolapa, son troncos aislados, cuya composición petrográfica varía de cuarzo-monzonita a granito (Negendank et al., 1987; Morán-Zenteno et al., 1993b). El tronco de Acapulco tiene contacto intrusivo con el complejo Xolapa y está cubierto con sedimentos del Reciente. Los fechamientos con Rb-Sr indican edades que van del Cretácico Temprano al Oligoceno (25 a $100 \mathrm{Ma}$ ) (Kohler et al., 1993). Por encima de dicho tronco se desarrolló un anfiteatro rodeado por serranías constituidas por rocas metamórficas del complejo Xolapa que al quedar inundadas por el mar dieron origen a la Bahía de Acapulco (De Cserna, 1965). La Bahía de Acapulco y las caletas cercanas corresponden a valles sumergidos. En esta región costera del Pacifico, se encuentra una angosta faja que consiste de algunos lomeríos formados por rocas metamórficas o graníticas. Dicha faja es de anchura irregular y es el resultado del relleno de valles sumergidos de profundidad variable. La faja costera que se extiende al este de Acapulco se llama La Costa Chica y la que se extiende al oeste de Acapulco se denomina Costa Grande de Guerrero.

Litología local.- La litología de las localidades en donde se tienen ubicados los detectores y dosímetros, así como los sitios en donde se realizó el muestreo de agua se mencionan a continuación:

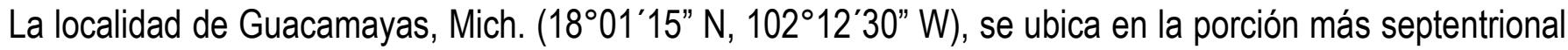
de la zona de estudio, la litología local está representada por rocas ígneas intrusivas y extrusivas, cálcicas continentales así como sedimentos aluviales. Las unidades geológicas en esta zona de estudio son sedimentos del Reciente $(Q)$ que ocasionalmente cubren en discordancia litológica a las rocas ígneas y clásticas del Terciario. La granulometría y el bajo grado de cementación hacen que actúe como zonas de recarga (CFE, 1983).

La localidad denominada La Unión, Gro. $\left(17^{\circ} 59^{\prime} 15^{\prime \prime} \mathrm{N}, 101^{\circ} 48^{\prime} 15^{\prime \prime} \mathrm{W}\right)$, está formada por areniscas (Tc) del Terciario.

El poblado de Papanoa, Gro. $\left(17^{\circ} 19^{\prime} 15^{\prime \prime} \mathrm{N}, 101^{\circ} 02^{\prime} 30^{\prime \prime}\right.$ W), está representado por rocas que varían del Paleozoico al Reciente, el basamento está constituido por el Complejo Xolapa. Ésta formación está 
cubierta discordantemente por rocas metamórficas del Triásico. Todas estas formaciones están afectadas por el macizo granítico de Guerrero, y están cubiertas por formaciones clásticas del Terciario Volcánico y por los depósitos aluviales del Reciente (Q) (Nuñez et al., 1981).

La región de San Luis la Loma, Gro. $\left(17^{\circ} 16^{\prime} 00^{\prime \prime} \mathrm{N}, 100^{\circ} 53^{\prime} 15^{\prime \prime} \mathrm{W}\right)$, se caracteriza por rocas Cretácicas del tipo granodiorítico, cubiertas por sedimentos del Reciente (Q).

En la localidad de El Cayaco, Gro., $\left(17^{\circ} 02^{\prime} 45^{\prime \prime} \mathrm{N}, 100^{\circ} 16^{\prime} 00^{\prime \prime}\right.$.W), se observan sedimentos del Reciente (Q) (SPP/DGGTENAL, 1981).

La Barra de Coyuca, Gro. (1656 $30^{\prime \prime} \mathrm{N}, 100^{\circ} 04^{\prime} 45^{\prime \prime}$ W), está constituida principalmente por sedimentos del Reciente $(Q)$.

En Acapulco (Centro) (1652'50" N, 9950'30" W), domina el tipo granítico (Tgr) (Morán-Zenteno et al., 2000) y las fracciones granodioríticas y sienitas se presentan en forma subordinada. La textura del granito varía de porfídica a equigranular. (Morán-Zenteno, 1992).

Acapulco (La Sabana) (16 $53^{\prime} 30^{\prime \prime} \mathrm{N}, 99^{\circ} 50^{\prime} 00^{\prime \prime}$ W), está asentada sobre sedimentos del Reciente (Q) que sobreyacen a rocas metamórficas del complejo Xolapa (Xog).

En el manantial El Cortés, Gro. (16 $43^{\prime} 30^{\prime \prime} \mathrm{N}, 99^{\circ} 30^{\prime} 30^{\prime \prime}$ W), se observa la unidad (Tgd-Tn) constituida por plutones del Terciario, que comprenden granodioritas y tonalitas (Morán-Zenteno, et al., 1993b) y por lo general tienen relación con horblenda, biotita, magnetita, apatita y circón como accesorios (Schaaf et al., 1995). Este manantial se une con el río del mismo nombre.

La zona en donde está asentada la población de San Marcos, Gro. $\left(16^{\circ} 47^{\prime} 45^{\prime \prime} \mathrm{N}, 99^{\circ} 23^{\prime} 15^{\prime \prime}\right.$ W), está formada por rocas plutónicas constituidas por granodioritas y tonalitas, así como hornblenda y biotita (TgdTn) (Morán-Zenteno et al., 1993b).

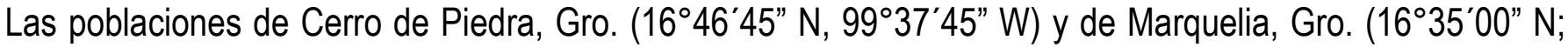
$98^{\circ} 48^{\prime} 30^{\prime \prime}$ W), se caracterizan por la presencia de sedimentos aluviales del Reciente (Q).

Clima local.- De acuerdo con la clasificación de W. Koeppen, el clima que predomina en la zona de estudio es Aw1(w)i el cual pertenece al cálido subhúmedo con lluvias de verano y escasa precipitación invernal (García, 1973; SPP/DGGTENAL, 1981). Los datos de los registros meteorológicos del observatorio meteorológico de la ciudad de Acapulco en el periodo que abarca el estudio (1993-1998) se muestran en el Apéndice II-1 y con ellos se construyó la Figura II-2. La región de estudio presenta dos estaciones climáticas bien definidas: la estación de lluvias y la de secas. La estación de lluvias en 1997 fue atípica debido a la perturbación meteorología de "El Niño". Esta estación se dividió en dos secciones: la primera fue de junio a julio, con una precipitación interrumpida por la sequía intraestival, la segunda fue de septiembre a noviembre en la cual se presentó un incremento en la precipitación debido a la presencia del ciclón tropical "Paulina", el cual hizo que la estación de lluvias se prolongara hasta noviembre con un valor anual de precipitación de $1171 \mathrm{~mm}$. Los periodos anteriores, incluyendo 1998, presentaron una distribución 
de la precipitación más homogénea con el periodo de lluvias iniciando en junio y terminando en octubre. En 1998 la precipitación anual fue de $1721 \mathrm{~mm}$. La hidrología local presenta acuíferos someros y pequeños ríos que fluyen solamente durante la estación de lluvias.

\section{COSTA DEL GOLFO DE MÉXICO}

El muestreo de la costa del Golfo de México se realizó en el estado de Veracruz en los alrededores de Planta Nuclear de Laguna Verde (CGMPNLV). La (PNLV) se sitúa al NE del Estado de Veracruz, en el municipio de Alto Lucero a $70 \mathrm{~km}$ al NW de la ciudad de Veracruz $\left(19^{\circ} 43^{\prime} 30^{\prime \prime} \mathrm{N} ; 96^{\circ} 24^{\prime} 09^{\prime \prime} \mathrm{W}\right)$. La altitud media es de $18 \mathrm{~m}$. (Segovia, et al., 1997b).

Geología local.- La estratigrafía de la zona de estudio está constituida por las siguientes unidades: el Grupo Volcánico Viejo, del Mioceno, que se localiza en Punta Delgada, está constituido por rocas volcánicas (basaltos, tobas y andesitas) intrusionadas por numerosos diques. Así mismo se presenta el Grupo Volcánico Joven, del Plioceno, integrado por 4 formaciones: la Formación El Espinazo, constituida por las sierras que contienen secuencias basáltico-andesíticas, la Formación Chiconquico-Inferior, formada por abanicos volcánicos de lavas y lajas que comprenden las sierras de Lumbre y Venados, la Formación El Oro, constituida por cenizas volcánicas, lavas intermedias-ácidas y tobas que se encuentran en los cerros y lomeríos y por ultimo la Formación Chiconquico-Superior, constituida por basaltos, lavas intermedias y tobas ignimbritas. El suelo del Reciente, está constituido por basaltos de olivino, conos cineríticos, depósitos aluviales y de costa. La PNLV se encuentra ubicada en la provincia fisiográfica de la Vertiente del Golfo de México y está localizada sobre derrames de lava basáltica del Plioceno-Pleistoceno que se extienden hacia el mar, siguiendo la topografía existente constituida principalmente por andesitas del Mioceno. Estos derrames forman una planicie con bahías, lagunas y mesetas ligeramente escarpadas y de un tipo ondulante en las lagunas Verde y Salada. En general dicha planicie está limitada al este por el Golfo de México y al oeste por un cordón montañoso, formado por espinas volcánicas y cuerpos de andesitas y dioritas del Oligoceno-Mioceno. (CFE, 1971) Fig. II-3.

La estratigrafía y litología de las localidades en donde fueron ubicados los detectores, así como los sitios en donde se realizó el muestreo de agua se mencionan a continuación: las zonas de El Viejón (EV), Rancho Nuevo (RN), Loma (L), Las Lajas (LL) y Palma (P) están localizadas, con respecto a la PNLV, a $3.5 \mathrm{~km}$ al S, $28 \mathrm{~km}$ al NW, $5 \mathrm{~km}$ al S, $22 \mathrm{~km}$ al SSW y $15 \mathrm{~km}$ al SSW respectivamente (Segovia et al., 1996; 1997b). Las estaciones de muestreo están localizadas en las siguientes unidades litológicas: La PNLN, El Viejón, Loma y Palma en depósitos del Reciente (Q) que subyacen a andesitas (And), en cuanto a Loma está ubicada sobre depósitos andesíticos (And) y por último Rancho Nuevo que se le considera como un área de fallamiento con movimientos recientes, está localizada en depósitos del Reciente (Q) que cubren a lavas basálticas (Ba) y éstas a su vez sobreyacen a depósitos de arcilla y tobas ignimbritas de edad Pliocenica que sobreyacen a rocas andesíticas del Mioceno (IG/UNAM, 1989).

Andesitas (And). Están constituidas por depósitos piroclásticos, compuestos por tobas de textura piroclástica (plagioclasa calcosódica), vidrios ácidos, hematita, magnetita. Son productos de algunas emisiones piroclastícas arrojadas por el Volcán Pico de Orizaba, por lo que su origen está asociado al 
volcanismo andesítico, subyace discordantemente a derrames lávicos andesíticos y brechas volcánicas. Es una zona con fallas normales, se le asignó edad del Terciario (CFE, 1971).

Basaltos (Ba). Están constituidos por derrames, los componentes mineralógicos son labradorita, andesina, clinopiroxeno, hematita, etc., con textura afanítica holocristalina e intergranular, presenta estructura vesicular y prismática. Forma parte del volcanismo básico que originó el Eje Volcánico. Los afloramientos de esta unidad se presentan como derrames de amplia extensión y como aparatos volcánicos. Se le asignó edad correspondiente al Cuaternario (CFE, 1971).

Depósitos aluviales (Q). Originados por la acción fluvial, constituyen un suelo poco consolidado (arenas gruesas, ligeramente gravosas, compuestos de vidrio volcánico, feldespatos, micas y fragmentos de roca), así como suelos limo-arenosos, escasamente consolidados. Se le asignó edad del Pleistoceno - Reciente. (CFE, 1971).

La zona de la PNLV se encuentra limitada por dos lagunas: Al norte por la Laguna Verde que es un cuerpo de agua salobre, de color verdoso, y al sur por la Laguna Salada que es un cuerpo de agua salada y drena hacia el mar en su extremo SE.

En el área de estudio se localiza el acuitardo de la PNLV y el acuífero de Valle del Viejón. En el acuitardo de la PNLV, los derrames basálticos se encuentran fracturados y están sellados por material arcilloso de un espesor del orden de $40 \mathrm{~m}$. Le subyacen depósitos de arcilla, arena, grava mal clasificada y piroclástos que en conjunto forman espesores entre 12 a $60 \mathrm{~m}$. El acuífero de El Viejón, es un acuífero libre, es el más importante y cercano a la PNLV y se forma en el Valle del mismo nombre. Consiste de una serie de intercalaciones de material granular y arcilloso y sobreyace al basamento impermeable andesítico, el cual se encuentra a profundidades que varían entre 25 y 55 m debajo de la superficie del terreno.

El nivel freático promedio en la zona de estudio es de $3.5 \mathrm{~m}$ con respecto a la superficie del terreno, el cual presenta elevaciones topográfica entre 2 y $-1 \mathrm{~m}$. La dirección del flujo subterráneo es de W a E. Se observan valores altos del nivel freático en los meses de agosto a octubre, que coinciden con el período de máxima precipitación en el área, es decir, existe una recarga del acuífero por escurrimiento e infiltración de las aguas pluviales. Los valores menores se observan entre noviembre y julio, debido a la disminución de las lluvias. La recarga del acuífero es por infiltración directa del agua de lluvia sobre el terreno y por el río El Viejón en la época de lluvia, cuando éste se vuelve influyente, es decir, recarga las aguas subterráneas del valle. En época de sequía el río se vuelve afluente (CFE, 1971). Los detalles de las características de los pozos se encuentran en el Apéndice II-2.

Se obtuvieron datos de los registros meteorológicos de la estación ubicada dentro de las instalaciones de la PNLV en el periodo que abarca el estudio (1994 - 1996). En el Apéndice II-3 se muestran los valores promedio de la precipitación y temperatura mensuales, con los que se construyó la Figura II-4. Las características meteorológicas de la zona de estudio están representadas por la presencia de masas polares que se manifiestan durante el invierno y a principios de primavera. Las perturbaciones tropicales son frecuentes, se observan durante la estación de lluvias (junio-octubre). La precipitación anual promedio fue de $1360.56 \mathrm{~mm}$, con el mes más lluvioso en septiembre y el más seco en febrero. La temperatura media anual fue de $24.5^{\circ} \mathrm{C}$, siendo los meses extremos enero $\left(18^{\circ} \mathrm{C}\right)$ y mayo $\left(24^{\circ} \mathrm{C}\right)$. 
Clima local.- De acuerdo con la clasificación de W. Koeppen, modificada por E. García, el clima que predomina en la zona de estudio es Aw1(w), el cual pertenece al cálido subhúmedo con lluvias de verano y escasa precipitación invernal. El mes más lluvioso es septiembre y el más seco febrero. La humedad es intermedia y la oscilación térmica es del tipo atenuado (CFE, 1971; SEDUE, 1987; Tejeda et al., 1989). 


\section{CAPITULO III PARTE EXPERIMENTAL}

En este capítulo se describen los métodos experimentales utilizados y las mediciones que se hicieron para determinar la evolución de la concentración del radón en suelo y agua subterránea, la contribución de la radiación gamma en suelo, la composición de elementos químicos mayores y traza diluidos en el agua, además del análisis mineralógico de rocas. Se presentan así mismo las características de los sitios específicos de muestreo

\section{MEDICIÓN DEL RADÓN}

En la detección del radón los detectores se colocaron en el suelo y en pozos de agua en dispositivos que permiten la llegada del radón y el registro de las partículas $\alpha$ del decaimiento de aquellos núcleos que se desintegran en la vecindad de dicho detector. En el presente trabajo se utilizaron para la detección de radón tanto en el suelo como en el agua subterránea detectores pasivos y activos.

Se utilizaron en este trabajo detectores LR-115 tipo II que son películas de nitrato de celulosa de $13 \mu \mathrm{m}$ de espesor fabricadas por Dosirad Co., Francia. Estas películas están adheridas a un soporte de polietileno de $100 \mu \mathrm{m}$ de espesor. Son del tipo peliculable y registran partículas $\alpha$ con energías entre 0.6 y $4.4 \mathrm{MeV}$ (Azimi-Garakani, 1989; Somogyi, 1990; Chavez et al., 1997; Papastefanou, 2003). Con esta película sensible se realizaron las mediciones de radón en suelo y agua subterránea en períodos largos de exposición en las zonas de estudio (De la Cruz Reyna et al., 1985; Segovia et al., 1989a; 1999c).

Los detectores se cortaron en piezas de $2.5 \mathrm{~cm}$ de diámetro y se colocaron en la parte superior de un dispositivo que está formado por un contenedor cilíndrico (tubo de PVC de $2.3 \mathrm{~cm}$ de diámetro externo y 30 $\mathrm{cm}$ de longitud), donde se fijaron, por medio de un tapón (De la Cruz Reyna et al., 1985). En el extremo inferior del tubo se colocó una membrana de látex permeable al radón para proteger de la humedad al detector. Este dispositivo se introdujo en un tubo de PVC de $1 \mathrm{~m}$ de longitud que a su vez se colocó verticalmente en el suelo (Fig. III-1).

Los detectores se dejaron en exposición en el campo aproximadamente 1 mes. Posteriormente se recogieron y se llevaron al laboratorio para su análisis. Las trazas latentes de las partículas $\alpha$ se grabaron por medio de un ataque químico sumergiendo el detector en una solución de $\mathrm{NaOH}(2.5 \mathrm{~N})$ a $56{ }^{\circ} \mathrm{C}$ durante 60 minutos. La densidad de trazas se determino usando un contador de chispa. La determinación de la densidad de trazas se presenta en el Apéndice A-III-1.

La densidad de trazas obtenida está relacionada con la concentración de radón (Yeager et al., 1994). Se han reportado las relaciones para calcular la densidad de trazas observables en detectores LR-115, colocados en contenedores cilíndricos de detección (Somogyi et al., 1984; Papastefanou, 2003). El factor de calibración de la respuesta del sistema permite la conversión de trazas $\mathrm{cm}^{-2}$ a Bq m $\mathrm{m}^{-3}$ día (Segovia y Cejudo, 1984), el factor de conversión para las condiciones especificas de este trabajo fue de 8.7 trazas $\mathrm{cm}^{-}$ 2 por kBq m³ día (Segovia et al., 1997a).

Como sistema activo se utilizó un equipo Clipperton que es un detector de diodo de silicio, para determinar el comportamiento de radón en tiempos cortos (Monnin y Seidel, 1998). En estos detectores el diodo está 
asociado a un procesador electrónico de datos y a unidades de almacenamiento de bajo consumo de energía. La parte sensible se encuentra en el extremo de un tubo de $50 \mathrm{~cm}$ de largo por $5 \mathrm{~cm}$ de diámetro. El diodo detector se encuentra a $30 \mathrm{~cm}$ de la parte inferior del tubo ya que está diseñado para muestreos en suelo a un metro de profundidad. Los pulsos generados por las partículas $\alpha$, se preamplifican y amplifican con un factor de 550. La información se registra en una memoria. El tiempo de registro en campo lo fija el operador entre un minuto y $48 \mathrm{~h}$. La información de la memoria se obtiene por medio de una PC portátil (Maldonado et al., 1996).

El detector Clipperton se introdujo en un tubo de PVC y en el extremo inferior se colocó una membrana de látex para protegerlo de la humedad. El equipo para detectar radón en el suelo se enterró verticalmente a 1 metro de profundidad. Para detectar radón en agua el detector se introdujo en el pozo a la profundidad deseada. El tiempo de conteo se programó cada dos horas. La sensibilidad de este tipo de detector reportada por el fabricante es de 1 cuenta. $h^{-1}=140 \mathrm{~Bq} \mathrm{~m}^{3}$ (Segovia et al., 1997b).

\section{MEDICIÓN DE LA DOSIS GAMMA AMBIENTAL}

La dosis gamma en el suelo se midió con detectores termoluminiscentes. Los detectores utilizados fueron pastillas de aproximadamente $4 \mathrm{~mm}$ de diámetro y $0.8 \mathrm{~mm}$ de espesor a base de cristales de sulfato de calcio activado con disprosio embebido en politetrafluoretileno ( $\mathrm{CaSO}_{4}$ :Dy + PTFE) que es uno de los materiales TL más sensibles utilizados en dosimetría (Azorin y Furetta, 1989; Azorin et al., 1993). Las pastillas se colocaron en porta detectores de plástico (Azorín y Gutiérrez, 1989). Este detector cumple con la norma ANSI-N 545 para monitoreo ambiental (Martínez et al., 1995).

Para exponer los DTL en campo se colocaron dos pastillas en un contenedor de plástico. Estos contenedores rotulados se colocaron en campo en la parte superior del tubo de PVC que contiene al dispositivo del detector LR-115. El tiempo de exposición en campo fue de 1 mes igual que para los detectores LR-115. Una vez expuestos los detectores se trasladaron al laboratorio en donde se hicieron las lecturas de las muestras utilizando el analizador TL Harshaw modelo 4000 acoplado a una computadora. La determinación de la dosis gamma ambiental se muestra en el Apéndice A-III-2. Los resultados se reportan en $\mathrm{nGy} \mathrm{h}^{-1}$.

\section{MUESTREO DE AGUA SUBTERRÁNEA}

Se hicieron muestreos de agua en los pozos de las zonas de estudio.

Objetivo del muestreo.- El objetivo del muestreo es recolectar una porción de material en un volumen pequeño para transportarse de forma adecuada para su manipulación en el laboratorio. Este objetivo implica que las proporciones relativas a estudiar serán representativas de las condiciones en campo.

Identificación de las muestras.- Se deben tomar las precauciones necesarias para que en cualquier momento sea posible identificar las muestras. Para ello se emplean etiquetas pegadas o se enumeran los frascos anotándose la información en las hojas de registros (NOM-AA-3-1986). 
Tipo de muestra simple.- Es aquella muestra individual tomada en un periodo corto. Esta muestra, se recolecta en un lugar y tiempo particular, representa solamente la composición de la fuente en ese tiempo y lugar. Para el presente trabajo se empleó este tipo de muestra.

Muestreo de agua de pozos.- Los muestreos se realizaron de acuerdo a la Norma Oficial Mexicana correspondiente para cada uno de los parámetros a determinar (NOM-127-SSA1-(1994). El número de muestras se calculó basándose en la máxima capacidad analítica de los laboratorios involucrados. Para la toma, transporte y conservación de muestras de agua, se consideraron los criterios establecidos para cada parámetro en las normas oficiales mexicanas y en los reportes bibliográficos (APHA-AWWA-WFPC, 1992; Olguin et al., 1993; Flores-Mendoza et al., 1992). .

Preparación de los envases para el muestreo de agua subterránea.- El muestreo de aguas para análisis de elementos químicos mayores, se realiza en botellas de polietileno de 1 litro de capacidad, las cuales se lavan con jabón neutro y se enjuagan tres veces con agua destilada. Para los elementos traza se utilizaron botellas de polipropileno $(60 \mathrm{~mL})$, con tapa y contratapa, agua deionizada, ácido nítrico de alta pureza 16 $\mathrm{Mol} / \mathrm{L}$ (Merck) y guantes de polietileno. Las botellas y las tapas se prepararon sumergiéndolas durante una semana en ácido nítrico al 20\%. Posteriormente se enjuagaron con agua deionizada y se remojaron durante una semana con ácido nítrico al 1\%. Un día antes del muestreo se enjuagaron las botellas tres veces y se llenaron con agua deionizada. Se tuvo la precaución en el muestreo de evitar el contacto del agua con todo tipo de metales.

Muestreo para elementos químicos mayores.- Para el muestreo las botellas se enjuagan tres veces en el cuerpo de agua a muestrear. Se llena la botella y se tapa perfectamente, asegurándose que no quede aire atrapado dentro de ella, evitando así que se disuelva el oxigeno contenido en el agua y se alteran los valores del pH. Posteriormente se marca la botella y se anota el nombre y clave de la muestra en una bitácora. Se coloca la muestra en una hielera a $4{ }^{\circ} \mathrm{C}$ para su transporte hasta llegar al laboratorio. La temperatura, el pH y la conductividad se determinan "in situ".

Muestreo para elementos traza en solución.- En el campo las botellas con agua deionizada se vacian y se enjuagan con el agua a muestrear. Las botellas se etiquetan con la fecha y lugar de muestreo y se colocan en la hielera hasta llegar al laboratorio donde la muestra se conservará en refrigeración a $4{ }^{\circ} \mathrm{C}$ hasta su envío a Francia, donde serán analizados. Es necesario preparar el blanco de campo, para lo cual se desecha el agua deionizada contenida en una botella y se vuelve a llenar con agua desionizada con la finalidad de obtener datos referentes a posibles contaminantes locales en el manejo de las muestras. El envase se etiqueta con los datos de fecha y lugar de muestreo e indicando que es el blanco. Es muy importante llevar a cabo este procedimiento para evitar las contaminaciones que puedan alterar los resultados debido a que se harán determinaciones a nivel de $\mu \mathrm{g} \mathrm{L}^{-1}(\mathrm{ppb})$. 


\section{ANÁLISIS DE PARÁMETROS FISICOQUÍMICOS IN SITU Y EN LABORATORIO DE MUESTRAS DE AGUA SUBTERRÁNEA}

En este estudio se determinaron parámetros fisicoquímicos (in situ y en laboratorio), así como elementos traza. Para la determinación de los iones principales y parámetros físico-químicos en aguas, se siguieron básicamente los procedimientos descritos en las Normas Mexicanas y en APHA-AWWA-WFPC (1992). Estos procedimientos analíticos se utilizan en el Laboratorio de Química Analítica del IGF/UNAM, Se basan en las metodologías más utilizadas a nivel internacional y se han adecuado al tipo de muestra y equipo disponible en dicho laboratorio. Los resultados analíticos se han comprobado con un estándar proporcionado por Environmental Protection Agency (EPA) de los Estados Unidos de América y a través del análisis del estándar en el Laboratorio de Geoquímica de la Universidad de Waterloo (Armienta, 1987; 1996).

Los procedimientos para medir $\mathrm{pH}$, temperatura y conductividad eléctrica in situ, utilizados en este trabajo se describen en el Apéndice A-III-3. Los procedimientos están basados en APHA-AWWA-WFPC (1992). La determinación de los parámetros químicos se hizo utilizando las siguientes técnicas analíticas: potenciometría, volumetría, flamometría, espectrofotometría de emisión y absorción atómica. Los parámetros fisicoquímicos analizados en laboratorio fueron: bicarbonatos, dureza, calcio, cloruros, sulfatos, sílice, hierro, magnesio, sodio, potasio y nitratos.

De los resultados de los análisis químicos de cada pozo, se efectúo el balance iónico, involucrando en éste al sodio, potasio, calcio, magnesio, bicarbonato, carbonato, sulfato y cloruro. El balance iónico se realizó calculando los equivalentes de cada uno de los iones (Custodio y Llamas, 1983; Appelo y Postma, 1993; Deutsch, 1997). La determinación del tipo de agua se realizó utilizando el diagrama triangular de Piper (Apéndice A-III-4).

La determinación de los elementos químicos a nivel de trazas se hizo por medio de espectrometría de masas por plasma de acoplamiento inductivo (ICP-MS) (Morton et al., 1996, 1998; Willard et al., 1991; Wyse y Fisher, 1994). Para los elementos químicos a nivel de trazas, que se encuentran en concentraciones muy bajas, es esencial conocer el límite de detección (LD) del instrumento utilizado para cada elemento analizado. Los límites de detección por lo general, se calculan a partir de los resultados obtenidos en los análisis sucesivos de 10 blancos. Los límites de detección están definidos como 3 veces la desviación estándar de los blancos (Pane, 1995).

Limites de detección (10-9)

\begin{tabular}{|c|c|c|c|c|c|}
\hline Elemento & LD & $\begin{array}{c}\text { Element } \\
0\end{array}$ & LD & $\begin{array}{c}\text { Element } \\
0\end{array}$ & LD \\
\hline $\mathrm{Cr}$ & 0.093 & $\mathrm{As}$ & 0.354 & $\mathrm{Cd}$ & 0.011 \\
$\mathrm{Mn}$ & 0.024 & $\mathrm{Rb}$ & 0.022 & $\mathrm{Cs}$ & 0.003 \\
$\mathrm{Co}$ & 0.026 & $\mathrm{Sr}$ & 1.686 & $\mathrm{Ba}$ & 0.108 \\
$\mathrm{Cu}$ & 0.033 & $\mathrm{Mo}$ & 0.007 & $\mathrm{U}$ & 0.011 \\
$\mathrm{Zn}$ & 0.510 & & & & \\
\hline
\end{tabular}




\section{ANÁLISIS DE ROCAS}

Las rocas que constituyen la corteza terrestre contienen concentraciones de uranio a nivel de trazas entre 2 y 4 ppm en promedio, algunas rocas ígneas contienen mayor concentración de uranio que las rocas metamórficas y sedimentarias. La importancia de identificar el tipo de roca estriba en que el uranio y su cadena de decaimiento emiten radiación $\alpha, \beta$ y $\gamma$ (Peña et al., 1999).

Para identificar la composición mineralógica de las muestras de roca, se utilizaron la técnica de secciones delgadas mediante un microscopio polarizante. Sin embargo, existen técnicas modernas como son el microscopio electrónico de barrido y el difractómetro de rayos $X$ entre otros, para identificar las fases cristalinas y los elementos básicos de algunos minerales que constituyen las rocas. Las muestras pétreas se extrajeron de los sitios localizados en el Terreno Guerrero (GSL) (zona 1) y en el terreno Xolapa (GAC) (zona 2), en los cuales se observaron diferencias en los valores de concentración de la emanación de radón y de la dosis gamma en el suelo.

Análisis mineralógico.- Para medir el contenido mineralógico de rocas se utilizó un microscopio electrónico de barrido PHILIPS, modelo XL 30 con una sonda de microanálisis EDAX, modelo DX4, usada para determinar la composición química elemental de las muestras. Así mismo para identificar los tipos de compuestos cristalinos se utilizó un difractrómetro de rayos X SIEMENS, modelo D 5000 con un monocromador de grafito, utilizando la línea $k \alpha(\mathrm{Cu})$ con longitud de onda $\lambda=1.5405 \AA$.

Análisis isotópico.- Se realizaron análisis de muestras de roca para determinar el contenido de ${ }^{226} \mathrm{Ra}$ y ${ }^{40 \mathrm{~K}}$. La actividad especifica en peso seco $\left(\mathrm{Bq} \mathrm{kg}^{-1}\right)$ se determino con un espectrómetro $\gamma$ de bajo fondo que cuenta con un detector HPGe Princeton Gamma Tech., Dusseldorf, modelo N-IGC 29, con una eficiencia relativa de $27.4 \%$. El análisis del ${ }^{226}$ Ra se realizó por medición directa del pico de $186.2 \mathrm{keV}$. Para calibrar el detector se utilizó la mezcla estándar apropiada para isótopos que emiten rayos gamma. Se utilizó un contenedor Marinelli de $500 \mathrm{~mL}$. El tiempo de medición fue de 100,000 s para alcanzar el limite de detección de $30 \mathrm{~Bq} \mathrm{~kg}^{-1}$ para ${ }^{40} \mathrm{~K}_{\text {y }} 9 \mathrm{~Bq} \mathrm{~kg}^{-1}$ para ${ }^{226} \mathrm{Ra}$. El error de conteo en las mediciones fue menor al $10 \%$.

El contenido de uranio en rocas se determinó por medio de la técnica de fluorometría utilizando un fluorómetro Galvanek-Morrison, Jarrell-Ach, modelo 26-000.

\section{TRATAMIENTO ESTADÍSTICO}

Para el análisis de los resultados de la emanación del radón y de la dosis gamma se calcularon los siguientes parámetros estadísticos: promedio aritmético, el promedio geométrico, la desviación estándar, valores anómalos de radón (mayor de $\xi+2 \sigma$ ), etc. (Fong-liang y Gui-ru, 1981; Igarashi y Wakita, 1990; Singh y Virk, 1994; Kitto et al., 1996). El estudio geoestadístico de los resultados de los análisis químicos de las aguas se llevó a cabo por medio del paquete estadístico XLSTAT (2000), aplicando en método de análisis multivariante de componente principal (Bry, 1995; Davis, 1986; Gangopadhyay et al., 2002; Hair et al., 1999; Johnson, 2000; Melloul y Colluin, 1992; Melloul, 1995; Pla, 1986; Sierra, 1994; Visauta, 1998). 
En la costa del Golfo de México, las correlaciones de los elementos químicos mayores mediante la técnica del análisis de componente principal, se hicieron con datos de periodos de muestreo, uno en abril de 1994 (época de secas) con 9 variables $\left(\mathrm{HCO}_{3}^{-}, \mathrm{SO}_{4}{ }^{2-}, \mathrm{Cl}^{-}, \mathrm{Na}^{+}, \mathrm{K}^{+}, \mathrm{Ca}^{2+}, \mathrm{Mg}^{2+}, \mathrm{D}\right.$ y $\mathrm{SiO}_{2}$ ) y el otro en agosto de 1994 (época de lluvias) con 3 variables más $\left(\mathrm{HCO}_{3}-\mathrm{SO}_{4}^{2-}, \mathrm{Cl}^{-} \mathrm{Na}^{+}, \mathrm{K}^{+}, \mathrm{Ca}^{2+}, \mathrm{Mg}^{2+}, \mathrm{D}, \mathrm{SiO}_{2}, \mathrm{~T}, \mathrm{CE}\right.$ y pH). En cuanto a los elementos traza, se realizaron en 2 periodos de muestreo uno en octubre de 1995 (época de lluvias) y otro en febrero de 1996 (época de secas) con 13 variables (As, B, Ba, Cd, Co, Cr, Cs, Cu, Li, $\mathrm{Mn}, \mathrm{Pb}, \mathrm{Rb}, \mathrm{U}, \mathrm{Zn})$.

En la costa de Guerrero, se realizaron con 15 variables $\left(\mathrm{T}, \mathrm{pH}, \mathrm{CE}, \mathrm{HCO}_{3}^{-}, \mathrm{SO}_{4}^{2-}, \mathrm{Cl}^{-} \mathrm{Na}^{+}, \mathrm{K}^{+}, \mathrm{Ca}^{2+}, \mathrm{Mg}^{2+}\right.$, $\mathrm{D}, \mathrm{Fe}, \mathrm{SiO}_{2}, \mathrm{NO}_{3}, \mathrm{NH}_{3}$ ) correspondientes a 12,9 y 10 periodos de muestreo analizados en las estaciones de Guacamayas, El Cayaco y El Cortés respectivamente. En cuanto a los elementos traza, se utilizaron 16 variables (As, B, Ba, Cd, Co, Cr, Cs, Cu, $\mathrm{Li}, \mathrm{Mo}, \mathrm{Mn}, \mathrm{Pb}, \mathrm{Rb}, \mathrm{U}, \mathrm{Zn}$ ), y 15 periodos de muestreo en las estaciones de Guacamayas, El Cayaco y El Cortés.

En este trabajo se tomó en consideración el criterio establecido por Adams et al. (2001) para una correlación moderada cuando $r$ oscile de 0.5 a 0.7 y una correlación fuerte para $r=>0.7$.

\section{LUGARES ESPECÍFICOS DE MUESTREO}

La localización de los diferentes sistemas para detectar radón y radiación gamma así como elementos mayores y traza en agua subterránea se presentan en la Figura III-2. Para determinar las coordenadas geográficas de cada punto de muestreo se utilizó un geoposicionador (Sistema global de posicionamiento GPS), modelo Magellan 300, el cual tiene capacidad para 12 proyecciones de satélite. El GPS se calibró por: región, ciudad, elevación, tiempo y unidades. Posteriormente se obtuvieron las coordenadas con precisión de \pm 1 segundo de geogrado.

\subsection{COSTA DEL GOLFO DE MÉXICO}

La zona de estudio comprende el área del sitio de la PNLV, del acuífero EI Viejón (EV), de Rancho Nuevo (RN), de Las Lajas (LL), Palma (P) y de Loma (L) (Fig. III-2 a,b). Los detectores se colocaron en pozos existentes en la PNLV y en EV para determinar radón (P1, P2, P3, P6, P8, P9, P10, LV1, LV2, LV5, AD4, M y R2) (Fig- III-2-b). Los detectores LR-115 se expusieron durante el periodo de 1994 a 1996 y los sistemas Clipperton, de julio a noviembre de 1996.

Se obtuvieron muestras de agua para el análisis de elementos mayores en los siguientes pozos: PNLV (LV1, LV2, LV6 y LV12) y EV (P1, P2, P3, P8 y P9), en abril (época de secas) y en agosto (época de lluvias) durante 1994. En cuanto a los elementos traza, se determinaron en los pozos (P1, P2, P3, P6, P8, P9, P10, LV1, LV2, LV5, R2, AD4, M y RN) en febrero de 1995 y en octubre de 1996 que corresponden a la estación de secas y de lluvias respectivamente. 
Las estaciones de la zona se definen de la siguiente manera:

\begin{tabular}{|c|c|c|c|c|}
\hline \multicolumn{3}{|c|}{ Detección del radón } & \multicolumn{2}{|c|}{ Muestreo de agua subterránea } \\
\hline $\begin{array}{l}\text { LR-115 } \\
\text { Suelo }\end{array}$ & $\begin{array}{c}\text { LR-115 } \\
\text { Agua }\end{array}$ & $\begin{array}{c}\text { Clipperton } \\
\text { Suelo }\end{array}$ & Elementos mayores & Elementos traza \\
\hline VRS-16, VRS-14 VRS-18 & VRA-14 & RN & LV2, LV1, LV12, P1, P2, P3, & LV2, LV1, LV5, R2, P1, P2, \\
\hline VRS-16, VRS-14, VRS-18 & VRA-6, VVA-10 & & P8, P9 & P3, P6, P8, P9, P10, AD4, M, \\
\hline VLS-11 & VLA-11 & PNLV & & \\
\hline VPS-13, VLS-19, VHHS & & & & \\
\hline
\end{tabular}

\subsection{COSTA DE GUERRERO}

Los detectores LR 115 se cambiaron con una periodicidad de aproximadamente un mes entre 1993 y 1998. Con los sistemas Clipperton en suelo se obtuvieron promedios en ACA de diciembre de 1994 a diciembre de 1998. Las medidas con los DTL se obtuvieron de mayo de 1997 a diciembre de 1998.

Se obtuvieron muestras de agua para el análisis de elementos mayores en los pozos de Guacamayas y El Cayaco desde diciembre de 1996 a diciembre de 1998, así como en el manantial El Cortés de marzo de 1997 a diciembre de 1998. Se realizaron en cada uno de los sitios los análisis físico-químicos in situ. Los elementos traza en solución se determinaron en Guacamayas desde marzo de 1996 a mayo de 1998, en El Cayaco desde marzo de 1996 a febrero de 1998, y en El Cortés de abril de 1997 a mayo de 1998.

La instalación de estaciones de radón en suelo y agua con detectores pasivos y activos, así como con DTL se describen a continuación:

\begin{tabular}{|c|c|c|c|c|c|}
\hline Localidad & Coordenadas & $\begin{array}{l}\text { LR-115 } \\
\text { en suelo }\end{array}$ & \begin{tabular}{|l} 
Clipperton \\
en suelo
\end{tabular} & \begin{tabular}{|c|} 
Clipperton \\
en agua
\end{tabular} & $\begin{array}{c}\text { DTL } \\
\text { en suelo }\end{array}$ \\
\hline Guacamayas, Mich. & $18^{\circ} 01^{\prime} 15^{\prime \prime} \mathrm{N}-102^{\circ} 12^{\prime} 30^{\prime \prime} \mathrm{W}$ & $M G$ & & GUACA & $M G$ \\
\hline La Unión, Gro. & $17^{\circ} 59^{\prime} 15^{\prime \prime} \mathrm{N}-101^{\circ} 48^{\prime} 15^{\prime \prime} \mathrm{W}$ & GLU & & & GLU \\
\hline $\begin{array}{c}\text { Papanoa-Escuela, } \\
\text { Gro. }\end{array}$ & $17^{\circ} 19^{\prime} 15^{\prime \prime} \mathrm{N}-101^{\circ} 02^{\prime} 30^{\prime \prime} \mathrm{W}$ & GPE & & & GPE \\
\hline Papanoa-Huerta, Gro. & $17^{\circ} 19^{\prime} 15^{\prime \prime} \mathrm{N}-101^{\circ} 02^{\prime} 30^{\prime \prime} \mathrm{W}$ & GPH & & & GPH \\
\hline San Luis la Loma, Gro. & $17^{\circ} 16^{\prime} 00^{\prime \prime} \mathrm{N}-100^{\circ} 53^{\prime} 15^{\prime \prime} \mathrm{W}$ & GSL & & & GSL \\
\hline El Cayaco, Gro. & $17^{\circ} 02^{\prime} 45^{\prime \prime} \mathrm{N}-100^{\circ} 16^{\prime} 00^{\prime \prime} \mathrm{W}$ & GEC & & CAYA & GEC \\
\hline $\begin{array}{c}\text { Coyuca de Benítez, } \\
\text { Gro. }\end{array}$ & $16^{\circ} 56^{\prime} 30^{\prime \prime} \mathrm{N}-100^{\circ} 04^{\prime} 45^{\prime \prime} \mathrm{W}$ & GCB & & & GCB \\
\hline Acapulco-Centro, Gro. & $16^{\circ} 52^{\prime} 50^{\prime \prime} \mathrm{N}-99^{\circ} 50^{\prime} 30^{\prime \prime} \mathrm{W}$ & GAC & ACA & & GAC \\
\hline $\begin{array}{c}\text { Acapulco-Sabana, } \\
\text { Gro. }\end{array}$ & $16^{\circ} 53^{\prime} 30^{\prime \prime} \mathrm{N}-99^{\circ} 50^{\prime} 00^{\prime \prime} \mathrm{W}$ & GAS & & & GAS \\
\hline Cerro de Piedra, Gro. & $16^{\circ} 46^{\prime} 45^{\prime \prime} \mathrm{N}-99^{\circ} 37^{\prime} 45^{\prime \prime} \mathrm{W}$ & GCP & & & GCP \\
\hline San Marcos, Gro. & $16^{\circ} 47^{\prime} 45^{\prime \prime} \mathrm{N}-99^{\circ} 23^{\prime} 15^{\prime \prime} \mathrm{W}$ & GSM & & & GSM \\
\hline Marquelia, Gro. & $16^{\circ} 34^{\prime} 45^{\prime \prime} \mathrm{N}-98^{\circ} 49^{\prime} 00^{\prime \prime} \mathrm{W}$ & GM & & & GM \\
\hline
\end{tabular}




\section{CAPITULO IV RESULTADOS Y DISCUSIÓN.}

\section{COSTA DEL GOLFO DE MÉXICO.}

La localización de los sismos que se observaron de 1994 a 1996 en la zona de CGMPNLV, se muestra en la Figura IV-1. Se determinó una zona relativamente pequeña (1.4 $\times 1.2$ de grado geodésico), en la cual se observaron 18 sismos $(M>2.9)$ y $176(M<2.9)$. Así mismo se tomaron áreas iguales $\left(100 \mathrm{~km}^{2}\right)$, en los alrededores de las localidades de RN, PNLV, L, EV, P, y LL, observándose que las zonas que presentaron mayor densidad sísmica fueron LL (39), seguido de RN (18), P (11), PNLV (5), EV (3) y L (2). Así mismo se presentaron 6 sismos $(M>3.8), 1$ en los alrededores de RN, 3 en los alrededores de $P$, EV y LL, 1 cerca de la ciudad de Veracruz y otro a $90 \mathrm{~km}$ al sureste de la PNLV. La localización de los epicentros de los sismos $(M=2.7)$ en el periodo de estudio, la profundidad, fecha, magnitud y distancia del epicentro a la PNLV, se muestra en la Tabla IV-1, en la cual se observa que las profundidades variaron de 4 a $49 \mathrm{~km}$, predominando las profundidades someras $(<20 \mathrm{~km})$. Uno de los sismos de mayor magnitud ocurrió el día 24 de marzo de $1994(\mathrm{M}=4)$ a una profundidad de $7 \mathrm{~km}$ y a una distancia de la PNLV de $12 \mathrm{~km}$. El 25 de agosto de 1994 ocurrió otro de la misma magnitud, con profundidad de $18 \mathrm{~km}$ y a $56 \mathrm{~km}$ de la PNLV. Los días 1, 3 y 16 de abril de 1994 se presentaron tres sismos ( $M=3.8,3.8$, y 3.9$)$ con profundidades de 5,5 y $12 \mathrm{~km}$ y a 16,10 y $52 \mathrm{~km}$ respectivamente de la PNLV. El 11 de noviembre de 1995 se manifestó un sismo $(M=3.8)$ con profundidad de $15 \mathrm{~km}$ y a una distancia de $85 \mathrm{~km}$. La sismicidad observada fue de baja magnitud y el número de sismos fue escaso.

La temperatura en $1994-1996$ fluctúo entre 20.3 y $28.1^{\circ} \mathrm{C}$, con mínimos en enero y máximos de mayo a septiembre. La distribución de la precipitación en 1994 fue regular, se observó que el periodo de lluvia inició en abril y finalizó en diciembre, teniendo su máximo valor en agosto. En cuanto a la distribución de 1995, fue irregular, pues inició en mayo, disminuyó notablemente en julio y finalizó en noviembre, su valor máximo se presentó en julio. La distribución de la lluvia de 1996 también fue irregular pues inició en mayo y finalizó en diciembre, su máximo se presentó en agosto, se observó una disminución en septiembre y octubre.

\subsection{RADÓN}

Los valores de la concentración de radón en agua $\left(\mathrm{kBqm}^{-3}\right)$, obtenidos con detectores $\mathrm{LR}-115$, en las estaciones de Rancho Nuevo (VRA-14), El Viejón (VVA-6 y VVA-10) y la PNLV (VLA-11), se muestran en la Tabla IV-2 y se grafican en la Figura IV-2, junto con la temperatura, precipitación y sismicidad.

Durante 1994, se observó un incremento de la concentración de radón en VRA-14, VVA-6 y VRA-10, que coincide con el final de la época de secas (mayo) y con un enjambre sísmico en marzo-abril. En las estaciones VVA-11 y VVA-6, se presentó una anomalía en noviembre que coincide con el final de las lluvias. Al final de la época de lluvias se observaron en tres estaciones los valores mayores de la concentración de radón del año.

En 1995, se observaron incrementos de la concentración de radón en las estaciones (VRA-14 y VVA-6) en mayo-junio, con una anomalía en VRA-14. Dicha anomalía coincide con una disminución de la precipitación. Al incrementarse en el siguiente mes (julio) la precipitación, se observó una disminución drástica en los valores de la concentración de radón. Este comportamiento del radón se debe a la recarga súbita del acuífero, diluyéndose la concentración de radón en el agua subterránea somera (Segovia et al., 
1997a). En VVA-11 el incremento de la concentración de radón ocurre en la parte media de la época de lluvias. Se registró poca sismicidad en el periodo de enero a septiembre, el resto del año los valores de radón y la sismicidad se mantuvieron bajos. El valor máximo de toda la zona corresponde a RN, en la época de lluvias de 1995, ausente de sismicidad, por lo que se puede inferir que el aumento de radón en junio-julio de 1995 se debe a la influencia meteorológica.

En 1996 se inicia el incremento de la concentración de radón en febrero, coincidiendo con un periodo de baja precipitación, los valores de radón se mantuvieron estables hasta junio. Se observó en la estación VRA-14, una anomalía en junio que coincide con la época de lluvias. En la estación VVA-10, se presentó una anomalía en noviembre.

Cabe mencionar que la precipitación en 1996 fue atípica con una disminución evidente en septiembre y octubre.

En la Tabla IV-3 y Figura IV-3, se muestran la media aritmética $(\xi)$ y su desviación estándar $(\sigma)$ así como los valores máximos de la concentración de radón en agua en cada una de las estaciones para los tres años de observación. Se muestran también los valores promedio de la media aritmética y geométrica $(\xi$, $\left.\xi_{g}\right)$ además de su desviación estándar $(\sigma, \sigma \xi)$ así como los valores máximos de la concentración de radón. La columna correspondiente a $\xi+2 \sigma$ muestra los valores por encima de los cuales se definen las anomalías de la concentración de radón. Se observa que los valores $\xi$ de radón fluctuaron de 0.13 a 1.50 $\mathrm{kBqm}^{-3}$. Los valores promedio de mayor a menor corresponden a EV, RN y PNLV. Las medidas tuvieron grandes desviaciones, siendo la PNLV la menos dispersa. Estos valores promedio pueden explicarse debido a la sismicidad local en el periodo de exposición en cada una de las estaciones. Aunque los sismos fueron de baja magnitud se puede apreciar (Fig. IV-1) que la mayor densidad de sismos fue al sur de EV seguido por RN. Se aprecia en la figura que no hubo prácticamente ningún sismo local en la PNLN. Por lo tanto se puede concluir que la sismicidad local permite un aumento de la emanación de radón de la roca.

Vasarhelyl et al. (1997), realizaron estudios sobre el radón en agua subterránea en Hungría en 1992, con DSTN. Determinaron radón en pozos, suponiendo que representaba el contenido de radón del acuífero en la vecindad del pozo. Encontraron valores de radón en agua con $\xi \mathrm{g}=6.8 \mathrm{kBqm}^{-3}$, los niveles de la concentración de radón en agua oscilaron de 0.1 a 273.2. Así mismo Zouridakis et al. (2002), determinaron en Grecia valores superiores de $160 \mathrm{kBqm}^{-3}$. Como se observa en nuestro estudio la dispersión de valores es semejante o está dentro del rango reportado. Dado que las medidas se realizaron en agua, la influencia de la dilución que se refleja en las medidas realizadas a lo largo del tiempo es contundente.

En la Figura IV-4 se muestra la gráfica de la concentración de radón en agua obtenida con la sonda Clipperton en las estaciones de RN y en la PNLV en el año de 1996. Las discontinuidades se deben a fallas en la fuente de energía que alimenta al sistema de la sonda. En la estación de RN, se observó que los valores de las fluctuaciones de la concentración de radón se incrementaron en la segunda mitad de octubre, siendo el promedio del orden de $1.4 \mathrm{kBqm}^{-3}$. En la estación de la PNLV con la segunda sonda Clipperton, se presentan los valores máximos de la concentración de radón en agua a mediados del mes de septiembre de 1996, cuando ocurre el decremento anómalo de precipitación. 
En un estudio de radón y otros grases con equipos automáticos, en la península de Izu, Japón, en diciembre 1995, Nishizawa et al. (1998), mostraron que las concentraciones de radón en el agua de manantiales se incrementaron en septiembre y octubre de 1995, cuando ocurrió un sismo el 11 de septiembre $1995(\mathrm{M}=4.8)$ a $30 \mathrm{~km}$ del pozo. El incremento anómalo del radón lo interpretaron los autores citados al tomar en cuenta la vida media de éste, la baja velocidad del flujo y transporte a grandes distancias del agua enriquecida con radón, así como los cambios en los esfuerzos relacionados con la actividad sísmica que puedan causar cambios en el flujo del agua subterránea. Estos autores estimaron que las concentraciones de radón en agua subterránea son proporcionales a la superficie del área de roca expuesta al agua. La formación de microfracturas debido a los esfuerzos de la compresión incrementa el área superficial de las rocas y pueden ser causa de cambios en la concentración del radón en agua subterránea. El incremento en la concentración de radón en este caso, se manifestó tres días después de la presencia de un conjunto de sismos, el posible mecanismo de las anomalías de radón fue explicado por la formación de microfracturas en el acuífero causadas por los esfuerzos de compresión que preceden a los sismos. En nuestro caso la sismicidad fue de baja magnitud $(M<4)$, los efectos del radón en agua, solo parecen responder a los efectos meteorológicos excepto en marzo-abril de 1994, cuando se presentó un enjambre de varios sismos.

Los valores de la concentración de radón en suelo $\left(\mathrm{kBqm}^{-3}\right)$ obtenidos durante el estudio con detectores LR115 (Tabla IV-4), en las estaciones de Rancho Nuevo (VRS-14, VRS-16 y VRS-18), El Viejón (VVS-6 y VVS-10), PNLV (VLS-11), Palma (VPS-13), Loma (VLS-19) y Las Lajas (VHHS), junto con la temperatura, precipitación y sismicidad durante el periodo de exposición, se grafican en la Figura IV-5.

Durante 1994, se observaron incrementos de la concentración de radón en RN (VLS-19, VRS-14 y VRS-16 y VRS-18) que coincidieron con el final de la época de secas. Al final de la época de secas se observaron en todas las estaciones los mayores valores de la concentración de radón del año. Cabe mencionar que en coincidencia con el sismo de noviembre de 1994, se obtuvo un pico de radón en suelo en todas las estaciones, excepto en VLS-11.

En 1995, se obtuvieron incrementos de la concentración de radón en las estaciones VLS-11, VPS-13, VS10 y VVS-6, en la época de lluvia, y en las estaciones VRS-14, VRS-16, VRS-18, VLS-19 y VHHS al final de la época de lluvias. Se observa, en la estación VRS-14, una anomalía de la concentración de radón en noviembre, que coincide con la disminución de la precipitación. En la estación VLS-11 se presenta una anomalía de la concentración de radón (mayo-junio), que coincide con el inicio de la época de lluvias por lo que el comportamiento de la concentración del radón quizás se deba a los factores meteorológicos (precipitación).

En 1996 se presentaron incrementos de la concentración de radón en suelo en la época de lluvias en todas las estaciones, así como al final de la estación de lluvias. En la estación VRS-16, se observa una anomalía de la concentración de radón en la época de lluvias (julio-agosto). En cuanto a las estaciones VRS-18, VVS-6, VPS-13 y VHHS, se presentaron anomalías de radon al final de la época de lluvias. Este comportamiento de la concentración de radón quizás se deba a la intensidad de la lluvia, ya que este año fue atípico pues existió una disminución en septiembre-octubre que fue precisamente en donde ocurrieron los incrementos y las anómalas de radón. El valor máximo de toda la zona corresponde a RN, en la época 
de lluvias de 1996, en una época ausente de sismos esporádicos, por lo que se puede inferir que el aumento de la concentración de radón en agosto-septiembre de 1996 se debe a la influencia meteorológica.

En la Tabla IV-5 y Figura IV-6, se muestran la media aritmética $(\xi)$ y su desviación estándar $(\sigma)$ así como los valores máximos de la concentración de radón en suelo en cada una de las estaciones para los tres años de observación. Se muestran también los valores promedio de la media aritmética y geométrica $(\xi$, $\left.\xi_{g}\right)$ además de su desviación estándar $(\sigma, \sigma \xi g)$ así como los valores máximos de la concentración de radón. Los valores de $\xi$ varían de 1.36 a $6.96 \mathrm{kBqm}^{-3}$. Se observa que los valores promedio de mayor a menor corresponden a L, RN, EV, LL, P y PNLV. Las medidas tuvieron grandes desviaciones, siendo la estación $P$ la menos dispersa. Por lo general durante el periodo de muestreo en las estaciones antes mencionadas, se observaron incrementos de la concentración de radón en suelo durante y al final de la época de lluvias.

La literatura reporta (Akerblom et al., 1984; Jonsson, 1995; Michel, 1987) que la concentración de radón puede variar de 2 a $30 \mathrm{kBqm}^{-3}$ para suelos constituidos principalmente por arenas, arcillas y basalto. Igasashi et al., (1995) y Garavaglia et al., (1999), reportan anomalías en el incremento de la concentración de radón en suelo, cerca de una falla y suponen que dicha concentración se debe a los esfuerzos originados alrededor de ésta. Zalewski et al. (2001), obtuvieron en Polonia valores de la concentración de radón en suelo constituido por gravas, arenas y arcillas, valores que oscilan entre 26 y $30 \mathrm{kBq} \mathrm{m}^{-3}$. Así mismo Wysocka et al. (2001), observaron cambios significativos en los valores de la concentración de radón en suelo en zonas falladas. En nuestro estudio los sitios están constituidos por basaltos principalmente, así como por suelo residual (arenas y arcilla) y los valores oscilaron de 0.09 a $15.1 \mathrm{kBq} \mathrm{m}^{-3}$.

Vasarhelyl et al. (1997), realizaron estudios sobre el radón en suelo en Hungría en 1992, con DSTN, encontraron que los valores oscilaron de 0.3 a $99.32 \mathrm{kBq} \mathrm{m}^{-3}$ con una $\xi \mathrm{g}=5.8 \mathrm{kBq} \mathrm{m}^{-3}$. Como se observa en nuestro estudio la dispersión de valores es semejante o está dentro del rango reportado. Dado que las medidas se realizaron en la superficie cerca del suelo, la influencia de la dilución en la atmósfera es contundente.

Turk et al. (1996), también reportaron concentraciones de radón en suelo, utilizando DSTN. El sitio que estudiaron es del Pleistoceno, constituido por sedimentos arcillosos con arenas y gravas. Observaron que los detectores muestran una periodicidad estacional, con máximos valores en verano y mínimos en invierno, de 6 a $0.2 \mathrm{kBqm}^{-3}$ respectivamente, por lo que sugieren la influencia meteorológica. La actividad especifica del radón en el suelo, muestra una dependencia del contenido del agua la cual está en función de la temperatura y de la precipitación. Los resultados muestran que la actividad del radón se incrementa cuando disminuye la cantidad del agua almacenada en el suelo. En nuestro trabajo se encontró una relación similar.

Papastefanou et al. (1997), midieron radón en suelo con DSTN, en 1992 y 1993 en Grecia. Observaron cambios en el flujo del radón que también atribuyen a los cambios de las condiciones meteorológicas, al comienzo del periodo de lluvias, en concordancia con el presente trabajo.

Segovia et al. (1995b, 1996, 1997a), publicaron resultados de la concentración del radón en suelo y agua subterránea de la zona de RN, EV y la PNLV, por medio de DSTN y de sondas Clipperton. La sismicidad 
reportada fue, como en éste caso menor a $(M=3.8)$. Las fluctuaciones de la concentración de radón en suelo fueron influenciadas por los patrones meteorológicos. Asimismo también en este reporte los valores máximos de la concentración de radón correspondieron a RN y los más bajos corresponden a la PNLV. La zona de RN se conoce como la zona de fractura que permite flujos preferentes de gases. Wysocka et al. (2001); Segovia et al. (1999c) y Tamimi y Abumurad (2001) reportaron que las mediciones realizadas en una zona con fallas geológicas, muestran que en muchos casos existen cambios significativos en la concentración de radón en suelo debido a dislocaciones tectónicas y fallamientos. Las anomalías de la concentración de radón en agua durante el periodo de muestreo fueron observadas al inicio de la estación seca (noviembre-abril), en concordancia con los presentes resultados. En nuestro caso los valores más altos corresponden a la concentración de radón en suelo.

\subsection{ELEMENTOS Y COMPUESTOS QUÍMICOS MAYORES}

Debido a que la zona de estudio es esencialmente volcánica del tipo basáltico y andesítico, las reacciones químicas principales serán aquellas donde intervengan los silicatos que forman las aguas volcánicas (Appelo y Postma, 1993). La química de las aguas subterráneas es el resultado de la interacción entre el agua y los materiales de las rocas que constituyen el acuífero. Los resultados obtenidos de aniones $\mathrm{HCO}_{3}{ }^{-}$ , $\mathrm{Cl}^{-}$y $\left.\mathrm{SO}_{4}{ }^{2-}\right)$ y cationes $\left(\mathrm{Ca}^{2+}, \mathrm{Mg}^{2+}, \mathrm{Na}^{+}\right.$y K$\left.{ }^{+}\right)$, además de la dureza y $\mathrm{SiO}_{2}$ se presentan en la Tabla IV-6 (a, b). Se puede observar lo siguiente:

Bicarbonatos $\left(\mathrm{HCO}_{3}^{-}\right)$.- Los valores promedio fueron semejantes para las dos regiones (PNLV y El Viejón). Sin embargo, los valores difieren en $15 \%$ entre las épocas de secas y de lluvias, siendo mayor en la época de lluvia. Estos valores se deben al arrastre durante la época de recarga. La presencia de bicarbonatos en agua subterránea, se debe a la disolución de las calizas y dolomitas por reacción del bióxido de carbono de la atmósfera y del suelo, ya que éste penetra en el agua en cantidades significativas al percolarse ésta a través del suelo (Gibson, 1974; Palmer, 1996; Adams et al., 2001). Este efecto ocurre en esta zona de Veracruz. Giggenbach y Corrales (1992) y Gosselin et al. (2001) observaron también que las aguas salitrosas dan incrementos de $\mathrm{HCO}_{3}{ }^{-}$debido a la interacción con las rocas volcánicas. En nuestro caso existe también la presencia de infiltraciones marinas.

Sulfatos $\mathrm{SO}_{4}{ }^{2-}$ ). Los valores promedio de los sulfatos fueron significativamente menores (50\%) en la zona de El Viejón y no variaron las concentraciones en las dos épocas (lluvias y secas). El contenido de sulfatos indica que las aguas subterráneas se transportan en rocas ígneas y metamórficas o en los sedimentos derivados de ellas. Los sulfatos junto con los cloruros y nitratos de los metales alcalinotérreos, son los que proporcionan al agua la dureza no carbonatada llamada dureza permanente (ASTM, 1991; Palmer, 1996). Los valores de los sulfatos en las dos zonas de estudio indican que las aguas circulan por estratos de composición semejante en ambas áreas.

Cloruros (Cl -).- El comportamiento de los cloruros mostró diferencias entre la época de secas y la de lluvias. En la primera, el valor promedio fue $60 \%$ mayor en El Viejón, mientras que durante las lluvias la zona de la PNLV sobrepasa al Viejón en $20 \%$. Este comportamiento es típico de una influencia salina, posiblemente unida a la infiltración de agua salobre del mar, durante la época de lluvias, en la zona de El Viejón que está a menor altura que la PNLV y cercana a la Laguna Salada, contaminando el acuífero. La variación de la concentración de cloruros se debe al cambio en la concentración hidráulica en el medio 
geológico, una disminución en la permeabilidad ocasiona un incremento en la concentración de cloruros y viceversa (Custodio y Llamas, 1983).

Sodio ( $\mathrm{Na}^{2+}$ ).- El sodio presenta un comportamiento semejante al $\mathrm{Cl}$, siendo $60 \%$ mayor en El Viejón, respecto a la PNLV, en la época de secas, mientras que durante las lluvias se igualan los valores de las dos zonas. Casi todos los compuestos de sodio son solubles, de modo que el sodio desprendido de las rocas 0 del suelo permanece en solución (Deutsch, 1997). El origen primordial de la mayor parte del sodio de las aguas naturales, se debe a la liberación de productos solubles durante la descomposición meteórica de los feldespatos del grupo de las plagioclasas (Davis y De Wiest, 1971; Pulido, 1978; APHA, AWWA, WPCF, 1992; Palmer, 1996). En nuestro caso el sodio puede provenir del mar que se encuentra a $5 \mathrm{~km}$. Banks, et al. (1995) y Gosselin et al. (2001), indican que en suelo Cuaternario, el cloro puede considerarse como un indicador de la influencia marina y que la diferencia $\mathrm{Na}-\mathrm{Cl}$ puede indicar una interacción agua-roca.

Potasio $\left(\boldsymbol{K}^{+}\right)$.- La concentración de potasio fue semejante en ambas zonas pero disminuyó a la mitad durante la época de lluvias, indicando una dilución del elemento. El sodio y el potasio son dos de las especies más constantes en las aguas subterráneas, su presencia se debe a la liberación de productos solubles que tiene lugar durante el intemperismo de las rocas ígneas y metamórficas, por lo que su presencia depende de la geología del lugar (Fletcher, 1995; Deutsch, 1997). Se ha reportado que la concentración de potasio en aguas naturales es por lo general menor que la del sodio y que la mayoría de las aguas subterráneas contienen menos de $10 \mathrm{mgL}^{-1}$ de potasio, variando entre 1 y $5 \mathrm{mgL}^{-1}$ (Armienta et al., 1996; Gosselin et al., 2001), lo cual concuerda con los valores obtenidos en la zona de estudio.

Calcio $\left(\mathrm{Cl}^{2+}\right)$.- El calcio se mantuvo constante en las áreas de estudio y las épocas del año. Las fuentes principales de los iones de calcio en el agua subterránea son los procesos geoquímicos que afectan a aquellos sedimentos que contienen una mayor proporción de este catión, como es el yeso, la anhidrita dolomía y la aragonita, así como los minerales volcánicos como son los piroxenos y la anortita (Appelo y Postma, 1993; APHA, AWWA, WPCF, 1992; Manahan, 1994; Deutsch, 1997). En nuestro caso los dos acuíferos estudiados están localizados sobre sedimentos del Reciente que subyacen a basaltos y andesitas, entre cuyos componentes mineralógicos, están las plagioclasas.

Magnesio $\left(\mathrm{Mg}^{2+}\right)$.- El promedio no varió ni entre sitios ni entre épocas. El magnesio es un componente común de las aguas subterráneas (APHA, AWWA, WPCF, 1992; Deutsch, 1997). En las rocas sedimentarias su presencia se debe a las dolomitas. La mayor parte de las calcitas contienen algo de magnesio y la disolución de calizas puede proporcionar al mismo tiempo grandes cantidades de calcio, magnesio y silicatos magnésicos. En las rocas ígneas, se debe al olivino, biotita, hornblenda y augita, al ataque de silicatos magnésicos y ferromagnésicos (Davis y De Wiest, 1971; Palmer, 1996). En nuestro caso, las estaciones de muestreo están ubicadas en suelos constituidos por rocas ígneas (basaltos) y depósitos sedimentarios.

Dureza Total (D).- La dureza fue mayor en la PNVL en las dos épocas indicando el efecto de la presencia de los bicarbonatos. La dureza total es la suma de la dureza temporal y permanente. En la dureza temporal el calcio y el magnesio se asocian a los bicarbonatos y en la permanente, estos elementos se 
asocian a los sulfatos y cloruros. La presencia de dichos elementos en el agua subterránea, se debe generalmente al paso de ésta por depósitos de dolomitas, yesos, calizas y evaporitas (Amienta et al., 1994).

Sílice $\left(\mathrm{SiO}_{2}\right)$.- Este elemento tuvo el mismo comportamiento que el calcio. Fue un poco mayor en la PNLV en la época de secas igualándose su concentración en las dos zonas en la época de lluvias. Los valores fueron bajos considerando que existen reportes que indican que en las aguas subterráneas de ambientes volcánicos, se observan concentraciones de sílice de alrededor de $100 \mathrm{mgL}^{-1}$ (Fletcher, 1995, Romero, 1999).

En resumen las concentraciones de $\mathrm{HCO}_{3}{ }^{-}, \mathrm{Cl}^{-}$, y $\mathrm{Na}$ - fueron semejantes en las dos zonas, siendo un poco mayores en la época de lluvias debido al efecto de dilución por arrastre durante la recarga. Por otro lado el potasio disminuyó a la mitad durante la época de lluvias indicando una dilución del elemento. Los sulfatos fueron distintos en las dos zonas y no variaron en el tiempo. Por su lado el $\mathrm{Ca}$ y el $\mathrm{SiO}_{2}$ fueron un poco mayores en el Viejón en la época de secas igualándose su concentración en las dos zonas en la época de lluvias. El magnesio no varió ni entre sitios ni entre épocas.

Se determinó el tipo agua para cada pozo muestreado tanto en la época de lluvias como de secas y los resultados se esquematizaron en el diagrama triangular de Piper (Figuras IV-7a y IV-7b). El diagrama que corresponde a la época de lluvias indica que las aguas estudiadas fueron bicarbonatada cálcica $\left[\left(\mathrm{HCO}_{3}^{-}\right)_{2^{-}}\right.$ $\mathrm{Ca}$ para LV1, P1, P3, y P9, bicarbonatada cálcico-magnésica $\left[\left(\mathrm{HCO}_{3}^{-}\right)_{2}-\mathrm{Ca}-\mathrm{Mg}\right]$ para $\mathrm{LV} 2$, y $\mathrm{P} 8$ y bicarbonatada cálcico-sódica $\left.\left[\left(\mathrm{HCO}_{3}\right)_{2}\right)_{2}-\mathrm{Ca}-\mathrm{Na}\right]$ para P2. Sin embargo, en la época de secas, se observaron cambios ya que LV1, LV6, P1 y P9 fueron del tipo bicarbonatada cálcica $\left[\left(\mathrm{HCO}_{3}\right)_{2}-\mathrm{Ca}\right]$; LV2 y P8 bicarbonatada cálcico-magnésica [( $\left.\left.\mathrm{HCO}_{3}{ }^{-}\right)_{2}-\mathrm{Mg}\right]$; y P2 y P3 bicarbonatada cálcico-sódica $\left[\mathrm{CHO}_{3}\right)_{2}-\mathrm{Ca}-\mathrm{Na}$ ]. Se observa que algunas aguas no variaron de tipo con el cambio de estación. Sin embargo, el pozo P3, que tuvo un gradiente de sodio entre la época de secas y la de lluvias cambió de bicarbonatada cálcica a bicarbonatada cálcico-sódica. Las dos zonas cuentan con un tipo de aguas subterráneas procedentes de rocas ígneas del tipo basáltico (Custodio y Llamas, 1983). Según el índice geoquímico y la diferenciación geoquímica de las aguas subterráneas se trata de aguas meteóricas de reciente infiltración. Las aguas bicarbonatadas son ricas en anhídrido carbónico y generalmente pobres en sulfatos y presentan una fuerte proporción de bicarbonatos. Este tipo es frecuente en las regiones de volcanismo Terciario y Cuaternario (Castany, 1971; Freeze y Cherry, 1979; Deutsch, 1997).

Araujo et al. (1999), realizaron estudios hidrogeológicos en acuíferos, localizados en areniscas fluviolacustres confinados con flujos basálticos semejantes a los de nuestra zona de estudio. Esos autores observaron que las familias de agua predominantes fueron las bicarbonatadas cálcicas $\left(\mathrm{HCO}_{3}^{-}\right)$, bicarbonatadas cálcico-magnésicas $\left[\left(\mathrm{HCO}_{3}^{-}\right)_{2}-\mathrm{Ca}-\mathrm{Mg}\right]$ y bicarbonatadas sódicas $\left[\left(\mathrm{HCO}_{3}^{-}\right)_{2}-\mathrm{Na}\right]$ como en nuestro caso.

Otros autores (Adams et al., 2001), reportaron que en una topografía montañosa (intrusiones dolomíticas), las aguas subterráneas estuvieron asociadas con fracturas y sistemas de juntas. Así mismo reportaron que los iones dominantes en las aguas subterráneas fueron $\mathrm{HCO}_{3}{ }^{-}, \mathrm{SO}_{4}{ }^{2-}$ y $\mathrm{Cl}$. Este comportamiento lo explicaron por el contacto de las rocas que se localizan en el área de estudio. Encontraron que los tipos de agua $\left[\left(\mathrm{HCO}_{3}{ }^{-}\right)_{2}-\mathrm{Ca}\right]$ se presentaron en áreas de recarga y fueron el resultado de la disolución de 
carbonatos; del tipo $\left(\mathrm{Na}^{+}-\mathrm{Cl}\right)$ en áreas de descarga. Sugirieron que el reemplazo de calcio por sodio a través del intercambio cationico, dá la formación de agua $\left[\left(\mathrm{HCO}_{3}^{-}\right)_{2}-\mathrm{Na}\right]$. Estos autores encontraron que la reducción del sulfato en aguas del tipo $\mathrm{Ca} \mathrm{SO}_{4}$ y $\mathrm{Na}_{2} \mathrm{SO}_{4}$, da la formación de $\left.\left[\left(\mathrm{HCO}_{3}\right)_{2}\right)_{2} \mathrm{Ca}\right]$ y $\left[\left(\mathrm{HCO}_{3}{ }^{-}\right)_{2}-\mathrm{Na}\right]$ respectivamente. Así mismo para topografías bajas, reportaron que el proceso dominante fue la lixiviación de evaporitas, $\mathrm{NaCl}$ y CaSO4 y la infiltración de agua. Los procesos de disolución, precipitación, intercambio iónico y reducción de sulfatos, controlaron la formación del tipo de agua como $\left[\left(\mathrm{HCO}_{3}{ }^{-}\right)_{2}-\mathrm{Ca}\right]$. Estos resultados fueron semejantes a los encontrados en nuestra zona de estudio.

\subsection{ELEMENTOS TRAZA EN SOLUCIÓN}

En la Tabla IV-7 (a,b), se muestran los valores de los elementos traza en solución. De las 13 especies determinadas el $B$ y el Ba se encuentran en mayor concentración. En dicha Tabla IV-7 (a, b) se observa lo siguiente:

Litio (Li).- El mayor valor de la concentración de litio, se observó en la época de secas, en el pozo R2. Durante el periodo de lluvias, los pozos P10 y M, fueron los que presentaron los valores más altos. El litio es un elemento poco común en la corteza terrestre, se encuentra principalmente en las rocas graníticas, la mayor parte de los compuestos de litio son solubles (Davis y De Wiest, 1971). Las concentraciones más elevadas de este metal se encuentran en las aguas minerales y en las salobres (Rodier, 1990), habiéndose reportado hasta $100 \mu \mathrm{g} \mathrm{L}^{-1}$ en aguas subterráneas. En nuestro caso los valores fueron muy bajos, menores a $1 \mu \mathrm{g} \mathrm{L}-1$.

Boro (B).- El mayor valor de la concentración de boro, se observó en la época de secas, en el pozo LV-5 y en periodo de lluvias, en el pozo M. Los pozos P1, P2, P3, P6, P9, P10, LV1, LV2 y R, están distantes entre ellos en menos de $300 \mathrm{~m}$ y se presentaron en ellos algunas variaciones en ambas épocas de año. La concentración del elemento probablemente se deba a la disolución de algún mineral con boro presente en las rocas volcánicas (Custodio y Llamas, 1983). Los valores obtenidos con un máximo de $57 \mu \mathrm{g} \mathrm{L}^{-1}$ son muy bajos ya que en aguas de lluvia se ha reportado un contenido de boro de aproximadamente $10 \mu \mathrm{g} \mathrm{L}^{-1}$. Sin embargo, Aggarwal et al. (2000), realizaron estudios en Islandia, observando que el boro y el cloro pueden tener interacción con los basaltos y el agua del mar.

Cromo (Cr).- Los mayores valores de la concentración de cromo, se observaron en P9 tanto en la época de secas como de lluvias. El cromo es un elemento poco común y su solubilidad es relativamente baja. Prácticamente es un elemento anormal en las aguas (APHA, AWWA, WPCF, 1992; Sawyer et al., 2001) y en nuestro caso los valores fueron muy inferiores $(1 \mu \mathrm{g} \mathrm{L}-1)$ a los permitidos por las normas internacionales para agua potable $\left(500 \mu \mathrm{g} \mathrm{L}^{-1}\right)$ (Asubiojo et al., 1997).

Manganeso (Mn).- Los valores en los pozos P9, P10 y LV1 fueron semejantes en la época de lluvias. En cuanto al periodo de secas, el pozo P8, fue el que presentó el valor más alto. El manganeso es un metal muy difundido en la corteza terrestre, es un elemento químico que frecuentemente se encuentra en las rocas volcánicas, constituyendo los minerales máficos, está presente en muchos suelos, sedimentos y rocas metamórficas (Manahan, 1994; Nalco, 1994) con valores hasta de $1 \mathrm{mg} \mathrm{L}^{-1}$. 
Cobalto (Co).- Los valores mayores de la concentración de cobalto, se observaron en la época de lluvias, siendo el pozo P9, el que presentó el valor más alto. En el periodo de secas, el pozo P3, fue el que presentó los valores más altos. El Cobalto es muy abundante en las rocas ígneas, pero es muy bajo en las aguas naturales (Rodier, 1990).

Cobre (Cu).- El mayor valor de la concentración de cobre, se observó en la época de lluvias en el pozo P8 y en LV5 en la época de secas. El cobre es un mineral relativamente común en la corteza terrestre. Es el resultado de la disolución de minerales constituidos por sulfuros, óxidos y carbonatos tales como calcopirita, cuprita o malaquita. Las concentraciones elevadas de cobre se deben al uso de insecticidas y fertilizantes, además de residuos, corrosión de tuberías y accesorios de cobre, latón, y bronce (APHA-AWWA-WPCF, 1992; Sawyer et al., 2001).

Arsénico (As).- El pozo R2 fue el que presentó los valores más altos tanto en la época de secas como de lluvias. El arsénico se encuentra en las rocas ígneas, así mismo se puede deber a fosfatos utilizados en fertilizantes y plaguicidas. Se llega a encontrar en los pozos para agua debido a las infiltraciones (Rodier, 1990; Palmer, 1996).

Rubidio (Rb).- El pozo P9, fue el que presentó el valor más alto durante el periodo de secas y el pozo R2, en el periodo de lluvias. El rubidio es un elemento relativamente abundante en la corteza terrestre, se encuentra en los feldespatos potásicos (Rodier, 1990; Palmer, 1996).

Cadmio (Cd).- El pozo P8, presentó el valor más alto en la época de lluvias y los pozos LV2, LV5 y M en la época de secas. El cadmio se incorpora al agua subterránea a través de vertidos industriales o por el deterioro de tuberías galvanizadas (APHA, AWWA, WPCF, 1992; Sawyer et al., 2001).

Cesio (Cs).- Los valores de la concentración de cesio, se mantuvieron estables durante el año.

Bario (Ba).- El mayor valor de la concentración de bario, se obtuvo en la época de secas en el pozo P10 y en cuanto al periodo de lluvias en el pozo P3. En los pozos P6, P8, LV1, AD4, M y R2 se observó poca variación entre la época de secas y la de lluvias; en nuestro caso los valores se encontraron por debajo de $50 \mu \mathrm{g} \mathrm{L}^{-1}$ que es un valor considerado como normal en aguas subterráneas.

Plomo $(P b)$.- Los valores mayores de la concentración de plomo, se observaron en la época de lluvias en el pozo LV2. El pozo LV5 fue el que presentó el valor más alto en el periodo de secas. El plomo es un componente menor pero ampliamente difundido en la corteza terrestre, donde está presente en forma de carbonatos, fosfatos, pero principalmente de sulfatos. En nuestro caso los valores de Pb fueron muy bajos.

Uranio (U).- El mayor valor de la concentración de uranio se observó en la época de secas en el pozo P10. En cuanto al periodo de lluvias, el pozo LV1, fue el que presentó el valor más alto. El uranio está incluido en la composición química de algunos minerales (petchblenda) (Rodier, 1990), pero en nuestro caso el contenido fue bajo.

Tomando en consideración las dos épocas de muestreo, tal como se presenta en la Tabla IV-7(a, b), se determinó para cada pozo el valor máximo de cada elemento. Se sumaron el número de eventos que 
representan el máximo valor para cada uno de los pozos y dicha suma se hizo igual al $100 \%$ en peso. Se determinó el porcentaje que le correspondió a cada uno de los pozos de acuerdo a los dos periodos de muestreo. Con estos datos se construyó la gráfica (Figura IV-8), en donde se muestra el porcentaje de los eventos de cada uno de los pozos que presentaron mayor mineralización en el periodo muestreado. Se observa que en promedio existe mayor mineralización en la época de secas (54\%), siendo los pozos P2, P3, P6, P8, LV2, LV5 AD4 , R2 y M, los que presentan los mayores porcentajes debido a que el volumen de agua es menor y por lo tanto la concentración de elementos disueltos aumenta. En el periodo de lluvias fueron los pozos P1, P9, P10 y LV1 los que tuvieron mayor porcentaje de mineralización. La menor mineralización en la época de lluvias se debe a la contribución de la recarga de los acuíferos, así como a la infiltración del agua de lluvia que disuelve los elementos solubles disminuyendo su concentración.

En la Figura IV-9 se describe la distribución de los elementos traza en los muestreos agrupando los pozos por su cercanía entre sí. En esta figura se observa en ambos muestreos que los pozos de cada grupo presentan valores semejantes en la mayoría de los elementos traza. Sin embargo, para Pb tanto en la época de secas como en la de lluvias se obtienen valores que difirieron en 1 orden de magnitud entre los grupos 1 y 3 . Por su cercanía los pozos que tuvieron las menores variaciones entre los dos muestreos fueron (P2, P3, P-8, P9, P10 y LV-1) y los pozos que presentaron los valores de las concentraciones mayores tanto en la época de secas como de lluvias fueron (P3, P8, P9, P10, LV1,LV5, R2 y RN). Así mismo se observa que en la época de secas se manifestaron los valores mayores de los elementos (As, $\mathrm{Ba}$, $\mathrm{B}, \mathrm{Cr}$, Li, $\mathrm{Rb}$ y U), en cuanto a la época de lluvias se presentaron los valores mayores de los elementos (Cd, $\mathrm{Co}, \mathrm{Cu}, \mathrm{Mn}$ y Pb). En la Figura IV-10, se esquematiza la variabilidad de los elementos traza en los dos periodos de muestreo, se puede observar que la evolución o cambios en el tiempo y en el espacio en cada uno de los elementos traza presentó poca variación. En general se observó un incremento en los valores de bario y boro. Estos elementos son característicos de las aguas que interaccionaron con rocas ígneas. Pane (1995) dice que la variabilidad de los elementos traza se debe a la interacción con rocas ígneas.

La evolución de cambios en la concentración en el tiempo y en el espacio de cada uno de los elementos traza se discute a continuación:

Litio.- En la Figura IV-10-a, se observan incrementos en los valores de este elemento hacia el noreste en la época de lluvias.

Boro.- En la Figura IV-10-b se observa una expansión radial de la disolución en la época de lluvias conservándose el núcleo de mayor concentración en el mismo lugar.

Cromo.- En la Figura IV-10-c, se observa que los valores altos de la concentración se incrementaron en la época de lluvias.

Manganeso, Cobalto, Arsénico, Cobre y Plomo.- En las Figuras IV-10-d, e, g, f, i, se observan los incrementos en los valores hacia el norte en la época de lluvias.

Rubidio.- En la Figura IV-10-h, se observa una dilución de este elemento en la interface suelo-agua en la época de lluvias. 
Cesio.- En la Figura IV-10-j, se observa que los valores de la concentración de este elemento se mantienen estables, esto quiere decir que no se observó el efecto de la litología.

Bario.- En la Figura IV-10-k, se observo un incremento en la época de lluvias en los pozos localizados en la porción norte, así como una dilución en la zona sur.

Uranio y Cadmio.- En las Figuras IV-10-m, i, se observa una dilución radial de los elementos en la época de lluvias.

En resumen el $\mathrm{Li}, \mathrm{Cr}, \mathrm{Mn}, \mathrm{Co}, \mathrm{Pb}, \mathrm{As}, \mathrm{Cu}$ y $\mathrm{Ba}$ aumentan en la zona norte en época de lluvia mientras que el $\mathrm{B}, \mathrm{Rb}, \mathrm{U}$ y $\mathrm{Cd}$ en la zona sur disminuye en ésta época. El Cs permaneció estable en las dos épocas del año.

Pane (1995) reportó una recopilación de los rangos de las concentraciones de cada uno de los elementos traza (Tabla IV-8). En nuestro caso todos los valores de las concentraciones estuvieron dentro del rango reportado por esta autora.

Tabla IV-8 Rango de concentraciones de los elementos traza en agua subterránea (Pane, 1995).

\begin{tabular}{|c|cc|c|c|c|}
\hline \multirow{2}{*}{ Elementos } & \multicolumn{2}{|c|}{ Concentraciones $\left(\mathrm{g} \mathrm{L}^{-1}\right)$} & \multirow{2}{*}{ Elementos } & \multicolumn{2}{|c|}{ Concentraciones $\left(\mathrm{g} \mathrm{L}^{-1}\right)$} \\
\cline { 2 - 3 } & Inferior & Superior & & Inferior & Superior \\
\hline $\mathrm{Cr}$ & 0.0026 & 164.9 & $\mathrm{Sr}$ & & 12750 \\
$\mathrm{Mn}$ & 0.0582 & 2640 & $\mathrm{Mo}$ & 0.1 & 15300 \\
$\mathrm{Co}$ & 0.0006 & 9.97 & $\mathrm{Cd}$ & 0.001 & 191 \\
$\mathrm{Cu}$ & 0.114 & 5.591 & $\mathrm{Cs}$ & 0.01 & 3 \\
$\mathrm{Zn}$ & 0.313 & 4590 & $\mathrm{Ba}$ & 0.5 & 11311 \\
$\mathrm{As}$ & 0.064 & 50000 & $\mathrm{U}$ & 0.01 & 1970 \\
$\mathrm{Rb}$ & 0.06 & 22.6 & & & \\
\hline
\end{tabular}

\section{COSTA DEL PACIFICO}

La localización de los sismos que se presentaron de 1993 a 1998 en la costa de Guerrero se muestra en la Figura IV-11. Se eligieron 2 zonas de igual área, en las cuales se observaron 109 sismos $(M>4)$. Se observa que la zona 2 fue la que presentó la mayor densidad sísmica en comparación con la zona 1, a una razón de 1:2. La localización de los epicentros de los sismos en el periodo de estudio, la profundidad, fecha y magnitud, se muestran en la Tabla IV-9. En la Figura I-4 se muestra la profundidad de los sismos, variaron 5 a $53 \mathrm{~km}$ (Segovia y Mena, 1997; Peña et al., 2001), predominando las profundidades someras $(<20 \mathrm{~km})$. El 24 de octubre de 1993 ocurrió un sismo (M=6.7) con profundidad de $30 \mathrm{~km}$; el 10 de diciembre 1994, se manifestó un sismo de (M=6.6) cuya profundidad fue de $53 \mathrm{~km}$; los días 14 de septiembre de 1995 y 15 de julio de 1996, se presentaron 2 sismos ( $M=7.3$ y 6.5); el día 11 de enero de 1997, se presentó un sismo (M=7.3) con profundidad de $40 \mathrm{~km}$.

Como ya se mencionó en el Capitulo II (Fig. II-2) la temperatura de 1993 a 1998, fluctuó entre 25 y $29.8^{\circ} \mathrm{C}$, con mínimos en enero y máximos de junio a agosto. La distribución de la precipitación en 1992 y 1993 fue homogénea, inició en junio y finalizó en octubre teniendo su máximo en agosto. En cuanto a 1994 fue 
atípica, pues la precipitación anual fue menor en comparación con la precipitación media anual. En los años de 1995 y 1996 fue típica, inició en mayo y finalizó en octubre, teniendo su máxima precipitación en agosto. En 1997 fue atípica debido a la perturbación meteorológica de "El Niño". Esta estación se dividió en 2 secciones: la primera fue de junio a julio, cuya precipitación fue interrumpida por la sequía intraestival, la segunda fue de septiembre a noviembre, en la cual se incrementó la precipitación debido a la presencia del ciclón tropical "Paulina", prolongando la estación de lluvias hasta noviembre.

\subsection{RADÓN}

Los valores de la concentración de radón en suelo $\mathrm{kBq} \mathrm{m}^{-3}$, obtenidos con detectores LR-115, en la Costa Grande de Guerrero (MG, GLU, GPH, GPE, GSL, GEC y GCB) y la Costa Chica de Guerrero (GAC, GAC, GCP, GSM y GM), se muestran en la Tabla IV-10 y se grafican en la Figura IV-12.

En 1993, se observaron incrementos de la concentración de radón en las estaciones GPH, GPE, GAC, GCP, MG y GSL, que coinciden con la época de secas (mayo). Así mismo se observaron incrementos de la concentración de radón al inicio de la época lluvias en GCB-1, MG, GLU y GSM, y al final de dicha época en la estación GAS, GEC y GCP. El incremento en GPH coincide con el sismo ocurrido en octubre $(M=6.7)$. En la estación MG, se observó una anomalía de la concentración de radón en mayo-julio, que correspondió a la época de lluvias, el comportamiento de la concentración del radón se pudo deber a los factores meteorológicos locales. En la estación GCP, se observó una anomalía en octubre-diciembre que correspondió a la época de secas, así mismo se observó que el 24 de octubre ocurrió un sismo $(\mathrm{M}=6.7)$ a $60 \mathrm{~km}$ de la estación de muestreo. El comportamiento de la concentración de radón se pudo deber tanto a los factores meteorológicos como a los sismos locales. Se observó una anomalía en la estación GCB-1 en junio-julio, que corresponde a la época de lluvias. El comportamiento de la concentración de radón coincide con el inicio de la lluvia por lo tanto, éste se debió a los factores meteorológicos. En la estación GSM, se observó una anomalía en julio-septiembre que corresponde a la época de lluvias y además, coincide el sismo $(M=6.7)$ del 24 de octubre. El comportamiento de la concentración de radón tal vez se debe tanto a los factores meteorológicos como a los sismos locales. En la estación GPE, se observó una anomalía de la concentración de radón en diciembre que correspondió a la época de secas, así como un sismo (M=6.6) el 10 de diciembre. El comportamiento de la concentración del radón tal vez se debe tanto a los factores meteorológicos como a los sismos locales. En la estación GAC, se observó una anomalía en enero-marzo, que comprendió la época de secas.

En 1994, se observaron incrementos de la concentración de radón en las estaciones MG, GAS, GCP, GSM, GEC, GCB-1 y GAC, que coinciden con la época de secas. Durante la época de lluvias se observaron incrementos de la concentración de radón en las estaciones GPE, GPH, GLU y GSL. En la estación GPE, se observó una anomalía en junio-septiembre que correspondió a la época de lluvias, el comportamiento de la concentración de radón se debió a los factores meteorológicos locales.

En 1995, se observaron incrementos de la concentración de radón en las estaciones GM, GAS, GAC, GCP y GSM que coinciden con la época de secas. Durante el inicio de la época de lluvias se observaron incrementos de la concentración de radón en las estaciones GPH, GLU, GSL, GEC, GCB-2 y GPE. En la estación GPE, se observó una anomalía de la concentración de radón en junio-julio que correspondió a la época de lluvias, así mismo ocurrió un sismo $(\mathrm{M}=7.3)$ el día 14 de septiembre. El comportamiento de la 
concentración del radón tal vez se debió tanto a los factores meteorológicos como a sismos locales. En la estación GCB-2, se observó una anomalía de la concentración de radón en abril-mayo, que correspondió a la época de lluvias. El comportamiento de la concentración del radón tal vez se debió tanto a los factores meteorológicos como sísmicos locales. En la estación GCP, se observó una anomalía en diciembre que correspondió a la época de secas. El comportamiento de la concentración del radón tal vez se debió a los factores meteorológicos.

En 1996, se observaron incrementos de radón en las estaciones MG, GSM, GCP, GEC, CB-2, GAS y GAC que coinciden con el inicio de la época de secas. Durante la época de lluvias se observaron incrementos de radón en las estaciones GM, GPH y GSL. En la estación GSL, se observó una anomalía en julioseptiembre, que correspondió a la época de lluvias, así mismo se observó un sismo ( $M=6.6)$ el día 19 de julio. El comportamiento de la concentración del radón tal vez se debió tanto a los factores meteorológicos como sísmicos locales.

En 1997, se observaron incrementos de la concentración de radón en las estaciones MG, GPH, GSL, GCP, GAS, GSM y GAC que coinciden con el inicio de la época de secas, así como en las estaciones GM y GLU, durante la época de lluvias. En las estaciones GM y GLU, se observaron anomalías en julio-septiembre, que correspondieron a la época de lluvias, así mismo se observó un sismo ( $\mathrm{M}=6.7)$ el día 19 de julio. El comportamiento de la concentración del radón tal vez se debió tanto a los factores meteorológicos como sísmicos locales.

En 1998, se observaron incrementos de la concentración de radón en las estaciones GCP, GLU, MG, GSM y GM que coinciden con el inicio de la época de lluvias, así como en las estaciones GCB-2, GSL, GAS, GAC y GPH al final de dicha época. En la estación GPH, se observó una anomalía en agosto-octubre, que correspondió a la época de lluvias, el comportamiento de la concentración de radón se debió a los factores meteorológicos locales.

En la Tabla IV-11 y Figura IV-13, se muestran la media aritmética $(\xi)$ y su desviación estándar $(\sigma)$ así como los valores máximos de la concentración de radón en suelo en cada una de las estaciones para los tres años de observación, se muestran también los valores de la media aritmética y geométrica $\left(\xi, \xi_{g}\right)$ y sus desviaciones estándar $\left(\sigma, \sigma_{\xi g}\right)$, así como los valores máximos de la concentración de radón. La columna correspondiente $a \xi+2 \sigma$ muestra los valores por encima de los cuales se definen las anomalías del radón. Se observa que los valores $\xi_{g}$ de la concentración de radón fluctuaron de 0.22 a $5.37 \mathrm{kBqm}^{-3}$. Los valores promedio de mayor a menor corresponden a GAC,GPE, GCB-1, GAS, GSM, GM, GCP, GEC, MG, GSL, GPH, GLU y GCG-2.

En la Tabla IV-10 se muestra los valores máximos de la concentración de radón en suelo, en las diferentes

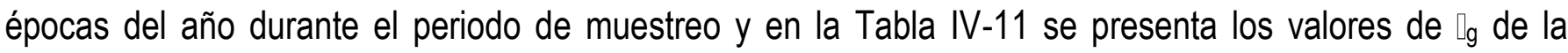
concentración de radón. Los valores máximos corresponden por lo general a la época húmeda (1993,

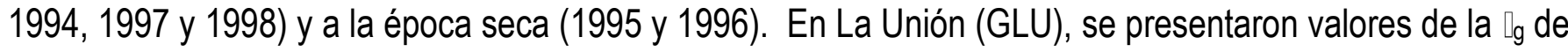
$1.09 \pm 1.09 \mathrm{kBqm}^{-3}$, los valores máximos ocurrieron en la época de lluvias (1993, 19941997 y 1998) y en la época de secas (1995 y 1996), los valores de la concentración de radón oscilaron de 0.1 a $10.8 \mathrm{kBqm}^{-3}$. En cuanto a Papanoa (Escuela) (GPE), la $\square$ g fue de $4.9 \pm 1.7 \mathrm{kBqm}^{3}$, se observaron por lo general valores máximos en la época de lluvias (1994) y en la época de secas (1993 y 1995), se presentaron oscilaciones 
en los valores de la concentración de radón de 1.6 a $13.8 \mathrm{kBqm}^{-3}$. En Papanoa (Huerta) (GPH), se presentaron valores de la $\square_{g}$ de $1.7 \pm 1.2 \mathrm{kBqm}^{-3}$, los valores máximos se manifestaron en la época húmeda (1994 y 1995) mientras que en la época seca $(1993,19961997$ y 1998) las oscilaciones de los valores de la concentración de radón fueron de 0.2 a $5.8 \mathrm{kBqm}^{-3}$. En San Luis La Loma (GSL), se presentaron valores $\square_{g}$ de $1.4 \pm 1.3 \mathrm{kBqm}^{-3}$, observándose en general que los valores máximos se presentaron en la época de lluvias (1995) y en la época de secas (1993, 19951997 y 1998). Las oscilaciones de los valores de la concentración de radón fueron de 0.1 a $8.7 \mathrm{kBqm}^{-3}$. La estación El Cayaco (GEC), se dieron valores de la [g de $2.6 \pm 1.5 \mathrm{kBqm}^{-3}$, se observaron valores máximos en la época de lluvias (1993 y 1997) y en la época de secas (1994, 1995 y 1996), los valores de la concentración de radón oscilan de 0.6 a $8.9 \mathrm{kBqm}^{-3}$. La estación Coyuca de Benítez, estuvo ubicada en dos sitios, primeramente (GCB-1), se estableció desde enero de 1992 hasta octubre de 1949, en el poblado del mismo nombre, la estación se localizó sobre suelo residual. Posteriormente, de abril de 1995 a 1998, se reubicó en la playa de la Barra de Coyuca (GCB-2) y se asentó en sedimentos de costa. En el primer sitio se observaron valores de la [g de $3.3 \pm 1.5 \mathrm{kBqm}^{-3}$, oscilan de 2.2 a $18.5 \mathrm{kBqm}^{-3}$, se observa un incremento de la concentración de radón en la época de lluvias de 1993 y de secas de 1994. En el segundo sitio se tuvo un valor de la $\mathrm{lg}$ de $0.2 \pm 0.35 \mathrm{kBqm}^{-3}$ y se presentaron los valores máximos en la época de lluvias (1995 y 1997) y de secas de (1996 y 1998). Las oscilaciones de los valores de la concentración de radón fueron de 0.1 a $1 \mathrm{kBqm}^{-3}$. En la estación Acapulco (Centro) (GAC), se obtuvo una $\square_{\mathrm{g}}$ de $5.4 \pm 2.4 \mathrm{kBqm}^{-3}$, los valores máximos por lo general se dieron en la época de lluvias (1998) y de secas (1993, 1994, 1995, 1996 y 1997), la oscilación de los valores de la concentración de radón fue de 1.3 a $20.6 \mathrm{kBqm}^{-3}$. En Acapulco (Sabana) (GAS), se observaron valores de la $\square_{\mathrm{g}}$ de $4.1 \pm 1.9 \mathrm{kBqm}^{-3}$, con una oscilación de 1.8 a $12.0 \mathrm{kBqm}^{-3}$. Los incrementos se observaron en la época de lluvia (1994, 1996, 1997 y 1998), así como en la época de secas (1993 y 1995). En la estación de

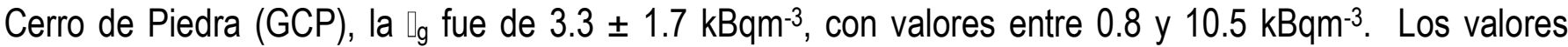
máximos se observaron en la época húmeda (1994 1997 y 1998) y de secas (1993, 1995 y 1996). En San Marcos (GSM), la \g fué de $3.7 \pm 1.8 \mathrm{kBqm}^{-3}$ con valores de 0.6 a 9.3. Los valores máximos se dieron en la época de lluvias $(1993,1994$ y 1998) y en la época de secas (1994 a 1997). En cuanto a la estación

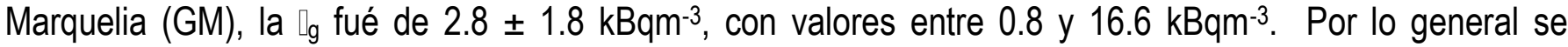
presentaron los valores máximos en la época de lluvias (1993, 1997 y 1998) y en la época de secas de (1994 a 1996).

En la Figura IV-14 se muestra un ejemplo de los resultados de radón en suelo en la estaciones de Acapulco utilizando la sonda Clipperton. Los incrementos de la concentración de radon se manifestaron desde el 10 de agosto hasta el 17 de septiembre de 1995, que coincide con la presencia de un sismo ( $M=7.3$ ) el día 14 de septiembre (Peña et al., 2001).

Danali-Cotsaki y Margomenou-Leonidopoulou (1993), observaron que la lluvia puede ser considerada como factor importante de la variación de la concentración de radón en agua. La lluvia tiene correlación inversa con la concentración del radón. El efecto de la lluvia es nulo cuando se presenta un gran número de sismos, En nuestro caso este comportamiento del radón-sismo-precipitación es muy semejante.

Fukui, (1987), observó cambios de la concentración del radón en suelo e interpretó que se incrementaba antes del aumento del nivel freático causado por la infiltración del agua; al ascender dicho nivel disminuye la concentración del radón por el efecto de la dilución causada por el agua. Los resultados del presente 
estudio muestran variaciones estaciónales en los niveles de las concentraciones de radón en suelo, durante el periodo de muestreo en sitios diferentes, son función de los parámetros meteorológicos y de las características geológicas. Al igual que otros autores (Hamada, 2000; Virk et al., 1999, 2000; Woith et al., 1999), observaron que los parámetros meteorológicos afectan la emanación del radón en suelo. Las fluctuaciones de radón muestran ocasionalmente dependencia con los parámetros meteorológicos relacionados durante la estación seca y de lluvias (Segovia et al., 1995a; Virk y Walia, 2001). En nuestro caso se observó que durante el periodo de muestreo, los incrementos de radón en suelo, en la mayoría de las estaciones el $53 \%$ de los casos de máxima concentración de radón ocurrieron en la época de secas, mientras que el $47 \%$ se presentó en la época de lluvias. Los datos que se adquirieron por medio de la sonda Clipperton muestran este comportamiento en la época de lluvias. Singh y Virk $(1994,1996)$ y Kasztovszky et al., (2000), observaron que la intensidad de la lluvia puede tener influencia en la concentración de radón. La emanación del radón en suelo es incrementada durante el verano y disminuye en el invierno. Una lluvia ligera puede causar un incremento en la concentración del radón en suelo o bien con una lluvia intensa. El comportamiento del radón al inicio de la época de lluvias se incrementa debido al efecto de "tapadera", impidiendo que el gas escape hacia la atmósfera. Una lluvia intensa puede causar una disminución rápida de la concentración del radón durante varios días y posteriormente incrementarse, esto se puede deber a la presencia de una gran humedad del suelo que lo satura, lo disuelve y difunde hacia abajo por infiltración. Para algunos suelos permeables, no se incrementa la concentración del radón, porque el gas es expelido hacia la atmósfera con las primeras lluvias (Papastefanou et al., 1999).

Los cambios en la concentración de radón en las aguas subterráneas fueron reportados por primera vez por Ulomov (Ulomov y Masashev, (1967),en medidas efectuadas de 1961 a-1966, en el valle de Tashkent, donde se observó un aumento de 18.5 a $55 \mathrm{kBq} \mathrm{m}^{-3}$. Las observaciones se realizaron durante la ocurrencia del sismo de abril de 1966, después de dicho sismo diminuyó bruscamente la concentración del radón.

Wakita et al., (1986) y Teng y Sun (1986), reportaron que existen variaciones bastante complicadas en los patrones de la concentración de radón en aguas subterráneas, la magnitud de las fluctuaciones difiere significativamente de un sitio de muestreo a otro. Igarashi y Wakita (1990), observaron en Japón de 19841988 , sismos $(M=6)$ cuyo epicentro fue a $100 \mathrm{~km}$, que relacionaron con el movimiento de placas tectónicas. Observaron, además, fallas inversas y de compresión y algunos sismos que pueden liberarse a actividad volcánica. El terreno que estudiaron está localizado sobre sedimentos del Terciario y Cuaternario, así como rocas de edad del Paleozoico al Mioceno, se midió el radón en pozos para agua de $200 \mathrm{~m}$ de profundidad, localizados sobre fallas activas. Observaron que los cambios en la concentración de radón parecen tener relación con sismos localizados a grandes distancias epicentrales y pequeñas magnitudes. Así mismo observaron que los patrones típicos de las anomalías del radón post-sísmicas decrecen con la magnitud y la distancia epicentral, no solamente con los sismos cercanos sino también con sismos ocurridos a gran distancia. Los sismos que ocurren a una distancia epicentral muy grande hacen suponer que los posibles incrementos pre-sísmicos pueden atribuirse a cambios en los esfuerzos locales. Danali-Cotsaki y Margomenou-Leonidopoulou (1993) reportaron que existe una correlación positiva entre los sismos y las concentraciones del radón cuando el tiempo entre la ocurrencia del sismo y el muestreo es relativamente (menor a la vida media del radón). Nuestro estudio se localiza sobre sedimentos del Terciario y Cuaternario y rocas del Paleozoico al Mioceno que incluyen rocas metamórficas y rocas volcánicas (granodioritas); los 
sismos ocurrieron a distancias epicentrales menores de $80 \mathrm{~km}$ del sitio de muestreo y se observaron sismos que ocurrieron después del incrementó del radón.

Igarashi y Wakita (1995), utilizando equipos automáticos, estudiaron anomalías de gases (radón) en el agua relacionadas con la actividad sísmica. Estos autores en el sismo de Kobe ( $M=7.2)$, ocurrido a $14 \mathrm{~km}$ de profundidad el 17 enero de 1995, observaron que la sismicidad se relaciona con las anomalías en la concentración del radón. La estación de observación se localizó sobre roca granítica y cerca de una falla activa a $20 \mathrm{~km}$ del epicentro. Observaron que las altas y bajas concentraciones de radón ocurrieron en invierno y verano respectivamente.

Con la finalidad de correlaciónar la concentración de radón con la actividad sísmica Heinicke y Koch (1995), determinaron en Alemania, radón en manantiales durante tres años. La zona que estudiaron es volcánica (granítica), de edad Cuaternaria, sísmicamente activa $(M>4)$ y somera. Las aguas del manantial presentaron valores de la concentración de radón de 1-2 Bq L-1 y en algunos casos hasta de $25 \mathrm{~Bq} \mathrm{~L}^{-1}$. Observaron que las anomalías de la concentración del radón se correlacionaron con un gran número de sismos localizados en el área. En nuestro caso con la instalación de la red monitoreo de radón en suelo en la Costa de Guerrero, los resultados obtenidos han mostrado patrones de comportamiento distintos a los observados a raíz del sismo de 1985 (Segovia et al., 1989). La sismicidad en la zona de estudio ha sido muy intensa y los DSTN no han podido distinguir los sismos consecutivos ocurridos en la zona.

Pane et al. (1995), realizaron en Francia, estudios de radón en acuíferos graníticos y calcáreos fracturados. Utilizaron DSTN, para la determinación de radón en suelo y sondas automáticas Clipperton en agua subterránea. Observaron que los valores oscilaron de 6.6 a $6.5 \mathrm{kBq} \mathrm{m}^{-3}$. Así mismo observaron un incremento en la concentración del radón en agua y una disminución en el suelo, esto se debió a que durante el periodo de lluvias, el radón fue atrapado por el agua. Con el equipo Clipperton observaron que la concentración del radón se incrementó en marzo y disminuyó en julio. Las altas concentraciones de radón en pozos se correlacionaron con la baja transmisibilidad y permeabilidad. Nosotros observamos en la estación de Acapulco, promedios de de la concentración radón con la sonda Clipperton de $10 \mathrm{KBq}^{-3}$, contrario de lo que determinaron estos autores, los valores más altos de la concentración de radón se obtuvieron en suelo y los más bajos en agua. Esto quizás se deba a que son pozos someros con baja transmisibilidad. La diferencia entre la concentración de radón en acuíferos con características similares se puede deber a los factores geológicos o a la eficiencia del transporte del radón en la fase sólida (Segovia et al., 1999b). También se observó que en la estación de Acapulco se incrementaron los valores de la concentración de radón al inicio de la época de secas y disminuyeron en la de lluvias.

Durante 1996-1998, otros autores (Virk et al., 1999), también observaron en la zona del Himalaya, diferencias de anomalías de radón con eventos sísmicos y no sísmicos en agua subterránea y suelo. Así mismo observaron que los parámetros meteorológicos afectan a la emanación del radón en suelo, no así en aguas subterráneas, por lo tanto supusieron que son preferentes los estudios de radón en agua subterránea ya que no están perturbados por las variaciones meteorológicas como es el caso del suelo. Yasuoka y Shinogi (1997), reportaron cambios anómalos de radón en agua asociados con el sismo de Kobe $(M=7.2)$ del 17 de enero de 1997. Las concentraciones de radón se midieron desde 1993 observándose promedios de $20 \mathrm{~Bq} \mathrm{~L}{ }^{-1}$. Este valor se incrementó gradualmente en 1994 y a finales de noviembre de 1994 se tenían 
valores de $60 \mathrm{~Bq}^{-1} \mathrm{~L}$, en enero de 1995, se incrementó el valor hasta $250 \mathrm{~Bq} \mathrm{~L}^{-1}$. Después del sismo de Kobe, se observó que no hubo precipitación de verano desde 1994 hasta la primavera de 1995, existe además una falla cercana al pozo de observación $(500 \mathrm{~m})$. La interpretación de estos autores en los incrementos anómalos de la concentración de radón cerca de la falla se pueden deber a los esfuerzos alrededor de la falla.

Noguchi y Wakita (1997), observaron en el sismo de Tashkent (M 5.5) del 26 de abril de 1996, una concentración máxima de radón en agua subterránea antes del sismo. También observaron correlaciones entre los cambios de la concentración del radón y los sismos posteriores. En nuestro estudio se observó una correlación del radón con la actividad sísmica antes de que ocurriera éste, aún con sismos pequeños.

En la Península de Izu, Japón, Nishizawa et al., (1998), monitorearon radón en agua de julio a diciembre de 1995. Observaron que las concentraciones de radón se incrementaron cuando se presentó un enjambre de sismos dentro del periodo de monitoreo. Los epicentros de los sismos se localizaron a $30 \mathrm{~km}$ del sitio. Inicialmente ocurrieron sismos pequeños $(<\mathrm{M} 3)$ y someros $(<8 \mathrm{~km})$ y posteriormente ocurrieron sismos de $(\mathrm{M}=4.8)$, también de profundidad somera $(2-3 \mathrm{~km})$. Observaron que las concentraciones de radón se incrementaron antes de la actividad sísmica, en este caso no se correlacionó la precipitación con los cambios de radón. Propusieron que las anomalías que se presentaron antes de la actividad sísmica fueron causadas por las microfracturas en el acuífero donde se localiza el sitio. Para nuestro estudio, estamos de acuerdo con el contexto, sin embargo, se debe de agregar que es importante incluir los patrones de recarga en los acuíferos. Las estaciones de Guacamayas y El Cayaco son acuíferos libres constituidos por sedimentos aluviales del Reciente. La recarga del agua para los acuíferos puede ser por medio de la infiltración debido al escurrimiento de numerosas corrientes que atraviesan el área, o debido a la percolación de la lluvia a lo largo de las sierras que se localizan en los alrededores; pueden ser también debidos a la infiltración por irrigación. En la estación de Acapulco, con datos de la sonda Clipperton (Fig. IV-14), se observaron valores máximos de la concentración de radón durante un periodo que abarca del 9 a I 17 de agosto de 1995, cuyos valores fueron alrededor de $100 \mathrm{kBq} \mathrm{m}^{-3}$; un sismo fuerte $(M=7.4)$ se presentó el día 14 de septiembre de 1995 (Fig. IV-9).

Fedeli et al. (2001) observaron con detectores automáticos de radón en manantiales termales cársticos en Italia, asociaciones del incremento de radón con sismos $(M=5.8)$ y profundidades $(51 \mathrm{~km})$ y a $10 \mathrm{~km}$ de distancia del epicentro a las estaciones de muestreo. Estos autores confirmaron que el radón es un trazador importante e informático de las variaciones de permeabilidad de la corteza y posiblemente ligada a los procesos de deformación de la misma. Segovia et al., (1989a), antes del sismo de 1985, obtuvieron en la zona de los Azufres, Mich., varios registros de radón en suelo que marcaban un comportamiento anómalo. El análisis de estos registros mostró una posible respuesta del radón en suelo y la presión ejercida por la placa de subducción en la costa de Michoacán. La concentración del radón en suelo o en agua subterránea 0 ambas pueden dar un aviso a tiempo de la actividad sísmica (Singh y Virk, 1994). Yasuaca y Shinogi (1997), observaron, durante el sismo de Tashkent en 1996, cambios en la concentración de radón en agua subterránea. Sin embargo, los detectores pasivos debido al tiempo de exposición tan grande, enmascaran las posibles anomalías de radón que puedan relacionarse con la sismicidad (Maldonado et al., 1996). 
Virk y Singh (1993, 1994), Singh y Virk (1994, 1996), Duarah, et al. (1997), Virk et al. (1997, 1999, 2000, 2001), Mukherji (1999) y Virk y Walia (2001), utilizaron DSTN y detectores automáticos para realizar medidas de radón, en el Himalaya y además asociaron parámetros meteorológicos (precipitación) con la respuesta de radón y la sismicidad local. Las estaciones se localizaron sobre grandes fallas, y la sismicidad parece deberse a esas grandes fallas; los promedios de radón fueron de 90 a $220 \mathrm{kBq} / \mathrm{m}^{3}$. Así mismo, observaron que la tendencia general de las anomalías de la concentración del radón variaron antes de la ocurrencia de sismos. En el sismo de Chamba ( $M=5.1)$ del 24 de marzo de 1995, se obtuvieron registros de la emanación del radón; las anomalías fueron observadas el 21 de marzo, tres días antes de que ocurriera el sismo, con lo cual establecieron que el radón en suelo es un precursor sísmico.

Algunos investigadores (Loria et al., 1995), estudiaron el radón en suelo con DSTN y sondas Clipperton en Costa Rica, de 1990 a 1992 y encontraron una relación entre las anomalías de radón y la actividad sísmica $(M>4)$. El estudio lo realizaron en dos zonas: la Universidad de San José y la falla de Santa Bárbara. En la falla de Santa Bárbara, se colocaron detectores de trazas durante 3 años, se presentó una intensa actividad sísmica durante el periodo de monitoreo, se observaron varias anomalías de la concentración de radón 84 días antes de que ocurrieran los sismos. Se presentó un sismo $(M=7.5)$ en abril de 1991, su epicentro se localizó a $125 \mathrm{~km}$ al sureste de la estación de monitoreo. En cuanto al sitio de la Universidad de San José, un área no fracturada, se utilizó la sonda Clipperton durante un año. Durante el monitoreo se observó intensa actividad sísmica $(M=5.7)$ en la zona. Observaron varios grupos de valores anómalos 1 día antes de la ocurrencia de los sismos.

Djeffal et al. (1995), estudiaron en Argelia la variación de la concentración del radón en suelo asociada a fallas sísmicas, con DSTN, durante el periodo de 1989 a 1993. Observaron que los incrementos fueron en la época de secas y que las anomalías de la concentración del radón se presentaron antes o después del sismo local $(\mathrm{M}<5.2)$. Estos autores expresan que si los sismos se localizan aproximadamente a $100 \mathrm{~km}$ de la zona de estudio, se tiene un efecto en la emanación del radón y se puede hacer una correlación entre ésta y la sismicidad.

Virk y Sharma (1997), observaron que la alta actividad sísmica puede influir en el comportamiento de la concentración de radón en suelo y que los cambios meteorológicos inducen a señales espúreas. En el caso de áreas con alta sismicidad, como en nuestro caso la respuesta del radón obtenida con detectores LR-115 refleja un comportamiento anómalo general (Segovia et al., 1997a).

Segovia et al. (1995a, b, 1997a, 1999c) y Segovia y Mena (1997), observaron en la costa del Pacífico, las variaciones de la concentración del radón y su posible relación con sismos en México con la finalidad de obtener parámetros adicionales para estimar el riesgo geofísico. El radón se determinó por medio de DSTN y de sondas Clipperton. Se observó que la concentración de radón en suelo se ve afectado por factores ambientales. Las fluctuaciones de la concentración del radón en suelo se obtuvieron en Acapulco de 1990 a 1994. Los promedios de la concentración de radón fueron de $8 \mathrm{kBq} \mathrm{m}^{-3}$ y se observaron diferencias en función de las características del suelo. Se observó un incremento en las concentraciones de junio de 1992 a junio de 1993. Dichas fluctuaciones globales no parecen tener una relación con la densidad o magnitud sísmica o con cualquier situación anómala dependiente en los mecanismos de subducción durante el periodo de estudio. Una posibilidad de tales patrones de radón en suelo, se puede relacionar con las 
características hidrológicas locales, algunas perturbaciones en acuíferos poco profundos pueden transmitir fluctuaciones, afectando la concentración de radón en suelo. La intensidad sísmica que se presentó en la zona de estudio dificultó el establecimiento de una relación univoca entre la misma y el comportamiento de la concentración de radón en periodos largos, sin embargo, se pudieron observar paquetes de la concentración de radón antes o después de ocurrir los sismos. La explicación de dicha relación se tiene con los pequeños cambios de esfuerzos que ocurren antes o después del sismo en zonas cercanas al área de ruptura y que pueden producir movimientos en los fluidos. En nuestro caso en la costa del Pacífico la sismicidad durante 1997 fue muy intensa, se observaron algunos picos en los valores de la concentración de radón en las estaciones GLU, GPH, GSL, GEC, GAS, GSM, GCP y GM, lo cual indica una perturbación regional.

En Venezuela (Horvath et al., 2000), determinaron radón en suelo y en manantiales térmicos localizados en rocas graníticas y volcánicas, estos autores observaron valores de radón en suelo de $122 \mathrm{kBq} \mathrm{m}^{-3}$ y dedujeron que las concentraciones dependían de las condiciones geológicas, así mismo observaron que las concentraciones de radón en manantiales graníticos se debían a la alta temperatura y descargas provenientes de rocas graníticas, por lo tanto a su contenido de uranio. En cuanto a los manantiales calientes provenientes de rocas volcánicas contenían bajos contenidos de uranio y por lo tanto bajas concentraciones de radón. Trabajos reportados por Cosma y Ristoiu (1999), Jonsson et al. (1999), Solecki (1999), Al-Jarallah (2001) y Zhuo et al. (2001), con detectores pasivos, colocados en manantiales localizados en granitos y gabros en suelos arenosos, indicaron valores superiores a los citados en nuestro estudio.

En nuestro caso el seguimiento de las diferentes estaciones con DSTN, muestran patrones de diferente respuesta dependiendo del tipo de suelo. Sin embargo, Singh y Virk (1996), reportaron que las variaciones de la concentración del radón en el suelo arenoso disminuyen cuando se incrementa la humedad del suelo. Así estaciones ubicadas en suelo residual y/o arenoso (MG, GLU y GCB-2), se observó por lo general niveles de la concentración de radón más bajos con respecto a aquellos que se encuentran en rocas fracturadas, como es el caso de las estaciones de GPE y GAC que se localizan sobre suelo metamórfico y granítico respectivamente en los cuales, observaron niveles más altos de radón. Las estaciones de radón (GCP, GSM y GM) cercanas que correspondan a la misma región geológica muestran respuestas semejantes. Las estaciones de GAS y GAC ubicadas en Acapulco se encuentran a $40 \mathrm{~km}$ de distancia una de otra, sin embargo, durante el desarrollo de este trabajo se observó diferencia entre ellas. La estación GAC está ubicada sobre material granítico, mientras que la estación GAS está sobre suelo residual, siendo la concentración de radón más baja en ésta última. 


\subsection{DOSIS GAMMA}

Se determinó la respuesta de los DSTN y DTL para la concentración de radón y la dosis gamma natural en el suelo, con el fin de relacionarla con los cambios climáticos o sísmicos, en la zona de estudio (Peña et al., 1998b; Peña et al., 2001; Tsvetkova et al., 2001).

En la Figura IV-15, se muestran las series de tiempo de la concentración del radón y de la dosis gamma, así como la sismicidad, precipitación y temperatura registradas en la zona de estudio durante el periodo de muestreo. Los valores de la concentración de radón se encuentran en un rango de 0.1 a $12 \mathrm{kBq} \mathrm{m}^{-3}$. Durante la estación de lluvias de 1997 (junio - noviembre), las variaciones de radón indican un incremento al inicio de dicha estación, seguido por un descenso a lo largo del año. Este comportamiento probablemente se relaciona con la lluvia en este año, que se presentó con mayor intensidad en un corto tiempo (octubre). Los valores altos de radón ocurrieron de julio a agosto en las estaciones GLU y GAS y se relacionan con el inicio de las lluvias y el estado del suelo a través de la sequía intraestival. En la estación de lluvias de 1998 el patrón de la precipitación fue más uniforme, dando como consecuencia un incremento sistemático de la concentración de radón, que mostró valores altos durante septiembre y octubre, los que están de acuerdo con los valores altos de la precipitación observada en septiembre, excepto para la estación GLU.

Por lo general se observa un incremento en la concentración de radón durante la estación de lluvias seguida por una disminución durante la estación de secas (noviembre - abril) (Peña et al., 2001). Los incrementos de radón observados se comparan con los reportados por Turk et al. (1996), con un suelo saturado. Este comportamiento se debe probablemente a la evapotranspíración potencial, que ocurre cuando existe una intensa precipitación y el agua almacenada en el suelo está en exceso. Tal como se observa en la Figura IV-15, la sismicidad regional fue muy intensa durante el periodo de monitoreo y solamente ser muestran los sismos con magnitudes $(M>4)$. La gran intensidad sísmica indica la dificultad para correlacionar la respuesta del radón.

La Tabla IV-12, muestra las pequeñas variaciones en la dosis gamma obtenidas en las diferentes estaciones durante el periodo de monitoreo; dichas variaciones están en el rango de 40 a $494 \mathrm{nGy} \mathrm{h}{ }^{-1}$. En algunas estaciones se observaron valores altos de la dosis gamma durante 1998, a la par con el incremento del radón durante la estación de lluvias. Este comportamiento probablemente se debe a que el radón y su progenie en el suelo contribuyen a la dosis gamma. El promedio mensual de los niveles de radón y la dosis gamma para cada estación variaron de 1.9 a $4.9 \mathrm{kBq} \mathrm{m}^{-3}$ y de 111 a $250 \mathrm{nGy} \mathrm{h} \mathrm{h}^{-1}$ respectivamente. El promedio de las concentraciones de radón obtenidas en todas las estaciones fueron relativamente bajas. Los valores más altos de radón y de la dosis gamma fueron en la estación GAS seguida por GAC y GSM localizadas al sureste del estado de Guerrero. Para analizar este comportamiento se definieron 2 zonas en la región: La zona 1 incluye a las estaciones MG, GLU,GPH, y GSL y la zona 2 incluye GAC, GAS y GSM.

Con los resultados promedio de la dosis gamma y de la concentración de radón en suelo (Tabla IV-13), se obtuvo un diagrama de correlación entre ambos, tal como se muestra en la Figura IV-16, así como un coeficiente de correlación entre ambos resultados con $90 \%$, que muestra al radón y a su progenie en el suelo contribuyendo a la dosis gamma (Peña et al., 2001). Este comportamiento coincide con los resultados reportados por Pressyanov et al. (1996) en experimentos de laboratorio donde estudiaron la respuesta de DTL y DSTN mostrando un alto grado de correlación para concentraciones menores a $22 \mathrm{kBq}$ 
$\mathrm{m}^{-3}$. Aunque existe una buena correlación entre los valores de la concentración de radón y los valores de la dosis gamma en el suelo para las diferentes estaciones, la evolución de las series de tiempo indican una influencia con los efectos geológicos, geofísicos y meteorológicos locales.

Se observa que los detectores de radón tienen una respuesta relacionada con las fluctuaciones climatológicas y las características geológicas especialmente con la porosidad del suelo en donde están ubicadas las estaciones, lo que induce variaciones en sus valores (Peña et al., 2001). En trabajos realizados en el Centro Nuclear de México, con el mismo tipo de dosímetros se observó un incremento en los valores de la dosis gamma en la época de secas, así como una disminución en la época de lluvias (Segovia et al.,1994), cuyos valores promedio fueron de $200 \mathrm{nGy} \mathrm{h}^{-1}$. En la Tabla IV-13, se muestra que las estaciones localizadas en suelo

granítico (GAC, GSL), los valores promedio de la dosis gamma fueron de 203 y $101 \mathrm{n} \mathrm{Gy} \mathrm{h}^{-1}$ respectivamente, en la estación (GAS), ubicada en suelo que subyace a rocas metamórficas fue de 203 NGy $\mathrm{h}^{-1}$, mientras que en las estaciones (MG, GPH y GSM), localizadas en suelos aluviales y residuales, los valores fueron de 111, 151 y $240 \mathrm{nGy} \mathrm{h}^{-1}$ respectivamente. Las estaciones que muestran alto contenido de la concentración de radón fueron (GAC, GSL) que corresponden a zonas granodioríticas y graníticas respectivamente. La zona de GAC muestra la mayor concentración de radionúclidos con respecto a la zona de GSL, lo que significa que los niveles de radiación alfa y gamma, se deben a las características litológicas, es decir que las rocas del tipo granítico presentan mayor concentración de ${ }^{226}$ Ra y por ende, la concentración del radón y su progenie son mayores en ésta zona.

\subsection{ANÁLISIS MINERALÓGICO}

Por medio del análisis macroscópico y microscópico polarizante, se observó que las muestras de rocas son del tipo granodiorítico y granítico, pertenecientes a las estaciones GSL y GAC respectivamente.

En la Tabla IV-14, se muestran los compuestos químicos de las diferentes fases cristalinas, pertenecientes a las rocas analizadas mediante el difractómetro de rayos X. En la Tabla IV-15, se muestra el análisis obtenido con el microscopio electrónico de barrido, en el cual se cuantificó el porcentaje en peso de los principales elementos que constituyen dichas muestras. Se observan pequeñas diferencias entre las dos zonas; las rocas de la zona 1 están constituidas por cuarzo, anortita, albita y ferroactinolita que son características de las rocas granodioríticas; las rocas de la zona 2 están constituidas por cuarzo, albita y microclina, pertenecientes a rocas graníticas.

En la Tabla IV-16, se muestran los valores del ${ }^{235} \mathrm{U},{ }^{226} \mathrm{Ra}$ y ${ }^{40 \mathrm{~K}}$, obtenidos en las rocas en las zonas 1 (GSL) y 2 (GAC, en número de sismos, la dosis gamma y la concentración de radón durante el periodo de estudio. Se calcularon las razones de los valores de las dos zonas y se obtuvo: para el $235 \mathrm{U}(0.5)$, para el ${ }^{226} \mathrm{Ra}(0.17)$ y para el ${ }^{40} \mathrm{~K}(0.36)$, número se sismos $(0.56)$, dosis gamma $(0.54)$ y concentración de radón (0.45), esto indica que la zona 1 en donde se localizan rocas del tipo granodiorítico, el contenido de radionúclidos es menos de la mitad en comparación con la zona 2 en donde se tienen rocas de tipo granítico (Peña et al., 2001). En trabajos realizados en Pakistán por Alam et al. (1998) se reportaron en sitios con litologías semejantes a nuestro estudio, valores superiores a los reportados en este estudio. Los 
valores promedio más altos se observaron en la zona en donde se tiene el doble de los sismos durante el tiempo de monitoreo, las variaciones del radón se deben a los cambios meteorológicos, al tipo de suelo y roca y a los sismos locales. Los resultados comprueban que la dosis gamma tiene una dependencia del radón y su progenie confinada.

\subsection{ELEMENTOS Y COMPUESTOS QUÍMICOS MAYORES}

Los resultados de los parámetros físico-químicos obtenidos en los pozos Guacamayas (Mich) y El Cayaco (Gro) y en el manantial El Cortés (Gro), se presentan en la Tabla IV-17. En ésta tabla se observa lo siguiente:

Temperatura.- La temperatura se mantuvo constante en los tres sitios durante el periodo de muestreo. Se registraron las mayores temperaturas en el manantial El Cortés. Desde el punto de vista térmico (Castany, 1971), a las aguas de Guacamayas y El Cayaco se les clasifica como de tipo hipotermal mientras las del EI Cortés como mesotermal. Las variaciones de temperatura en agua subterránea en Guacamayas y El Cayaco pueden depender de la temperatura ambiente local (Castany, 1975); no así en el manantial El Cortés donde la temperatura puede deberse al efecto del gradiente geotérmico, así como a flujos regionales que pueden ser captados por acuíferos profundos (Fletcher, 1995; Segovia, et al., 1999a). Araujo et al. (1999) reportaron temperaturas de manantiales superiores a $55^{\circ} \mathrm{C}$, explicando que el gradiente térmico puede ser el producto de fluidos altamente calentados por un basalto cristalino estancado.

pH.- El pH, presentó valores promedio mayores en El Cortés. En Guacamayas y El Cayaco, el pH fue muy semejante y cerca de la neutralidad. El valor de pH se incrementó en la época de secas en Guacamayas y El Cayaco, mientras que en El Cortés aumentó esporádicamente en la de lluvias. El incremento del pH quizá se deba a la influencia que puedan tener algunos minerales que se hayan incorporado durante el transporte del agua. El intervalo de pH para aguas subterráneas varía entre 6 y 8.6 (Di Bernardo, 1993; Armienta et al., 1996; Palmer, 1996), valores superiores a 8.3 se pueden deber al contenido de carbonatos e hidróxidos derivados de las rocas (Fletcher, 1995; Domenico y Schwartz, 1998). El pH, muestra que las aguas en Guacamayas y El Cayaco son del tipo básico, mientras que en El Cortés arrojó valores promedio de lo cual indica que son aguas del tipo alcalino.

Conductividad eléctrica.-Los mayores valores promedio se observaron en Guacamayas y los menores en El Cortés. En la época de secas los valores fueron ligeramente mayores tanto en Guacamayas como El Cayaco, en cambio en El Cortés esto ocurrió en la época de lluvias. Rodier (1990) define los grados de mineralización del agua de acuerdo con la Tabla IV-18. 
Tabla IV-18 Distintos grados de mineralización (Rodier, 1990).

\begin{tabular}{|c|c|}
\hline Conductividad Eléctrica & Grados de mineralización \\
\hline$<100$ & Mineralización muy débil \\
$100-200$ & Mineralización débil \\
$200-333$ & Mineralización media acentuada \\
$333-666$ & Mineralización media \\
$666-1000$ & Mineralización importante \\
$>1000$ & Mineralización excesiva \\
\hline
\end{tabular}

De acuerdo a la Tabla IV-18 se deduce que los pozos de Guacamayas y El Cayaco presentaron mineralización media, mientras que en El Cortés presentó mineralización media acentuada. Estos resultados pueden interpretarse como productos de un transporte relativamente rápido desde la zona de recarga hasta los puntos de afloramiento para los dos primeros y un origen profundo para El Cortés.

Dureza.- Los valores promedio de la dureza fueron mayores en Guacamayas que en El Cayaco, tanto en la época de lluvias como de secas.

Calcio.- Los pozos de Guacamayas y El Cayaco tuvieron valores semejantes, mientras que El Cortés presentó valores muy bajos de $\mathrm{Ca}$. En ambas épocas del año se presentaron valores promedio parecidos. La variabilidad del calcio se debe a que es un ion muy móvil en la hidrósfera. Por lo general el $\mathrm{CaCO}_{3}$ se disuelve en el agua con ayuda del ácido carbónico en bicarbonatos y carbonatos, si el pH disminuye, disminuye la relación de los iones bicarbonato y carbonato y en consecuencia el $\mathrm{CaCO}_{3}$, que es muy soluble, tiende a aumentar la concentración de calcio en las muestras de agua (Appelo y Postma, 1993; Deutsch, 1997). Esto muestra diferencias en las rocas por donde circula el agua. En El Cortés el calcio se diluye durante las lluvias.

Magnesio.-El magnesio también presentó valores semejantes en Guacamayas y El Cayaco mientras que en El Cortés los valores fueron dos ordenes de magnitud menores. En las dos épocas del año se observó semejanza en los valores. Las concentraciones de magnesio se deben al ataque del agua sobre los silicatos magnésicos y ferromagnésicos (Custodio y Llamas, 1983; Appelo y Postma, 1993).

Sodio y potasio.- El sodio y el potasio presentaron comportamientos diferentes. En El Cortés se presentaron los valores más altos de sodio seguidos por Guacamayas y El Cayaco, con estabilidad a lo largo del año. El potasio fue mayor en El Cayaco seguido por Guacamayas y El Cortés. El sodio y el potasio son las especies más constantes en las aguas subterráneas, su presencia se debe a la liberación de productos solubles que tienen lugar durante la acción meteórica en las rocas ígneas y metamórficas (Alley, 1993; Davis y De Wiest, 1971). La presencia de sodio se debe al ataque de feldespatos y feldespatoides, y la de potasio se debe al ataque de la ortoclasa y otros silicatos (micas y arcillas) (Custodio y Llamas, 1983; Appelo y Postma, 1993).

Cloruro.- El cloruro presentó los valores promedio mayores en El Cortés seguido por Guacamayas y El Cayaco, con estabilidad durante el año. El cloruro forma parte de la mineralización que tienen las rocas ígneas en la zona de estudio, generalmente las variaciones en las concentraciones de cloruros se deben al 
cambio en las condiciones hidráulicas en el medio geológico, una disminución en la permeabilidad ocasiona un incremento en la concentración de cloruros y viceversa; un aumento en la permeabilidad ocasiona una disminución en la concentración (Custodio y Llamas, 1983). El cloro puede considerarse como un indicador de la influencia marina. Banks et al., (1995) y Buzek y Michalicek, (1997) observaron en Noruega y en la Republica Checa respectivamente, en una zona granítica localizada lejos de la costa, que las concentraciones de cloro no se derivaban de la litología local, sino de una relación marina. Toutain et al. (1997), observaron en los Pirineos Franceses valores anómalos del cloruro antes y después de la ocurrencia de un sismo $(M=5.2)$, éstos valores fueron atribuidos a los cambios de esfuerzos presísmicos, que indujeron una mezcla geoquímica de diferentes acuíferos, conformando así a los manantiales como sitios de señales naturales óptimos para estudios de precursores de sismos. Así mismo se han reportado cambios en la concentración de radón y $\mathrm{Cl}$, relacionados con el sismo de Kobe (Silver y Wakita, 1996 y Wakita, 1996). Kingsley et al. (2001) en Kamchatka (Rusia), observaron anomalías de elementos químicos en agua subterránea asociadas con la actividad sísmica. En nuestro caso los sismos cercanos fueron de baja magnitud y no se apreciaron cambios significativos en los cloruros. Solo puede mencionarse que en El Cortés, que tiene mayor concentración de $\mathrm{Cl}$ y Na existe probablemente una intrusión marina.

Sulfatos.- Los valores promedio de sulfatos fueron mayores en Guacamayas. Los incrementos se manifestaron en la época de secas, por concentración del compuesto al disminuir el nivel del agua. Los valores en forma decreciente aparecen en El Cortés y El Cayaco. En El Cayaco también hay un incremento en la época de secas, mientras que en El Cortés es estable. El contenido de sulfatos indica que las aguas subterráneas tienen un trayectoria en las rocas ígneas y metamórficas o en sedimentos derivados de ellas (Alley, 1993). Proceden de la oxidación de sulfuros en todo tipo de rocas (Custodio y Llamas, 1983; Palmer, 1996). Tsunogai y Wakita (1995), observaron en Japón que las concentraciones de los iones cloruro y sulfato en aguas subterráneas en pozos localizados cerca al epicentro del sismo de Kobe, aumentaron por encima del valor de fondo, así mismo observaron una relación lineal entre estos iones. Woith et al. (1999) observaron en Turquía cambios físico-químicos antes de la actividad sísmica. Las variaciones indicaron cambios en las mezclas de agua de los acuíferos que se deben posiblemente a: a) efectos climatológicos, b) creación de un nuevo patrón de flujos subterráneos y cierre de algunos existentes, c) una redistribución de esfuerzos creando diferencias en la presión en el acuífero, d) efectos artificiales. En nuestro caso no observamos cambios con la sismicidad local.

Bicarbonatos.- Los valores mayores corresponden a El Cayaco seguido por Guacamayas y El Cortés, con estabilidad en los dos primeros y fluctuaciones en El Cortés con disminución en la época de lluvias. Garavaglia et al. (1999), supusieron que la química del agua muestra que si los sulfatos y los carbonatos prevalecen, se puede considerar como el resultado de una lenta interacción con las evaporitas y carbonatos. Así mismo observaron que la temperatura del agua es constante y no varía estacionalmente. La influencia del gradiente geotérmico puede ser reducido localmente debido al flujo de una gran cantidad de agua meteórica.

Hierro.- Los valores de hierro fueron bajos y estables. La presencia de Fe se debe al ataque de ferrosilicatos y a algunas rocas sedimentarias (Custodio y Llamas, 1983; Palmer, 1996). 
Sílice.- Los valores fueron fluctuantes obteniéndose el mayor promedio en Guacamayas seguido por El Cayaco y El Cortés. La sílice presenta valores altos debido a que el paso del agua subterránea por rocas ígneas permite la saturación de la sílice amorfa. La concentración de sílice procede de ataques de silicatos y otras rocas que contengan sílice soluble (Custodio y Llamas, 1983; Palmer, 1996).

Nitratos.- Los valores promedio más altos se presentaron en Guacamayas seguido de El Cayaco. En El Cortés los valores fueron muy bajos. Las rocas ígneas presentan pequeñas cantidades de nitratos (Custodio y Llamas, 1983; Palmer, 1996). Los nitratos se puede considerar como indicadores del impacto antropogénico (Banks et al., 1995; Jain, 2002). El pozo El Cayaco se encuentra descubierto y cercano a fosas sépticas. Se esperaría una contaminación de éstas debida a la filtración hacia los niveles freáticos existentes, sin embargo, los valores de nitratos fueron relativamente bajos; en agua de pozo se ha reportado entre 0.1 y $10 \mathrm{mg} \mathrm{L}^{-1}$

Se realizó el balance iónico para cada uno de las muestras de agua; el balance recomendado como límite de confiabilidad es menor al 10 \% (Custodio y Llamas, 1983; Appelo y Postma, 1993; Deutsch, 1997). En general los valores estuvieron dentro de este rango indicando confiabilidad en las medidas.

Se determinó el tipo agua para cada pozo, y sus resultados están esquematizados en el diagrama triangular de Piper (Fig. IV-17). Dicha figura muestra que el agua que corresponde a Guacamayas es del tipo sulfatada cálcica [ $\mathrm{SO}_{4}{ }^{-}-\mathrm{Ca}$ ]; mientras que en El Cayaco es del tipo bicarbonatada cálcica [( $\left.\left.\mathrm{HCO}_{3}\right)_{2}\right)_{2} \mathrm{Ca}$ ] y en el manantial El Cortés es clorurada sódica [Cl-Na]. Las aguas sulfatadas cálcicas se caracterizan por el elevado contendido de sulfatos y son ricas también en sodio y potasio (Castany, 1971). El agua bicarbonatada cálcica generalmente pertenece a agua subterránea que procede de rocas ígneas (Custodio y Llamas, 1983; Segovia et al., 1999a). En aguas clorurada-sódicas predominan los cloruros, son ricas en $\mathrm{Cl}$ y $\mathrm{Na}$ y se caracterizan por ausencia de carbonatos. El agua subterránea en el área de El Cayaco probablemente sea una mezcla de aguas de reciente infiltración, y de recarga por flujos laterales regionales. Así mismo se considera que, como lo reporta Steinich et al. (1998), el patrón de flujo puede ser breve en aguas típicas de la familia de las bicarbonatadas. En este trabajo la composición de elementos mayores en las muestras de agua indican que el agua es de origen meteórico de reciente infiltración (Segovia et al., 1997a; Larsen et al., 2001).

En resumen al analizar la evolución de los elementos químicos en el tiempo se observó que las causas del incremento en las concentraciones de las especies químicas estudiadas se pueden deber generalmente a dos causas: A la contribución de la recarga del acuífero, permitiendo así una mayor disolución de la matriz sólida (época de lluvias) y a la disminución del volumen de agua por disminución de la recarga del acuífero (época de secas). La temperatura del agua fue relativamente constante durante todo el año. En Guacamayas y El Cayaco la conductividad eléctrica fue ligeramente mayor en la época de secas debido a la disminución del volumen de agua, ya que aumenta la concentración de sólidos disueltos. En Guacamayas se observaron incrementos en los valores de $\mathrm{Ca}, \mathrm{Mg}, \mathrm{SO}_{4}$, y SiO 2 , en la época de secas. En cuanto a El Cayaco se observaron los valores mayores de $\mathrm{Ca}, \mathrm{K}, \mathrm{HCO}_{3}$, y $\mathrm{NH}_{3}$ y los más bajos de $\mathrm{Na}, \mathrm{Cl}$, $\mathrm{SO}_{4}$ y Fe. En El Cortés se presentaron los valores más altos de la temperatura del agua, el pH, $\mathrm{Na}$ y $\mathrm{Cl}$ durante todo el año. Sin embargo, los promedios de la conductividad eléctrica fueron los más bajos, así como la dureza, $\mathrm{Ca}, \mathrm{Mg}, \mathrm{K}, \mathrm{Fe}$, y $\mathrm{SiO}_{2}$. Esto indica diferencias muy notables en el origen del agua de los 
tres sitios de muestreo. Los resultados de las mediciones de los parámetros físico-químicos realizados en la zona de estudio indican un sistema de flujo local para Guacamayas y El Cayaco (con valores de temperatura y conductividad eléctrica menores) y un flujo regional para El Cortés (con valores de temperatura y pH mayores) (Segovia et al., 1999a; Carrillo, 2000).

\subsection{ELEMENTOS TRAZA EN SOLUCIÓN}

En la Tabla IV-19, se muestran los resultados de los muestreos de elementos traza realizados en Guacamayas, El Cayaco y El Cortés. Se observan diferencias sustanciales entre los tres sitios. En Guacamayas los valores mayores corresponden al Sr seguido por Ba y B; en El Cayaco, Sr seguido por B y Ba y en El Cortés, cuya diferencia con los anteriores es notable, la mayor concentración corresponde a $B$ seguido por $\mathrm{Li}$.

Litio.- Los mayores valores de litio se obtuvieron en El Cortés. Se observa un pequeño incremento en la época de secas. Los valores obtenidos fueron menores a $100 \mathrm{~g} \mathrm{~L}^{-1}$ que corresponde a los máximos reportados en agua subterránea (Rodier, 1990). Es evidente la diferencia entre El Cortés, con valores hasta de 36 [g L-1, comparada con Guacamayas $\left(0.83 \mathrm{Lg} \mathrm{L}^{-1}\right)$ y El Cayaco $\left(7.31 \mathrm{gg} \mathrm{L}{ }^{-1}\right)$. Esto evidencia la diferencia entre las rocas de los tres acuíferos.

Boro.- En este caso el boro tuvo valores inferiores a $100 \mathrm{~g} \mathrm{~L}^{-1}$ en Guacamayas y El Cayaco mientras que El Cortés indica valores de centenas de $\llbracket g \mathrm{~L}^{-1}$ por lo que la roca de éste último acuífero seguramente tiene influencia magmática.

Cromo.- El cromo fue semejante en los tres sitios y muy bajo comparado con los normas para agua potable $\left(500 \mathrm{gg} \mathrm{L^{-1 }}\right)$

Manganeso.- Al igual que el cromo la concentración de manganeso fue semejante para todos los sitios de muestreo y muy baja.

Cobalto. El cobalto tampoco presentó valores significativos en este estudio.

Cobre. La concentración de este elemento tampoco fue significativa, tuvo fluctuaciones habiéndose llegado en algunos periodos de muestreo a valores comparables a los valores máximos reportados por Pane (1995). Sin embargo la mayoría de los valores fueron bajos .

Cinc. Este elemento tuvo la menor concentración en El Cortés y la mayor en El Cayaco. Sin embargo, los valores de todos los muestreos fueron muy inferiores al limite superior reportado por Pane (1995) y Asubiojo et al. (1997).

Arsenico.- Los valores fueron todos comparables cercanos al limite superior reportado por Pane (1995).

Rubidio.- Los valores fueron bajos en general pero en El Cayaco se obtuvieron las mayores concentraciones. 
Estroncio.- Se observaron diferencias sustanciales entre las concentraciones de El Cortés y aquellas obtenidas en los dos otros sitios. El Cortés tuvo un orden de magnitud menor de $\mathrm{Sr}$ con respecto a los otros pozos mostrando diferencias de origen evidentes entre los sitios.

Molibdeno.- Solo fue significativo en El Cortés aunque sus valores estuvieron muy por debajo de las concentraciones superiores reportadas por Pane (1995).

Cadmio.- Los valores fueron en los tres sitios un orden de magnitud superior a los valores mínimos reportados por Pane (1995).

Cesio.- También en este caso El Cortés tuvo un orden de magnitud por encima de Guacamayas y El Cayaco pero con valores muy bajos.

Bario.- Los valores mayores se observaron en Guacamayas con un orden de magnitud por encima de El Cayaco, sin embargo los valores estuvieron por debajo de las concentraciones reportadas por Asubiojo et al (1997).

Plomo.- Los valores fueron semejantes y bajos

Uranio.- Solamente El Cayaco tuvo un valor de uranio por encima de $1 \mathrm{gg} \mathrm{L}-1$, que corresponde a valores muy bajos según Pane (1995).

Al igual que en la costa de Veracruz se determinó el porcentaje de aquellas estaciones que presentaron mayor mineralización con respecto a los periodos de muestreo correspondientes a las estaciones de secas y de lluvias, tal como se presenta en la Tabla IV-19 se determinó para cada pozo el valor máximo de cada elemento. Se sumaron el número de eventos que representan el máximo valor para cada uno de los pozos y dicha suma se hizo igual al $100 \%$ en peso. Se determinó el porcentaje que le correspondió a cada uno de los pozos de acuerdo a los dos periodos de muestreo. Con estos datos se construyó la gráfica Figura IV18 , en donde se muestra el porcentaje de los eventos de cada uno de los pozos que presentaron mayor mineralización en el periodo de muestreo. Se presentan los valores de los mayores porcentajes en la época de secas en Guacamayas, El Cayaco y El Cortés con 77, 86 y 85 \% respectivamente. Este comportamiento se debe a la disminución del volumen de agua y de la velocidad del transporte del fluido como consecuencia de la disminución de la recarga del acuífero, ocasionando que exista mayor concentración de los elementos debido al mayor tiempo de residencia de estos en los acuíferos. La variabilidad de las especies químicas se debe a la interacción con las rocas en las cuales se transporta.

En las Figuras IV-19a, IV-19b y IV-19c, correspondientes a los pozos de Guacamayas, El Cayaco y El Cortés respectivamente, se muestran gráficamente las concentraciones de los elementos de la Tabla IV-19. En ellos se aprecia la diferencia de concentraciones. Guacamayas se caracteriza por altos valores de Sr, $\mathrm{Ba}$ y $\mathrm{B}$ y eventualmente $\mathrm{Cr}$. En el Cayaco solo es significativo el $\mathrm{Sr}$ y en El Cortés solo el B. La Figura IV20, también muestra el comportamiento de cada uno de los elementos traza en Guacamayas, El Cayaco y El Cortés para los muestreos realizados. 
Se observa en El Cortés que los parámetros Sr y Ba presentan valores un orden de magnitud menor que los otros pozos y por lo tanto no presenta influencia volcánica que pueda dar el origen al agua del manantial, pero muestra que existe una zona fracturada que promueve la circulación hidrotermal. Las concentraciones en El Cayaco de U, y Rb son mayores que en Guacamayas mostrando que estos elementos provienen del basamento granítico. Así mismo se observan niveles similares de Co, Mo, As, y Sr en El Cayaco y Guacamayas, mostrando un tiempo de residencia comparable de las aguas de los dos acuíferos. Las concentraciones de Ba y B fueron menores en El Cayaco que en Guacamayas indicando un contenido pobre de estos elementos en Guacamayas. Los elementos traza tienen gran contenido de B, Zn y Ba en Guacamayas y gran contenido de Li, Rb, Sr y U, en El Cayaco (Segovia et al., 1997a).

\section{ANÁLISIS DE ELEMENTOS QUÍMICOS MAYORES Y TRAZA POR MEDIO DE COMPONENTE PRINCIPAL}

\subsection{COSTA DEL GOLFO DE MÉXICO}

\section{Elementos químicos mayores}

En la Tabla IV-20-A, se muestra la matriz de correlación entre las variables obtenidas en la época de secas y en la Figura IV-21-A, se observa la variancia acumulada de los ejes 1 y 2 , cuyo valor fue de $80 \%$ ( $57 \%$ en el eje 1 y $24 \%$ en el eje 2). Se observa que en la parte positiva en el eje 1 , se tiene un grupo de elementos (Ca-Mg-SiO $2-\mathrm{SO}_{4}$ ) cuya asociación permite definirlo como representativo del tiempo de permanencia de los minerales constituyentes de las rocas en las aguas del acuífero. En la parte negativa se tiene una correlación fuerte entre (Cl-Na). En la figura de correlación muestral se observaron dos agrupamientos que se encuentran en los planos principales, estos grupos indican que los pozos P2, P3 y P9 por un lado y P1, P8, LV1, LV2 y LV6, por el otro, tienen características comunes.

En la Tabla IV-20-B, se muestra la matriz de correlación entre las variables obtenidas en la época de lluvias y en la Figura IV-21 B, se tiene la variancia acumulada de los ejes 1 y 2 , cuyo valor es de $80 \%$ ( $41 \%$ en el eje 1 y $39 \%$ en el eje 2). Así mismo se observa que en la parte positiva del eje 1, se tiene un grupo de elementos (Mg-Ca), cuya asociación indica que es representativo del tiempo de permanencia de los minerales constituyentes de las rocas en las aguas del acuífero. En la parte negativa, se tiene una correlación fuerte entre (Na-K), y en el eje 2 en la parte positiva, se observa la correlación de $\left(\mathrm{pH}-\mathrm{T}-\mathrm{HCO}_{3}-\right.$ $\mathrm{CE}$ ). En la figura de correlación muestral se observan tres agrupamientos que se encuentran en los planos principales. El grupo a, contiene a los pozos P3, P8, P9, LV1 y LV2, y los grupos $b$ y $c$, a los pozos P2 y P1 respectivamente. Estos grupos tienen características comunes en cuanto a su mineralización.

\section{Elementos traza}

En la Tabla IV-21-A se observa la matriz de correlación. En la Figura IV-22-A, que comprende el muestreo de la época de lluvias, se muestra la varianza acumulada de los ejes 1 y 2 , que le corresponden $51 \%(33 \%$ en el eje 1 y $18 \%$ en el eje 2). En dicha figura se observa que el eje 1 en la parte positiva, tiene un grupo de elementos (Mn-Co-U), cuya asociación permite difundirlos como representativos del tiempo de permanencia de los minerales constituyentes de las rocas en las aguas del acuífero. En la figura que 
corresponde a la correlación muestral se observan dos agrupamientos que se encuentran en los planos principales. El grupo a (P2, P3, P9, P10, LV1, M, R2 y RN), el grupo b (P1, P6, P8, LV2, LV5 y AD4) que presentan características comunes de mineralización.

En la Tabla IV-21-B, se observa la matriz de correlación. En la Figura IV-22-B, que comprende el muestreo de en la época de secas, se muestra la varianza acumulada en los ejes 1 y 2 , que les corresponden 44\% (26\% en el eje 1 y $18 \%$ en el eje 2 ). Se observa en dicha figura que el eje 1 en la parte positiva, tiene el grupo de elementos (CU-Pb-B), cuya asociación permite definirlos como representativos del tiempo de permanencia de los minerales constituyentes de las rocas en las aguas del acuífero. En la figura que comprende a la correlación muestral se observan 3 agrupamientos que se encuentran en los planos principales. El grupo a (P2, P3, P10, LV1 y M), el grupo $b(P 9, R N)$ y el grupo $c(P 1, P 8, P 6, A D 4$ y LV2), que presentan características comunes de mineralización.

Los elementos químicos mayores presentaron una correlación fuerte $(\mathrm{Na}-\mathrm{Cl})(>0.7)$ en la época de secas y (Na-K) en la época de lluvias, así mismo una correlación en ambas épocas del año de (Ca-D). En lo que respecta a los elementos traza se observó que en los pozos que están cercanos entre sí, se presentaron las mayores concentraciones durante el año.

\subsection{COSTA DE GUERRERO}

\section{Elementos químicos mayores}

Estación Guacamayas.- La Tabla IV-22-A, muestra la matriz de correlación y en la Figura IV-23-A, se observa la varianza acumulada para los ejes 1 y 2 cuyo valor es del $58 \%$ (34 \% en el eje 1 y $24 \%$ en el eje 2). En la parte positiva del Eje 1, se correlacionan fuertemente ( $\mathrm{pH}-\mathrm{D}-\mathrm{Ca})$ y en la parte negativa $\left(\mathrm{NO}_{3},-\mathrm{NH}_{3},-\right.$ $\mathrm{HCO}_{3}, \mathrm{Na}$ ). En cuanto a la figura que representa la correlación muestral, se observaron dos agrupamientos. El grupo a (G7, G9, G10, G11 y G12) y el grupo b (G4, G5, y G6) que presentan características comunes de mineralización.

Estación El Cayaco.- En la Tabla IV-22-B, se muestra la matriz de correlación y en la Figura IV-23-B se observa la acumulación de la varianza para los ejes 1 y 2 con valor de $73 \%$ (45\% en el eje 1 y 28 \% en el eje 2). En la parte positiva del eje 1, le corresponden elementos tales como ( $\left.\mathrm{Cl}-\mathrm{Ca}-\mathrm{SO}_{4}-\mathrm{Mg}_{-}-\mathrm{HCO}_{3}\right), \mathrm{cuya}$ asociación permite definirlos como representativos del tiempo de permanencia de los minerales constituyentes de las rocas en las aguas del acuífero. En la parte negativa, se tiene la correlación $\left(\mathrm{NO}_{3}{ }^{-}\right.$ $\mathrm{Na})$; en la parte positiva del eje 2 , se tienen los grupos $\left(\mathrm{NH}_{3}-\mathrm{SiO}_{2}\right)$ y $(\mathrm{CE}-\mathrm{pH})$. En la figura que corresponde a la correlación muestral se observan tres agrupamientos. El grupo a constituido por los pozos (C4, C5 y C7), el grupo b (C9) y el grupo c (C6) que presentan características comunes de mineralización.

Estación El Cortés.- En la Tabla IV-22-C, se muestra la matriz de correlación y en la Figura IV-23-C se observa la varianza acumulada en los ejes 1 y 2 con valores de $59 \%$ (35\% en el eje 1 y $23 \%$ en el eje 2 ). En la parte positiva del eje 1, se correlacionan fuertemente el grupo (temperatura-pH-dureza), ésta asociación permite definirlo como representativo del tiempo de permanencia de los minerales constituyentes de las rocas en las aguas del acuífero. En cuanto a la figura que representa la correlación muestral se 
tienen 2 grupos: el grupo a (E7, E9, E10, E11 y E12) y el grupo $b$ (E5 y E6) que presentan características comunes de mineralización.

\section{Elementos traza}

Estación Guacamayas.- En la Tabla IV-23 A, se presenta la matriz de correlación y en la Figura IV-24-A, se observa la varianza acumulada en los ejes 1 y 2 que es de $46 \%$ (25\% en el eje 1 y $21 \%$ en el eje 2 ). En la parte positiva del eje 1, se correlacionan fuertemente ( $\mathrm{Cd}-\mathrm{Co})$, la asociación de éste grupo permite definir a este eje como representativo del tiempo de permanencia de los minerales constituyentes de las rocas en las aguas del acuífero. En la parte negativa del eje 2, se tiene la correlación ( $\mathrm{Zn}-\mathrm{Mn}-\mathrm{Cu})$ y en la parte negativa (Ba-Sr-As). En la figura que representa a la correlación grupal se visualizan tres grupos de muestreo que se reparten en los planos principales. El grupo a (G3, G4, G5, G6, G7, G8, G11, G12, G13 y G14), el grupo $b(\mathrm{G} 9, \mathrm{G} 10, \mathrm{G} 15)$ y el grupo $c(\mathrm{G} 1)$ que presentan características comunes de mineralización.

Estación El Cayaco.- En la Tabla IV-23-B, se presenta la matriz de correlación y en la Figura IV-24-B, se observa que la variación acumulada en los dos ejes fue de $48 \%$ (27\% en el eje 1 y $41 \%$ en el eje 2 ). En la parte positiva del eje 1, se tiene (As-Li-Sr), la asociación de éste grupo se tomó como representativo del tiempo de permanencia de los minerales constituyentes de las rocas en las aguas del acuífero. En la parte positiva del eje 2, se correlacionaron los elementos (Ba-Rb-B). En la figura de correlación grupal se visualizan 2 grupos que se reparten en los planos principales. El grupo a (C1, C4, C5, C7, C8 y C14) y el grupo $b(\mathrm{C} 2, \mathrm{C} 3, \mathrm{C}$, C10, C11 y C12) que presentan características comunes de mineralización.

Estación El Cortés.- En la Tabla IV-23-C, se presenta la matriz de correlación y en la Figura IV-24-C, se observa que la variación acumulada en los dos ejes fue de $75 \%$ (47 \% en el eje 1 y $28 \%$ en el eje 2). En la parte positiva del eje 1, se correlacionó fuertemente (Li-Sr-Mo-Cs-Rb-B), la asociación de éste grupo permite definirlo como representativo del tiempo de permanencia de los minerales constituyentes de las rocas en las aguas subterráneas y en la parte positiva del eje 2, se correlacionaron fuertemente (Mn-Co-U$\mathrm{Cu}-\mathrm{Cd}$ ). En la figura que representa la correlación muestral se visualizan dos grupos que se reparten en los planos principales. El grupo a (CT8, CT9, CT10, CT11, CT12, CT13 y C15), el grupo $b$ (CT14) que presentan características comunes de mineralización.

Estaciones Guacamayas, El Cayaco y El Cortés.- Para realizar el análisis de componente principal se utilizaron 261 variables y 22 muestreos de los elementos mayores y traza. En la Tabla IV-24 se muestra la matriz de correlación y en la Figura IV-25 se observa que la varianza acumulada es en los ejes es de $56 \%$ ( $40 \%$ en el eje 1 y $16 \%$ en el eje 2). En la parte positiva del eje 1, se correlacionaron (Sr-Mg-Ca-HCO $-\mathrm{D}$ ) y en la parte negativa (Li-B-Mo-Cs-Cl). La asociación del primer grupo permite definirlo como representativo del tiempo de permanencia de los minerales constituyentes de las rocas en las aguas del acuífero. Se reconoce un grupo de parámetros de origen termal. La mineralizaron de las aguas subterráneas parece tener un origen diferente ya que se puede inferir una interacción agua-roca. En el eje 2 se tiene una correlación ( $\mathrm{Mg}-\mathrm{Ba}-\mathrm{SO}_{4}-\mathrm{NO}_{3}$ ) por el lado positivo y en el lado negativo se tiene la correlación con (pH-CE). En la correlación grupal se observó una separación geoquímica de los grupos, definiendo así que se trata de acuíferos que provienen de diferentes tipos de formaciones rocosas. 
En Guacamayas se presentó una correlación fuerte entre $\left(\mathrm{NO}_{3}\right.$ y NH 3$)$ indicando una contaminación en el pozo por materia orgánica, así como (Cd-Cs), (Zn-Mn-Cu) y (Ba-As-Sr). así mismo se puede inferir una componente sulfato-bárica, probablemente relacionada con rocas ígneas cálcicas continentales y areniscas, 0 aún de origen granítico diferente al del Cayaco. En El Cayaco, se presentó una correlación fuerte entre (Ca-Mg-SO ${ }_{4}-\mathrm{Cl}-\mathrm{HCO}_{3}-\mathrm{SiO}_{2}-\mathrm{NH}_{3}$ ), aquí nuevamente se observa la presencia de nitratos, así como (As-Li-Sr) y (Ca-Rb-B). La composición química de las aguas del acuífero probablemente está relacionada con el basamento granítico y los depósitos aluviales subyacentes. Se observa que ambos pozos no tienen correlación entre sí, ya que pertenecen a litologías diferentes. En cuanto a El Cortés, se observaron correlaciones fuertes entre los elementos (B-Rb-Sr-Mo-Cs-Li) y (Mn-Co-Cu-Cd-U), además de (pH-D-T), ya que el agua pertenece a un manantial termal, así mismo se observa que tiene una correlación directa con el polo térmico. 


\section{CAPÍTULO V CONCLUSIONES.}

Los aspectos más relevantes obtenidos en este trabajo, se resumen como sigue:

\section{ZONA DE LOS ALREDEDORES DE LA PLANTA NUCLEAR DE LAGUNA VERDE (CGMPNLV).}

Los sismos ocurridos en la zona durante el período de estudio fueron esporádicos y de baja magnitud y se localizaron esencialmente en las zonas de El Viejón y Rancho Nuevo. Prácticamente no hubo sismicidad en el sitio de la Planta Nuclear.

\section{Radón en agua}

Las mayores concentraciones de radón en agua subterránea de la zona se observaron en Rancho Nuevo que es una zona de falla donde hay un movimiento preferente de fluidos. Las concentraciones menores se obtuvieron en los pozos ubicados en el sitio de la PNLV. Los mayores incrementos de la concentración de radón se observaron en El Viejón y Rancho Nuevo al inicio y final de la época de lluvias. Se observaron anomalías en El Viejón en la época de secas, en Rancho Nuevo al inicio de las lluvias y en la PNLV tanto en la época de secas como en las lluvias, sin embargo, ninguna de estas anomalías pudo correlacionarse con la sismicidad local que fue de baja magnitud y esporádica. Su origen se debe esencialmente a factores meteorológicos.

Ninguno de los valores medidos de la concentración de radón en agua fue mayor al valor máximo permisible para agua potable (11.3 $\left.\mathrm{Bq} \mathrm{L} \mathrm{L}^{-1}\right)$.

\section{Radón en suelo}

Las mayores concentraciones de radón en suelo de la zona se observaron en la estación Loma y las menores en el sitio de la PNLV. Hubo pocas fluctuaciones drásticas de la concentración de radón en suelo durante el período de estudio, excepto a finales de 1995 y mediados de 1996. En este último periodo la sismicidad fue poco significativa, pero el patrón de las lluvias fue distinto a los años anteriores. Se observaron anomalías en El Viejón, Palma, Rancho Nuevo y Las Lajas durante julio-agosto de 1996 y en la PNLV en abril de 1995, esta última en época de secas. Ninguna de estas anomalías pudo correlacionarse con la sismicidad local que fue de baja magnitud y esporádica. Su origen se debe esencialmente a factores meteorológicos. Los niveles de la concentración de radón en suelo fueron relativamente bajos, correspondiendo a lo reportado en suelos arenosos con influencia marina. Las medidas de periodos cortos indicaron fluctuaciones de baja intensidad debida esencialmente a los factores meteorológicos con valores promedio bajos.

Las fluctuaciones de la concentración de radón en suelo $\left(0.09-15.1 \mathrm{kBq} \mathrm{m}^{-3}\right)$ son mayores que las concentración de radón en agua (0.01-6.30 $\left.\mathrm{kBq} \mathrm{m}^{-3}\right)$ debido a la influencia de los factores meteorológicos en superficie $(70 \mathrm{~cm})$.

\section{Elementos y compuestos químicos mayores.}

Las concentraciones de elementos y compuestos químicos mayores en las muestras de agua subterránea de los pozos de la Planta Nuclear de Laguna Verde y El Viejón, indican una componente que proviene de 
rocas ígneas, siendo ambas aguas de tipo meteórico de reciente infiltración. Se observaron concentraciones altas de sales que se deben a la cercanía que tiene con la Laguna Salada.

Las concentraciones de $\mathrm{HCO}_{3}-\mathrm{Cl}^{-}$, y Na- fueron semejantes en las dos zonas, siendo un poco mayores en la época de lluvias, debido al efecto de arrastre durante la recarga. Por otro lado el potasio disminuyó a la mitad durante la época de lluvias indicando una dilución del elemento. Los sulfatos fueron distintos en las dos zonas y no variaron con el tiempo. El Ca y el $\mathrm{SiO}_{2}$ fueron un poco mayores en El Viejón en la época de secas igualándose su concentración en las dos zonas en la época de lluvias. El Mg no varió ni entre sitios ni entre épocas. La dureza fue mayor en la PNLV en las dos épocas del año.

Las aguas de la PNLV, pertenecen al tipo bicarbonatada cálcico-magnésica y las aguas de EV, son bicarbonatada cálcico-magnésica y bicarbonatada cálcico-sódica.

En la época de secas se obtuvieron correlaciones fuertes (>0.85) entre $\mathrm{Cl}-\mathrm{Na}, \mathrm{D}-\mathrm{Ca}-\mathrm{Mg}$ y SiO $2-\mathrm{SO}_{4}$, y se observó una correlación moderada (0.50-0.70) entre $\mathrm{HCO}_{3}-\mathrm{Ca}-\mathrm{Mg}-\mathrm{D}$. En la época de lluvias se obtuvieron correlaciones fuertes entre $\mathrm{Mg}-\mathrm{Ca}, \mathrm{Na}-\mathrm{K}$ y $\mathrm{HCO}_{3}-\mathrm{CE}-\mathrm{pH}-\mathrm{T}$.

\section{Elementos químicos traza.}

Los mayores valores promedio de elementos traza se obtuvieron en la época de secas, donde a su vez se tuvieron los valores mayores de As, Ba, B, Cr, Li, Rb y U. En cuanto a la época de lluvias se observaron los valores mayores de $\mathrm{Cd}, \mathrm{Co}, \mathrm{Cu}, \mathrm{Mn}$ y $\mathrm{Pb}$. Los cambios en el tiempo y en el espacio para cada uno de los elementos traza fueron pequeños. Excepto para el $\mathrm{Mn}$ en donde se observaron incrementos significativos en su concentración en cuanto a la distribución espacial, debido principalmente al efecto geológico durante el contacto agua-roca, ya que los pozos en donde se tomaron las muestras de agua tienen diferente profundidad, por lo tanto el área de contacto del agua y los estratos son diferentes en cada uno de los pozos. Así mismo se observaron diferencias en cuanto a la concentración en las diferentes épocas del año, siendo la de lluvias la que presentó los valores más altos debido al efecto de la disolución del Mn. En general se observó un incremento en los valores de Ba tanto en la época de secas como de lluvias, así mismo se observaron incrementos de $B$ en ambas épocas del año. Estos elementos muestran una interacción entre el agua y las rocas ígneas.

Los valores de los elementos traza obtenidos en esta región se encuentran dentro de los valores normales reportados en la literatura para el tipo de geología local.

Se observó una alta variancia acumulada $(50 \%)$ en los dos periodos de muestreo. En la época de lluvias se obtuvieron correlaciones fuertes entre $\mathrm{Li}-\mathrm{U}$ y $\mathrm{Mn}-\mathrm{Co}$, así como una correlación moderada entre $\mathrm{Mn}-\mathrm{Co}-\mathrm{Cr}$ y $\mathrm{B}-\mathrm{U}$. En la época de secas se obtuvieron correlaciones fuertes entre $\mathrm{Cu}-\mathrm{Pb}-\mathrm{B}$ y una correlación moderada entre Li-Rb.

ZONA DE LA COSTA DEL PACÍFICO: ESTADO DE GUERRERO (CPEG).

La zona presentó una sismicidad alta. Hubo 261 sismos en el periodo de 1993-1998 con magnitud (M> 4) a profundidades menores de $20 \mathrm{~km}$. 


\section{Radón en suelo}

Las mayores concentraciones de radón en suelo se observaron en Acapulco (Centro) seguido por Papanoa (Escuela) y Coyuca de Benitez que están ubicados en suelo granítico, metamórfico y residual respectivamente. Las menores concentraciones se observaron en sedimentos de playa. El nivel de la concentración de radón mostró un comportamiento que depende de la geología local, es decir, la respuesta de la concentración de radón en el suelo depende del tipo de sustrato. Los valores de la concentración de radón en suelo corresponden a valores normales para la geología del sitio de estudio.

Los valores máximos de la concentración de radón se observaron esencialmente en la época de lluvia.

El comportamiento de la concentración de radón en suelo medido en periodos largos de tiempo no respondió con picos uno a uno a los sismos locales. Se encontró cierto comportamiento específico del radón en el corto plazo que coincidió con el sismo de mayor intensidad ocurrido durante el periodo de monitoreo. Cabe mencionar que la sismicidad fue muy intensa en la región. Sin embargo, se identificaron dos zonas donde la relación del número de sismos, la concentración de radón y la dosis gamma promedio mostraron correlación entre ellos. .

Las variaciones de la concentración de radón y de la radiación gamma mostraron una correlación de 0.9 entre sí.

\section{Elementos y compuestos químicos mayores en agua.}

Las concentraciones de elementos y compuestos químicos mayores en las muestras de agua subterránea mostraron la mayor concentración en Guacamayas seguida por El Cayaco y finalmente El Cortés. La temperatura del agua fue relativamente constante durante todo el año, correspondiendo la mayor temperatura a El Cortés. Los tres sitios mostraron diferencias muy notables en los elementos químicos mayores lo cual muestra que los sistemas acuíferos son distintos para cada uno de ellos.

En época de secas se observaron cambios en parámetros físico-químicos relacionados con la disminución del volumen de agua.

Los tres sitios mostraron pertenecer a familias de agua con diferente mineralización, debido a la litología, y a los mecanismos de recarga. Los tipos de agua fueron sulfatado-cálcico en Guacamayas, bicarbonatado cálcico en El Cayaco y clorurado-sódico en El Cortés.

De los resultados de los parámetros físico-químicos se puede suponer que existe un sistema de flujo local para Guacamayas y El Cayaco (baja temperatura y conductividad eléctrica) y un flujo regional para El Cortés (alta temperatura y conductividad eléctrica).

Se observó durante los periodos de muestreo una variancia acumulada de 58, 73 y $59 \%$ para Guacamayas, El Cayaco y El Cortés respectivamente. En Guacamayas se observó una correlación fuerte entre $\mathrm{NO}_{3}-\mathrm{NH}_{3}$, lo cual indica una contaminación por materia orgánica. En El Cayaco, se observó una correlación fuerte entre $\mathrm{Cl}-\mathrm{Ca}-\mathrm{Mg}_{-} \mathrm{SO}_{4}-\mathrm{HCO}_{3}, \mathrm{NH}_{3}-\mathrm{SiO}_{2}$ y CE-pH observándose nuevamente la presencia de nitratos que indica una contaminación en las aguas del pozo. En El Cortés, se observó una correlación 
fuerte entre $\mathrm{pH}-\mathrm{T}-\mathrm{D}$. El agua pertenece a un manantial termal y la influencia de la temperatura está directamente correlacionada con el pH y con la dureza.

El agua del pozo Guacamayas es para uso potable, mientras que El Cayaco no es recomendable para ese uso.

\section{Elementos químicos traza.}

Mientras Guacamayas y El Cayaco tienen la mayor concentración de Sr. El Cortés por ser un manantial termal esta influenciado por rocas que contienen B y Li indicando mayor profundidad.

Se observaron incrementos en la concentración de los elementos traza en la época de secas, debido a la disminución de la recarga de los acuíferos, ocasionando la existencia de mayor concentración de dichos elementos debido al mayor tiempo de residencia.

En Guacamayas se observó una correlación fuerte entre CD-Co, Mn-Zn Cu y Ba-Sr-As. En El Cayaco, se presento correlación fuerte entre Li-Sr-As y Ba-Rb-B. En cuanto a El Cortés, se presento correlación fuerte entre Li-B-Rb-Sr-Mo-Cs, así como una correlación moderada entre Mn-Co-U-Cu-Cd.

Cada conjunto agrupa a los muestreos de cada pozo, definiendo así que se trata de acuíferos que provienen de diferentes tipos de formaciones rocosas.

\section{CONCLUSIÓN GENERAL.}

La diferencia entre las dos zonas estudiadas (CGMPNLV y CPEG) radica en que la sismicidad en la primera fue de baja magnitud y las variaciones geoquímicas, incluyendo al radón, solo presentaron anomalías debido a la meteorología y geología local. En cuanto al Pacifico la sismicidad fue muy intensa cubriendo un rango amplio de magnitudes. En las mediciones de periodos cortos de tiempo, se encontró una relación que coincide con los sismos de mayor intensidad $(M>7.3)$. Mientras que en mediciones de radón en periodos largos de tiempo, la actividad sísmica que se presentó en la zona de estudio dificultó el establecer una relación unívoca entre la misma y las concentraciones de radón. Los parámetros geoquímicos mostraron cambios que se relacionaron con la sismicidad local, con la meteorología y con el tipo de suelo. Se observó una correlación entre la respuesta de la concentración de radón y la dosis gamma en el suelo. 


\section{RECOMENDACIONES}

1. De los resultados obtenidos se recomienda para trabajos futuros estudiar zonas costeras acotadas alrededor de la brecha sísmica de Guerrero ubicada entre las coordenadas $16^{\circ} 45^{\prime}-17^{\circ} 30^{\prime} \mathrm{N}$ y $100^{\circ} 15^{\prime}$ $101^{\circ} \mathrm{W}$.

2. Realizar un muestreo geoquímico espacial y temporal de manantiales y pozos (elementos químicos mayores y trazas) en la zona elegida, así como datos meteorológicos locales y la correlación hidrogeológica de los mismos.

- Realizar un censo de manantiales y pozos.

- Realizar muestreos mensuales con el fin de obtener una base sistemática de datos geoquímicos de elementos químicos mayores y trazas que representará el fondo de elementos mayores y traza.

- Evidenciar las anomalías durante los periodos de monitoreo.

- Obtener las correlaciones entre las anomalías geoquímicas, los cambios meteorológicos y la sismicidad local.

3. Realizar un monitoreo de la concentración de radón en suelo a corto y largo plazo en la zona elegida para obtener las correlaciones con la sismicidad local.

4. Diseñar un sistema de monitoreo de radón en suelo en el corto plazo, con sistemas de telemetría fijados probablemente a las estaciones sísmicas que tiene Alarma Sísmica a lo largo de la Costa de Guerrero.

5. Establecer un modelo donde se tengan en cuenta las características geoquímicas (elementos químicos mayores y trazas y concentración de radón en suelo) con la ocurrencia de la sismicidad de alta magnitud del área de estudio. 


\section{REFERENCIAS}

Abbad, S., M.C.Robe, M.Bernat, V.Labed, (1995). Influence of meteorological and geological parameter variables on the concentration of radon in soil gases application to seismic forecasting in the ProvenceAlpes-Cote. In: Gas Geochemistry, (C.Dubois, edit), Science Reviews, Northwood, 35-48.

Abu-Jarad, F. And J.H.Fremlin, (1983). Effect of internal wall covers on radon emanation inside houses. Health Phys. 44, 243-248.

Abumurad, K.M. and M. Al-Tamimi, (2001). Emanation power of radon and its concentration in soil and rocks. Radiat. Meas., 34, 423-426.

Adams, S., R.T.Titus, K.Pretersen, G.Tredoux, C.Harris, (2001). Hydrochemical characteristics of aquifer near sutherland in the Western Karoo, South Africa. J. Hidrol., 241, 91-103.

Aggarwal, J.K., M.R.Palmer, T.D.Bullen, S.Arnorsson, K.V. Ragnarsdottir, (2000). The boron isotope systematic of Icelandic geothermal waters:1.Meteoric water charged systems. Geochim. Cosmochim. Acta., 64, 579-585.

Akerblom, G., P.Anderson, B.Clavensjo, (1984). Soil gas radon a source for indoor daughters. Radiat. Prot. Dosim., 7, 49-54.

Alam, K,B., A.Amanat, A.Aziz, (1998). Estimation of environmental gamma background radiation levels in Pakistan. Health Phys., 75, 63-66.

Al-Bataina, B.A., A.M.Ismail, M.K.Kullab, K.M.Abumurad, H.Mustafa, (1997). Radon measurements in different types of natural waters in Jordan. Radiat. Meas., 28, 591-594.

Al-Jarallah, M., (2001). Radon exhalation from granites used in Saudi Arabia. J. Environ. Radioact., 53, 9198.

Al-Tamimi, M.H. and K.M.Abumurad, (2001). Radon anomalies along faults in North of Jordan. Radiat. Meas., 34, 397-400.

Alley, W., (1993). Regional Groundwater Quality. Van Nostrand Reinltold, New York.

Amrani, D., D.E.Cherouati,M.E.H.Cherchali, (2000). Groundwater radon measurements in Algeria. J. Environ. Radioact., 51, 173-180.

APHA, AWWA, WPCF, (1992). Métodos Normalizados para el Análisis de Aguas Potables y Residuales. Editorial Díaz de Santos, S.A., Madrid.

Appelo, C.A.J. and D.Postma, (1993). Geochemical, Groundwater and Pollution. Editorial A.A.Balkema, Rotterdam.

Araujo, L.M., A.B.Franca, P.E.Potter, (1999). Hydrogeology of the Mercosul aquifer system in the Parana and Chalco-Parana Basins, South America, and comparison with the Navajo-Nugget aquifer system, USA. Hydrogeol. J., 7, 317-336.

Armienta, M:A., (1992). Contribución al estudio de los mecanismos de transporte del cromo en el acuífero de Leon, Gto. Tesis Doctoral, IGF/UNAM, México, D.F.

Armienta, M.A., V.Zamora, F.Juárez, (1996). Manual para el análisis químico de aguas naturales, en el campo y en laboratorio. Comunicaciones Técnicas. Serie de docencia y divulgación No 4, Instituto de Geofísica, UNAM, México, D.F.

Asikainen, M. and H.Kahlos, (1980). Natural radioactivity of drinking water in Finland. Health Phys., 39, 7783.

ASTM, American Society for Testing and Materials, (1991). Manual de Aguas para Usos Industriales. Editorial Noriega-Limusa, México, D.F. 
Asubiojo, O.I., N.A.Nkono, A.O.Ogunsua, A.O.Oluwole, N.I.Ward, O.A.Akanle, N.M.Spyrou, (1997). Trace elements in drinking and groundwater samples in Southern Nigeria. Sci. Total Environ., 208, 1-8.

Azimi-Garakani, D., (1989). Spark counting for alpha particle registration. Workshop on Radon Monitoring in Radioprotection Environmental Radioactivity and Earth Sciences, Trieste, 1-7.

Azorín, J., (1990). Luminescence Dosimetry: Theory and Applications. Ediciones Técnico Científicas S.A. de C.V., México, D.F.

Azorín, J., (1997). Introducción a la Física Nuclear. Ediciones Científicas, AZUEG, México, D.F.

Azorín, J., C.Furetta, A.Scacco, (1993). Preparation and properties of termoluminiscent materials. Phys. Stat. Sol., 138, 9-46.

Azorín, J. and A.Gutierrez, (1989). Preparation and performance of a CaSO4: Dy, Tm TL phosphor for longterm gamma measurements. Health Phys., 56, 551-559.

Azorín, J. and C.Furetta, (1989). Some observations on the annealing of $\mathrm{CaSO}_{4}$ :Dy + PTFE dosimeters produced at ININ. Nucl. Sci. J., 26, 512-516.

Banks, D., C.Reiman, O.Royset, H.S.Karhagen, O.H.Salther, (1995). Natural concentrations of major and trace elements in some Norwegian bedrock groundwater. Appl. Geochem., 10, 1-16.

Beaubien, S.E. and S.Lombardi, (2001). Laboratory experiments into dubble/microbubble generation and migration. Proc. $5^{\text {th }}$ Int.Conf.Rare Gas Geochemistry, (I.Hunyadi, I.Csige, J.Hakl, edit.), Debrecen, 257266.

Bella, F. and E.Pettinelli, (1997). Radon monitoring aimed to study seismic precursors. In: Rare Gas Geochemistry, Applications in Earth and Environmental Science, (H.S.Virk, edit), Guru Nanak Dev University, Amritsar, 275-294.

Bevis, M. and B.L.Isacks, (1984). Hypocentral trend surface analysis: Probing the geometry of the Benioff zones. J.Geophys. Res., 89, 6153-6170.

Biagi, P.F., F.Bella, E.Cozzi, A.Ermini, G.Martinelli, Y.M.Khatkevich, E.I.Gordeev, D.Zilpimiani, (1999). Groundwater helium content related to the Spitak (Armenia) and Karymski (Russia) earthquakes. II Nuovo Cimento, 22C, 399-405.

Bird, R.B., W.E.Stewart, E.N.Lightfoot, (1992). Fenómenos de Transporte. Editorial Reverte, S.A., México, D.F.

Bonotto, M.D. and J.N.Andrews, (1997). The implications of laboratory ${ }^{222 R n}$ flux measurements to the radioactivity in groundwater: the case of karstic limestone aquifer. Appl. Geochem., 12, 715-726.

Bry, X., (1995). Analyses Factorielles Simples. Editorial Economica, Paris.

Burbach, G., F.C.Penninton, T.Matumoto, (1984). Seismicity and tectonics of the subducted Cocos plate. J. Geophys. Res., 89, 7719-7735.

Buzek, F. and M.Michalicet, (1997). Origin of formation waters of S-E parts of the Bohemia Massif and the Vienna Basin. Appl. Geochem., 12, 333-343.

Campa, U.M.F, (1978). La evolución tectónica de Tierra Caliente, Gro. Soc. Mex. Geol. Tomo XXXIX, 6264.

Campa, U.M.F. and P.J.Coney, (1983). Tectono-stratigraphic terrane and mineral resource distributions in Mexico. Can. J. Earth Sci., 20, 1040-1051.

Cardona, B.A., R.J.Carrillo, M.A.Armienta, (1993). Elementos traza: contaminación y valores de fondo en aguas subterráneas de San Luis Potosí, SLP, México. Geof. Int., 32, 227-286.

Carrillo, R.J., (2000). Application of the groundwater-balance equation to indicate interbasin and vertical flow in two semi-arid drainage basins, Mexico. Hydrogeol. J., 8, 503-520. 
Castany, G., (1971). Tratado Práctico de las Aguas Subterráneas. Editorial Omega, Barcelona.

Castany, G., (1975). Prospección y Explotación de las Aguas Subterráneas. Editorial Omega, Barcelona.

Castro, E.R.R., (1994). Estudios de atenuación sísmica en la zona de subducción de México. En: La Sismología en México: 10 Años Después del Temblor de Michoacán del 19 de Septiembre de 1985 (M=8.1), Monografía 2, UGM, 157-164, México, D.F.

Castro-Morales, D.A. and J.J.LaBrecque, (1999). Determination of radon-222 in a natural thermal water spring shortly before and after the July 9,1997 , earthquake (Ms=6.8) in the state of Sucre Venezuela. J.Radioanal. Nucl. Chem., 242, 115-118.

Centeno-Garcia, E., J.Ruiz, J.P.Coney, J.P.Patchett, F.Ortega-Gutierrez, (1993). Guerrero terrene of Mexico: Its role in the southern cordillera from new geochemical data. Geology, 21, 419-422.

CFE, (1971). Final Safety Analysis Report, Laguna Verde Nuclear Power Station. Cap. 2, Sec. 2.5, Geology, Seismology and Geotechnical Engineering, México, D.F.

CFE, (1983). Evaluación geohidrológica preliminar para la localización del sitio de la termoeléctrica Lázaro Cárdenas. Informe EGH-17-01, México, D.F.

Cosma, C. and D.Ristoiu, (1999). Study of rare gases in geothermal waters from Herculane area, Romania. II Nuovo Cimento, 22C, 3317-323.

Cothern, C. P., (1987). Propeties. In: Environmental Radon, (Cothern C. P. and J.E.Smith, edit), Plenum Press., New York, 1-29.

Cross, W.G. and L.Tommasino, (1970). Rapid reading technique for nuclear particle damage tracks in thin films. Radiat. Eff. 5, 85.

Csige, I.; J.Haki, I.Lakaton, (1995). Measurements of effective diffusive coefficient of radon in porous media with etched track radon monitors. Radiat. Meas., 25, 659-660.

Custodio, E. y M.Llamas, (1983). Hidrología Subterránea, Tomo I y II, Editorial Omega, Barcelona.

Chadha, D.K., (1998). A proposed new diagram for geochemical classification of natural waters and interpretation of chemical data. Hidrogeol. J., 7, 431-439.

Chavez, A., M.Monnin, N.Segovia, J.L.Seidel, P.Peña, A.Moreno, M.Balcazar, (1997). Automatic SSNTD exchanger for soil radon determinations. Radiat. Meas., 27, 587-591.

Chen, R and McKeever, W.S.S., (1997). Theory of Thermoluminescence and Related Phenomena. World Scientific, Singapore.

Danali-Cotsaki, S. and G.Margomenou-Leonidopoulou, (1993). ${ }^{222 R n}$ in Greek spa waters. Correlation with rainfall and seimic activities. Health Phys., 64, 605-612.

Davis, C.J., (1986). Statistics and Data Analysis in Geology. John Wiley and Sons, Inc., New York.

Davis, S.M. and R.DeWiest, (1971). Hidrogeología, Edit. Ariel, Barcelona.

De Cserna, Z., (1965). Reconocimiento geológico en la Sierra Madre del Sur de México, entre Chilpancingo y Acapulco, Edo. de Guerrero. IG/UNAM, Boletín 62, México, D.F.

De la Cruz-Reyna, S., (1994). Los procesos volcánicos. En: Ciencias de la Tierra Hoy (S. De la CruzReina, compilador), FCE, México, D.F., 72-93.

De la Cruz-Reyna, S., M.Mena, N.Segovia, J.F.Chalot, J.L.Seidel, M.Monnin, (1985). Radon emanometry in soil gases and activity in ashes from El Chichon Volcano. PAGEOPH, 123, 407-421.

De la Fuente, G.J. y S.P.Verma, (1993). Catálogo de aparatos volcánicos de la parte centro-occidental del CVM. Geof. Int., 32, 351-386.

De Mets, C. and S.Stein, (1990). Present-day kinematics of the Rivera Plate and implications for tectonics in southwestern Mexico. J. Geophys. Res., 95, 931-948. 
De Mets, C., .R.G.Gordon, D.F.Argus, S.Stein, (1990). Current plate motions. Geophys. Res. J. Int., 101, 425-478.

Dean, B.W. and C.L.Drake, (1978). Focal mechanism solution and tectonics of the Middle America arc. J.Geol., 86, 111-121.

Delgado-Argote, L.A., R.Rubinovichcogan, A.García-Duran, (1986). Descripción preliminar de la geología y mecánica de emplazamiento del complejo ultrabásico del Cretácico de Loma Baya, Gro., México. Geof. Int., 25, 537-558.

Deutsch, W.J., (1997). Groundwater Geochemistry. Fundamental and Applications to Contamination. Lewis Publishers, New York.

Dewey, F.J., (1982). La Tectónica de Placas. En: El Redescubrimiento de la Tierra. CONACYT, 165-182, México, D.F.

Di Bernardo, L., (1993). Métodos y Técnicas de Tratamiento de Agua. Associación Brasileira de Engenharia Sanitaria e Ambiental, I, Rió de Janeiro.

Djeffal, S., M.Allad, M.T.Chalal, K.Morsli, (1995). Further investigations on radon emanation along seismic faults in northern Algeria. In: Gas Geochemistry, (C.Dubois, edit), Science Reviews, Northwood, 165-175.

Domenico, P.A. and F.W.Schwartz, (1998). Physical and Chemical Hydrogeology. John Wiley \& Sons, Inc., New York.

Drever, J.I., (1988). The Geochemistry of Natural Waters. Prentice Hall, New Jersey.

Duarah, R., S.Baruah, D.Yadav, M.V.D.Sitaram, (1997). Anomalies in radon emanation as earthquake precursor phenomena: Mikir plateau, NE Himalaya. In: Rare Gas Geochemistry, Applications in Earth and Environmental Science, (H.S.Virk, edit), Guru Nanak Dev University, Amritsar, 175-187.

Edmunds, W.M., J.J.Carrillo-Rivera, A.Cardona, (2002). Geochemical evolution of groundwater beneath Mexico City. J. Hydrol. 258, 1-24.

Eissler, H., L.Astiz, H.Kanamori, (1994). Ambiente tectónico y parámetros de fuente del terremoto del 19 de septiembre de 1985 de Michoacán, México. En: La Sismología en México: 10 Años Después del Temblor de Michoacán del 19 de Septiembre de 1985 (M=8.1), Monografía 2, UGM, 1-11, México, D.F.

Espíndola J.M., Z.Jiménez, (1995). Terremotos y Ondas Sísmicas. Cuadernos del Instituto de Geofísica 1, I Geof/UNAM.

Espinosa, G., (1994). Trazas Nucleares en Sólidos. IF/UNAM, México, D.F.

Etiope, G., (1998). Transport of radioactive and toxic matter by gas microbubbles in the ground. J. Environ. Radiact., 40, 11-13.

Etiope, G.and G.Martinelli, (2002). Migration of carrier and trace gases in the geosphere: an overview. Phys. Earth Plan. Int., 129, 185-204.

Etiope, G.and J.Hakl, (2001). The "geogas" theory. Proc. $5^{\text {th }}$ Int. Conf. Rare Gas Geochemistry, (I.Hunyadi, I.Csige, J,Hakl, edit), Debrecen, 7-19.

Fedeli, G., F.Frondini, F.Italiano, M.Lemmi, G.Martinelli, (2001). Radon behaviour in the selected spring of Triponzo during the 1997-1998 Umbria Marche seismic sequence. Proc. 5th Int. Conf. Rare Gas Geochemistry, (I.Hunyadi, I.Csige, J.Hakl, edit), Debrecen, 55-60.

Fletcher, G. D., (1995). Groundwater and Wells. Johnson Screens, St. Paul, 87-107.

Flores-Mendoza, J., J.L.Iturbe, R.Jimenez, (1992). Separation and elecrodepositation of ${ }^{226 R a, ~ J . ~ R a d i o n a l . ~}$ Nucl. Chem.,1,131-138.

Fong-liang, J. and L.Gui-ru, (1981). The application of geochemical methods in earthquake prediction in China. Geophys. Res. Lett., 8, 469-477. 
Freeze, R.A. and J,A.Cherry, (1979). Groundwater. Prentice Hall, New Jersey.

Fukui, M., (1987). Soil water effects on concentration profiles and variations of ${ }^{222} \mathrm{Rn}$ in a vadosa zone. Health Phys., 53, 181-186.

Gangopadhyay, S., A.D.Gupta, M.H.Nachabe, (2002). Evaluation of groundwater monitoring network by principal component analysis. Ground Water, 39, 181-191.

Garavaglia, M.C., C.Brartenberg, M.Zadro, F.Quattrocchi, (1999). Radon measurements in soil and water in the seismic Frioli area. II Nuovo Cimento, 22C, 415-422.

García, E., (1973). Modificaciones al sistema de clasificación climática de Koeppen. Instituto de Geografía. UNAM, México, D.F.

García, V.J.R., (1999). Transport du radon en milieu poreux (expérimentation et modélisation): implication pour la réalisation et l'interprétation de measures in situ. These Doctorat, Universite de Montpellier, France.

Garduño-Monroy, V.H. y C.A.Gutiérrez-Negrin, (1992). Magmatismo, hiatus y tectonismo de la Sierra Madre Occidental y del Cinturon Volcánico Mexicano. Geof. Int., 31, 417-429.

Gascoyne, M. and E.M.Durrance, (1993). Fracture detection and groundwater flow characterization using $\mathrm{He}$ and Rn in soil gases, Manitoba, Canada. Appl. Geochem., 8, 223-233.

George, C.A., (1996). State-of the-art instruments for measuring radon, thoron and their progeny in dwellings-A review. Health Phys., 70, 451-463.

Gibson, U.P., (1974). Manual de los Pozos Pequeños. Editorial Limusa, México, D.F.

Giggenbach, F.W. and R.Corrales, (1992). Isotope and chemical composition of water and steam discharges from volcanic-magmatic-hydrothermal systems of Guanacaste geothermal Province, Costa Rica. Appl. Geochem., 7, 309-322.

González, B.F. (1982). Introducción a la Geoquímica. Series Química Monografías, SG/OEA, Washington.

González, M.P.R., (1999). Fechamiento geológico y arqueológico por termoluminiscencia. Tesis doctoral, UAM-I, México, D.F.

Gosselin, D.C., F.E.Harvey, C.D.Frost, (2001). Geochemical evolution of ground water in the Great Plains (Dakota) aquifer of Nebraska: Implications for the management of a regional aquifer system. Ground Water, 39, 98-108.

Guerra, M. and E.Etiope, (1999). Effects of gas-water partitioning, stripping and channeling processes on radon and helium gas distribution in fault areas. Geochem. J., 33, 141-151.

Hair, F. J., R.E.Andeson, R.I.Tatham, W.C.Black, (1999): Análisis Multivariante. Prentice Hall Iberia, Madrid.

Hakl, J., I.Hunyyad, R.Varga, J.Csige, (1995). Determination of radon an radium content of water samples by SSNTD technique. Radiat. Meas., 25, 657-658.

Hamada, H., (2000). Estimation of groundwater flow rate using the decay of ${ }^{222 R n}$ in a well. J. Environ. Rad., 47, 1-13.

Havskov, J. and M.Macias, (1983). A coda-lenght magnitude scale for some Mexican stations. Geof. Int., 22, 205-214.

Heinicke, J. and U.Koch, (1995). $\mathrm{CO}_{2}$ and radon measurements in the Vogtland area (Germany) a contribution to earthquake prediction research. Geophys. Res. Lett., 22-7, 771-774.

Hem, J.D. (1992). Study and Interpretation of the Chemical Characteristics of Natural Water. U.S. Government Printing Office, Washington. 
Hess, C.T., (1985). The occurrence of radioactivity in public water supplies in the United States. Health Phys., 48, 553-586.

Hines, L.A. y R.N.Maddox, (1987). Transferencia de Masa: Fundamentos y Aplicaciones. Prentice Hall, México, D.F.

Horvath, A., L.O.Bohus, F.Urbani, G. Marx, A.Piroth, E.D.Greaves, (2000). Radon concentrations in hot spring waters in northern Venezuela. J. Environ. Rad., 47, 127-133.

Houston, H., y H.Kanamori, (1994). Características de la fuente del terremoto de 1985 de Michoacán, México, a periodos de 1 a 30 segundos. En: La Sismología en México: 10 Años Después del Temblor de Michoacán del 19 de Septiembre de 1985 (M=8.1), Monografía 2, UGM, 38-43, México, D.F.

lelsch, G., D.Thieblemont, V.Labed, P.Richon, G.Tymen, C.Ferry, M.C.Robe, J.C.Baubron, F.Bechennec. (2001). Radon $\left({ }^{222} \mathrm{Rn}\right)$ level variations on a regional scale: nfluence of the basement trace element $(U$, Th) geochemistry on radon exhalation rates. J. Environ. Radioact., 53, 75-90.

IG/UNAM, (1989), Carta Geológica del Estado de Veracruz, 1:50,000. México D.F.

Igarashi, G. and H.Wakita, (1990). Groundwater radon anomalies associated with earthquakes. Tectonophys., 180, 237-254.

Igarashi, G. and H.Wakita, (1995). Geochemical and hydrological observations for earthquake prediction in Japan. J. Phys. Earth., 43, 585-598.

Igarashi, G., S.Saeki, N.Takahata, K.Sumikawa, S.Tasaka, Y.Sasaki, M.Takahashi, Y.Sano, (1995). Ground water radon anomaly before the Kobe earthquake in Japan. Science, 269, 60-61.

Irwin, W.P. and I.Barnes, (1975). Effect of geologic structure and metamorphic fluids on behavior of the San Andreas fault system in central and northten California. Geology, 3, 713-716.

Iturbe, J.L., (2001). Fundamentos de Radioquímica. UAEM, Toluca.

Jain, C.K., (2002). A hydro-chemical study of a mountainous watershed: the Ganga, India. Wat. Res., 36, 1262-1274.

Johnson, E.E., (1966). El Agua Subterránea y los Pozos. Johnson, División, U. O.P.Inc, Saint Paul.

Johnson, E. D., (2000). Métodos Multivariantes Aplicados al Análisis de Datos. International Thomson Edit., México, D.F.

Jonsson, G., (1995). Radon gas -Where from and what to do. Radiat. Meas., 25, 537-546.

Jonsson, G., K.A.Kornfalt, I.Tell, (1999). Radon levels in different types of soil. Proc. $5^{\text {th }}$ Int. Conf. Rare Gas Geochemistry, (I.Hunyadi, I.Csige, J.Hakl, edit), Debrecen, 287-297.

Karpinska, M., S.Wolkowicz, Z.Mnich, M.Zalewski, K.Mamont-Ciesla, J.Kapala, (2002). Comparative studies of health hazard from radon $\left({ }^{222} \mathrm{Rn}\right)$ in two selected lithologic formations in the Suwalki region (in Poland). J. Environ. Radioact., 61, 149-158.

Kasztovszky, Z., L.Sajo-Bohus,B.Fazekas, (2000). Parametric changes of radon (222Rn) concentration in groundwater in northeastern Hungary. J. Environ. Radioact., 49, 171-180.

Kelleher, J., L.Sykes, J.Oliver, (1973). Possible criteria for prediction earthquake locations and their application to major plate boundaries of the Pacific and Caribbean, J. Geophys. Res., 78, 2547-2585.

Khan, H.A. and A.A.Qureshi, (1994). Solid state nuclear track detection: A useful geological/geophysical tool. Nucl. Geophys, 8, 1-37.

Kharatian, K., Y.Travi, V.Igoumnov (2002). Radon soil gas concentrations and local seismicity: case of the Arax basin (Armenia). Comp. Rend. Geosci., 334, 179-185.

King, C.Y., (1980). Episodic radon changes in subsurface soil gas along active faults and possible relation to earthquakes. J. Geophys. Res., 85, 3065-3078. 
King, C.Y., D.Basler, T.S.Presser, W.C.Evans, L.D.White, A.Minissale, (1994). In search of earthquake related hydrology and chemical changes along Hayward Fault. Appl. Geochem., 9, 83-91.

King, C.Y., N.Koizumi, T.Kitagawa, (1995). Hidrogeochemical anomalies and the 1995 Kobe earthquake. Science, 269, 38-39.

Kingsley, S.P., P.F.Biagi, R.Piccolo, V.Capozzi, A.Ermini, Y.M.Khatkevich, E.I.Gordeev, (2001). Hydrochemical precursors of strong earthquakes: a realistic possibility in Kamchatka. Phys. Chem- Earth (C), 10-12, 769-774.

Kitto, E.M., M.K.Kuhland, R.E.Dansereau, (1996). Direct comparison of three methods for the determination of radon in well water. Health Phys., 70, 358-362.

Kleis, T., W.Enge, H.Worth, (1992). Radon monitoring with plastic detectors in earthquake prediction. Nucl. Tracks Radiat. Meas., 20, 495-503.

Kohler, H. Shaaf, P., D.J.Moran-Zenteno, G.Solis-Pichardo, (1993). Age and origin of granitoids along the Pacific coast of Mexico. In: Proceedings of the First Circum-Pacific and Circum-Atlantic Terrane Conference, IG/UNAM, 74-75, México, D.F.

Kostoglodov, V. y J.F.Pacheco, (1999). Cien Años de Sismisidad en México. IGF-UNAM, México, D.F.

Kostoglodov, V., R.Bilham, J.A.Santiago, V.Manea, M.Manea, V.R.Hernandez, (2002). Long-baseline fluid tiltmeter for seismotectonic studies of Mexican subduction zone. Geof. Int., 41, 11-25.

LaBrecque, J.J., P.R.Codoves, P.A.Rosales, F.Audemard, G.Romero, (2001). Monitoring of radon anomalies in the Rio Caranay and thermal spring near the Pilar fault shortly after the July 9, 1997 earthquake $(M w=6.9)$ in the state of Sucre (Venezuela). J. Radioanal. Nucl. Chem. 250, 239-245.

Larsen, D., G.H.Swihart, Y.Xiao, (2001). Hydrochemistry and isotope composition of springs in the Tecopa basin, southeastern California, USA. Chem. Geol., 179, 17-35.

Lawson, A:C:, (1908). The California earthquake of April 18, 1906. Report of the State Earthquake Investigation Committee, Sacramento.

Lobo, R., (1997). Principios de Transferencia de Masa. UAM-I, México, D.F.

Lomnitz, C., (1994). Ondas sísmicas: Propagación y efectos. En: Ciencias de la Tierra Hoy (S. De la CruzReina, Compilador), FCE, 62-71, México, D.F.

Loria, L., J.Brenes, E.Fernández, R.Jimenez, R.García, M.Monnin, J.L.Seidel, N.Segovia, M.Balcazar, (1995). Radon and seismicity in Costa Rica. In: Gas Geochemistry, (C.Dubois, edit.), Science Reviews, Northwood, 213-219.

Low, R, (1996). Radon as a natural groundwater tracer in the chalk aquifer, UK. Environ. Int., 22, S333S338.

Maldonado, S.C., M.Monnin, N.Segovia, J.L.Seidel, (1996). A radon measuring network to study radon anomalies as precursors of strong earthquakes in the Guerrero seismic gap. IIWCEE, CD Rom, ISBN: 0.08428223, Eleventh World Conference on Earthquake Engineering. Pergamon. Paper No. 1772, 6p, Amsterdam.

Manahan, S. E., (1994). Environmental Chemistry. Lewis Publishers, Boca Raton.

Marini, L., M.Canepa, F.Cipolli, G.Ottonello, M.V.Zuccolini, (2001). Use of stream sediment chemistry to predict trace element chemistry of groundwater. A case study from the Bisagno valley (Genoa, Italy). J. Hydrol. 241, 194-220.

Martinelli, G., (1998). Gas geochemistry and 222Rn migration processes. Radiat. Prot. Dos. 78, 77-82.

Martínez, T., L.Cabrera, M.Navarrete, J.J.García, P.González, A.Ramírez, U.Martínez, (1995). Gamma radiation and radon levels in Mexico City dwellings. J. Radioanal. Nucl. Chem., Articles, 193, 259-268. 
Mason, B., (1960). Principios de Geoquímica. Editorial Omega, Barcelona.

Matsuda, T. and M.lkeya, (2001). Variation of nitric oxide concentration before the Kobe earthquake, Japan. Atm. Environ., 35, 3097-3102.

McNally, C. K., J.R.Gonzalez-Ruiz, C.Stolte, (1994). Sismogenesis del gran terremoto $(M=8.1)$ de Michoacán, México de 1985. En: La Sismología en México: 10 años Después del Temblor de Michoacán del 19 de Septiembre de 1985 (M=8.1), Monografía 2, UGM, 22-27, México, D.F.

Melchiorre, E.B.and R.E.Criss, (1999). Relationship between seismicity and subsurface fluids, Central Coast Range California. J. Geophys Res., 104, 921-939.

Melloul, J A. and M.Collin, (1992). The principal components statistical methods as a complementary approach to geochemical methods in water quality factor identification; application to the Coastal Plain aquifer of Israel . J. Hidrol., 140, 49-73.

Melloul, J A., (1995). Use of principal components analysis for studying deep aquifers with scarce dataapplication to the Nubia sandstone aquifer, Egypt and Israel. Hidrogeol. J., 3, 19-39.

Metcalf, and Eddy, (1994). Tratamiento y Depuración de Aguas Residuales. Editorial Labor. S. A., Barcelona.

Michaud, F., J.J.Dañobeitia, R.Carbonell, R.Bartolome, D.Cordoba, L.Delgado, F.Nuñez-Cornu, T.Monfret, (2000). New insights into the subducting oceanic crust in the Middle American Trench of western Mexico $\left(17-19^{\circ} \mathrm{N}\right)$. Tectonophys., 318, 187-200.

Michel, J., (1987). Sources. In: Environmental Radon, (Cothern, C.R. and Smith, J.R., edit). Plenum Press., New York.

Miles, J.C.H. and J.Sinnaeve, (1984). The performance of different types of etched-track radon dosimeter in two international intercomparisons. Nucl. Tracks Radiat. Meas., 2, 735-738.

Molnar, P. and R.L.Sykes, (1969). Tectonics of the Caribbean and Middle American region from local mechanisms and seismicity. Geol. Soc. Am. Bull., 8, 1639-1684.

Monnin, M. and J.L.Seidel, (1992). Radon in soil-air and in ground water related to major geophysical events: A survey. Nucl. Instrum. Meth. Phys. Res., A314, 316-330.

Monnin, M. and J.L.Seidel, (1998). An automatic radon probe for earth science studies. J. Appl. Geophys., 39, 209-220.

Moran-Zenteno, B.Martiny, G.Tolson, G.Solís-Pichardo, L.Alba-Aldave, M.S.Hernández-Bernal, C.MaciasRomo, R.G.Martínez-Serrano, P.Schaaf, G.Silva-Romo, (2000). Geocronología y características geoquímicas de las rocas magmáticas Terciarias de la Sierra Madre del Sur. Bol. Soc. Geol. Mex., LIII, 27-58.

Moran-Zenteno, D.J., (1992). Investigaciones isotópicas de Rb-Sr y Sm-Nd en rocas cristalinas de la región de Tierra Colorada-Acapulco-Cruz Grande, Edo. de Guerrero. Tesis Doctoral, IGF/UNAM, México, D.F.

Moran-Zenteno, D.J., (1993). Southern Mixteca and northern Xolapa terrane. In: Terrane Geology of Southern Mexico. Guidebook to the Field Trip B of the First Circum-Pacific and Circum-Atlantic Terrane Conference, Guanajuato, Mexico, IG/UNAM, 34-45, México, D.F.

Moran-Zenteno, D.J., P.Schaaf, H.Kohler, H.Bohnel, J.Urrutia-Fucugauchi, (1993a). Consideración sobre la petrogénesis de los intrusivos de la región de Acapulco basadas en datos isotópicos de $\mathrm{Sr}$, $\mathrm{Nd}$., Contribuciones a la Tectónica del Occidente de México. Monografías 1, UGM, IGF/UNAM, 305-326, México, D.F. 
Moran-Zenteno, D.J., G.Tolson, G.Solis-Pichardo, M.S.Hernandez-Bernal, J.Urrutia-Fucugauchi, (1993b). Origin and tectonic relation ships of the Xolapa terrane, southwestern Mexico. In: Proceedings of the First Circum-Pacific and Circum Atlantic Terrane Conference, IG/UNAM, 97-99, México, D.F.

Moran-Zenteno, D.J., P.Corona-Chavez, G.Tolson, (1996). Uplift and subduction erosion in southwestern Mexico since the Oligocene: Pluton geobarometry constraints. Earth Planet. Sci. Lett., 141, 51-65.

Morton, O., M.A.Armienta, E.Hernández, E.Lovnejera, (1996). Espectrómetro de masas de acoplamiento inductivo del Instituto de Geofísica (UNAM). Actas INGAGEQ, 2, 149-154.

Morton, O., E,Lounejeva, E.Hernanadez, J.L.Seidel, N.Segovia, (1998). Evaluación de la calidad de blancos: determinación de elementos traza en agua desionizada y/o destilada. Actas INAGEQ, 4, 107-112.

Muir-Wood, R. and King, G.C.P., (1993). Hydrologic signatures earthquake strain. J.Geophys. Res., 98, 22,035-22,068.

Mukherji, P., (1999). A brief description on radon monitoring in India in some seismically sensitive areas. II Nuevo Cimento, 22, 501-522.

Murck, W.B., B.J.Skinner, S.C.Porter, (1996). Environmental Geology. John Wiley and Sons, Inc., New York.

Nalco, (1994). Manual del Agua. Su Naturaleza y Tratamiento. Aplicaciones. Tomo I, Mc Graw Hill, México, D.F., 1-23.

Nava, P.A., (1994). Peligro y predicción sísmica. En: Ciencias de la Tierra Hoy, (S. De la Cruz-Reina, compilador), FCE, México, D.F., 41-61.

Navarrete, M. y L.Cabrera, (1993). Introducción al Estudio de los Radioisótopos. FQ/UNAM, México, D.F.

Negarestani, A., S.Setayeshi, M.Ghannadi-Maragheh, B.Akashe, (2002). Layered neural networks based analysis of radon concentration and environmental parameters in earthquake prediction. J. Environ. Radioact., 62, 225-233.

Negendank, J.F.W., R.Emmermann, N.Nun, B.Schulz-Dobrick, H.Tobschall, R.Krawczyk, (1987). The granitoid complexes of Acapulco, Xaltianguis and Ocotito (Sierra Madre del Sur, Mexico). Zbl. Geol. Palaont. Teil, I, 705-708.

Negendank, J.F.W., R.Emmermann, R.Krawczyk, F.Mooser, H.Tobschall, D.Werle, (1985). Geological and geochemical investigations on the eastern Trans Mexican Volcanic Belt. Geof. Int., 24, 437-475.

Nelson, R.A., (1987). Measurements of uncertainties of long-term ${ }^{222 R n}$ averages at environmental levels using alpha track detectors. Health Phys., 53, 447-453.

Nishenko, S.P. y S.K.Singh, (1987). Conditional probabilities for the recurrence of large and great interplate earthquakes along the Mexican subduction zone. Bull. Seism. Soc. Am., 77, 2095-2114.

Nishizawa, S., G.Igarashi, Y.Sano, (1998). Radon, $\mathrm{Cl}^{-}$and $\mathrm{SO}_{4}{ }^{2-}$ anomalies in hot spring water associated with the 1995 earthquake swarm of the east coast of the Izu Peninsula, central Japan. Appl. Geochem., 13, 89-94.

Nixon, G.T.A., (1982). The relationship between Quaternary volcanism in central Mexico and the seismicity and structure of the suboceanic lithosphere. Geol. Soc. Am. Bull., 93, 514-532.

Nixon, G.T.A., R.C. Demant, J.E.Harakal, (1987). K-Ar and geological data bearing on the age and evolution of the Tras Mexican Volcanic Belt. Geof. Int., 26, 109-158.

Noguchi, M. and H.Wakita, (1997). A method for continuous measurement of radon in groundwater for earthquake prediction. J. Geophy. Res., 82, 1353-1357. 
NOM-127-SSA1-(1994). Salud Ambiental Agua para Uso y Consumo Humano. Límites Permisibles de Calidad y Tratamiento a que debe Someterse el Agua para su Potabilización. Diario Oficial de la Federación. México, 15 de agosto de 1994.

NOM-AA-72-(1981). Determinación de Dureza en Agua. Diario Oficial de la Federación. México, 9 de febrero de 1981.

NOM-AA-73-(1981). Determinación de Cloruros en Agua. Diario Oficial de la Federación. México, 11de noviembre de 1981.

NOM-AA-74-(1981). Determinación de Ion Sulfato en Agua. Diario Oficial de la Federación. México, 12 de diciembre de 1981.

NOM-AA-79-(1986). Determinación de Nitrógeno de Nitritos en Agua. Diario Oficial de la Federación. México, 14 de abril de 1986.

NOM-AA-3-(1986). Aguas Residuales "Muestreo" Diario Oficial de la Federación. México, 11 de febrero, 1-5.

Noureddine, A., A.Baggoura, J.J.Larosa, N.Vajda, (1997). Gamma and alpha emitting radionuclides in some Algerian soil samples. Appl. Radiat. Isot., 48, 1145-1148.

Nuñez, E.J., T.U.Salgado, G.Z.Segura, (1981). Reconocimiento geológico del área cromifera de PapanoaPetatlan, Gro. Geomimet, 114, 46-64.

Núñez-Cornu, F.J., (1994). La estructura de la corteza terrestre: Aplicación de métodos sísmicos. En Ciencias de la Tierra Hoy (S. De la Cruz-Reina, compilador), FCE, 22-40, México, D.F.

OIEA, (1984). La Energía Nucleoeléctrica, el Medio Ambiente y el Hombre. OIEA/OMS. Viena.

OIEA, (1996). International Basic Safety Standards for Protection Against lonizing Radiation and for Safety of Radiation Sources. Safety Series 115, OIEA, Austria.

Olguin, M.T., N.Segovia, E.Tamez, M.Alcantara, S.Bulbulian, (1993). Radon concentration levels in groundwater from the City of Toluca, Mexico. Sci. Total Environ., 130-131, 43-40.

Palmer, C.M., (1996). Contaminant Hidrogeology. Lewis Publishers, Boca Raton.

Pane, M.B, (1995). Utilisation des elements en trace comme traceurs des circulations subterraines en Milieu karstique. These Doctorat, Universite de Montpellier, France.

Pane, M.B., J.L.Seidel, M.Monnin, L.P.Morin, (1995). Radon as a tracer of fluid motion in fractured aquifers. In: Gas Geochemistry, (C.Dubois, edit), Science Reviews, Northwood, 325-334.

Papastefanou, C. (2003). An overview of instrumentation for measuring radon in soil gas and groundwater. J. Environ. Rad., In press.

Papastefanou, C., M.Manolopoulou, S.Stoulos, A.Loannidou, E.Gerassopoulos, (1999). Radon measurements in association with earthquakes. II Nuovo Cimento, 22 C, 393-398.

Papastefanou, C., S.Stoulos, M.Manolopoulow, A.Loannidou, (1997). Radon detectors for earthquake prediction studies. In: Rare Gas Geochemistry, Applications in Earth and Environmental Science, (H.S.Virk, edit), Guru Nanak Dev University, Amritsar, 189-193.

Papastefanou, C., (2003). An overview of instrumentation for measuring radon in soil gas and groundwater. J. Environ Radiat. (in press).

Pardo, M.y G. Suarez, (1994). Sismotectónica del sur de México: Subducción de las placas de Ribera y Cocos bajo la placa Norteamericana. En: La Sismología en México: 10 años Después del Temblor de Michoacán del 19 de Septiembre de 1985 (M=8.1), Monografía 2, UGM, 165-180. México D.F.

Pelig-Ba, K.B. (1996). Trace elements in groundwater from some crystalline rocks in the upper regions of Ghana. Wat. Air, Soil Poll., 103, 71-89. 
Peña, P. E.Tamez, S.Ceballos, B.Chavez, C.Martínez, N.Segovia, (1992). Emanometría del radón en suelo, agua y atmósfera. IV Congreso Técnico-Científico ININ-SUTIN, 144-148, Salazar.

Peña, P., E.Tamez, J.I.Iturbe, P.Aranda, A.Hernanadez, J.L.Seidel, N.Segovia, (1998a). Radón y elementos traza en manantiales y suelo del volcán Popocatépetl. IX Seminario IIE-IMP-ININ, Sobre Especialidades Tecnológicas. 101-105, Salazar.

Peña, P., N.Segovia, J.Azorin, P.Gonzalez, T.Rivera, (1998b). Niveles de radón y de radiación gamma en suelo en la Costa de Guerrero. I Conferencia Internacional, XI Congreso Nacional sobre Dosimetría de Estado Sólido, 157-162, México, D.F.

Peña, P., J. De la Torre, T.Falcón, J.Azorin, N.Segovia, (1999). Caracterización de muestras de rocas localizadas en algunos sitios de la Costa del Pacífico Mexicano. Memorias de la II Conferencia Internacional, XII Congreso Nacional sobre Dosimetría de Estado Sólido, 39-45, Puebla.

Peña, P., N.Segovia, J.Azorin, M.Mena, (2001). Soil radon and gamma dose rate a coastal region in Mexico. J. Radioanal. Nucl. Chem., 247, 39-43.

Pla, E.L., (1986). Análisis Multivariado: Método de Componente Principal. OEA/PRDCT, Washington.

Planinic, J., V.Radolic, Z.Lazanin, (2001). Temporal variations of radon in soil related to earthquakes. Appl. Radiat. Isot., 55, 267-272.

Poole, C.J., G.W.McNeill, S.L.Langman, F.Dennis, (1997). Analysis of noble gases in water using a quadrupole mass spectrometer in static mode. Appl. Geochem., 12, 707-714.

Porstendorfer, J., (1993). Properties and Behavior of Radon and Thoron and their Decay Products in the Air. Fifth International Symposium on the Natural Radiation Environment, Session Tutorial, Radiation Protection, Commission of the European Communities EUR 1441-EN, 69-150.

Porstendorfer, J., G.Butterweck, A.Reineking, (1994). Daily variation of the radon concentration indoors and outdoors and the influence of meteorological parameters. Health Phys., 67, 283-287.

Pressyanov, D.S., M.G.Guelev, D.Klein, P.P.Kritidis, (1996). Measurements of ${ }^{222} \mathrm{Rn}$ in soil gas by combination of thermoluminescent and solid-state nuclear track detectors. Environ. Int., 22, S491-S493.

Priestley, F.K. y T.G.Masters, (1994). Mecanismos de la fuente del terremoto de Michoacán del 19 de septiembre de 1985 y sus implicaciones. En: La Sismología en México: 10 Años Después del Temblor de Michoacán del 19 de Septiembre de 1985 (M=8.1), Monografía 2, UGM, 44-48, México, D.F.

Pulido, C.J.L., (1978). Hidrogeología Práctica. Editorial Urmo, Bilbao.

Reghunath, R., T.R.S.Murthy, B.R.Raghavan, (2002). The utility of multivariate statistical techniques in hydrogeochemical studies: an example from Karnataka, India. Wat. Res., 36, 2437-2442.

Rodier, J., (1990). Análisis de las Aguas. Editorial Omega, Barcelona.

Romero, R.J.A., (1999). Calidad del Agua. Editorial Alfaomega, México, D.F.

Sabina, J.F., (1994). Dispersión y alineación sísmica. En: La Sismología en México: 10 años Después del Temblor de Michoacán del 19 de Septiembre de 1985 (M=8.1), Monografía 2, UGM, 68-75, , México, D.F.

Saito, K., N.Petoussi-Henss, M.Zankl, (1998). Calculation of the effective dose and its variation from environmental gamma ray sources. Health Phys., 74, 698-706.

Salazar, S., M.Martinez, C.A.Dorantes, N.Segovia, (1993). A study of environmental gamma radiation at the Laguna Verde Nuclear Facility, Mexico. Radiat. Prot. Dosim., 48, 285-289.

Salbu,B. and E.Steinnes, (1995). Trace Elements in Natural Waters. CRC Press Inc., Boca Raton. 
Salinas-Prieto, J.C., O.Monod, M.Faure, (1993). Deformación dúctil progresivo en el limite oriental del terreno Guerrero, suroeste de Mexico. In: Proceedings of the First Circum-Pacific and Circum-Atlantic Terrane Conference, IG/UNAM, 130-132, , México, D.F.

Sawyer, N.C., C.P.McCarty, F.G.Parkin, (2001). Química para Ingeniería Ambiental. Mc Graw Hill, Bogotá.

Schaaf, P., D.J.Moran-Zenteno, M.S.Hernandez-Bernal, A.Solis-Pichardo, G.Tolson, H.Kohler, (1995). Paleogene continental margin truncation in southwestern Mexico: Geochonological evidence. Tectonics, 14, 1339-1350.

Schumann, R.R. and C.S.L.Gundersen, (1996). Geological and climatic controls on the radon emanation coefficient. Environ. Int., 22, S439-S446.

SEDUE, (1987). Ordenamiento ecológico y proyecto de decreto de las zonas de exclusión e influencia media y baja de la Planta Nucleoeléctrica de Laguna Verde, Anexo I. México, D.F.

Segovia, N., (1994). Métodos nucleares: Aplicación a las ciencias de la Tierra. En: Ciencias de la Tierra Hoy, (S. De la Cruz-Reyna, compilador), FCE, México, D.F., 140-161.

Segovia, N. and S.Bulbulian, (1992). Radon determination in groundwater. Rev. Mex. Fís., 38, 242-248.

Segovia, N. and J.Cejudo, (1982). Study of the behavior of track detectors in gamma dose fields and high temperature conditions. in: Solid State Nuclear Track Detectors. P. H. Fowler and V. M. Claphan, Eds. Pergamon Press, 425-428, Oxfoerd.

Segovia, N. and M.Mena, (1997). Soil radon and geophysical network along the seismic area on the Pacific coast of Mexico. In: Rare Gas Geochemistry, Applications in Earth and Environmental Science. (H.S.Virk, edit), Guru Nanak Dev University, Amritsar, 167-174.

Segovia, N., S.De la Cruz-Reyna, M.Mena, E.Ramos, M.Monnin, J.LSeidel, (1989a). Radon in soil anomaly observed at Los Azufres geothermal field, Michoacán. A possible precursor of the (Ms=8.1) Mexico earthquake. Natural Haz., 1, 319-329.

Segovia, N., M.I.Gaso, A.Tejera, E.Tamez, (1989b). Environmental radioactivity survey in site studies. J. Radioanal. Nucl. Chem., 132, 339-348.

Segovia, N., E.Tamez, J.P.Morin, M.Monnin, J.L.Seidel, (1993). Recommendations for the setting up a radon in soil network based upon a decennial study. Nucl. Tracks Radiat. Meas., 22, 441-444.

Segovia, N., E.Tamez, P.Peña, M.I.Gaso, F.Mireles, I.Davila, L.Quirino, (1994). Atmospheric radon: Origin and transfer. Radiat. Prot. Dosim., 56, 157-160).

Segovia, N., M.Mena, J.L.Seidel, M.Monnin, E.Tamez, P.Peña, (1995a). Short and long term radon in soil monitoring for geophysical purposes. Radiat. Meas., 25, 547-552.

Segovia, N,. M.Mena, E.Tamez, P.Peña, S.Salazar, M.Monnin, J.L.Seidel, (1995b). Radon mapping in hazardous zones in Mexico. In: Gas Geochemistry (C.Dubois, edit.), Scientific Reviews, Northwood, 203211.

Segovia, N., E.Tamez, F.Abascal, P.Peña, S.Salazar, R.Mendoza, C.Alvarez, M.Mena, F.Juárez, (1996). Radon in soil and ground water survey around the Laguna Verde nucleoelectric facility Mexico. Environ. Int., 22, S275-S278.

Segovia, N., E.Tamez, P.Peña, S.Salazar, M.Mena, J.L.Seidel, M.Monnin, (1997a). Fluctuations of groundwater radon and chemical species in basaltic aquifers. Radiat. Meas., 28, 741-744.

Segovia, N., M.Mena, M.Monnin, P.Peña, J.L.Seidel, E.Tamez, (1997b). Radon in soil variations related to volcanic activity. Radiat. Meas., 28, 741-750. 
Segovia, N., E.Tamez, P.Peña, J.Carrillo, E.Acosta, M.A.Armienta, J.L.Iturbe, (1999a). Groundwater flow system in the Valley of Toluca: An assay of natural radionuclides specific activities. Appl. Radiat. Isot., 50, 589-598.

Segovia, N., E.Tamez, J.L.Iturbe, P.Peña, E.Tamez, A.Hernandez, P.Aranda, R.López-Castañares, (1999b). Radon and Radium Determination in Groundwater from a Volcanic Zone in Central Mexico. In: Environmental Radiochemical Analysis, (G.W.A. Newton, edit.), The Royal Society of Chemistry, Cambridge.

Segovia, N., M.Mena, P.Peña, E.Tamez, J.L.Seidel, M.Monnin, C.Valdés, (1999c). Soil radon time series: surveys in seismic and volcanic areas. Radiat. Meas., 31, 307-312.

Semat, H.and J.R.Albright, (1972). Introduction to Atomic and Nuclear Physics. Holt, Rinehart and Winston Inc., New York.

Sesana, L., S.Raineri, R.Valsecchi, V.Facchini, (1999). Study on Rn-222 concentration in the soil. II Nuovo Cimento, 22 C, 457-462.

Shenber, M.A., (1997). Measurement of natural radioactivity levels in soil in Tripoli. Appl. Radiat. Isot., 48, 147-148.

Shwerkani, R., Graddui, T.G., Durrani,S.A., (1995). The effect of soil parameters on the radon concentration values in the environment. Radiat Meas., 25, 581-588.

Sierra, B.R., (1994). Análisis Multivariables, Teoría y Ejercicios. Editorial Paraninfo, Madrid.

Silver, G.P. and H.Wakita, (1996). A search for earthquake precursors. Science, 273, 77-78.

Singh, B. and S.H.Virk, (1994). Investigation of radon-222 in soil-gas as an earthquake precursor. Nucl. Geophys., 8, 185-193.

Singh, B. and S.H.Virk, (1996). Effect of soil and sand moisture content on radon diffusion using plastic track etched detector. Radiat. Meas., 26, 49-50.

Singh, M., N.P.Singh, S.Singh, H.S.Virk, (1984). Radon - thoron estimation in soil using LR 115 plastic track detector. Nucl. Tracks Radiat. Meas., 8, 415-418.

Singh, S.K. and F.Mortera, (1991). Source time functions of large Mexican subduction earthquakes, morphology of the Benioff zone, age of the plate, and their tectonic implications. J. Geophys. Res., 96, 21487-21502.

Singh, S.K. y M.Ordaz, (1994). La Medida de los Temblores. En: Ciencias de la Tierra Hoy, (S. De la CruzReina, compilador), FCE, 9-21, México, D.F.

Singh, S.K., J.G.Anderson, M.Rodríguez, (1998). Triggered seismicity in the Valley of Mexico from major Mexican earthquakes. Geof. Int., 37, 3-15.

Singh, S.K., L.Astiz,J.Havskov, (1981). Seismic gaps and recurrence periods of large earthquakes along the Mexican subduction zone: A reexamination. Bull. Seism. Soc. Am., 71, 827-843.

Solecki, A.T., (1999). Monitoring of Rn in waters of various aquifers by means of Kodak LR-115. Proc. $5^{\text {th }}$ Int. Conf. Rare Gas Geochemistry, (I.Hunyadi, I.Csige, J.Hakl, edit.), Debrecen, 316-319.

Somogyi, G., (1990). Methods for measuring radium isotopes. Track detection. In: The Environmental Behavior of Radon. Vol. I. Technical Reports Series 310, IAEA, Vienna, 229-256.

Somogyi, G., B.Papipas, Z.S.Varga, (1984). Measurement of radon, radon daughters and thoron concentration by multi-detector device. Nucl. Tracks Radiat. Meas., 8, 423-427.

SPP/DGGTENAL, (1981), Atlas del Medio Físico, Escala 1:1000000, México, D.F.

Sroor, A., S.M.El-Bahi, F.Ahmed, A.S.Abdel-Haleem, (2001). Natural radioactivity and radon exhalation rate of soil in southern Egypt. Appl. Radiat. Isot., 55, 873-879. 
Steinich, B., O.Escolero, L.E.Morin, (1998). Salt-water intrusion and nitrate concentration in the Valley of Hermosillo and El Sahuaral coastal aquifer, Sonora, Mexico. Hidrogeol. J., 6, 518-526.

Stoiber, R.E. and M.J.Carr, (1973). Quaternary volcanic and tectonic segmentation of Central America. Bull Volcanol., 37, 304-325.

Stumm, W. and J.J.Morgan, (1981). Aquatic Chemistry: An Introduction Emphasizing Chemical Equilibria in Natural Waters. John Wiley and Sons. Inc., New York.

Suarez, G., T.Monfret, G.Wittlinger, C.David, (1990). Geometry of subduction and depth of the seismogenic zone in the Guerrero gap, Mexico. Nature, 345, 336-338.

Sugisaki, R., I.Ito, I. Nagamine, (1996). Gas geochemical change at mineral springs associated with the 1995 southern Hyogo earthquake M = 7.2, Japan. Earth Sci. Lett., 139, 239-249.

Takahata, N., Igarashi, I., Sano, Y., (1997). Continuous monitoring of dissolved gas concentrations in groundwater using a quadrupole mass spectrometer. Appl. Geochem., 12, 377-382.

Tamimi, H.H. and F.M.Abumurad, (2001). Radon anomalies along fault in North of Jordan. Radiat. Meas., 34, 397-400.

Tanner, A.B. and C.R.Olsen, (1992). Technical highlights of the availability and entry projects of the US Department of Energy's radon research program. Radiat. Prot. Dosim., 45, 367-372.

Tarbuck, J.E. and F.E. Lutgens, (1999). Ciencias de la Tierra. Una Introducción a la Geología Física. Prentice Hall, Madrid.

Tejeda, M.A., F.A.Acevedo, E.Jauregui, (1989). Atlas Climático del Estado de Veracruz. Universidad Veracruzana, Textos Universitarios, Xalapa.

Teng, T.L., and L.F.Sun, (1986). Research on groundwater radon as a fluid phase precursor to earthquake. J. Geophys. Res., 91, 12305-12313.

Thomas, J.H., A.H.Welch, M.S.Lico, J.L.Hughes, R.Whitney, (1993). Radionuclides in groundwater of the Carson River Basin, western Nevada and eastern California, USA. Appl. Geochem., 8, 447-471.

Tidjani, A., M.Monnin, J.L.Seidel, (1990). Enhancement of radon signals in geophysical studies with the track technique. PAGEOPH., 132, 495-504

Tommasino, L., (1990). Radon monitoring by alpha track detection. In: Radioprotection, Environmental Radioactivity and Earth Sciences, World Scientific,, Singapore, 123-132.

Toutain, J.P. and J.C.Baubron, (1999). Gas geochemistry and seismotectonics: a review. Tectonophys., $304,1-27$.

Toutain, J.P., M.Muñoz, F.Portrasson, A.C.Lienard, (1997). Spring water chloride ion anomaly prior to a $\mathrm{M}=$ 5.2 Prynenean earthquake. Earth Planet. Sci. Lett., 149, 113-119.

Tsunogai, U. and H.Wakita, (1995). Precursory chemical changes in ground water: Kobe earthquake, Japan, Science, 269, 61-63.

Tsvetkova, T., M.Monnin, I.Nevinsky, V.Perelygin, (2001). Research on variation of radon and gamma background as a prediction of earthquakes in the Caucasus. Radiat. Meas., 33, 1-5.

Turk, M., B.Volaric, B.Antolkovic, (1996). Radon activity concentration in the ground and its correlation with the water content of the soil. Appl. Radiat. Isot., 47, 377-381.

Udias, V.A., (1971). Introducción a la Sismología y Estructura Interna de la Tierra. Universidad Complutense, Madrid.

Ulomov, U.I. and B.Z.Mavashev, (1967). A precursor of strong tectonic earthquakes. Dokl. Acad. Sci. USSR, Earth Sci. Sect., 176, 9-11. 
Ulomov, U.I. and B.Z.Mavashev, (1971). Precursori dei terremoto di Tashkent. Dokl. Acad. Sci. USSR, 188 200.

Valdéz, C. y Novelo, D.A., (1997). The western Guerrero, Mexico, sismogenic zone from the microseismicity associated to the 1979 Petatlan and 1985 Zihuatanejo earthquakes. Tectonophys., 187, 271-277.

Varhegyi, A, J.Hakl, M.Monnin, J.P.Morin, J.L.Seidel, (1992). Experimental study of radon transport in water as test for a transportation model. J. Appl. Geophys., 29, 37-46.

Vasarhelyl, A., I.Csige, J.Hark, I.Hunyady, (1997). Spatial distribution of radon content of soil-gas and wellwaters measured with etched track radon monitors. Radiat. Meas., 28, 685-690.

Viers, J., B.Dupre, J.J.Braun, S.Deberdt, B.Angeletti, J.N.Ngoupayou, A.Michard, (2000). Major and trace element abundances, and strontium isotopes in the Nyong basin rivers (Cameroon):constraints on chemical weathering processes and element transport mechanisms in humid tropical environments. Chem. Geol., 169, 211-241.

Virk, H.S. and A.K. Sharma, (1997). Microseismicity trends in N-W Himalaya using radon signals. In: Rare Gas Geochemistry, Applications in Earth and Environmental Science. (H.S.Virk, edit.), Guru Nanak Dev University, Amritsar, 117-135.

Virk, H.S. and B.Singh, (1993). Radon anomalies in soil-gas and groundwater as earthquake precursor phenomena. Tectonophys., 227, 215-224.

Virk, H.S. and B.Singh, (1994). Radon recording of Uttarkashi eathquake. Geophys. Res. Lett., 21, 737-740.

Virk, H.S. and B.Singh, (1995). Radon recording of the Uttarkashi earthquake. In: Gas Geochemistry, (C.Dubois, edit.), Science Reviews, Northwood, 221-229.

Virk, H.S., (1999). Radon/helium studies for earthquake prediction N-W Himalaya. II Nuovo Cimento, 22C, 423-429.

Virk, H.S. and V.Walia, (2001). Helium/radon precursory signals of Chamoli earthquake, India. Radiat. Meas., 34, 379-384.

Virk, H.S., M.Singh, R.C.Ramola, (1997). Radon monitoring for uranium exploration, earthquake prediction and environmental health hazard in Himachal Pradesh, India: An appraisal. In: Rare Gas Geochemistry, Applications in Earth and Environmental Science, (H.S.Virk, edit.), Guru Nanak Dev University, Amritsar, 89-99.

Virk, H.S., V.Walia, A.Kumar Sharma, N.Kumar, R.Kumar, (1999). Radon anomalies on their correlation with microseismic events in Kangra and Chamba valleys of N-W Himalaya. Proc. $5^{\text {th }}$ Int. Conf. Rare Gas Geochemistry, (I.Hunyadi, I.Csige, J.Hakl, edit.), Debrecen, 43-53.

Virk, H.S., V.Walia, A.Kumar Sharma, N.Kumar, R.Kumar, (2000). Correlation of radon anomalies with microseismic events in Kangra and Chamba valleys of N-W Himalaya. Geof. Int., 39, 221-227.

Virk, H.S., V.Walia, N.Kumar, (2001). Helium/radon precursory anomalies of Chamoli earthquake, Garfwal Himalaya, India. J. Geodyn., 31, 201-210.

Visauta, Ub, (1998), Análisis Estadístico con SPSS para Window's. Vol II Estadística Multivariable. Mc Graw Hill, Madrid.

Wakita, H., (1996). Geochemical challenge to earthquake prediction. Proc. Nat. Acad. Sci. USA, 93, 37813786.

Wakita, H., Y.Nakamura, Y.Sano, (1986). Background fluctuations in groundwater radon observation. J. Phys. Earth., 34, S81-S89.

Wakita, H., Y.Nakamura, Y.Sano, (1988). Short-term and intermediate-term geochemical precursor. PAGEOPH, 126, 1-12. 
Wheat, C.G. and M.J. Mottl, (2000). Composition of pore and spring waters from Baby Bare: global implications of geochemical fluxes from a ridge flank hydrothermal system. Geochim. Cosmochim. Acta, 64, 629-642.

Willard, H:H., L.L.Merritt, A.J.Dean, A.F.Settle, (1991). Métodos Instrumentales de Análisis. Editorial Iberoamericana, México, D.F.

Woith, H., C.Milkereit, U.Maiwald, A.Pekdeger, (1999). Physico-chemical behaviour of underground water after the October 1, 1995 Dinar earthquake, SW Turkey. II Nuovo Cimento, 22 C, 387-391.

Wyse, E.J. and D.R.Fisher, (1994). Radionuclide bioassay by inductively coupled plasma mass spectrometry (ICP/MS). Radiat. Prot. Dosim., 55, 199-206.

Wysocka, M., J.Skowronek, S.Chalupnik, K.Skubacz, (2001). Changes of radon concentration in soil gas over some main fault in upper Silesian Coal Basin. . Proc. $5^{\text {th }}$ Int. Conf. Rare Gas Geochemistry, (I.Hunyadi, I.Csige, J.Hakl, edit.), Debrecen, 61-70.

XLSTAT, (2000). fahmy@xlstat.com

Yang, C.H., P.H.Cheng, J.I.You, L.L.Tsai, (2002). Significant resistivity changes in the fault zone associated with the 1999Chi-Chi earthquake, west central Taiwan. Tectonophys., 350, 299-313.

Yasuoka, Y. and M.Shinogi, (1997). Anomaly in atmospheric radon concentration: A possible precursor of the 1995 Kobe, Japan, earthquake. Health Phys., 72, 759-761.

Yeager, M.W., F.N.Rolman, B.S.White, A.M.Boyd, W.S.Poppell, (1994). A performance evaluation of bare alpha track detectors. Health Phys., 66, 163-171.

Zalewski, M., M.Karpiñska, Z.Mnich, J.Kapa, P. Zalewki, (2001). Study of ${ }^{222 R n}$ concentrations in drinking water in the north-eastern hydroregions of Poland. J. Environ. Radioat., 53, 167-173.

Zhang, Z. and W.Zhang, (1999). The correlation between variation of radon content in groundwater and earthquakes. II Nuovo Cimento, 22C, 399-405.

Zhaocheng, Z. and W.Zhang, (1999). The correlation between variation of radon content in groundwater and earthquakes. II Nuovo Cimento, 22 C, 443-448.

Zhu, L., (2000). Crustal structure across the San Andreas Fault, southern California from teleseismic converted waves. Earth Plan. Sci. Lett., 179, 183-190.

Zhuo, W., T.lida, X.Yang, (2001). Occurrence of ${ }^{222} \mathrm{Rn},{ }^{226} \mathrm{Ra},{ }^{228} \mathrm{Ra}$ and $\mathrm{U}$ in groundwater in Fujian Province, China. J. Environ. Radioact., 53, 111-120.

Zmazek, B., M.Zivcic, J.Vaupotic, M.Bidovec, M.Poljak, I.Kobal, (2002). Soil radon monitoring in the Krsko basin, Slovenia. Appl. Radiat. Isot., 56, 649-657.

Zouridakis, N., K.M.Ochsenkuhn, A.Savidou, (2002). Determination of uranium and radon in potable water samples. J.Environ. Radiat. 61, 225-232.

Zuñiga, R.F., M.A.Reyes, C.Valdes, (2000). A general overview of the catalog of recent seismicity compiled by the Mexican Seismological Survey. Geof. Int. 39, 161-170. 


\section{APÉNDICE l-1}

\section{GLOSARIO}

Este glosario se complementa con el Apéndice I-2

Abanico aluvial.- Depósito de sedimentos en forma de abanico, se forma cuando la pendiente de una corriente fluvial disminuye abruptamente.

Actividad.- Número de átomos desintegrados de un material radiactivo en la unidad de tiempo.

Acuífero.- Formación, grupo de formaciones o parte de una formación, que está saturada y es lo suficientemente permeable para transmitir cantidades de agua de captaciones y manantiales económicamente rentables.

Agua subterránea.- Es la existente entre los intersticios del terreno bajo la superficie.

Aluvial.- Terreno compuesto por aluviones.

Aluvión.- Depósito de materiales sueltos (cantos rodados, gravas, arenas, arcillas, etc.), transportado por las corrientes de agua y depositado en un cuerpo receptor, generalmente en las planicies próximas a la desembocadura de los ríos.

Andesita.- Roca ígnea volcánica, compuesta de plagioclasas, minerales máficos y frecuentemente vidrio volcánico.

Anfiteatro.- Valle o depresión en forma elipsoidal o circular con laderas escalonadas.

Arcilla.- Roca sedimentaria no cementada, formada de cuarzo y minerales arcillosos, es plástica, admite fácilmente el agua. Procede de silicatos primarios contenidos en la roca, tales como micas, feldespatos, piroxenos, anfiboles, etc. Está constituida por partículas menores a $0.005 \mathrm{~mm}$.

Arena.- Granos minerales como cuarzo, feldespato, micas, restos de organismos, etc. Es producto de la meteorización de la roca y de la selección de materiales detríticos llevada a cabo por agentes móviles. Esta clasificación varía entre 0.005 y $2 \mathrm{~mm}$.

Barra.- Banco de arena o grava que se forma en el mar delante de la desembocadura de los ríos, debido al transporte transversal de sedimentos del fondo del mar hacia la costa.

Basalto.- Roca ígnea volcánica básica, consiste principalmente de plagioclasa, augita y con frecuencia olivino, es una roca densa y porosa, presenta estructuras de derrames, forma mesetas de lava.

Blanco de reactivo.- Muestra que se utiliza como referencia en análisis ambientales.

Caliza.- Rocas sedimentarias de origen marino o clástico. Se componen principalmente de calcita. Con frecuencia contienen minerales de dolomita, arcilla o arenas. 
Ceniza volcánica.- Material piroclástico de grano fino, compuesto de material de hierro desmenuzado y cristales de otros minerales acompañados o remplazados por substancias pétreas criptocristalinas 0 microcristalinas. Es producto de volcanes del tipo explosivo.

Clastos.- Depósito de roca que se compone de fragmentos inalterados, modificados químicamente, los cuales proceden de rocas preexistentes de cualquier clase 0 de productos magmáticos diversos. Pueden estar aglutinados o no por distintos tipos de cemento (arenas, areniscas, conglomerados, cuarcitas, brechas, etc.)

Conglomerado.- Roca sedimentaria detrítica compuesta por guijarros redondeados cementados en una matriz de material más fino: limo, arena, el cementante generalmente es oxido de hierro, caliza, sílice u otros.

Cuarcita.- Roca sedimentaria o metamórfica, está formada por granos de cuarzo, cementada con sílice. Es altamente resistente.

Cuarzo.- Es un mineral que pertenece al grupo de los silicatos. Químicamente es $\mathrm{SiO}_{2}$ puro. Es el componente fundamental de muchos tipos de roca. Después de los feldespatos es el mineral más abundante en la corteza terrestre especialmente en las rocas ígneas ácidas. Aparece también en rocas sedimentarias y metamórficas por ser resistente. Es incoloro sin impurezas y su color varía dependiendo de las sustancias con que está mezclado.

Depósito aluvial.- Se forma por acción conjunta de corrientes fluviales. Se origina en las porciones inferiores de valles por alternancia de la acumulación aluvial (guijarros-arenas), durante las crecidas.

Depósito de playa.- Acumulación de detritos (guijarros, gravas, arenas) y material orgánico en la zona de influencia del oleaje. Generalmente tienen poco espesor y estratificación diagonal tipo playa. Se amplían al lado del mar y quedan cubiertos al descender éste.

Depósito deltaico.- Forma acumulativa de sedimentos que se origina en la zona de desembocadura de un río, mar o lago, principalmente por la acción fluvial y en menor grado por el oleaje y las mareas.

Detector.- Dispositivo que determina cualitativa o cuantitativamente un fenómeno físico o químico.

Detrito.- Resultado de la descomposición de una masa sólida en partículas.

Diorita.- Roca ígnea intrusiva, constituida por anfiboles, plagioclasa y cantidades pequeñas de minerales ferromagnesianos, como hornblenda, biotita y piroxenos, con pequeñas cantidades de cuarzo. La andesita es su equivalente extrusivo.

Dique.- Intrusión tabular que corta perpendicular o diagonalmente a la estratificación, masa ígnea u otras intrusiones y cuyo espesor es pequeño respecto a su longitud.

Dosímetro.- Dispositivo para medir la dosis absorbida por la radiación ionizante.

Dosis absorbida.- Cantidad de energía por unidad de masa que absorbe un material al ser expuesto a la radiación ionizante. La unidad es el gray (Gy). 
Electrodo.- Cada uno de los elementos terminales de un circuito eléctrico.

Electronvoltio (eV).- El electrón voltio es la energía adquirida por un electrón cuando es acelerado por una diferencia de potencial de 1 voltio. El megaelectronvoltio (MeV) corresponde a 1 millón de electrón voltios.

Elementos traza.- Aquellos elementos químicos que están presentes de manera natural, en concentraciones muy bajas, en el agua o en el aire $(<0.1 \mathrm{mg} / \mathrm{L})$.

Emanación.- Sustancia volátil que exhala o se desprende de un cuerpo.

Equivalente químico.- Es el cociente entre la masa atómica del elemento considerado y su valencia.

Excitación.- Incremento en la energía de los electrones en los sistemas enlazados a niveles superiores, o de los nucleones en los núcleos. Puede ser provocado por la interacción de la radiación en los materiales. Al relajarse la excitación en los sistemas enlazados, se pueden emitir rayos $\mathrm{X}$ en los sistemas atómicos, y rayos gamma en los núcleos.

Falla.- Plano o zona de ruptura en el substrato rocoso a lo largo de la cual se produce un desplazamiento.

Filitas.- Rocas metamórficas compactas, de brillo sedoso, foliadas, formadas de cuarzo y otros minerales. Se rompen fácilmente en láminas delgadas, se forman por el metamorfismo de la lutita.

Fotones.- Paquetes de energía en forma de ondas electromagnéticas, que constituyen las ondas de radio, de radar, la luz infrarroja, la luz visible, los rayos $\mathrm{X}$ y gamma, entre otros.

Gas noble.- Cualquiera de los elementos gaseosos: helio, neón argón kriptón xenón y radón. Tienen la última capa electrónica completa por lo que son de baja reactividad química y en condiciones normales no reaccionan con otras sustancias debido a la estabilidad de su estructura química.

Granito.- Roca ígnea intrusiva ácida, consistente de feldespato potasio, plagioclasa, cuarzo, mica, anfíbol y otros minerales.

Granodiorita.- Roca ígnea ácida intermedia entre el granito y la dorita de cuarzo. Consiste en cuarzo, plagioclasa, feldespato potásico, así como horblenda, biotita, piroxeno y otros minerales, es análoga a la dacita.

Grava.- Roca sedimentaria compuesta de detritos gruesos no consolidados y pulidos. Proceden de la meteorización de la roca, su tamaño varía para gravas finas (1 a $1.5 \mathrm{~mm}$ ), gravas medias (2.5 a 5 $\mathrm{mm})$ y gravas gruesas $(5$ a $10 \mathrm{~mm})$.

Gray.- Es la unidad de dosis absorbida, equivalente a la deposición por la radiación ionizante de 1 julio de energía por kilogramo de materia.

Ignimbrita.- Roca volcánica piroclástica, compuesta de fragmentos de lava y ceniza, con inclusiones de vidrio. 
Ionización.- Consecuencia de la interacción de la radiación con la materia. Consiste en la separación de un átomo eléctricamente neutro en dos o más partes cargadas.

Isótopo.- Átomos del mismo elemento, con igual número atómico $(\mathrm{Z})$, y diferente número de masa y número de neutrones.

Laguna.- Extensión de agua salada aislada del mar por una lengua de tierra estrecha.

Lava.- Masa fundida, generalmente silicatada, de líquida a semisólida que fluye en la superficie terrestre durante las erupciones de los volcanes.

Lutita.- Sedimento o roca sedimentaria, consiste principalmente de arcilla y limo compactado, es de grano fino, de apariencia homogénea.

Meseta.- Terreno elevado y plano de gran extensión, constituido por estratos horizontales o derrames de lava.

Minerales máficos.- Minerales en los que abunda el hierro y el magnesio.

Nivel freático.- Lugar geométrico de los puntos que se encuentran a la misma presión que la atmosférica y equivale a la superficie libre del acuífero.

Partículas alfa $(\alpha)$.- Están constituidas por núcleos de átomos de helio, 2 neutrones y 2 protones y 2 de carga positiva. Son las partículas radiactivas menos penetrantes, pero las más peligrosas desde el punto de vista de exposición interna.

Partículas beta $(\beta)$.- Están formadas por electrones. Son más penetrantes que las partículas alfa pero producen menos ionización específica.

Piroclásticos.- Fragmento rocoso, tal como la ceniza, arena, etc, arrojados durante las erupciones volcánicas explosivas. En conjunto originan tobas, brechas y otras rocas. Por su forma pueden ser bombas (> de $32 \mathrm{~mm}$ redondeados), bloques (> $32 \mathrm{~mm}$ angulosos), lapilli (4 a $32 \mathrm{~mm})$, arenas ( 0.25 a $4 \mathrm{~mm}$ ), cenizas ( $<0.25 \mathrm{~mm}$ ), incluyen también escoria, pómez y otros materiales.

Plagioclasa.- Mezcla de feldespato sódico (albita) y feldespato cálcico (anortita). Son componentes de rocas magmáticas.

Plutón.- Es una roca ígnea que ha sido formada debajo de la superficie de la Tierra por consolidación del magma.

Productos de decaimiento (progenie).- Isótopos que se forman por el decaimiento radiactivo de los núcleos.

Radiación.- Emanación de partículas atómicas o fotones electromagnéticos de una fuente que puede ser un isótopo natural 0 artificial.

Radiación cósmica.- Formada por radiación electromagnética y partículas de alta energía que se forman fuera de la atmósfera de la Tierra. 
Radiación electromagnética.- La que está constituida por fotones o paquetes de energía en forma de ondas electromagnéticas, por ejemplo, puede ser $\mathrm{X}$ ó gamma.

Radiación gamma $(\gamma)$.- Son las ondas electromagnéticas que se producen en el núcleo atómico, sin carga y sin masa. Son las más penetrantes de las emisiones radiactivas.

Radiación ionizante.- Cualquier radiación corpuscular (alfa o beta) o electromagnética, que puede inducir la ionización de manera directa o indirecta o por una mezcla de ambas. Las partículas directamente ionizantes son aquellas cargas (electrones, protones, partículas alfa, etc.) que tienen suficiente energía cinética para causar ionización durante sus colisiones con las moléculas de los materiales que atraviesan. Las partículas indirectamente ionizantes son neutras, tales como los neutrones.

Radiación natural.- La radiación a la que se está expuesto en todo momento, incluye la cósmica, la que proviene del suelo, la de los materiales de construcción y la del cuerpo humano.

Radiactividad.- Fenómeno de desintegración espontánea de ciertos isótopos, que se hace patente por la emanación de partículas atómicas y/o de fotones electromagnéticos.

Radionúclido.- Átomo inestable definido por su número másico $(\mathrm{A}=$ número total de protones + neutrones), número atomico ( $\mathrm{Z}=$ número de protones), número neutrónico ( $\mathrm{N}=$ número de neutrones) y su estado de energía nuclear.

Riolita.- Roca ígnea volcánica, ácida, consiste principalmente de cuarzo, feldespato alcalino y plagioclasa. Es equivalente al granito (intrusivo).

\section{Roca ígnea.- Se forma por enfriamiento y solidificación del magma.}

Roca ígnea extrusiva o volcánica.- Ocurre en la superficie después de la efusión.

Roca ígnea intrusiva o plutónica.- Ocurre a profundidad, en el interior de la corteza terrestre

Roca metamórfica.- Es aquella cuya composición mineralógica, estructura y textura, está condicionada por procesos de metamorfismo, así como por los rasgos de las rocas primarias sedimentarias o magmáticas. La roca de metamorfismo local o de contacto se forma por la influencia de altas temperaturas, sin deformación y se caracteriza por una estructura no esquistosa. La roca de metamorfismo regional generalmente presenta estructura esquistosa o gnéisica.

Roca sedimentaria.- Se forma por la acumulación de materiales en un medio acuático o subaéreo, puede ser consolidada y no consolidada, se clasifica en orgánica y química.

Sequía intraestival.- Llamada también Canícula o sequía de medio verano. En México es la sequía relativa o mínimo secundario de la precipitación. Se presenta a mediados de la estación lluviosa como un receso de la cuantía de las lluvias de ésta época.

Sienita.- Roca ígnea intrusiva, de composición alcalina, sin cuarzo, contiene principalmente feldespato alcalino, y plagioclasa además de minerales máficos (horblenda, biotita, piroxeno y otros).

Toba.- Roca formada por materiales arrojados por las erupciones volcánicas, tales como ceniza y lapilli, posteriormente compactadas y cementadas. 
Trinchera.- Fosa oceánica profunda, alargada, de decenas de varios miles de kilómetros, con forma plana 0 arqueada y con perfil transversal asimétrico. Es considerada como un límite de las placas tectónicas. Es una región de alta sismicidad donde se localizan los principales epicentros sísmicos.

Tronco.- Masa de roca ígnea circular o elíptica que intrusiona a cualquier tipo de roca y cuyo tamaño aumenta hacia abajo.

Valle sumergido.- Es una hondonada que penetra toda o una parte bajo las aguas del mar a causa de movimientos epirogénicos.

Vida media.- Tiempo en que la actividad de un isótopo radiactivo determinado, se reduce a la mitad de su valor inicial; es una característica de cada isótopo.

Zona de recarga.- Superficie terrestre donde se introduce el flujo hacia los acuíferos. La recarga se debe principalmente al agua de lluvia y a la infiltración del agua de los ríos y lagos. 


\section{APÉNDICE I-2}

\section{CARACTERÍSTICAS FISICOQUÍMICAS DE ALGUNOS COMPUESTOS Y ELEMENTOS QUÍMICOS MAYORES Y TRAZA DEL AGUA.}

El agua filtrada que circula a través de las rocas de la corteza terrestre proviene principalmente de la precipitación, de acuerdo con los aniones y cationes que éstas liberan, se forman distintos tipos de agua (Mason, 1960; Johnson, 1966; Castany, 1971; Custodio y Llamas, 1983; Stumm y Morgan, 1981; González, 1982; ASTM, 1991; Di Bernardo, 1993; Palmer, 1996; Deutsch, 1997; Domenico y Schwartz, 1998; Sawyer et al., 2001).

Clasificación del tipo de agua dependiendo del contenido iónico.

- Aguas bicarbonatadas.- El calcio es el catión principal y el menos abundante el sodio. El sodio de las aguas procede en gran parte de la descomposición de la plagioclasa sódica (albita). Las aguas más bicarbonatadas son las que se filtran a través de las rocas calizas.

- Aguas sulfatadas.- Adquieren las sales por la oxidación de los sulfatos y la disolución del yeso $\left(\mathrm{CaSO}_{4} 2 \mathrm{H}_{2} \mathrm{O}\right)$ muy común en los sedimentos.

- Aguas cloradas- Se forman principalmente por los sedimentos marinos recientes y en las zonas costeras por sales marinas acarreadas por los vientos.

\section{CATIONES}

\section{Calcio $\left(\mathrm{Ca}^{2+}\right)$}

Características químicas. - El calcio es muy abundante en la corteza terrestre y muy móvil en la hidrósfera, resulta por ello uno de los iones más comunes en las aguas subterráneas. Se presenta como sales de solubilidad moderada a alta, que se precipitan fácilmente como carbonato de calcio $\left(\mathrm{CO}_{3} \mathrm{Ca}\right)$.

Concentraciones:- Las aguas dulces contienen de 10 a $250 \mathrm{mg} \mathrm{L}^{-1}$ de calcio, las aguas marinas $400 \mathrm{mg} \mathrm{L-}$ ${ }^{1} \mathrm{y}$ las salmueras $50000 \mathrm{mg} \mathrm{L}^{-1}$.

\section{Procedencia:}

Rocas sedimentarias. - Las aguas subterráneas en contacto con las rocas sedimentarias de origen marino obtienen la mayor parte de su contenido de calcio a partir de la disolución de calcita $\left(\mathrm{CaCO}_{3}\right)$, aragonita $\left(\mathrm{CaCO}_{3}\right.$ ), dolomita $\left(\mathrm{CaMg}\left(\mathrm{CO}_{3}\right)_{2}\right)$, anhidrita $\left(\mathrm{CaSO}_{4}\right)$ y yeso (Appelo y Postma, 1993; Manahan, 1994; Nalco, 1994; Deutsch, 1997).

Rocas ígneas y metamórficas. - La descomposición meteórica también libera calcio de minerales como apatita, fluorita $\left(\mathrm{CaF}_{2}\right)$ y varios miembros de los feldespatos (anfíboles y piroxenos) y otros silicatos cálcicos. El carbonato de calcio se disuelve fácilmente en el agua, con la condición de que ésta contenga abundantes iones $\mathrm{H}^{+}$(Pulido, 1978; Palmer, 1996; Romero, 1999).

Otros.- Los efectos que produce en la salud son insignificantes. Sin embargo, las aguas que sobrepasan los $200 \mathrm{mg} \mathrm{L}^{-1}$; presentan inconvenientes para el uso domestico y la utilización de calderas, debido a las incrustaciones que ocasiona. 


Clasificación de la dureza $\left(\mathbf{m g ~ L}^{-1}\right)$ (Palmer, 1996$)$
\begin{tabular}{|c|c|}
\hline Índice & Tipo \\
\hline $0-60$ & Blanda \\
$61-120$ & Moderadamente dura \\
$121-180$ & Dura \\
$>180$ & Muy dura \\
\hline
\end{tabular}

\section{Magnesio $\left(\mathrm{Mg}^{2+}\right)$}

Características químicas.- Las sales de magnesio son muy solubles, difíciles de precipitar. A pesar de la gran solubilidad de sus compuestos, el magnesio se encuentra generalmente en las aguas naturales en menor concentración que el calcio. Contribuyen a la dureza del agua y puede ocasionar incrustaciones (Rodier, 1990; Hem, 1992; Nalco, 1994; Deutsch, 1997).

Concentraciones: Las aguas dulces contienen de 1 a $100 \mathrm{mg} \mathrm{L}^{-1}$ de magnesio, las aguas de mar $1200 \mathrm{mg}$ $\mathrm{L}^{-1}$ y las aguas salinas miles de $\mathrm{mg} \mathrm{L}^{-1}$. Las normas internacionales indican como límite máximo permisible una concentración de $150 \mathrm{mg} \mathrm{L}^{-1}$.

Procedencia. El magnesio es un elemento común en muchos minerales.

Rocas sedimentarias.- El agua subterránea al estar en contacto con rocas sedimentarias, adquiere el contenido de magnesio de las dolomitas, magnesita y algunas variedades de arcilla y al lavado de evaporitas con contenidos de magnesio. La mayor parte de las calizas contienen magnesio (la disolución de calizas puede proporcionar al mismo tiempo cantidades de calcio y de magnesio) y silicatos de magnesio.

Rocas ígneas.- El agua subterránea al estar en contacto con rocas ígneas obtiene magnesio del olivino $\left((\mathrm{Mg}, \mathrm{Fe})_{2} \mathrm{SO}_{4}\right)$, biotita $\left(\left(\mathrm{K}(\mathrm{Mg}, \mathrm{Fe})_{3}(\mathrm{OH}, \mathrm{F})_{2}\right)\right.$, horblenda $\left(\mathrm{Ca}_{2}(\mathrm{Mg}, \mathrm{Fe})_{5}(\mathrm{OH})_{2}(\mathrm{Al}, \mathrm{Si})_{8} \mathrm{O}_{22}\right)$ y augita $\left(\mathrm{Ca}_{3}\right.$ $\left.(\mathrm{Mg}, \mathrm{Fe}, \mathrm{Al})(\mathrm{AL}, \mathrm{Si})_{2} \mathrm{O}_{6}\right)$ y del ataque de silicatos magnésicos y ferromagnésicos. La presencia del magnesio en el agua es poco común (Davis y De Wiest, 1971; Palmer, 1996).

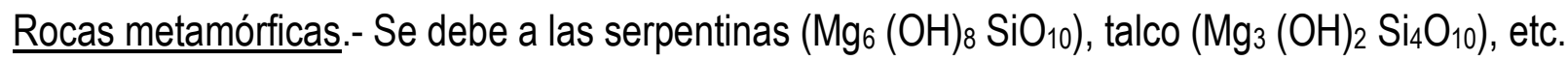

\section{Sodio $\left(\mathrm{Na}^{+}\right)$}

Características químicas.- Es el elemento más abundante de los alcalinos que se encuentran presentes en la naturaleza (Fletcher, 1995; Deutsch, 1997). En su mayoría las sales de sodio son altamente solubles en agua y raramente se precipitan a menos exista una gran concentración (Armienta et al., 1996; Romero, 1999). Debido al alto grado de solubilidad de sus compuestos, el sodio se concentra por efecto de la evaporación en el mar y en las extensas cuencas endorreicas de las zonas desérticas. Las aguas subterráneas que contienen considerables cantidades de carbonato de sodio o bicarbonato de sodio son alcalinas y alcanzan valores de pH mayores de 9 (Fletcher, 1995; Palmer, 1996; Romero, 1999; Sawyer et al., 2001).

Concentraciones: En las aguas subterráneas el sodio, se encuentra en bajas concentraciones (10 a 100 $\mathrm{mgL}^{-1}$ ), pero en las aguas del mar, es el ion metálico más abundante (cerca de $10000 \mathrm{mg} \mathrm{L}^{-1}$ ). La Norma 
Oficial Mexicana establece una concentración máxima permisible para agua potable de $200 \mathrm{mg} \mathrm{L}^{-1}$ (NOM127-SSA1-1994).

\section{Procedencia.}

Rocas sedimentarias.- La presencia de sodio en agua subterránea se debe al lavado de sedimentos de origen marino, así como a la disolución de sal gema $(\mathrm{NaCl})$ (halita), al sulfato sódico (depósitos evaporíticos) y de los minerales arcillosos que ocasionalmente liberan cantidades de sodio por intercambio iónico.

Rocas ígneas y metamórficas.- El origen primordial de la mayor parte del sodio en las aguas naturales, se debe a la liberación de productos solubles que tienen lugar durante la descomposición meteórica de los feldespatos del grupo de las plagioclasas, feldespatoides y otros silicatos (Davis y De Wiest, 1971; Pulido, 1978; Fletcher, 1995; Palmer, 1996). Raras veces de las emanaciones y fenómenos relacionados con procesos magmáticos (Armienta et al., 1996; Sawyer et al., 2001).

\section{Potasio $\left(K^{+}\right)$}

Características químicas.- Es un elemento ligeramente más abundante que el sodio en las rocas ígneas, pero se encuentra en mayor proporción que éste en rocas sedimentarias, es un metal alcalino soluble. Se origina en las aguas naturales principalmente por el intemperismo de minerales de silicatos. La vegetación también puede concentrar potasio (Armienta et al., 1996; Marini et al., 2001).

Concentraciones: El agua subterránea contiene $10 \mathrm{mg} \mathrm{L}^{-1}$, el agua de lluvia y nieve contienen $0.11 \mathrm{mg} \mathrm{L}^{-1}$, las salmueras $100000 \mathrm{mg} \mathrm{L}^{-1}$. Se recomienda un límite en agua potable de 1000-2000 $\mathrm{mg} \mathrm{L}^{-1}$ (Romero, 1999).

Procedencia.

Rocas sedimentarias.- Las aguas que se percolan en el interior de depósitos de evaporitas pueden llegar a contener grandes cantidades de potasio como resultado de la disolución del nitrato potasico (Armienta et al., 1996; Deutsch, 1997).

Rocas ígneas y metamórficas.- El contenido de potasio en las aguas subterráneas en contacto con las rocas ígneas y metamórficas se debe entre otros factores a minerales como la ortoclasa, biotita, etc., y a la presencia de otros silicatos (micas, arcillas, etc) (Davis y De Wiest, 1971; Appelo y Postma, 1993).

\section{Hierro $\left(\mathrm{Fe}^{2+}\right)$}

Características químicas.- En la corteza terrestre abundan los yacimientos de hierro y prácticamente todas las aguas naturales están contaminadas por hiero (Armienta et al., 1996). Sin embargo, en las aguas subterráneas, la concentración de iones de hierro está limita da probablemente por la solubilidad de los carbonatos ferrosos, habiéndose encontrado concentraciones de 1 a $10 \mathrm{mg} \mathrm{L}^{-1}$ en aguas con pH de 68 y concentraciones de bicarbonatos relativamente bajas. Frecuentemente se observa que una muestra de agua subterránea que originalmente fue clara se torna turbia y eventualmente café, esto se debe a que generalmente, aunque el contenido de oxigeno disuelto en las aguas subterráneas es bajo puede incrementarse al entrar en contacto con la atmósfera, produciéndose así la oxidación de los iones ferrosos (Armienta et al., 1996; Sawyer et al., 2001). El agua contenida en un pozo que ha permanecido inactivo, tendrá un contenido mayor de hierro que el agua de un pozo activo. Las aguas subterráneas y 
superficiales movilizan en solución pequeñas cantidades de hierro; no obstante, una movilización considerablemente mayor suele tener lugar a través de la erosión. El contenido de hierro en el agua en importante ya que pequeñas cantidades afectan seriamente la utilidad del agua en el uso doméstico así como en la industria (Fletcher, 1995).

Concentraciones:- Concentraciones de 1 a $5 \mathrm{mg} \mathrm{L}^{-1}$ son comunes en el agua subterránea.

Procedencia.

Rocas ígneas y metamórficas.- Las aguas subterráneas con abundancia de hierro han circulado por minerales que tienen gran cantidad de hierro, como piroxenos, anfibolitas, pirita $\left(\mathrm{S}{ }_{2} \mathrm{Fe}\right)$, biotita y granate; la descomposición de estos minerales por la acción de los agentes meteóricos deja en libertad grandes cantidades de hierro que generalmente pasan a formar óxidos relativamente estables (Davis y De Wiest, 1971; Palmer,1996).

\section{ANIONES}

\section{Bicarbonatos $\left(\mathrm{HCO}_{2}^{-}\right)$}

Procedencia.- Las aguas subterráneas con alto contenido de bicarbonatos, se deben a la disolución de rocas carbonatadas (calizas, dolomías, etc) como resultado de la disolución del bióxido de carbono de la atmósfera y del suelo. El bióxido de carbono entra en el agua en cantidades apreciables al percolarse ésta a través del suelo en el que crecen plantas o bien, disuelto en el agua en forma de ácido carbónico el cual, junto con los carbonatos y bicarbonatos, controla el $\mathrm{pH}$ de la mayoría de las aguas subterráneas (Gibson, 1974; Davis y De Wiest, 1971; Palmer,1996). La concentración de bicarbonatos varía de 5 a $500 \mathrm{mg} \mathrm{L}-1$ como $\mathrm{CaCO}_{3}$ a valores de pH menores a 8.3 (Hem, 1992; Nalco, 1994; Rodier, 1990; Deutsch, 1997).

\section{Cloruros (Cl)}

Características químicas.- Los cloruros son un componente menor de la corteza terrestre, son uno de los constituyentes más importantes en la mayor parte de las aguas subterráneas. Son sales solubles, estables en disoluciones y difíciles de precipitar. No se oxidan ni se reducen en aguas naturales. Se presentan casi siempre en forma sódica y potásica (Palmer,1996).

Concentraciones: Las aguas de lluvia contienen $<1 \mathrm{mg} \mathrm{L}^{-1}$, las aguas dulces de 10 a $250 \mathrm{mg} \mathrm{L}^{-1}$, las aguas subterráneas <100 mg L-1 y las aguas de mar de 18000 a 21000 mg L-1 (Hem, 1992; Manahan, 1996; Romero, 1999). La concentración máxima permisible para agua potable establecida por la Norma Oficial Mexicana es de 250 mg L-1 (NOM-127-SSA1-1994).

Procedencia.

Rocas sedimentarias.- El cloro proviene de la disolución de la sal común (sal gema) y de minerales afines que existen en las formaciones de evaporitas. Proviene también de los acuíferos costeros con acceso directo al mar o que estuvieron comunicados con él alguna vez en el pasado (Gibson, 1974; Domenico y Schwartz, 1998).

Rocas ígneas. El contenido de cloro en las aguas subterráneas y que están en contacto con las rocas ígneas por lo general es bajo y se debe al ataque de ciertos minerales, como son la sodalita y la apatita 
ya que son los únicos minerales frecuentes en las rocas ígneas y metamórficas que contienen cloruros como constituyente fundamental. Las micas y hornblenda que aparecen en las rocas y minerales son también otra fuente natural de los cloruros (Pulido, 1978; Deutsch, 1997).

\section{Sulfatos $\left(\mathrm{SO}_{4}^{2-}\right)$}

Características químicas.- Los sulfatos junto con los cloruros y nitratos de los metales alcalinotérreos, son los que proporcionan al agua la dureza no-carbonatada, también llamada dureza permanente.

Concentraciones: En las aguas subterráneas el contenido oscila entre 2 y $150 \mathrm{mg} \mathrm{L}^{-1}$, en las aguas potables, la concentración máxima de sulfatos es de $250 \mathrm{mg} \mathrm{L}^{-1}$, las aguas saladas contienen más de $5000 \mathrm{mg} \mathrm{L}^{-1}$ en presencia de calcio, (Pulido, 1978). La Norma Oficial Mexicana establece como limite máximo permisible en agua potable de $400 \mathrm{mg} \mathrm{L}^{-1}$ (NOM-127-SSA1-1994).

\section{Procedencia.}

Su presencia en aguas subterráneas se debe a la disolución de yacimientos evaporíticos como yesos y anhidritas y a la disolución de minerales sulfurosos disueltos por la acción del agua percolada rica en oxigeno disuelto. También proceden de depósitos naturales de sulfato de magnesio, calcio y/o sodio, de la oxidación de la pirita, del lavado de terrenos formados en condiciones de gran aridez 0 en ambiente marino, de la oxidación de sulfuros de rocas ígneas, metamórficas o sedimentarias, de concentraciones de agua de lluvia, así como de actividad urbana, industrial y en ocasiones agrícolas (Hem, 1992; Armienta et al., 1996; Palmer,1996).

\section{Sílice $\left(\mathrm{SiO}_{2}\right)$}

Características químicas.- Después del oxigeno, el silicio es el elemento más abundante de la corteza terrestre. El silicio combinado con el oxígeno en la forma de oxido $\mathrm{SiO}_{2}$ se llama sílice. El cuarzo es casi sílice en la forma cristalina. El silicio puede encontrarse en otras rocas en forma no cristalina.

Procedencia.- Se cree que la presencia de sílice en el agua subterránea se debe a la descomposición de silicatos presentes en gran cantidad de rocas. La meteorización de las rocas las transforma en minerales arcillosos, resultando en general silicio. La temperatura, la cantidad de agua disuelta y la velocidad del movimiento del agua a través de las rocas, con presencia de ácidos como el carbónico afecta la meteorización y el grado en que la sílice entra en solución en el agua. La sílice no contribuye a la dureza del agua, sin embargo, la sílice constituye una parte importante de los incrustantes o costras formadas por algunas aguas, tal como el depositado en algunas tuberías de pozos. La costra es por lo general silicato de sodio o magnesio. La costra de silicato de calcio no puede ser disuelta por ácidos u otros reactivos químicos que se utilizan en el tratamiento de los pozos. Si el contenido de sílice aumenta, el agua pudo haber circulado por rocas de origen volcánico y sedimentos derivados de rocas graníticas y volcánicas. El valor de $\mathrm{pH}$ es muy importante, se precipita la sílice si éste desciende, es el principal compuesto disuelto en el agua subterránea para valores de pH entre 6 y 9 , así mismo el $\mathrm{CO}_{2}$ representa un papel importante en su disolución. La sílice puede ser un indicador del tipo de terreno atravesado por el agua subterránea (Fletcher, 1995; Romero, 1999).

Concentraciones: En aguas subterráneas sus concentraciones pueden llegar hasta $100 \mathrm{mg} \mathrm{L}^{-1}$, en aguas superficiales su concentración varia de 1 a $30 \mathrm{mg} \mathrm{L}^{-1}$ (Rodier, 1990). 


\section{Compuestos nitrogenados}

Bajo este nombre se agrupa el amoniaco $\left(\mathrm{NH}_{3}\right)$, los nitritos $\left(\mathrm{NO}_{2}\right)$ y los nitratos $\left(\mathrm{NO}_{3}\right)$. Su procedencia tiene diversos orígenes en donde la fijación del nitrógeno representa un papel importante proceso que consiste en la conversión del nitrógeno molecular estable a compuestos nitrogenados. Durante las tormentas eléctricas puede fijar el nitrógeno para la producción endotérmica del oxido nítrico (NO) en la atmósfera; se combina con el oxigeno del aire formando dióxido de nitrógeno $\left(\mathrm{NO}_{2}\right)$ y reacciona a su vez con el agua formando ácido nítrico $\left(\mathrm{HNO}_{3}\right)$. El nitrógeno es un constituyente fundamental de las proteínas de todos los organismos vivos. Cuando la materia orgánica (desperdicios humanos y/o animales y otros productos de desecho agrícola), se descomponen por la acción bacteriana, las proteínas se transforman sucesivamente en aminoácidos, amoníaco, nitritos y finalmente, en nitratos. Algunos de los nitratos así originados pueden ser lavados posteriormente por el agua que se percola a través del suelo, llegando de este modo a alcanzar las aguas subterráneas en donde es la especie de nitrógeno más común.

Los nitratos son sales muy solubles, tienen la tendencia a ser estables y es muy difícil que se precipiten, solamente pueden ser movilizados en las aguas naturales a través de la actividad orgánica o mediante los procesos de evaporación (Armienta et al., 1996; Fletcher, 1995). La variación del contenido de nitratos en diferentes aguas es alta y algunas de ellas no guardan relación con ninguna formación geológica. El contenido de nitrato en las aguas subterráneas suele ser más alto que en el agua superficial. La mayor parte del ion nitrato en las aguas subterráneas no es elevado, tienen un origen orgánico o procede de elementos químicos agrícolas, ganaderos, industriales y urbanos (Armienta et al., 1996; Manahan, 1994). Las altas concentraciones de nitratos en el agua subterránea son causa de preocupación, ya que se originan por descargas de contaminantes en las aguas superficiales 0 infiltraciones por aguas superficiales contaminadas (Fletcher, 1995). Las rocas ígneas contienen pequeñas cantidades de nitrato soluble. Muchas veces es un indicador de la contaminación en cuyo caso suele estar estratificado, dominando las concentraciones mayores en la parte superior del acuífero libre. Raramente procede del lavado de ciertos minerales nitrogenados, de suelos antiguos y emanaciones volcánicas.

Concentraciones:- El agua dulce contiene de 0.1 a $10.0 \mathrm{mg} \mathrm{L}^{-1}$, el agua de lluvia de 0.1 a $0.3 \mathrm{mg} \mathrm{L}^{-1}$ y el agua de $\mathrm{mar}<1 \mathrm{mg} \mathrm{L}^{-1}$.

\section{CARACTERÍSTICAS GENERALES}

Dureza.- Es la suma de las concentraciones de los iones metálicos divalentes. Es la propiedad del agua que le confieren los iones de calcio y magnesio en forma de bicarbonatos y menos frecuentemente como sulfatos y cloruros; esta dureza se evidencia por la producción de incrustaciones en tuberías y equipos y por la facilidad con la cual vuelve el jabón para producir espumas. No se producen espumas en un agua dura hasta que los minerales que causan la dureza son eliminados por combinación química con compuestos del jabón, mientras más alta es la dureza más jabón se requiere para producir espuma (Rodier, 1990; Romero, 1999; Sawyer et al., 2001).

lones que causan dureza

\begin{tabular}{|c|c|}
\hline Cationes & Aniones \\
\hline $\mathrm{Ca}^{+}$ & $\mathrm{Cl}^{-}$ \\
\hline
\end{tabular}




\begin{tabular}{|c|c|}
\hline $\mathrm{Mg}^{2+}$ & $\mathrm{HCO}_{3}^{-}$ \\
$\mathrm{Sr}^{2+}$ & $\mathrm{NO}_{3}^{-}$ \\
$\mathrm{Fe}^{2+}$ & $\mathrm{SO}_{4}^{2-}$ \\
$\mathrm{Mn}^{2+}$ & $\mathrm{SiO}_{3}{ }^{2-}$ \\
\hline
\end{tabular}

La dureza total (DT), es la suma de las concentraciones de Ca y Mg.

$$
D T=D t+D p
$$

Donde:

$\mathrm{Dt}=$ Dureza carbonatada (dureza temporal), es la suma de las alcalinidades carbonatadas y bicarbonatadas.

$D p=$ Dureza no carbonatada (dureza permanente), es toda dureza que no esté químicamente relacionada con los bicarbonatos (sulfatos, cloruros, nitratos de calcio y magnesio).

La presencia de estos elementos en el agua subterránea se debe generalmente al paso de ésta por depósitos de dolomitas, yesos, calizas y evaporitas (Pulido, 1978; Armienta et al., 1996).

Conductividad eléctrica.- Es una expresión numérica de la habilidad de una determinada sustancia para conducir la corriente eléctrica, es justamente lo opuesto de la propiedad denominada resistencia eléctrica. La conductividad constituye un índice útil de la pureza del agua destilada, además, sirve para el control de la calidad del agua. Este es un parámetro muy significativo, ya que es una función de la calidad y cantidad de los iones presentes en el agua residual, y de igual modo para el monitoreo de la calidad en abastecimiento de alta pureza, por ejemplo en agua desmineralizada (ASTM,1991; Metcalf y Eddy, 1994; Pelig-Ba,1996). El agua químicamente pura ostenta una conductividad eléctrica muy baja, significando esto que es un buen aislante. Sin embargo, una pequeña cantidad de minerales disueltos en el agua la vuelve conductiva. Esto tiene lugar cuando el material disuelto se separa en iones que llevan cargas negativas y positivas. Cuando mayor es la carga de iones, mayor será la conductividad de la solución. La conductividad de una solución en agua aumenta conforme aumenta la temperatura (Metcalf y Eddy, 1994; Pelig-Ba, 1996). En consecuencia para comparar valores medidos deben referirse a la misma temperatura. Debido a que la electricidad se transporta por la migración de los iones en solución, la conductividad se relaciona con la concentración iónica total (Armienta et al., 1996; Palmer,1996). Se reporta en $\mathrm{mS} \mathrm{cm}^{-1}$.

Temperatura.- La temperatura del agua es un parámetro muy importante en las reacciones químicas, en las velocidades de reacción y en la aplicabilidad del agua, tiene además, un importante efecto en la vida acuática. Comúnmente al incrementarse la temperatura se incrementa la solubilidad de los minerales. Se reporta en ${ }^{\circ} \mathrm{C}$ (Hem, 1992; Metcalf y Eddy, 1994; Fletcher, 1995; Romero, 1999).

PH.- El valor de $\mathrm{pH}$ en las aguas naturales está controlado por las especies químicas disueltas y por las reacciones que pueden llevarse a cabo entre ellas y con el agua misma. Es un parámetro que permite estimar la acidez 0 alcalinidad del agua. En las aguas subterráneas el pH varía entre 6 y 8.5 , aunque en manantiales termales puede ser menor. Se estima que valores mayores de 8.3 se deben al contenido de $\mathrm{CO}_{3}{ }^{2-}$ y $\mathrm{OH}$ y valores inferiores a 8.3 y superiores a 4.4 , se deben a la presencia de $\mathrm{CO}_{2}$; 
aquellos inferiores a 4.4 se deben a la presencia de ácidos fuertes (Pulido, 1978; Di Bernardo, 1993; Armienta et al., 1996; Palmer,1996; Romero, 1999).

\section{ELEMENTOS TRAZA}

Arsénico (As).- Está presente en la litosfera en forma de arsenato en los depósitos de mineralización. Los compuestos orgánicos de arsénico son menos tóxicos que sus sales minerales. La presencia de arsénico en el ambiente se puede deber a la combustión de carbón, así como a los fosfatos utilizados en los abonos y en el detergente. Puede encontrarse en lugares en donde se utilizan cantidades considerables de insecticida, raticida, etc. La solubilidad del arsénico en el agua es tan baja que su presencia suele ser un indicador de las operaciones en minas o de tipo metalúrgico. En el lecho de los ríos 0 en áreas agrícolas puede deberse a la utilización de materiales (plagioclasas) con arsénico. Se llega a encontrar en los pozos para agua debido a las infiltraciones (Rodier, 1990). La Norma Oficial Mexicana establece como límite máximo permisible en agua potable $0.05 \mathrm{mg} \mathrm{L}^{-1}$ (NOM-127-SSA1-1994).

Bario (Ba).- Se presenta principalmente en forma de sulfatos (baritina) $\left(\mathrm{SO}_{4} \mathrm{Ba}\right) 0$ de (carbonatos) witherita $\left(\mathrm{BaCO}_{3}\right)$ y en la composición de los feldespato potásicos. La toxicidad de las sales de bario es función de su solubilidad, las sales más tóxicas son las de cloruros, nitratos y carbonatos. El sulfato de bario es poco soluble en el agua. En el agua que contiene bicarbonatos y sulfatos, la solubilidad del bario está por debajo de $0.1 \mathrm{mg} \mathrm{L}^{-1}$ y rara vez se encuentra en concentraciones mayores a $0.05 \mathrm{mg} \mathrm{L}^{-1}$. Las concentraciones altas se pueden deber a procesos industriales (APHA, AWWA, WPCF, 1992). Se utiliza en la industria (fotografía, cristalería, pintura, etc.); en la agricultura (rodonticida, plaguicida, etc.) (Rodier, 1990). La Norma Oficial Mexicana establece como limite máximo permisible en agua potable $0.7 \mathrm{mg} \mathrm{L}^{-1}$ (NOM-127-SSA1-1994).

Boro (B).- Es el elemento con menor abundancia en la naturaleza. Generalmente se encuentra en combinación química con el oxigeno, como borato. Los minerales más comunes son el bórax $\left(\mathrm{Na}_{2} \mathrm{~B}_{4} \mathrm{O}_{7}\right.$ $\left.{ }_{10} \mathrm{H}_{2} \mathrm{O}\right)$ y la kermita $\left({ }_{2} \mathrm{~B}_{4} \mathrm{O}_{7}{ }_{4} \mathrm{H}_{2} \mathrm{O}\right)$ en depósitos evaporíticos. La termalita $\left[(\mathrm{NaCa})(\mathrm{LiMgFeAl})_{3}\right)\left(\mathrm{AlFe}_{3}\right)_{6}$ $\left.\mathrm{B}_{3} \mathrm{Si}_{6} \mathrm{O}_{17}\right)$ ] es el borosilicato más importante y es un mineral típico de ambiente volcánico. La presencia del boro está ligada a fertilizantes como el bórax y al tetraborato de sodio, pues el boro es un micronutriente y se utiliza además, para prevenir ciertas enfermedades. Así mismo se utiliza en la fabricación de vidrios, detergentes, pavimentos y revestimientos cerámicos (Rodier, 1990). El contenido de boro en el agua de lluvia es de $0.01 \mathrm{mg} \mathrm{L}^{-1}$, en los océanos es de $4.6 \mathrm{mg} \mathrm{L}^{-1}$ y en las aguas superficiales su concentración es 400 veces menor que en el agua del mar. Esta concentración probablemente se deba a la existencia de una disolución de algún mineral con boro presente en las rocas volcánicas (Custodio y Llamas, 1983). Las normas internacionales permiten como concentración máxima permisible para agua potable $1 \mathrm{mg} \mathrm{L}^{-1}$ (Rodier, 1990).

Cadmio (Cd).- Está generalmente asociado con yacimientos de cinc o de plomo y es uno de los metales más tóxicos. Se utiliza para revestimiento de metales, en ciertas aleaciones, para la fabricación de acumuladores, pinturas y de materiales plásticos. Se incorpora al agua subterránea a través de vertidos industriales o por el deterioro de tuberías galvanizadas (APHA, AWWA, WPCF, 1992). Las normas internacionales recomiendan un límite máximo permisible de $0.01 \mathrm{mg} \mathrm{L}^{-1}$ (Palmer, 1996). 
Cinc (Zn).- Se encuentra especialmente en las rocas ígneas y se asocia a diferentes yacimientos especialmente pentlandita (sulfuro de hierro, níquel y la pirita). Su presencia en el agua subterránea se debe a la lixiviación natural de minerales de cinc, operación inadecuada de minas, descargas industriales o deterioro de tuberías galvanizadas. La concentración de cinc en las aguas subterráneas está controlada por su disponibilidad en las rocas y suelos (Rodier, 1990). La Norma Oficial Mexicana establece como límite máximo permisible en agua potable $5 \mathrm{mg} \mathrm{L}^{-1}$ (NOM-127-SSA1-1994).

Cobalto (Co).- Es muy abundante en las rocas ígneas y se encuentra asociado con yacimientos de níquel, argentita, plomo y cobre. Es muy bajo en las aguas naturales. En solución acuosa la forma divalente del cobalto dominante es absorbida por los óxidos de manganeso, se oxida rápidamente a trivalente en las aguas oxigenadas. Se utiliza en la industria metalúrgica; las sales de cobalto se emplean en pinturas, cerámicas y como catalizador. Se considera como concentración límite máximo permisible en agua potable $1 \mathrm{mg} \mathrm{L}^{-1}$ (Rodier, 1990).

Cobre (Cu).- Es un elemento relativamente común de la corteza terrestre. Es el resultado de la disolución de minerales constituidos por sulfuros, óxidos y carbonatos tales como calcopirita ( $\mathrm{CuFeS}_{2}$ ), bornita $\left(\mathrm{Cu}_{5} \mathrm{FeS}_{4}\right)$, calcosina $\left(\mathrm{Cu}_{2} \mathrm{~S}\right)$, cuprita $\left(\mathrm{Cu}_{2} \mathrm{O}\right)$, malaquita $\left[\mathrm{Cu}_{2}(\mathrm{OH})_{2} \mathrm{CO}_{3}\right]$, azurita $\left[\mathrm{Cu}_{3}(\mathrm{OH})_{2}\left(\mathrm{CO}_{3}\right)_{2}\right]$ y sales sulfatadas. Las concentraciones elevadas de cobre se deben al uso de insecticidas y fertilizantes, así como residuos, corrosión de tuberías y accesorios de cobre, latón, y bronce (APHA-AWWA-WPCF, 1992). En algunas aguas llegan a tener concentraciones inferiores a $1 \mathrm{mg} \mathrm{L}^{-1}$ (Rodier, 1990). La Norma Oficial Mexicana establece como límite máximo permisible en agua potable $2 \mathrm{mg} \mathrm{L}^{-1}$ (NOM-127-SSA1-1994).

Cromo (Cr).- Es un elemento poco común, se encuentra principalmente en los yacimientos de cromitas y en un gran número de minerales. Su solubilidad es relativamente baja. El cromo hexavalente es tóxico y se presenta en aguas subterráneas generalmente en forma iónica $\mathrm{Cr}_{4}{ }^{2-}$. El cromo se emplea muy poco en la industria, aparte de la fabricación de aceros especiales, en cambio sus derivados como por ejemplo los dicromatos son muy utilizados en la industria química, en procesos industriales, en los vertidos de la galvanoplastía. Prácticamente es un elemento anormal en las aguas (APHA, AWWA, WPCF, 1992). Las normas internacionales recomiendan un límite máximo permisible en agua potable $0.5 \mathrm{mg} \mathrm{L}^{-1}$ (Palmer, 1996).

Estroncio (Sr).- Es un constituyente común de las rocas ígneas (Davies y De Wiest, 1971), está generalmente asociado al calcio en el silicato. Se reemplaza por el calcio y el potasio. El estroncio se encuentra disperso en la corteza terrestre como elemento traza, sin embargo, puede encontrarse como mineral en depósitos hidrotermales, rocas sulfatadas como la estroncianita $\left(\mathrm{SrCO}_{3}\right)$ y carbonatadas como la celestina $\left(\mathrm{SrSO}_{4}\right)$. También las plagioclasas y feldespatos potasicos (minerales de origen ígneo) concentran estroncio. Sus propiedades fisiopatológicas son semejantes a las del bario, y se consideran poco peligrosas. En general en aguas subterráneas los límites de solubilidad no son alcanzables (Rodier, 1990).

Escandio (Sc).- Está dentro de los 50 elementos que constituyen la corteza terrestre y está presente a nivel de trazas en las aguas subterráneas. 
Manganeso (Mn).- El manganeso es un metal muy difundido en la corteza terrestre, es un elemento químico que frecuentemente se encuentra en las rocas volcánicas, constituyendo los minerales máficos. Está presente en muchos suelos, sedimentos y rocas metamórficas, los más importantes son en forma de óxidos como la pirolusita $\left(\mathrm{MnO}_{2}\right)$ y rodocrosita $\left(\mathrm{MnCO}_{3}\right)$. Muchas de las aguas con altos contenidos de manganeso proceden de fuentes termales. Este elemento es muy común en las aguas subterráneas donde se encuentra en cantidades de alrededor de $1 \mathrm{mg} \mathrm{L}^{-1}$ (Manahan, 1994; Nalco, 1994). La Norma Oficial Mexicana establece como limite máximo permisible en agua potable $0.15 \mathrm{mg} \mathrm{L}^{-1}$ (NOM-127-SSA11994).

Molibdeno (Mo).- Se encuentra en los minerales como la molibdenita y la wulfenita. En el agua, el molibdeno está presente en diferentes valencias en forma de aniones hidróxido. Las normas internacionales indican $0.5 \mathrm{mg} \mathrm{L}^{-1}$ como concentración máxima permisible (Rodier, 1990).

Litio (Li).- Es un elemento poco común en la corteza terrestre, se encuentra principalmente en rocas graníticas, la mayor parte de los compuestos de litio son solubles (Davies y De Wiest). El litio interviene como espesador en los aceites lubricantes en forma de estereato, como fundente en soldadura y como oxidante en ciertas aleaciones. También se utiliza en la industria del vidrio y la química (el hipoclorito de litio se utiliza como fuente de cloro en las piscinas). Las concentraciones más elevadas de este metal se encuentran en las aguas minerales y en las salobres. Algunas aguas dulces pueden contener algunos miligramos por litro y en las aguas subterráneas se pueden encontrar cantidades del orden de $0.1 \mathrm{mg} \mathrm{L}^{-1}$ (Rodier, 1990).

Plomo (Pb).- Es un componente menor pero ampliamente difundido en la corteza terrestre, donde está presente en forma de carbonatos (cerusita) $\left(\mathrm{PbSO}_{3}\right)$, fosfatos, pero principalmente de sulfuros (galena) $(\mathrm{PbS})$ y angesita $\left(\mathrm{PbSO}_{4}\right)$. Esta sal poco soluble se puede transformar en hidróxido 0 en carbonato, después de haber sido oxidada a sulfato. Debido a esta regularización su presencia en el agua subterránea comúnmente es menor a $8 \mathrm{mg} \mathrm{L-1}$. Es un veneno serio acumulativo, las principales fuentes de plomo para las aguas naturales son el lixiviado de calizas, galena, tuberías de plomo, descargas de fundición, procesos industriales y los gases de combustión de automóviles (APHA, AWWA, WPCF, 1992). Las normas internacionales indican $0.05 \mathrm{mg} \mathrm{L}^{-1}$ como concentración máxima permisible en agua potable (Rodier, 1990).

Rubidio ( $R$ b).- Es un elemento relativamente abundante en la corteza terrestre, se encuentra en los

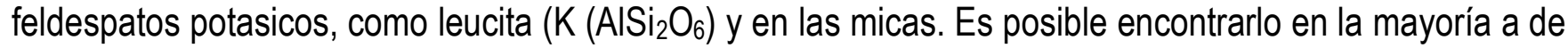
las aguas en concentraciones entre 0.0001 y $0.1 \mathrm{mg} \mathrm{L-1}$ (Rodier, 1990).

Uranio (U).- Está incluido en la composición química de los minerales, como son la pechblenda $\left(\mathrm{UO}_{2}\right)$, la autinita (fosfato de uranio y de calcio) y ocasionalmente se presenta en los circones. Existen varios isótopos del uranio, el ${ }^{238} \mathrm{U}$ es el dominante (Rodier, 1990). 


\section{APÉNDICE II-1}

\section{PARÁMETROS METEOROLÓGICOS DE ACAPULCO (CPEG) VALORES PROMEDIO MENSUALES.}

TEMPERATURA MEDIA $\left({ }^{\circ} \mathrm{C}\right)$

\begin{tabular}{|c|c|c|c|c|c|c|c|c|c|c|c|c|}
\hline $\mathrm{A} / \mathrm{M}$ & $\bar{E}$ & $F$ & M & $\mathrm{A}$ & $M$ & $\mathrm{~J}$ & $\mathrm{~J}$ & $A$ & $S$ & 0 & $\mathbf{N}$ & $\bar{D}$ \\
\hline 1992 & 26.0 & 25.3 & 27.5 & 28.2 & 26.9 & 29.3 & 28.9 & 28.9 & 28.4 & 28.1 & 27.4 & 27.0 \\
\hline 1993 & 26.7 & 26.9 & 27.0 & 26.5 & 27.8 & 28.7 & 27.5 & 28.7 & 26.3 & 28.7 & 28.2 & 26.9 \\
\hline 1994 & 26.9 & 27.2 & 27.1 & 27.2 & 28.5 & 29.7 & 29.8 & 29.2 & 29.3 & 28.8 & 28.5 & 27.4 \\
\hline 1995 & 27.1 & 28.4 & 27.3 & 26.9 & 28.4 & 29.4 & 29.8 & 28.6 & 29.1 & 27.8 & 29.1 & 26.9 \\
\hline 1996 & 25.8 & 26.2 & 26.7 & 27.3 & 29.1 & 27.9 & 28.6 & 28.9 & 29.6 & 28.0 & 27.3 & 26.7 \\
\hline 1997 & 25.4 & 26.2 & 27.1 & 26.6 & 28.7 & 29.1 & 29.6 & 29.5 & 28.3 & 27.7 & 27.7 & 26.8 \\
\hline 1998 & 25.5 & 25.0 & 26.4 & 26.7 & 26.8 & 29.6 & 28.4 & 28.9 & 27.1 & 28.5 & 27.7 & 26.8 \\
\hline PROM & 26.2 & 26.5 & 27.0 & 27.1 & 28.0 & 29.1 & 28.9 & 29.0 & 28.3 & 28.2 & 28.0 & 26.9 \\
\hline \multicolumn{4}{|c|}{$\begin{array}{l}\text { PROMEDIO ANUAL } \\
27.8\end{array}$} & & & & & & & & & \\
\hline
\end{tabular}

PRECIPITACIÓN TOTAL (mm)

\begin{tabular}{|c|c|c|c|c|c|r|r|r|c|c|c|c|}
\hline A/M & E & F & M & A & M & \multicolumn{1}{|c|}{ J } & \multicolumn{1}{|c|}{ J } & \multicolumn{1}{|c|}{ A } & \multicolumn{1}{c|}{ S } & 0 & N & D \\
\hline 1992 & 30.6 & 33.1 & 0 & 0 & 0 & 92.0 & 255.6 & 366.5 & 227.4 & 261.4 & 4.0 & 26.0 \\
\hline 1993 & 0 & 0 & 0 & 0 & 0 & 491.0 & 235.8 & 551.1 & 348.1 & 127.8 & 0 & 0 \\
\hline 1994 & 0 & 0 & 0 & 0 & 103.4 & 43.1 & 54.5 & 20.1 & 131.1 & 136.0 & 0 & 0 \\
\hline 1995 & 0 & 16.7 & 0 & 3.2 & 31.5 & 138.4 & 159.4 & 559.9 & 230.6 & 4.0 & 8.5 & 42.3 \\
\hline 1996 & 0 & 0 & 0 & 0 & 27.5 & 376.8 & 288.9 & 366.7 & 281.8 & 189.9 & 3.1 & 0 \\
\hline 1997 & 1 & 0 & 0 & 0 & 0 & 56.0 & 87.6 & 24.9 & 218.8 & 639.3 & 105.3 & 37.8 \\
\hline 1998 & 0 & 0 & 0 & 0 & 0 & 250.9 & 388.5 & 321.1 & 587.5 & 174.4 & 0 & 0 \\
\hline PROM & 4.5 & 7.1 & 0 & 0.5 & 23.2 & 206.9 & 210.0 & 315.8 & 289.3 & 219.0 & 17.3 & 15.2 \\
\hline
\end{tabular}




\section{APÉNDICE II-2}

\section{CORTE LITOLÓGICO DE LOS POZOS DE LA PNLV (GMPNLV).}

A continuación se describe el nivel topográfico (N.T.), nivel estático (N.E.), así como el corte litológico de algunos de los pozos en donde se colocaron los detectores de trazas en la PNLV.

\begin{tabular}{|cl|}
\hline VA 6 & Acuífero EI Viejón \\
\hline N.T. $7.79 \mathrm{~m}$ & \\
N.E. $5.00 \mathrm{~m}$ & \\
$0-3$ & arcilla \\
$3-8$ & arena \\
$8-9$ & arcilla con arena \\
$9-11$ & arcilla y boleo \\
grande & \\
$11-13$ & arena y boleo \\
granular & \\
$13-15$ & arcilla con arena \\
$15-22$ & arena con boleo \\
$22-23$ & arcilla con boleo \\
$23-28$ & arena con boleo \\
$28-38$ & arcilla con arena \\
$38-42$ & andesita \\
\hline
\end{tabular}

\begin{tabular}{|ll|}
\hline VVS 10 & Acuífero El Viejón \\
\hline N.T. $2.89 \mathrm{~m}$ & \\
N.E. $5.00 \mathrm{~m}$ & \\
$0-5$ & arena \\
$5-7$ & arcilla \\
$7-12$ & boleo \\
$12-17$ & arena \\
$17-18$ & boleo \\
$18-24$ & boleo con arena \\
$24-27$ & arena con arcilla \\
$27-48$ & boleo \\
$48-54$ & brecha \\
$54-55$ & boleo arcilloso \\
$55-60$ & andesita algo \\
brechoide & \\
\hline
\end{tabular}

\begin{tabular}{|l|l|}
\hline VLA-11 $P N L V$ \\
\hline N.T. $15.47 \mathrm{~m}$ \\
NE. $15.16 \mathrm{~m}$ \\
$0-25$ arena \\
$25-40$ basalto fracturado \\
$40-42$ & brecha alterada \\
$42-45$ & toba poco alterada \\
$45-50$ & andesita \\
\hline
\end{tabular}




\section{APÉNDICE II-3}

PARÁMETROS METEOROLÓGICOS DE LA PNLV (CGMPNLV) VALORES PROMEDIO MENSUALES.

TEMPERATURA MEDIA $\left({ }^{\circ} \mathrm{C}\right)$

\begin{tabular}{|l|c|c|c|c|c|c|c|c|c|c|c|c|c|}
\hline A/M & E & F & M & A & M & J & J & A & S & O & N & D & A \\
\hline 1994 & 21.7 & 19.9 & 22.5 & 24.9 & 27.1 & 27.4 & 27.5 & 26.9 & 26.5 & 25.5 & 25.5 & 21.0 & 24.7 \\
\hline 1995 & 21.7 & 22.4 & 23.2 & 24.8 & 28.1 & 27.4 & 27.1 & 27.4 & 27.1 & 26.1 & 24.7 & 22.5 & 25.2 \\
\hline 1996 & 20.3 & 21.0 & 24.5 & 23.8 & 27.2 & 27.3 & 27.3 & 27.3 & 28.3 & 26.2 & 24.8 & 22.6 & 24.8 \\
\hline $\begin{array}{l}\text { PRO } \\
\text { M }\end{array}$ & 21.0 & 21.1 & 23.4 & 24.5 & 27.5 & 27.4 & 27.3 & 27.2 & 27.3 & 25.9 & 25.0 & 22.0 & 24.9 \\
\hline
\end{tabular}

PRECIPITACIÓN TOTAL (mm)

\begin{tabular}{|c|c|c|c|c|c|c|c|c|c|c|c|c|c|}
\hline $\mathrm{A} / \mathrm{M}$ & $E$ & $F$ & $M$ & $\mathrm{~A}$ & $M$ & $\mathrm{~J}$ & $\mathrm{~J}$ & $\mathrm{~A}$ & S & 0 & $\mathbf{N}$ & $D$ & $\mathrm{~A}$ \\
\hline 1994 & \begin{tabular}{|l|}
68.0 \\
\end{tabular} & 7.8 & 0.0 & \begin{tabular}{|l|}
47.4 \\
\end{tabular} & 89.3 & $\overline{71.5}$ & 153.3 & 290.2 & 118.4 & 148.7 & $\overline{93.0}$ & 20.0 & 1107.6 \\
\hline 1995 & 9.7 & 8.0 & 22.7 & 3.3 & 121.6 & 21.1 & 343.4 & 235.1 & 295.9 & 122.8 & 129.7 & 23.2 & 1336.5 \\
\hline 1996 & 2.1 & 9.1 & 32.9 & 22.9 & 36.2 & 112.6 & 155.5 & 210.2 & 26.3 & 40.3 & 174.0 & 33.2 & 1155.2 \\
\hline $\begin{array}{l}\text { PRO } \\
\text { M }\end{array}$ & 26.6 & 8.3 & 18.5 & 24.5 & $\overline{82.4}$ & $\overline{68.4}$ & 217.4 & 245.2 & 146.9 & 103.9 & $\overline{132.2}$ & 25.5 & 1199.8 \\
\hline
\end{tabular}


APÉNDICE III-1

\section{DETERMINACIÓN DE LA DENSIDAD DE TRAZAS}

\section{Grabado de la película}

Las trazas latentes de las partículas $\alpha$ se grabaron por medio de un ataque químico sumergiendo el detector en una solución de $\mathrm{NaOH}(2.5 \mathrm{~N})$ a $56^{\circ} \mathrm{C}$ durante 60 minutos.

La solución actúa como un solvente químico de la película, se colocó en un baño María con un agitador de baja velocidad (30 rpm). Los detectores se fijaron en un bastidor en el eje del agitador que se sumergió en la solución manteniéndose a temperatura constante durante todo el proceso de ataque. Una vez transcurrido el tiempo de ataque químico se lavaron los detectores con agua simple hasta que no quedaron residuos de $\mathrm{NaOH}$ en ellos. Con este procedimiento el espesor residual de cada detector se normalizó a $6.5 \mu \mathrm{m}$. Para verificarlo se midió el espesor de cada detector antes y después del grabado. Una vez aplicado el grabado se desprendió el soporte de polietileno de la película sensible.

\section{Contador de chispa.}

La densidad de trazas se determinó usando un contador de chispa que es un dispositivo electrónico que tiene la finalidad de detectar el número de trazas nucleares presentes en un detector de plástico (película sensible) mediante un contador analógico. Este sistema reportado por Cross y Tommasino (1970) está constituido por 2 eléctrodos: uno delgado (Mylar aluminizado de $100 \mu \mathrm{m}$ ) y otro grueso (latón) (Fig. A-III-1 ). El detector de plástico se coloca entre ellos, al cerrar el circuito, se carga el capacitor $\mathrm{C}$ obteniéndose una descarga eléctrica 0 chispa a través de los canales huecos de las trazas grabadas en el detector. La chispa pasa a través de las trazas con bastante energía, de tal manera que se evapora la capa de revestimiento de aluminio impidiendo otras descargas en el mismo lugar. El capacitor $C$ se descarga y el voltaje produce pulsos en la resistencia $R$ que se registran mediante un escalador electrónico. Cada cuenta en el escalador corresponde a una traza grabada. En general se realiza un prechispeo para abrir los canales y un chispeo a menor voltaje para hacer el conteo. En el caso que nos ocupa se utilizó un equipo de chispeo con un área del electrodo de latón de $0.5 \mathrm{~cm}^{2}$. Así mismo se utilizaron factores de corrección debido a diferencias de espesor residual aplicando la Tabla A-1II-1. A los detectores grabados se les aplicó un prerompimiento de las trazas a $1200 \mathrm{~V}$ con el fin de definir claramente las trazas presentes.

Tabla A-III-1 Factores de corrección por espesor en detectores LR-115 tipo II

\begin{tabular}{|c|c|}
\hline $\begin{array}{c}\text { DETECTOR } \\
(\text { espesor } \mu \mathrm{m})\end{array}$ & $\begin{array}{c}\text { FACTOR DE } \\
\text { CORRECCIÓN }\end{array}$ \\
\hline 6.0 & 1.1515 \\
6.5 & 1 \\
7.0 & 0.8455 \\
\hline
\end{tabular}




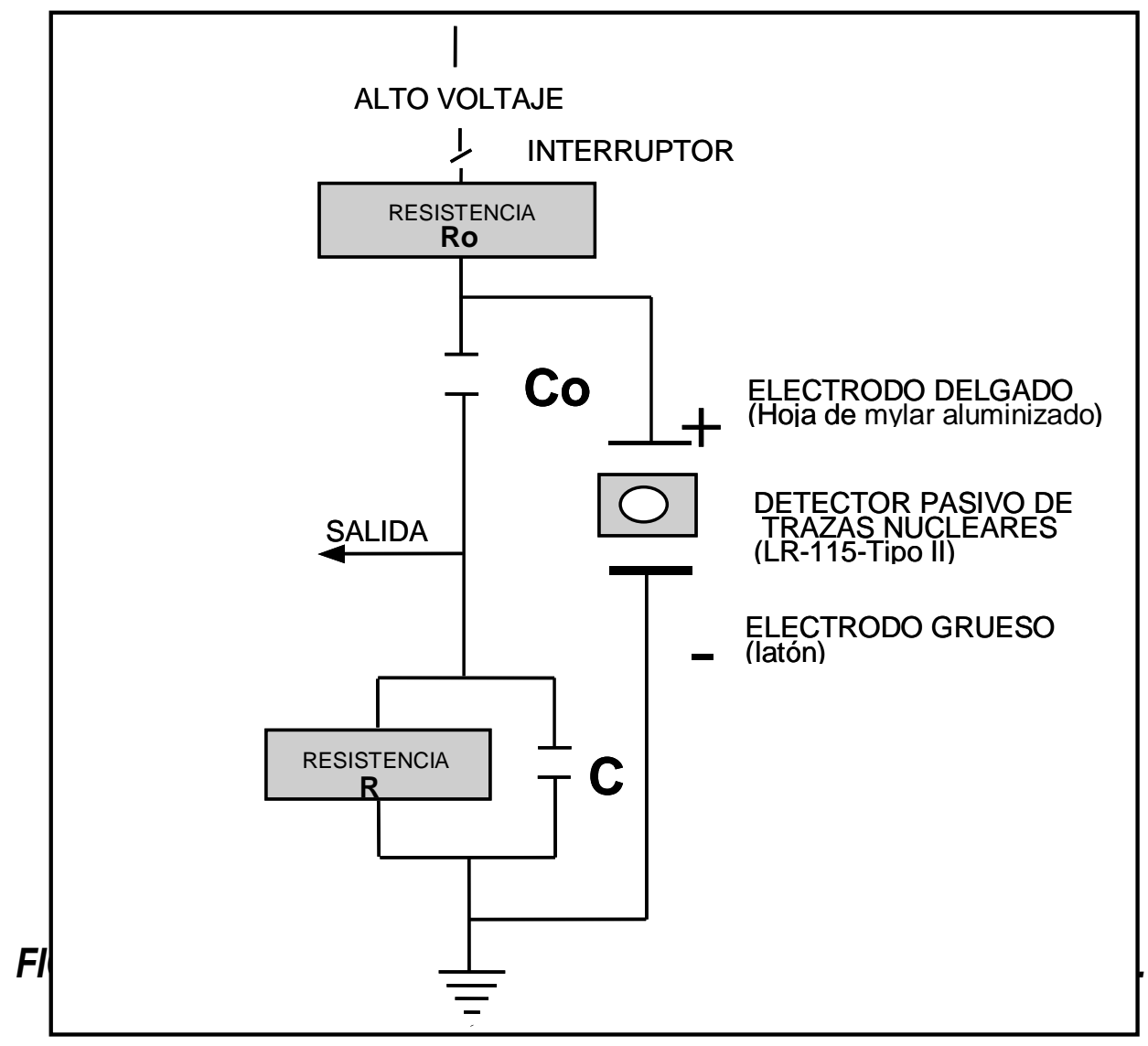

Cálculo de la densidad de trazas.

Se realizaron 5 lecturas del número de trazas a $750 \mathrm{~V}$ y se obtuvo el promedio $(\xi)$ y la desviación estándar $(\delta)$. Se calculó el error estadístico (e) el cual debe ser inferior a $4 \% \quad[e=(\delta / \xi)]$. La densidad de trazas se reporta en número de trazas $/ \mathrm{cm}^{2}$ por 7 días utilizando las relaciones:

$$
T d=\left[\frac{(\bar{x}-F) E}{F c \cdot A \cdot T \exp }\right]
$$

Donde:

$\xi \quad=$ Promedio del número de trazas

$\mathrm{F}=$ Número promedio de trazas de fondo para el detector $=\left(4\right.$ trazas $\left./ \mathrm{cm}^{2}\right)$

$\mathrm{E} \quad=$ Tiempo estandarizado (7 días)

Fc = Factor de corrección por espesor residual (normalizado a $6.5 \mu \mathrm{m}$ ).

A $=$ Área del electrodo positivo $\left(0.5 \mathrm{~cm}^{2}\right)$

Texp = Tiempo de exposición. 
APÉNDICE III-2

\section{DETERMINACIÓN DE LA DOSIS GAMMA AMBIENTAL}

Elaboración del dosímetro termoluminiscente (DTL).

Para la elaboración del material $\mathrm{TL}$ de $\mathrm{CaSO}_{4}$ se hizo reaccionar nitrato de calcio con ácido sulfúrico concentrado y óxido de disprosio.

$$
\mathrm{Ca}\left(\mathrm{NO}_{3}\right)_{2}+\mathrm{H}_{2} \mathrm{SO}_{4}+\mathrm{Dy}_{2} \mathrm{O}_{3} \rightarrow \mathrm{CaSO}_{4}: \mathrm{Dy}+\mathrm{HNO}_{3}
$$

Las pastillas se obtuvieron colocando una mezcla de PTFE (material aglutinante) con el material TL en polvo, en un dado de acero y aplicando presión. Las pastillas obtenidas así se sintetizaron sometiéndolas a un tratamiento térmico. En la Tabla A-III-2-1 se describen las características técnicas del detector TL utilizado en este trabajo.

Tabla A-III-2-1 Características técnicas del DTL (CaSO4:Dy + PTFE) desarrollado en el ININ.

\begin{tabular}{|l|l|}
\hline \multicolumn{1}{|c|}{ PARÁMETROS } & CARACTERÍSTICAS \\
\hline Material Termoluminiscente & CaSO 4 :Dy \\
\hline Material Aglutinante & PTFE \\
\hline Forma Física & Discos \\
\hline Densidad & $2.5 \mathrm{~g} / \mathrm{cm}^{3}$ \\
\hline Z Efectiva & 15.5 \\
\hline Numero de picos de la curva & 3 \\
\hline Temperatura del pico principal & $453 \mathrm{~K}$ \\
\hline Intervalo de Linealidad & $25 \mathrm{mGy}-300 \mathrm{~Gy}$ \\
\hline Desvanecimiento & $4 \%$ año \\
\hline
\end{tabular}

Para clasificar las pastillas se reagruparon en lotes con masas semejantes $(\sigma= \pm 3 \%)$. La reproducibidad de respuesta TL se determinó irradiando con radiación gamma de ${ }^{60} \mathrm{Co}$ a una dosis de 5 mGy una muestra aleatoria de un lote cualquiera de pastillas en 10 ocasiones. Si las lecturas se desvían en promedio en $\pm 5 \%$, se consideran con buena reproducibidad. Las lecturas de los DTL se realizaron en el equipo lector Harshaw 4000.

\section{Proceso para la obtención de la dosis gamma con un DTL}

\section{Borrado del DTL}

El DTL antes de ser expuesto en el campo se sometió a un tratamiento térmico de borrado de fondo anterior. Para ello se colocaron las pastillas en un crisol previamente lavado con alcohol, el cual se introdujo en una mufla marca Thermolyne Tipo 46100 Furnace, calentándose a $300{ }^{\circ} \mathrm{C}$ durante 30 minutos, que son la temperatura y el tiempo óptimos para una respuesta adecuada del material de $\mathrm{CaSO}_{4}$ :Dy + PTFE (Azorín y Furetta, 1989). Para determinar el fondo se sometió el DTL al tratamiento térmico de borrado y a continuación se procedió a tomar la lectura. 


\section{Lectura del DTL}

La lectura de un DTL es secilla y directa, se efectúa en un tiempo relativamente corto. La integración de la señal TL se llevó a cabo entre 100 y $300^{\circ} \mathrm{C}$, con una taza de calentamiento de $10^{\circ} \mathrm{C} \mathrm{s}^{-1}$. Todas las lecturas se tomaron en atmósfera de nitrógeno.

\section{Curva de calibración para el DTL.}

Para la elaboración de la curva de calibración en función de la dosis se utilizaron dosímetros del mismo lote. Se les dio el tratamiento térmico de borrado a $300{ }^{\circ} \mathrm{C}$ durante 30 min y se dejaron enfriar a temperatura ambiente, se colocaron en portadosímetros por duplicado y se irradiaron con una fuente de radiación gamma de ${ }^{137} \mathrm{Cs}$, en un intervalo de dosis entre 0.043 y $8.7 \mathrm{mGy}$.

Con la lectura promedio de los DTL irradiados se elaboró la curva de calibración graficando Dosis absorbida ( $m$ Gy) vs Intensidad TL ( $u$ a) ( $u$ a = unidades arbitrarias), donde el ajuste de la recta se llevó a cabo por el método de mínimos cuadrados. Los resultados de prueba de los DTL en forma de pastilla presentaron una respuesta lineal en el intervalo entre 0.043 y $0.870 \mathrm{mGy}$, como se muestra en la curva de calibración (Fig. A-III-2). Una vez trazada la curva y por medio de interpolaciones se obtuvo la dosis absorbida.

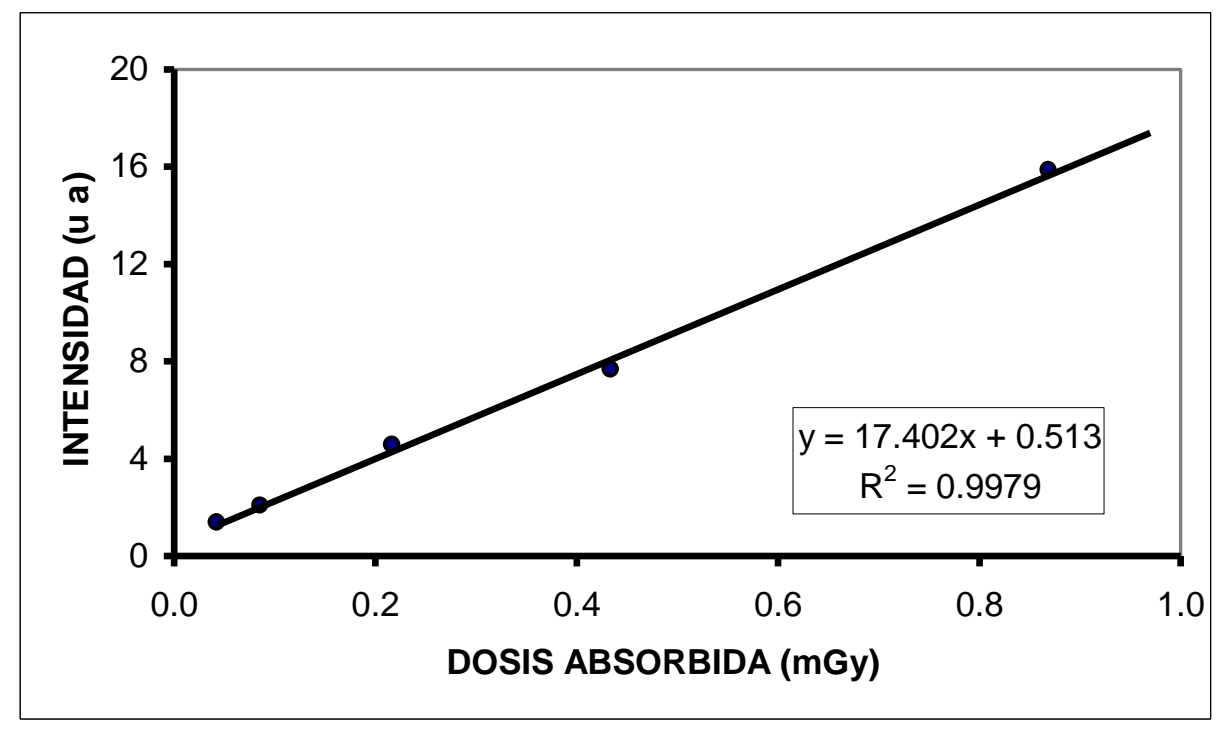

FIG. A-III-2 Curva de calibración. 


\section{APÉNDICE III-3}

\section{MÉTODOS PARA LA DETERMINACIÓN DE PARÁMETROS FISICOQUÍMICOS DE MUESTRAS DE AGUA SUBTERRÁNEA IN SITUY EN LABORATORIO.}

\section{DETERMINACIÓN IN SITU.}

Determinación de la Temperatura.

La temperatura se determinó in situ utilizando un termómetro digital Tegam 871. Para la medición se instala el electrodo en el equipo, se sumerge el electrodo en la muestra y se selecciona la medición en grados centígrados. La lectura da la temperatura de la muestra.

\section{Determinación del $\mathrm{pH}$.}

El pH se determinó in situ utilizando un equipo portátil Conductronic Modelo 10. Se enciende el equipo y se coloca el electrodo, posteriormente se calibra el equipo con dos soluciones bufer de pH 4 y 7 , ajustando la temperatura de la solución con la perilla de control. Se retira el electrodo de la solución patrón y se enjuaga con agua destilada. Se introduce el electrodo en la muestra y se obtiene la lectura del valor de $\mathrm{pH}$ a la temperatura de la muestra. Después de la medida se retira y enjuaga el electrodo.

\section{Determinación de la conductividad.}

La conductividad se determinó in situ utilizando un equipo portátil Conductronic Modelo CL8. Se sumerge la celda en la muestra, cuidando que el nivel del líquido esté $1 \mathrm{~cm}$ arriba de los agujeros de ventilación de la celda. Se agita la celda de arriba abajo para quitar las burbujas de aire que pudieran estar atrapadas en la celda. Posteriormente se selecciona el rango más adecuado (0 - 200, 0 - 2000 ó $0-20000 \mu \Omega \mathrm{cm}^{-1}$ ) y se toma la lectura. Después de cada medida se retira y enjuaga la celda con agua destilada.

\section{DETERMINACIÓN EN LABORATORIO.}

Determinación de dureza total (NOM-AA-72-1981).

Se miden $50 \mathrm{~mL}$ de la muestra (se recomienda que el volumen de muestra no gaste más de $15 \mathrm{~mL}$ de la solución de EDTA), se agrega $2 \mathrm{~mL}$ de la solución amortiguadora de amonio y de 1 a 2 gotas o una cantidad adecuada, del indicador eriocromo negro T. Posteriormente, se titula con la solución patrón de EDTA lentamente con agitación continua, hasta que la solución tome un color azul (vire de rojoazul). La determinación de la dureza total se realiza a partir de los volúmenes gastados por cálculos

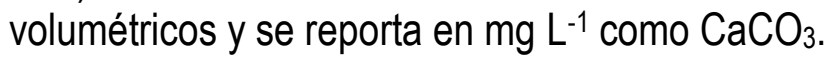

La dureza total se define como la suma de las concentraciones de calcio y magnesio, ambas expresadas como carbonato de calcio. Cuando la dureza es numéricamente mayor que la suma de las alcalinidades de carbonato y bicarbonato, ésta cantidad de dureza equivalente a la alcalinidad total se denomina dureza carbonatada. La cantidad de dureza que excede a ésta se llama dureza no carbonatada. Cuando la dureza es numéricamente igual o menor que la suma de alcalinidades de 
carbonato y bicarbonato, toda la dureza es de carbonato, estando ausente la de bicarbonato (APHA, AWWA, WPCF, 1992).

Solución EDTA.- Se pesa $4 \mathrm{gr}$ de la sal disódica del ácido etilendiamino tetraacetico, se disuelve en $800 \mathrm{~mL}$ de agua y se deja reposar 1 semana en un recipiente.

Solución amortiguadora de amonio.- Se pesa $16.9 \mathrm{gr}$ de $\mathrm{NH}_{4} \mathrm{Cl}$ y se disuelve en $134 \mathrm{~mL}$ de $\mathrm{NH}_{4} \mathrm{OH}$, se agita y se afora a $250 \mathrm{~mL}$ con agua.

Solución indicadora de eriocromo negro T.- Se mezcla con $4.5 \mathrm{gr}$ de clorhidrato de hidrorilamina, se disuelve y se diluye en $100 \mathrm{~mL}$ de alcohol etílico al $95 \%$.

Determinación de cloruros (NOM-AA-73-1981).

Para la determinación de cloruros, se miden $100 \mathrm{~mL}$ de muestra y se ajusta el $\mathrm{pH}$ de la muestra entre 7 y 10 con ácido sulfúrico $1 \mathrm{~N}$ y/o hidróxido de sodio $1 \mathrm{~N}$, utilizando el potenciómetro. Posteriormente, se agrega $1 \mathrm{~mL}$ de la solución indicadora de cromato de potasio y se titula con la solución valorada de nitrato de plata hasta el vire de amarillo a rojo ladrillo. Al mismo tiempo, se analiza un testigo con agua destilada en la misma forma que la muestra. La cantidad de cloruros se determina por cálculos volumétricos.

Indicador de cromato de potasio.- Se disuelve $5 \mathrm{gr}$ de cromato de potasio en agua, se agrega lentamente la solución de nitrato de plata $0.0141 \mathrm{~N}$, hasta formar un precipitado rojo definido, se deja reposar $12 \mathrm{hrs}$, se filtra y se diluye a $100 \mathrm{~mL}$.

Solución de nitrato de plata 0.0141 N.- Se pesa $2.397 \mathrm{gr}$ de nitrato de plata en agua y se afora a $1 \mathrm{~L}$.

Determinación de sulfatos (NOM-AA-74-1981).

Para la determinación de sulfatos se utilizó un espectrofotómetro UV. Se prepara una curva de calibración con una solución patrón de sulfatos en incrementos de $5 \mathrm{mg} \mathrm{L}^{-1}$ en los límites de 0 a 40 $\mathrm{mg} \mathrm{L}^{-1}$. La curva se establece hasta ese rango ya que decrece la exactitud del método por arriba de $40 \mathrm{mg} / \mathrm{L}$, perdiendo estabilidad la solución de sulfato de bario. La medición se realizó a $420 \mathrm{~nm}$. La medición en la muestra se efectúa en dos partes; la primera es la formación del sulfato de bario y la segunda, la medición de la turbiedad del sulfato de bario. Se transfirieren a un matraz $100 \mathrm{~mL}$ de la muestra, se añaden $5 \mathrm{~mL}$ del reactivo acondicionador (T.H.Q.-tetrahidroxiquinona) y se mezcla en un aparato agitador. Mientras la solución se está agitando, se añade el contenido de una cucharilla (aproximadamente $0.3 \mathrm{~g}$ ) de cristales de cloruro de bario y se empieza a medir el tiempo inmediatamente. La agitación se realiza durante un minuto a una velocidad constante. Inmediatamente después de terminar el período de agitación se vierte la muestra a la celda de absorción del espectrofotómetro y se mide la turbiedad a longitud de onda de $420 \mathrm{~nm}$. La concentración del ion sulfato en la muestra se estima comparando la lectura de turbiedad con una curva de calibración preparada con el uso de patrones de sulfato. 
Determinación de sílice soluble (APHA-AWWA-WPCF, 1992).

La determinación de sílice soluble se realiza en dos partes que son el desarrollo de color y la valoración del contenido de sílice. En la primera parte se miden y vierten $100 \mathrm{~mL}$ de muestra en un matraz, se adiciona $1 \mathrm{~g}$ de molibdato de amonio y $5 \mathrm{~mL}$ de ácido clorhídrico al $10 \%$, se agita vigorosamente y se dejan transcurrir 10 minutos para el desarrollo del color. Para la segunda parte en otro matraz se agrega una alícuota de $100 \mathrm{~mL}$ de muestra y se titula con una solución que contiene $0.053 \mathrm{~g} / 100 \mathrm{~mL}$ de cromato de potasio hasta que la coloración se iguale a la del matraz anterior. La concentración de sílice se determina por cálculos volumétricos.

Determinación de hierro y magnesio (APHA-AWWA-WPCF, 1992).

La determinación de hierro y magnesio se efectuó utilizando un espectrofotómetro de absorción atómica.

Estandarización.- Se prepara una serie de soluciones estándar del metal en el intervalo de concentración óptima, mediante la dilución apropiada de la solución stock, que se lee en el equipo. Se escogen al menos 3 soluciones que cubran el intervalo de concentración esperada del metal en la muestra. Se aspira cada una en turno en la flama y se registra la absorción emitida a una longitud de onda de $248 \mathrm{~nm}$.

Análisis de las muestras.- Se limpia el nebulizador con aspiración de agua deionizada, se atomiza el blanco y se pone en cero el aparato, posteriormente se atomizan las muestras y se determina su concentración.

Determinación de sodio y potasio (APHA-AWWA-WPCF, 1992).

La medición de sodio y potasio se efectuó en un flamómetro, se preparan estándares de 0,10 y 20 ppm de sodio o potasio según el caso. Se coloca en posición de aspiración un recipiente con agua deionizada para que el estándar se aspire y se calibra en 0 ppm con el botón respectivo. Posteriormente, se da lectura a la solución estándar de $20 \mathrm{mg} / \mathrm{L}$ y se estandariza hasta que la pantalla marque 20 en la escala del elemento respectivo. Después se lee cada uno de los patrones preparados, obteniéndose así la curva de calibración. A continuación se procede a leer cada una de las muestras obteniendo la concentración de sodio o potasio en $\mathrm{mg} / \mathrm{L}$. Los cálculos se realizan utilizando la curva de calibración.

Determinación de nitrógeno de nitratos $\left(\mathrm{N}_{-} \mathrm{NO}_{2}{ }^{-1}\right.$ y nitrógeno de nitritos $\left(\mathrm{N}-\mathrm{NO}_{3}{ }^{-1}\right)$-(NOM-AA-791986).

Para la determinación de nitratos se utilizó un espectrofotómetro UV. La curva de calibración se realiza con una solución patrón de nitrato equivalente a $10 \mathrm{mg}$ de $\mathrm{N}-\mathrm{NO}_{3}$, de la cual se toman alícuotas para obtener patrones de $0,0.3,0.6,1.4,2,3,4,6$, y $7 \mathrm{mg}$ de N-NO$/ 3 \mathrm{~mL}$. Además, se añade $1 \mathrm{~mL}$ de ácido clorhídrico $1 \mathrm{~N}$ a cada una de las soluciones de la curva y se agita vigorosamente. Las lecturas de absorbancia se efectúan a $220 \mathrm{~nm}$. Para la obtención de la curva de calibración de nitritos se agrega a cada una de las diluciones $1 \mathrm{~mL}$ de peróxido de hidrógeno para reducir los nitratos a nitritos. Posteriormente, se obtienen las absorbancias para cada una de las concentraciones a $220 \mathrm{~nm}$. Para el análisis de la muestra problema se miden y vierten $50 \mathrm{~mL}$ de muestra en un matraz y se agrega $1 \mathrm{~mL}$ de ácido clorhídrico $1 \mathrm{~N}$ con agitación vigorosa (para la 
determinación de nitritos se añade $1 \mathrm{~mL}$ de peróxido de hidrógeno). Las lecturas de absorbancia de las muestras se realizan a $220 \mathrm{~nm}$. La concentración de nitrógeno en forma de nitratos y nitritos se obtiene directamente de la curva de calibración correspondiente. Las concentraciones de nitratos y nitritos se obtienen por cálculos estequiométricos. 


\section{APÉNDICE III-4}

\section{ELABORACIÓN DEL DIAGRAMA TRIANGULAR DE PIPER}

El agrupamiento, la comparación e interpretación de los análisis químicos es posible realizarlo mediante la elaboración de gráficas o diagramas, tales como los diagramas triangulares 0 de Piper que se basan en las concentraciones de los iones dominantes presentes en el agua. Para ello se utilizan los porcentajes de equivalentes por millón. La interpretación se muestra en la Figura A-III-3 que representa el diagrama y su simbología. El triángulo inferior izquierdo se utiliza para representar las concentraciones catiónicas expresadas en porcentajes, mientras que el triangulo inferior derecho representa a los porcentajes de los aniones encontrados en la muestra. En ambos casos la representación son puntos, los cuales se proyectan sobre el rombo para obtener en el punto de intersección la representación característica de la muestra (Custodio y Llamas, 1983; Appelo y Postma, 1993.

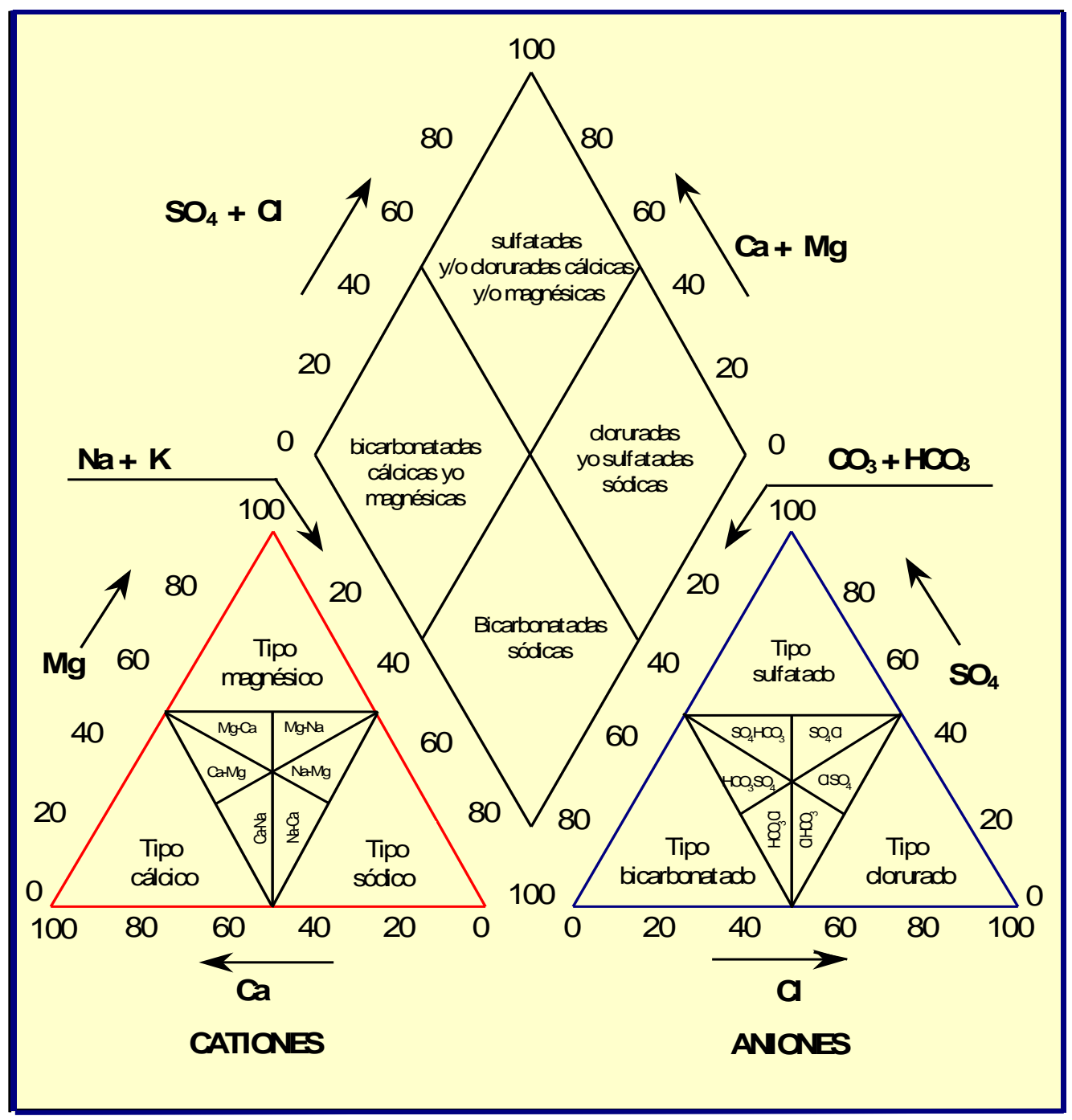

FIG: A-III-3 Diagrama triangular de Piper. 